Florida International University

FIU Digital Commons

FIU Electronic Theses and Dissertations

University Graduate School

$9-7-2018$

\title{
Improved Methods for Network Screening and Countermeasure Selection for Highway Improvements
}

Md Asif Raihan

Florida International University, mraih001@fiu.edu

Follow this and additional works at: https://digitalcommons.fiu.edu/etd

Part of the Civil Engineering Commons, and the Transportation Engineering Commons

\section{Recommended Citation}

Raihan, Md Asif, "Improved Methods for Network Screening and Countermeasure Selection for Highway Improvements" (2018). FIU Electronic Theses and Dissertations. 3846.

https://digitalcommons.fiu.edu/etd/3846

This work is brought to you for free and open access by the University Graduate School at FIU Digital Commons. It has been accepted for inclusion in FIU Electronic Theses and Dissertations by an authorized administrator of FIU Digital Commons. For more information, please contact dcc@fiu.edu. 


\section{FLORIDA INTERNATIONAL UNIVERSITY}

Miami, Florida

\section{IMPROVED METHODS FOR NETWORK SCREENING AND \\ COUNTERMEASURE SELECTION FOR HIGHWAY IMPROVEMENTS}

A dissertation submitted in partial fulfillment of

the requirements for the degree of

DOCTOR OF PHILOSOPHY

in

CIVIL ENGINEERING

by

Md Asif Raihan 
To: Dean John L. Volakis

College of Engineering and Computing

This dissertation, written by Md Asif Raihan, and entitled Improved Methods for Network Screening and Countermeasure Selection for Highway Improvements, having been approved in respect to style and intellectual content, is referred to you for judgment.

We have read this dissertation and recommend that it be approved.

Mohammed Hadi

Xia Jin

Wensong $\mathrm{Wu}$

Priyanka Alluri, Co-Major Professor

Albert Gan, Co-Major Professor

Date of Defense: September 7, 2018

The dissertation of Md Asif Raihan is approved.

Dean John L. Volakis

College of Engineering and Computing

Andrés G. Gil

Vice President for Research and Economics Development and Dean of the University Graduate School

Florida International University, 2018 
(C) Copyright 2018 by Md Asif Raihan

All rights reserved. 


\section{DEDICATION}

I dedicate this dissertation to my parents, Nilufar Fatema and Mohammad Farhad

Hossain, parents-in-law Dr. Zinat Mahrukh Banu and Dr. Md. Anwarul Islam, to my wife

Shahrin Anwar, and my sons Tanzif and Tawfeeq for their unconditional love and

support. 


\section{ACKNOWLEDGMENT}

I thank Almighty Allah for favoring me to successfully complete this research work.

Dr. Priyanka Alluri, Assistant Professor, Department of Civil and Environmental Engineering, Florida International University, has been an excellent supervisor. She has always shared her exceptional engineering knowledge with me and inoculated the meaning of good values of life in me. Thank you very much, Dr. Alluri.

My mentor, teacher and guide Dr. Albert Gan, Professor, Department of Civil and Environmental Engineering, Florida International University, has been supportive to this work from its inception. He always made himself available for any research related discussion. His constructive criticism and suggestions, throughout the course of this work, was invaluable. He discovered my strengths and weaknesses and made me what I am today. I owe so much to you, Sir, you are really wonderful.

I would also like to thank all my committee members, Dr. Mohammed Hadi, Dr. Xia Jin and Dr. Wensong Wu for showing interests in my research. I sincerely appreciate their invaluable time for reading the dissertation and providing comments and suggestions to improve it.

I cannot forget Dr. Wu who taught me statistics. She inspired me and created interests in research in me.

The research associates at Lehman Center for Transportation Research (LCTR), Dr. Wanyang Wu, Mr. Haifeng Wang, and Dr. Kaiyu Liu, were always ready to help me.

I value the unconditional friendship with my colleagues at LCTR. They have been a source of inspiration during my stay at the university. 
I acknowledge the financial support of the Florida Department of Transportation for my research.

Finally, I would like to thank my parents Nilufar Fatema and Mohammad Farhad Hossain, my parents-in-law Dr. Zinat Mahrukh Banu and Professor Dr. Md. Anwarul Islam, my younger brother Shabib, my beloved wife Shahrin, and my gifts from God, my sons Tanzif and Tawfeeq for their support, encouragement and love. 


\begin{abstract}
OF THE DISSERTATION
IMPROVED METHODS FOR NETWORK SCREENING AND

COUNTERMEASURE SELECTION FOR HIGHWAY IMPROVEMENTS
\end{abstract}

by

Md Asif Raihan

Florida International University, 2018

Miami, Florida

Priyanka Alluri, Co-Major Professor

Albert Gan, Co-Major Professor

Network screening and countermeasure selection are two crucial steps in the highway improvement process. In network screening, potential improvement locations are ranked and prioritized based on a specific method with a set of criteria. The most common practice by transportation agencies has been to use a simple scoring method, which, in general, weighs and scores each criterion and then ranks the locations based on their relative overall scoring. The method does not deal well with criteria that are qualitative in nature, nor does it account for the impacts of correlation among the criteria. The introduction of Analytic Hierarchy Process (AHP) provides agencies with a method to include both quantitative and qualitative criteria. However, it does not address the issue on correlation. This dissertation explores the use of both Analytic Network Process (ANP) and Fuzzy Analytic Network Process (FANP) for their potential capabilities to address both issues. Using urban four-lane divided highways in Florida for bicycle safety improvements, 
both ANP and FANP were shown to provide more reasonable rankings than AHP, with FANP providing the best results among the methods.

After the locations are ranked and prioritized for improvements, the next step is to evaluate the potential countermeasures for improvements at the selected top-ranked locations. In this step, the standard practice has been to use Crash Modification Factors (CMFs) to quantify the potential impacts from implementing specific countermeasures. In this research, CMFs for bicycle crashes on urban facilities in Florida were developed using the Generalized Linear Model approach with a Zero-Inflated Negative Binomial (ZINB) distribution. The CMFs were tested for their spatial and temporal transferability and the results show only limited transferability both spatially and temporally. The CMFs show that, in general, wider lanes, lower speed limits, and presence of vegetation in the median reduce bicycle crashes, while presence of sidewalk and sidewalk barrier increase bicycle crashes. The research further considered bicycle exposure using the bicycle activity data from the Strava smartphone application. It was found that increased bicycle activity reduces bicycle crash probabilities on segments but increases bicycle crash probabilities at signalized intersections. Also, presence of bus stops and use of permissive signal phasing at intersections were found to increase bicycle crash probabilities. 


\section{TABLE OF CONTENTS}

CHAPTER

PAGE

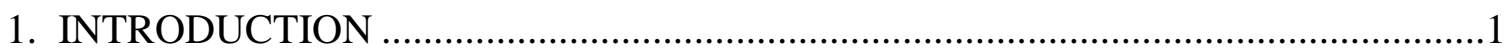

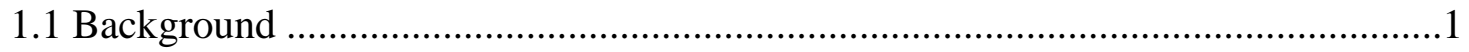

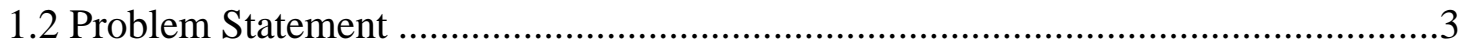

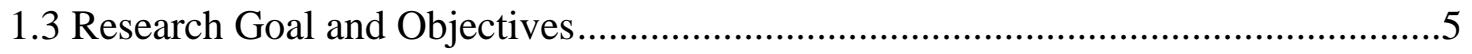

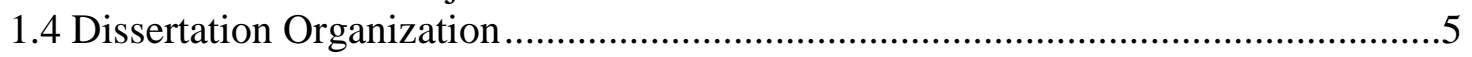

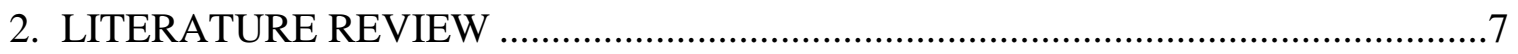

2.1 Network Screening Methods for Highway Improvements......................................

2.1.1 State-of-the-practice Methodologies ........................................................... 8

2.1.2 State-of-the-art Methodologies..................................................................... 9

2.2 Risk Factors Affecting Bicycle Safety and the Bicycle CMFs ..............................16

2.2.1 Bicycle Safety................................................................................... 17

2.2.1.1 Statistical Methods ........................................................................ 17

2.2.1.2 Spatial Frameworks ..................................................................... 24

2.2.1.3 Descriptive Data Analyses .............................................................. 29

2.2.1.4 Combination of Methods ................................................................ 30

2.2.2 Bicycle Crash Countermeasures and CMFs .................................................. 33

2.2.2.1 Bicycle Lanes ........................................................................... 33

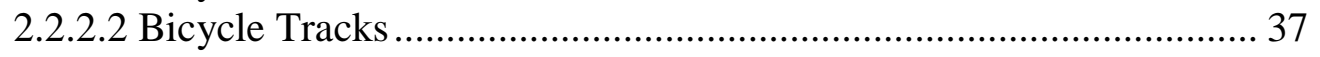

2.2.2.3 Bicycle Boulevards........................................................................ 39

2.2.2.4 Wide Curb Lanes .............................................................................. 39

2.2.2.5 Traffic Calming Measures ........................................................... 42

2.2.2.6 Roadway and Intersection Geometry .............................................. 44

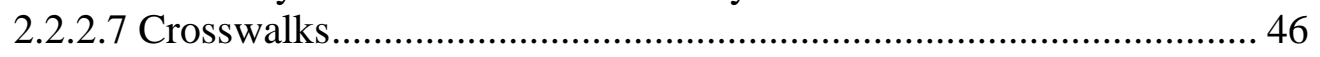

2.2.2.8 Roadway Lighting ......................................................................... 46

2.2.2.9 Parking Treatments......................................................................... 47

2.2.3 Crash Frequency Modeling .................................................................... 48

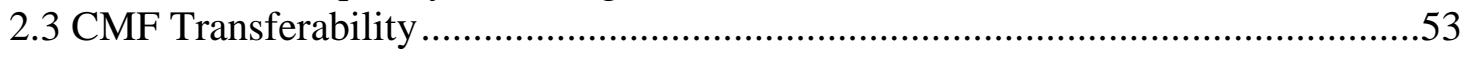

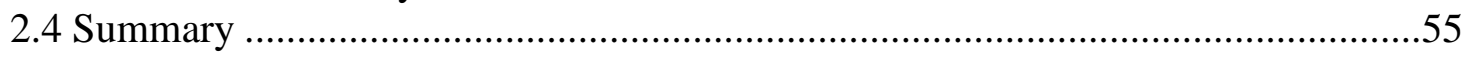

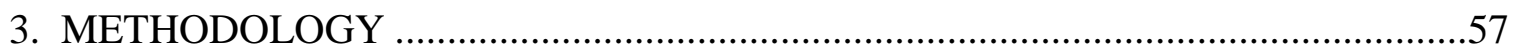

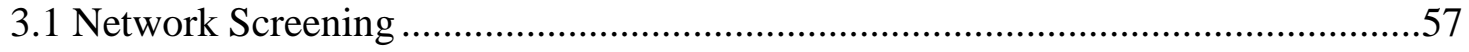

3.1.1 Analytic Hierarchy Process (AHP) ……………....................................... 57

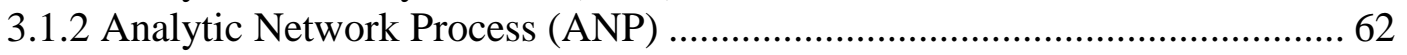

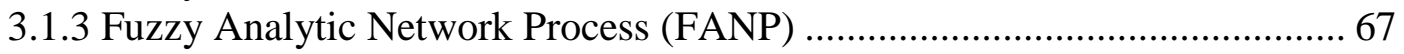

3.2 Crash Modification Factor (CMF) Development ....................................................

3.2.1 Cross-sectional Analysis .......................................................................... 74

3.2.2 Zero Inflated Negative Binomial (ZINB) Models ......................................... 75

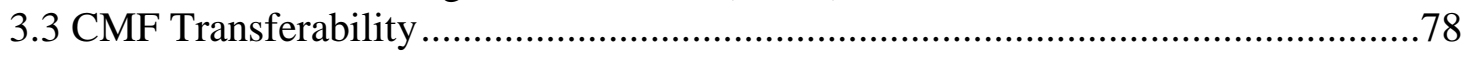

3.3.1 Transferability Assessment ………………….......................................... 78

3.3.2 Goodness of Fit (GOF) ........................................................................... 79 


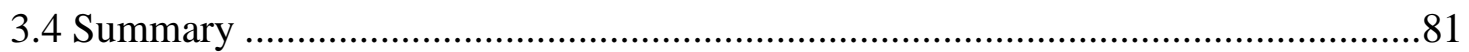

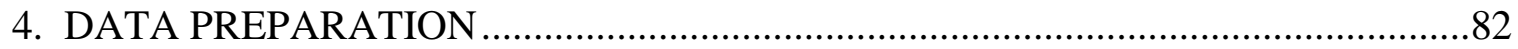

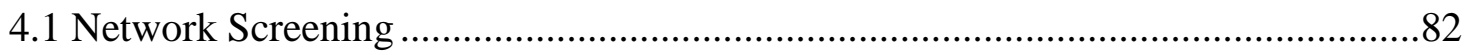

4.1.1 Crash Analysis Reporting (CAR) System ................................................. 83

4.1.2 Roadway Characteristics Inventory (RCI) ………………......................... 84

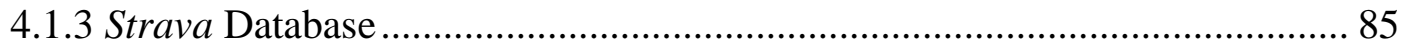

4.1.4 Florida Geographic Data Library (FGDL) …………................................ 86

4.1.5 Florida Transit Information System (FTIS) ………………….................... 88

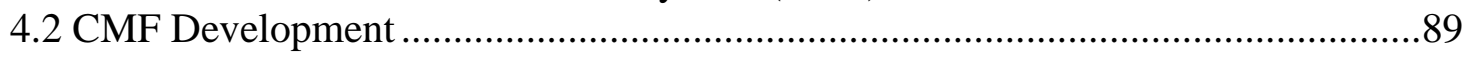

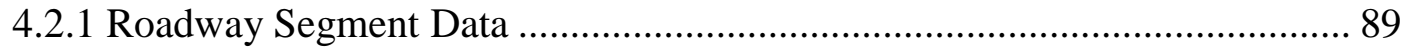

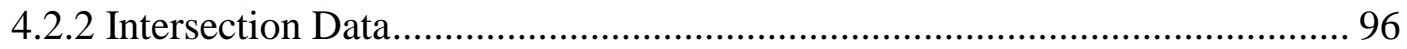

4.2.3 Bicycle Exposure Data …………….......................................................... 97

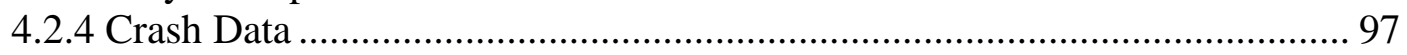

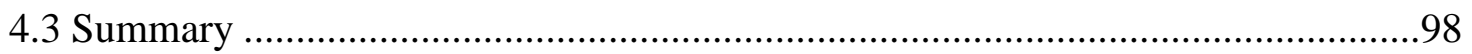

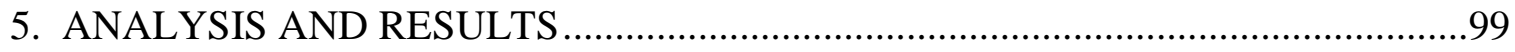

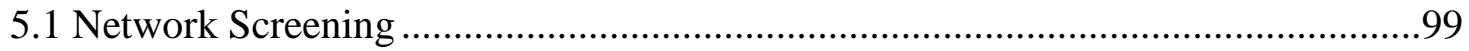

5.1.1 Analytic Hierarchy Process (AHP) ........................................................... 99

5.1.2 Analytic Network Process (ANP) .............................................................. 105

5.1.3 Fuzzy Analytic Network Process (FANP) …………………….................. 109

5.1.4 Comparison of Results ...................................................................... 115

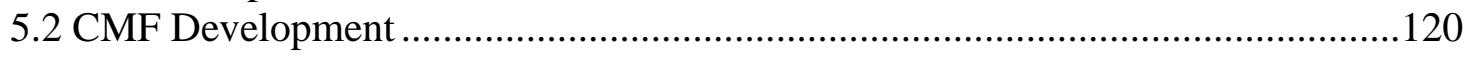

5.2.1 Urban Two-lane Divided Segments ........................................................... 121

5.2.2 Urban Four-lane Divided Segments ........................................................... 125

5.2.3 Urban Six-lane Divided Segments ............................................................ 127

5.2.4 Urban Four-leg Signalized Intersections ................................................ 130

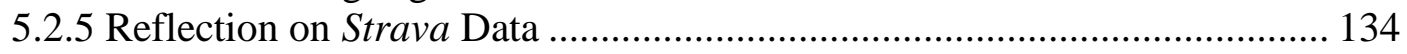

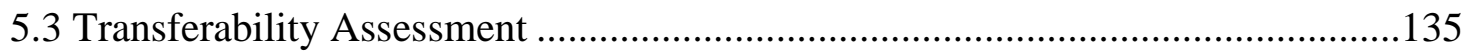

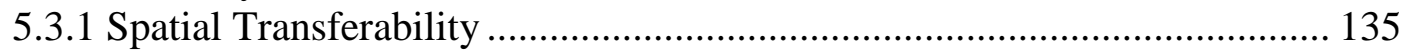

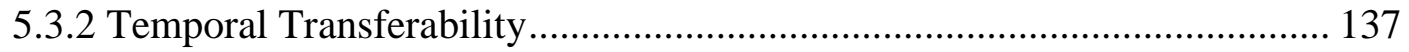

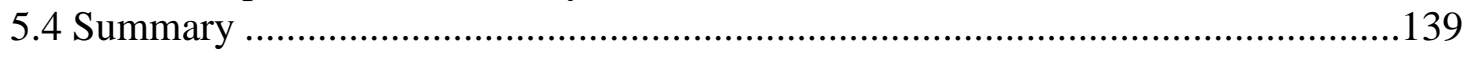

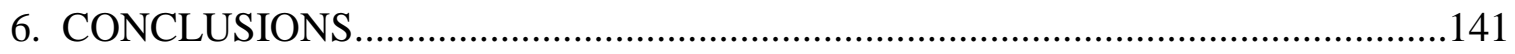

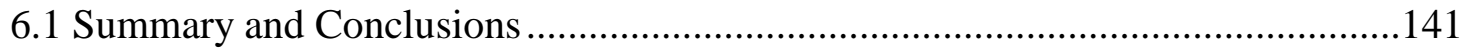

6.2 Research Contributions ..............................................................................144

6.3 Recommendations for Future Research ........................................................145

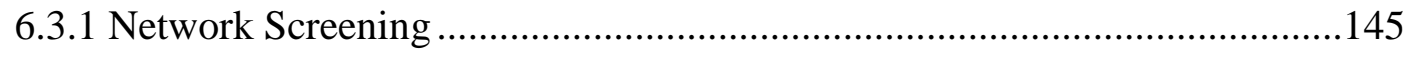

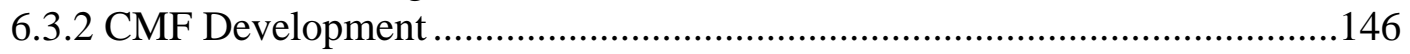

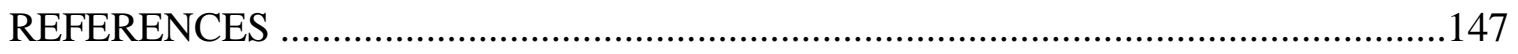

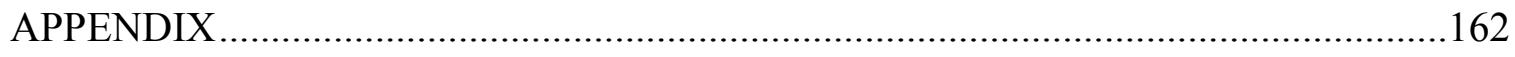

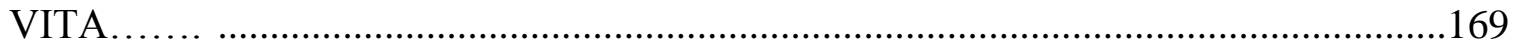




\section{LIST OF TABLES}

TABLE

PAGE

Table 3-1: Values of Random Consistency Indices ....................................................62

Table 3-2: TFN-linguistic Scale for Importance....................................................69

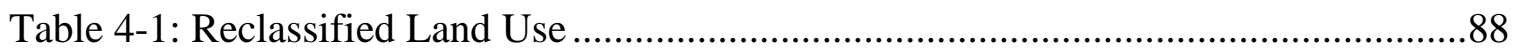

Table 4-2: RCI Variables Extracted for CMF Development .......................................90

Table 4-3: HSM Recommended Rounded Median Widths ...........................................91

Table 4-4: HSM Recommended Rounded Lane Widths .............................................93

Table 4-5: Codes for Median Type ........................................................................... 94

Table 4-6: Codes for Shoulder Type, Shoulder Type2, and Shoulder Type3...................94

Table 5-1: Pre-defined Scaling for Bicycle Volume.................................................102

Table 5-2: Pre-defined Scaling for Land Use ........................................................ 103

Table 5-3: Cluster Level Priorities with Respect to Goal ............................................104

Table 5-4: Sub-cluster Level Priorities with Respect to Bicycle Crash..........................106

Table 5-5: Sub-cluster Level Priorities with Respect to Bicycle Facility .......................106

Table 5-6: Sub-cluster Level Priorities with Respect to Bicycle Volume .......................106

Table 5-7: Sub-cluster Level Priorities with Respect to AADT ...................................106

Table 5-8: Sub-cluster Level Priorities with Respect to Auto Ownership......................107

Table 5-9: Sub-cluster Level Priorities with Respect to Land Use ................................107

Table 5-10: Sub-cluster Level Priorities with Respect to Transit Stops .........................107

Table 5-11: Expanded Supermatrix Framework....................................................108

Table 5-12: Lower Bound Cluster Level Priorities with Respect to Goal ......................109

Table 5-13: Modal Cluster Level Priorities with Respect to Goal.................................109 
Table 5-14: Upper Bound Cluster Level Priorities with Respect to Goal 110

Table 5-15: Lower Bound Sub-cluster Level Priorities with Respect to Bicycle Crash .110

Table 5-16: Modal Sub-cluster Level Priorities with Respect to Bicycle Crash 110

Table 5-17: Upper Bound Sub-cluster Level Priorities with Respect to Bicycle Crash ..110

Table 5-18: Lower Bound Sub-cluster Level Priorities with Respect to Bicycle Facility.....

Table 5-19: Modal Sub-cluster Level Priorities with Respect to Bicycle Facility 111

Table 5-20: Upper Bound Sub-cluster Level Priorities with Respect to Bicycle Facility.....

Table 5-21: Lower Bound Sub-cluster Level Priorities with Respect to Bicycle Volume .111

Table 5-22: Modal Sub-cluster Level Priorities with Respect to Bicycle Volume

Table 5-23: Upper Bound Sub-cluster Level Priorities with Respect to Bicycle Volume

Table 5-24: Lower Bound Sub-cluster Level Priorities with Respect to AADT

Table 5-25: Modal Sub-cluster Level Priorities with Respect to AADT. .112

Table 5-26: Upper Bound Sub-cluster Level Priorities with Respect to AADT

Table 5-27: Lower Bound Sub-cluster Level Priorities with Respect to Auto Ownership. 113

Table 5-28: Modal Sub-cluster Level Priorities with Respect to Auto Ownership 113

Table 5-29: Upper Bound Sub-cluster Level Priorities with Respect to Auto Ownership. .113

Table 5-30: Lower Bound Sub-cluster Level Priorities with Respect to Land Use.........114

Table 5-31: Modal Sub-cluster Level Priorities with Respect to Land Use .114

Table 5-32: Upper Bound Sub-cluster Level Priorities with Respect to Land Use .114 
Table 5-33: Lower Bound Sub-cluster Level Priorities with Respect to Transit Stops...114

Table 5-34: Modal Sub-cluster Level Priorities with Respect to Transit Stops .115

Table 5-35: Upper Bound Sub-cluster Level Priorities with Respect to Transit Stops ...115

Table 5-36: Top 30 Prioritized Locations using AHP, ANP, and FANP Approaches ....116

Table 5-37: Scenario 1 - Comparison of Ranks from AHP, ANP, and FANP ...............118

Table 5-38: Scenario 2 - Comparison of Ranks from AHP, ANP, and FANP ................118

Table 5-39: Descriptive Statistics for Segment Facility Types ..................................122

Table 5-40: Bicycle CMFs for Urban Two-lane Divided Segments ...........................126

Table 5-41: Bicycle CMFs for Urban Four-lane Divided Segments ............................126

Table 5-42: Bicycle CMFs for Urban Six-lane Divided Segments .............................128

Table 5-43: Descriptive Statistics for Urban Four-leg Signalized Intersections ............131

Table 5-44: Bicycle CMFs for Urban Four-leg Signalized Intersections ......................133

Table 5-45: FDOT District-wise Urban Four-lane Divided Segments ..........................136

Table 5-46: Spatial TI Indices for FDOT Districts ...................................................136

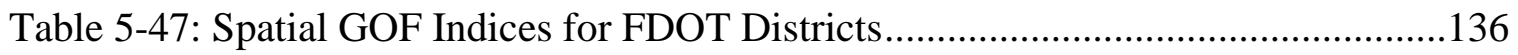

Table 5-48: Temporal TI Indices for 2011-2012 and 2015 Periods..............................137

Table 5-49: Temporal GOF Indices for 2011-2012 and 2015 Periods .........................137

Table 5-50: Temporal D5 TI Indices for 2011-2012 and 2015 Periods..........................139

Table 5-51: Temporal D5 GOF Indices for 2011-2012 and 2015 Periods .....................139 


\section{LIST OF FIGURES}

FIGURE

PAGE

Figure 2-1: Geographic Region in Melbourne, Australia, Selected for Detailed Case

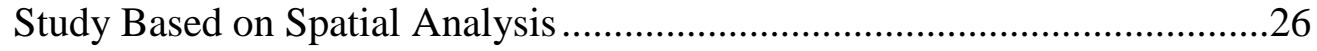

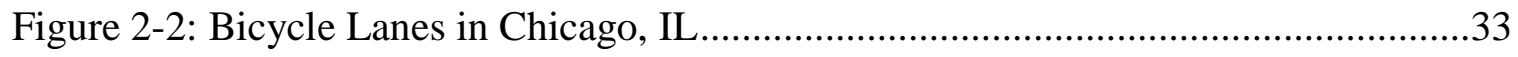

Figure 2-3: Green-colored Pavement and Accompanying Signing in a Bicycle Lane Weaving Area in St. Petersburg, FL.........................................................36

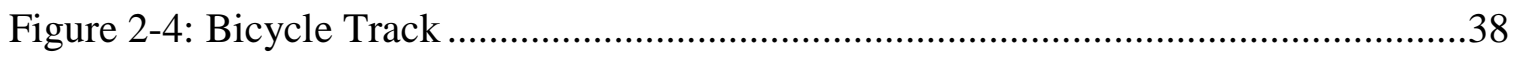

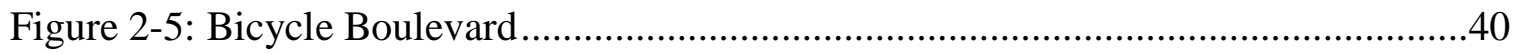

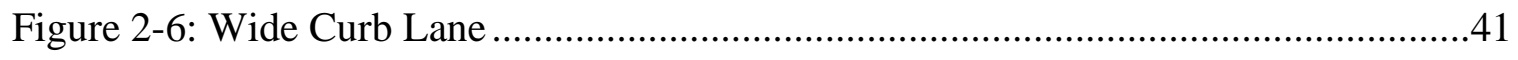

Figure 3-1: Hierarchical Structure of Highway Improvement Location Selection............59

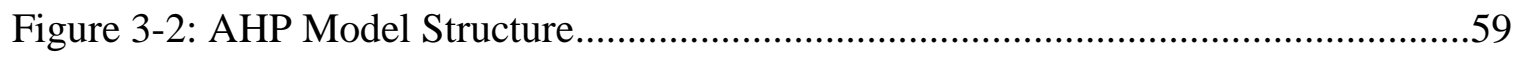

Figure 3-3: Difference between Hierarchy and Network Decision Making Process.........63

Figure 3-4: Network and Hierarchical Model Structures .........................................65

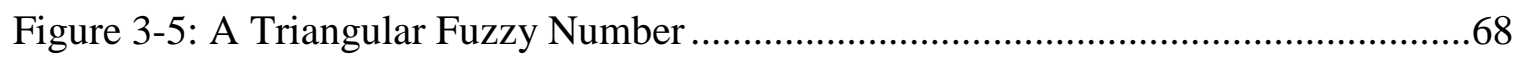

Figure 3-6: Fuzzy Membership Function Scale ...................................................... 70

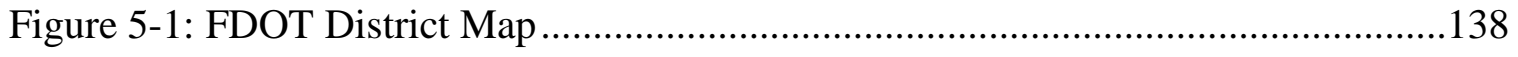




\section{LIST OF ACRONYMS}

\begin{tabular}{|c|c|}
\hline AADT & Annual Average Daily Traffic \\
\hline AASHTO & American Association of State Highway and Transportation Officials \\
\hline ADTT & Average Daily Truck Traffic \\
\hline AHP & Analytic Hierarchy Process \\
\hline AIC & Akaike Information Criterion \\
\hline ANP & Analytic Network Process \\
\hline $\mathrm{B} / \mathrm{C}$ & Benefit-cost \\
\hline $\mathrm{CMF}$ & Crash Modification Factor or Function \\
\hline DOT & Department of Transportation \\
\hline EI & Environmental Impact \\
\hline GAM & Goal Achievement Matrix \\
\hline GOF & Goodness of Fit \\
\hline ISS & Innovation Support System \\
\hline LRTP & Long Range Transportation Plan \\
\hline MAD & Mean Absolute Deviation \\
\hline MCDM & Multi Criteria Decision Making \\
\hline MEB & Modified Empirical Bayes \\
\hline MLP & Multi-Layer Prioritization \\
\hline MNB & Modified Negative Binomial \\
\hline MNL & Multinomial Logit \\
\hline MSPE & Mean Squared Predicted Error \\
\hline MPB & Mean Predicted Bias \\
\hline
\end{tabular}




$\begin{array}{ll}\text { MPO } & \text { Metropolitan Planning Organization } \\ \text { MRZINB } & \text { Multivariate Random-parameter Zero-Inflated Negative Binomial } \\ \text { NB } & \text { Negative Binomial } \\ \text { NHTSA } & \text { National Highway Traffic Safety Administration } \\ \text { OECD } & \text { Organization for Economic Cooperation and Development } \\ \text { OLS } & \text { Ordinary Least-Square } \\ \text { RCI } & \text { Roadway Characteristics Inventory } \\ \text { REP } & \text { Random Effect Poisson } \\ \text { REZIP } & \text { Zero-Inflated Poisson with Random Effects } \\ \text { R\&D } & \text { Research and Development } \\ \text { SPF } & \text { Safety Performance Function } \\ \text { TFN } & \text { Triangular Fuzzy Number } \\ \text { TI } & \text { Transferability Index } \\ \text { TIP } & \text { Transportation Improvement Program } \\ \text { TNB } & \text { Traditional Negative Binomial } \\ \text { TOPSIS } & \text { Technique for Order Preference by Similarity to an Ideal Solution } \\ \text { v/c } & \text { Volume to Capacity } \\ \text { VRU } & \text { Vulnerable Road User } \\ \text { ZI } & \text { Zero-Inflated } \\ \text { ZINB } & \text { ZIP }\end{array}$




\section{CHAPTER 1 INTRODUCTION}

\subsection{Background}

Transportation agencies ideally would like to improve all the locations that have a transportation problem. However, it is not feasible due to financial constraints. Transportation engineers and planners are, therefore, tasked with selecting the potential locations that provide maximum benefit for improvements. This is commonly termed as network screening. Network screening is the first and the most important aspect of making investment decisions.

In network screening, potential improvement locations are ranked and prioritized based on a specific method with a set of criteria. Transportation agencies have been screening highway locations using simple scoring and ranking method which assigns fixed weight to each of the criterion. In this method, each of the selected quantitative criterion is assigned a maximum score. The actual score of each criterion is then determined based on site-specific characteristics. Finally, for each location, scores from all the criteria are summed up to obtain the overall score which is then used in ranking. Top-ranked locations are then scrutinized using qualitative criteria to determine the final location list for potential funding.

The criteria for screening can either be quantitative or qualitative, with the qualitative criteria requiring subjective judgment. Moreover, some measures could be correlated requiring the screening method to consider their interdependencies. The simple scoring method, however, cannot efficiently address these issues, and thus agencies have 
become more interested in advanced screening methods that are transparent, effective, accountable, and defendable.

After the locations are prioritized and selected for improvements, the next important step is to evaluate the potential countermeasures for improvements at the selected top-ranked locations. How changes in roadway characteristics affect safety is one of the critical issues to be considered. The safety impacts of roadway characteristics can be evaluated from expected changes in number of crashes after implementing a countermeasure. This can be attained by Crash Modification Factors (CMFs). A CMF is a multiplicative factor which is used to compute the expected number of crashes when a particular countermeasure is implemented at a specific site. A CMF greater than 1.0 indicates an expected increase in crashes, while a CMF less than 1.0 indicates an expected reduction in crashes when a particular countermeasure is implemented (Gross et al., 2010).

The preferred methods for developing CMFs can be classified into two broad categories: before-after study, and cross-sectional study. Although before-after study is usually preferred over cross-sectional design, it is not always practical because there could be insufficient locations to allow for credible results (Gross et al., 2010). Cross-sectional studies are thus often adopted. The most common norm to develop CMFs using crosssectional method is through Negative Binomial (NB) models. Crashes are rare and random events. Therefore, the crash data is expected to be zero inflated. In other words, several locations (i.e., roadway segments and intersections) may not have experienced any crashes during the analysis period. Traditional NB models may not be able to handle the datasets that have a large number of zero crash observations. 


\subsection{Problem Statement}

Network screening criteria can be quantitative and qualitative, and interdependent. For example, if an agency prioritizes highway locations based on safety, annual average daily traffic (AADT), and land use, it is quite clear that safety and AADT can be measured quantitatively in terms of crash frequency and number of vehicles per day, respectively. On the other hand, land use needs to be assessed qualitatively. In decision making that involves multiple criteria, the Analytic Hierarchy Process (AHP) is being widely used for its capability to organize quantitative and qualitative criteria in a systematic way, and provide a structured yet relatively simple solution to decision making problem (Skibniewski and Chao, 1992). Thus, the AHP can overcome the limitation of addressing qualitative criteria along with quantitative criteria.

AHP, however, structures the problem hierarchically; thus, it does not consider the impacts of interdependencies that may exist among the criteria. For example, if an agency screens highway locations based on AADT, volume to capacity (v/c) ratio, delay, truck volume, and truck percentage, it is quite clear that AADT and v/c ratio are interdependent, so are truck volume and truck percentage. Further, delay and v/c (thus AADT) are also interdependent as delay is a function of v/c (Raihan et al., 2016). It can thus be concluded that several of the criteria can essentially be interdependent. Therefore, a method that can take into account the impacts of such interdependencies will yield more meaningful and defendable results. In summary, a desirable network screening method should address:

- qualitative and quantitative criteria,

- interdependencies of the criteria, and

- undue weight of any criterion on decision making. 
The method should also be simple and easily applicable for the transportation agencies to adopt and implement.

Once the locations are prioritized and ranked, the next step is to determine what to improve. Since traffic safety has enormous scopes, this research particularly focuses on bicycle safety improvements. Bicyclists are vulnerable road users who are at a greater risk for fatal or serious injury when involved in a crash with a motor vehicle. While bicycling accounts for only $1 \%$ of all trips taken in the United States (Pucher et al., 2011), bicycle fatalities constitute over $2 \%$ of all traffic fatalities (NHTSA, n.d.). Moreover, bicycle fatalities across the nation have increased by $31 \%$ from 2010 to 2015 . During the same period, Florida has led the nation with over 750 bicycle fatalities, representing approximately $18 \%$ of the nation's total (NHTSA, 2017). These grim statistics underscore the need for a thorough investigation of bicycle crashes and forms the rationale for this research.

Improving bicycle safety is a different challenge compared to improving the safety and mobility of motorized vehicular traffic because of the following reasons: bicycle crashes are rare and often severe; bicycle exposure is different from vehicle exposure and is difficult to quantify; and bicycle crash trends are quite distinctive and are dependent on land use, existing bicycle infrastructure, socio-economic factors, etc. A thorough analysis of these factors is therefore required to improve bicycle safety. The unavailability of data and the zero inflation in crash data pose additional challenge to address bicycle safety. Therefore, the following issues need to be considered while developing the CMFs:

- roadway characteristics, i.e., the cross-sectional properties,

- existing bicycle infrastructure, 
- bicycle exposure,

- the surrogate measures of bicycle exposure, and

- the zero inflated crash data.

Furthermore, the applicability of a CMF depends on the data from which the CMF is estimated. It may vary by crash severity, crash type, and/or site condition (Gross et al., 2010). This instigates the question whether CMFs developed using state-wide data are applicable to different jurisdictions and for different time periods, i.e., are CMFs spatially and temporally transferable.

\subsection{Research Goal and Objectives}

The goal of this research is to improve the traffic safety of Florida's state roads by determining an appropriate network screening method, and quantifying the safety impacts of critical cross-sectional geometrics. The specific objectives of this research are:

1. to explore and determine the most suitable network screening method for bicycle safety improvements;

2. to quantify the impact of roadway characteristics, bicycle infrastructure, and bicycle exposure on bicycle safety; and

3. to explore the scope of spatial and temporal transferability of the CMFs for bicycle crashes.

\subsection{Dissertation Organization}

This dissertation is comprised of six chapters. Chapter 2 presents a comprehensive literature review of the state-of-the-art and state-of-the-practice network screening methods, potential factors affecting bicycle crashes, existing bicycle CMFs, crash 
frequency modeling, and studies on CMFs transferability. Chapter 3 discusses the potential network screening methodologies, and CMF development and transferability assessment methodologies adopted to attain the research objectives. Chapter 4 describes the detailed data collection and preparation efforts undertaken in this dissertation. Chapter 5 presents the analyses and discusses the results. The most suitable network screening method and Florida-specific bicycle CMFs are provided in this chapter. The possibility of CMFs transferability is also discussed. Chapter 6 concludes this dissertation by summarizing the contributions of this research and providing recommendations for future research. 


\section{CHAPTER 2}

\section{LITERATURE REVIEW}

This chapter provides a comprehensive literature review on three topics: (a) network screening practices and methods; (b) risk factors affecting bicycle safety, and the bicycle crash countermeasures and CMFs; and (c) the transferability aspects of the CMFs. Section 2.1 discusses the state Departments of Transportation (DOTs') network screening practices and the screening methods developed or adopted by different researchers. Section 2.2 focuses on different risk factors, causes, patterns, contributing factors associated with bicycle crashes, and bicycle crash countermeasures and CMFs. Finally, Section 2.3 presents the literature on transferability of CMFs.

\subsection{Network Screening Methods for Highway Improvements}

This section reviews different screening methods. It is divided into two broad subsections: (a) the network screening, i.e., project location prioritization practices that are either currently being applied or being considered for adoption by the state DOTs, Metropolitan Planning Organizations (MPOs), and local transportation agencies across the country; and (b) the state-of-the-art screening, i.e., prioritization methodologies.

A state-of-the-practice review of the screening methods revealed that none of the agencies focused on identifying improvement locations. However, a majority of the methods prioritize projects, rather than highway improvement locations. This is in contrast to the principle of differentiating the prioritization process into two categories: (a) screening for highway project locations with potential for improvement; and (b) prioritizing projects. Nonetheless, the approaches discussed to prioritize projects are to a 
large extent applicable to screening highway improvement locations, and could potentially be used to screen the locations for improvements.

\subsubsection{State-of-the-practice Methodologies}

This section summarizes the prioritization methodologies currently being applied or being considered for adoption by the following 12 state DOTs: Delaware, Florida, Indiana, Missouri, North Carolina, Ohio, Oregon, Texas, Utah, Virginia, Washington, and Wisconsin, and by eight MPOs and local transportation agencies from North Central Pennsylvania, Hampton Roads, Fredericksburg Area, Broward, Winston-Salem Urban Area, Boston Region, Nashville Area, and Metrolinx. Gan et al. (2016) provides detailed discussion on the methodologies.

It is evident from the review that most of the transportation agencies are still relying on simple scoring and ranking algorithm for prioritizing the projects thus the project locations; and the criteria used for prioritization are quantitative and qualitative requiring subjective judgments. In addition to the simple scoring method, agencies were found to use rating scale, and the Technique for Order Preference by Similarity to an Ideal Solution (TOPSIS) approaches. Rating scale is just an alternate form of simple scoring. Instead of giving direct point to any project for any particular criterion, rating scale provides the point values in terms of a scale. The potential best criterion is given the highest rating and the potential worst criterion is given the lowest rating; the rest lies in between. Thus it makes the scale continuous and therefore easy to assign points to any project for that criterion. TOPSIS's principle is that any chosen alternative should have the shortest distance from the positive-ideal solution and the farthest distance from the negative-ideal solution. Hence, 
it eventually applies the simple scoring algorithm in the methodological steps. Thus, most of the state transportation agencies are confined with the limitations of simple scoring methodological approach.

\subsubsection{State-of-the-art Methodologies}

Researchers have used several methods including Analytic Hierarchy Process (AHP), Conjoint-based AHP, Analytic Network Process (ANP), Fuzzy-ANP (FANP), Multi-layer prioritization, Goal Achievement Matrix, etc. to prioritize locations for highway improvements. Studies that applied these methods are discussed in the following paragraphs.

Amponsah (2013) presented the potential of AHP in prioritizing highway projects. A hierarchical structure was constructed based on commonly known factors used by highway agencies for selecting projects. Social, Legal, Environmental, Economical, Political, and Technological (SLEEPT) influence of roads were incorporated in this study to form an integrated factor base (IFB) to prioritize the highway projects systematically. Candidate projects were prioritized in a descending order through AHP.

Outwater et al. (2011) presented a conjoint-based AHP to prioritize projects. They determined that the AHP is useful in developing weights for multiple goals; however, it has a limitation in determining the ways to achieve goals through quantitative performance measures. A conjoint-based approach specifically designed to complement an AHP weighting exercise was developed. Several performance measures were manifested for each goal and conjoint exercises were structured for each goal in such a way that it was able to elicit information about the relative importance of each of the performance 
measures in achieving that goal. The number of conjoint exercises required for each goal depends on the number of performance measures being tested for that goal as well as the number of levels to be tested. In brief, AHP provided the platform to develop the weights of the goals for the transportation projects and conjoint method estimated stakeholders' weights for each measure in their study.

The ANP methodology has been applied to solve decision making problems in various fields including business, construction, and transportation. For example, ElAbbasy et al. (2013) integrated ANP and Monte Carlo simulation to prioritize competitive contractors at the pre-bidding stage for highway projects. Sadeghi et al. (2012) used the ANP for supplier selection. Macura et al. (2011) applied ANP for prioritizing rail infrastructure investment projects in Serbia. Banai (2010) also utilized the ANP for light rail route selection in Memphis, Tennessee. The study highlighted the fact that the analysis of land use and transportation was facilitated by the ANP methodology. Tuzkaya and Önüt (2008) employed a fuzzy ANP-based approach to transportation-mode selection between Turkey and Germany. Cheng and Li (2005) demonstrated the potential of the ANP for construction project selection. Cheng and Li (2004) applied ANP for the contractor selection process. Azis (2003) compared ANP and AHP while studying the impact of highway construction, and found that ANP model is more stable and robust compared to the AHP model.

Mohanty et al. (2005) applied the fuzzy ANP approach for research and development (R\&D) project selection case study. Ramík (2007) also proposed a decision algorithm using ANP and fuzzy inputs. The algorithm provides the platform of doing the pairwise comparisons using fuzzy numbers. The author discussed the extended arithmetic 
operations with fuzzy numbers, and the procedure adopted to order the fuzzy relations to compare the outcomes.

Tuzkaya and Önüt (2008) conducted a case study to prioritize the different freight transportation modes between Turkey and Germany. Both qualitative and quantiative criteria were incorportated in the study. The research presented the potential of fuzzy analytic network process (FANP). Furthermore, the analysis results were compared with the results of the ANP. The results of the FANP and ANP procedure did not differ in prioritizing the transportation modes. However, the researchers stated that consideration of the upper or lower values of the ranking algorithm affect the final verdict of the decision maker in decision making process. As the study included imprecise data, giving lower and upper values with triangular fuzzy numbers was considered preferable over crisp numbers, and therefore, the FANP was considered to be more reliable compared to the ANP.

Dağdeviren et al. (2008) employed the FANP framework to evaluate work system safety and identify faulty behavior risk (FBR). Work system safety is a function of many factors, and is dynamic and complex. Thus the study used the FANP algorithm to determine the factors' and sub-factors' weights to calculate the FBR. The authors concluded that the methodology's analytical framework made it possible to make better decision.

Guneri et al. (2009) used the FANP approach in selecting an appropriate location for a shipyard. Chen and Chen (2010) developed a conjunctive multi-criteria decision making (MCDM) approach based on decision making trial and evaluation laboratory (DEMATEL), FANP, and TOPSIS to develop an innovation support system (ISS) for Taiwanese higher education. The approach was able to address the dependent relationships among the measurement criteria. Later, Büyüközkan and Çifçi (2012) used the fuzzy 
DEMATEL, FANP, and fuzzy TOPSIS to evaluate green suppliers. The study also proposed a case study for green supplier evaluation in a specific company, namely Ford Otosan.

Sevkil et al. (2011) proposed SWOT (i.e., Strengths, Weakness, Opportunities, and Threats) FANP methodology to rank the business factors for the Turkish airline industry. The study results showed that the SWOT FANP is a viable and highly capable methodology over the traditional SWOT methodology in providing invaluable insights for strategic management decisions for the airline industry in Turkey. The authors concluded that a better method was indeed needed for complex business situations triggered by continuous stringent constraints of global marketplace demands while optimizing multiple goals and considering inherent uncertainty. Yücenur et al. (2011) compared the fuzzy AHP and FANP approaches in global supply chains for supplier selection. The analyses from the two models selected the same supplier as the best alternative; however, ordering of the triggering factors for alternative selection differed in the two models. Bhattacharya et al. (2014) used the FANP framework for green supply chain performance measurement.

Ayağ and Özdemir (2012) evaluated machine tool alternatives through modified TOPSIS and alpha-cut based fuzzy ANP. The study utilized a fuzzy extension of ANP to address uncertain qualitative preferences as input in the decision making process and used modified TOPSIS to determine the rank of the competing machine tool alternatives in terms of overall performance. Although fuzzy logic is useful to model vague and uncertain judgments of the decision makers and is insensitive to noisy data, it is computationally intensive and time and resource consuming. Therefore, the modified TOPSIS algorithm was utilized to eliminate the time consuming fuzzy calculations of the FANP method. 
However, the authors (Ayağ and Özdemir, 2007) proposed a FANP approach to select enterprise resource planning (ERP) software before.

Lu and Wang (2005) implemented Multi-Layer Prioritizing (MLP) method to prioritize intersections for improvements. Safety was integrated with operational considerations to generate a more rational prioritized list. The MLP method was employed with three criteria, benefit-to-cost ratio of safety performance, delay reduction, and existing delay. The authors adopted two priority categories, one with safety ahead of operations, and the other with operations ahead of safety. Accordingly, when safety was prioritized, the criteria for the first layer was benefit-to-cost ratio of safety performance, followed by delay reduction in the second layer, and existing delay as the criterion in the last layer. On the other hand, when operations was prioritized, delay reduction, safety, and existing delay were considered in the three layers, respectively. The intersection improvement projects were ranked and clustered into the layers based on similarity. The sequential process continued until the final priority list was obtained. However, the thresholds regarding choosing the layer criteria were beyond the scope of their study.

Berechman and Paaswell (2005) presented the Goal Achievement Matrix (GAM) methodology to prioritize transportation investment projects in New York. The following paragraphs briefly discuss the three phase methodology used by Berechman and Paaswell (2005) to evaluate, rank, and prioritize the projects in New York.

Out of a number of competing proposals, eight most visible and important projects that meet basic transportation and economic needs, and thus had the best chance to be considered for implementation were selected in the first phase. However, no comprehensive regional analyses were carried out to test the needs or to set the priority list. 
The projects were mainly Manhattan-oriented-passenger-transportation-type projects. Cost-benefit analysis of transportation and economic development impacts was the second phase of the study. Transportation benefits were measured using two variables: expected number of riders at the completion of the project's construction, and the amount of time saved per rider. A growth model with declining growth rate was used to measure the expected number of riders. The growth model is:

$$
g(t)=\frac{g}{1+\alpha\left(t-T_{c}\right)} \text { for } t>T_{c}
$$

where

$$
\begin{aligned}
& g(t)=\text { the growth in ridership over time }(t), \\
& g \quad=0.523 \% \text { (annual growth rate), } \\
& T_{c}=\text { construction period, and } \\
& \alpha \quad=0.1 \text { (attenuation rate). }
\end{aligned}
$$

The time savings variable included two aspects: direct time saved, and indirect time saved on other applicable transit lines. Transportation cost mainly comprised of operation costs and maintenance costs. Projects' respective sources of funding always pose a question to assessing the cost of a project. Therefore, the funding sources were also considered during the study by factoring the Net Present Value (NPV) formula into debt service costs, which should be borne by the project. The NPV of transportation benefits for the Cost Benefit Analysis (COBA) was calculated as:

$$
N P V\left(C, T_{c}, B_{t}\right)=-\left[\sum_{t=1}^{T_{c}} \frac{\left(\frac{C}{T_{c}}\right)+r \cdot C}{(1+r)^{T}}\right]+\sum_{t=T_{c}}^{T+T_{c}} \frac{B_{t} \cdot\left[\left(1+g(t)^{\left(t-T_{c}\right)}\right)\right]+(R)-(M O)-(r . C)}{(1+r)^{t}}
$$


where

$$
\begin{aligned}
& T_{c}=\text { construction period, } \\
& C=\text { capital costs } \\
& r=\text { discount factor }(5 \%), \\
& r \cdot C=\text { debt service (assumed to be paid during construction period and then during } \\
& \quad \text { life span of the project), } \\
& B_{t}=\text { annual transportation benefits for effective year of project completion, } \\
& g(t)=\text { ridership growth function (shown in Equation } 2-1), \\
& R=\text { fare box revenue, } \\
& M O=\text { maintenance and operating costs, } \\
& t \quad=\text { year index, and } \\
& T \quad=\text { life span of a project (assumed } 50 \text { years). }
\end{aligned}
$$

The equation is based on consumer and producer surplus, capital costs, debt service, and operating and maintenance costs. The study identified that the projects could not be justified by transportation benefits alone; however, most of the projects generated positive net economic development benefits. Thus, the final step of the three-phase methodology was to employ a GAM method to address this critical issue in a systematic manner and to rank, i.e., prioritize, projects unequivocally. Obviously, another crucial component of GAM method is the weights of the criteria. A modified Delphi approach was applied to determine the weights. A modified Delphi approach is a process in which a panel of experts determine the most appropriate criteria weights for the concerned projects.

Herbel et al. (2010) presented a variety of methods including benefit-cost analysis, ranking, and optimization approaches to prioritize safety improvement programs. They 
emphasized on quantitative analysis procedures rather than qualitative judgment in prioritizing safety projects. However, they highlighted innovative design standards, project development effort, competing transportation needs, unfamiliarity of countermeasures, and constituent concerns as important hindrances in the project prioritization process. The authors concluded that a combination of project prioritization strategies and concerns of other agencies (e.g., DOT district or regional offices, FHWA division safety staff, etc.) should be taken into account to rank the projects for sequential selection and implementation.

Schweikert and Chinowsky (2013) stressed on including social concerns in prioritizing rural roads. They highlighted the fact that most prioritization processes utilize technical and economic benefit-cost analysis and completely ignore the most vulnerable needy communities that could gain the most from any roadway project. The existing prioritization processes consider rural road projects with low rate of return as "low priority". This study proposed to incorporate a social impact score metric system combining rural mobility, rural accessibility, urban accessibility and mobility, and employment into the prioritization methodology.

\subsection{Risk Factors Affecting Bicycle Safety and the Bicycle CMFs}

This section presents a brief review of the literature on bicycle safety. The section is divided into three major sub-sections. The first sub-section includes a review of recent literature on different risk factors affecting bicycle crashes. It also includes studies that focus on the causes, patterns, and contributing factors associated with bicycle crashes. As researchers have used several statistical and spatial models to evaluate bicycle safety, this 
sub-section is therefore organized according to the analytical methods applied in the reviewed literature. The second sub-section presents a review of literature on the safety performance of the existing engineering-related bicycle crash countermeasures. Particularly, the following countermeasures are discussed:

- bicycle lanes,

- bicycle tracks,

- bicycle boulevards,

- wide curb lanes,

- traffic calming measures such as speed humps and road diets (i.e., lane reductions),

- roadway and intersection geometry related countermeasures such as raised medians,

- crosswalks,

- roadway lighting, and

- on-street parking treatments.

The third sub-section focuses on crash frequency modeling approaches. The pros and cons of different approaches are included in this discussion.

\subsubsection{Bicycle Safety}

\subsubsection{Statistical Methods}

This section discusses the studies that have applied statistical models including logit models, probit models, odds models, multivariate Poisson-lognormal models, and regression models to identify the factors affecting bicycle safety. 


\section{Logit Models}

Klassen et al. (2014) analyzed the severity of bicycle crashes using spatial mixed logit model for Edmonton, Canada. A total of 424 intersection-related and 147 mid-blockrelated bicycle crashes that occurred during 2006-2009 were investigated. Corridor design, human, temporal, and environmental factors were considered as covariate categories. The authors did not identify any common factor contributing to bicycle crash severity at intersections or mid-block locations. However, the interaction between roadway and approach-control type, the existence of partial crosswalks and bicycle signs, and the bicyclist's gender and age were identified as significant factors affecting bicycle crash severities at intersections. Roadway classification, on-street parking, and driver's age were found significant for mid-block bicycle crash severities.

Moore et al. (2011) also differentiated the factors for intersection and nonintersection bicycle crashes. A total of 10,029 bicycle crashes that occurred from 20022008 in Ohio were analyzed. Standard multinomial logit and mixed logit models were developed to estimate the injury severity factors. Roadway geometry (horizontal curve and vertical grade), vehicle type (van, heavy truck, etc.), bicyclist safety devices (helmet), drug and alcohol usage, and driver insurance played a significant role in determining the injury severity of bicycle crashes at intersections and mid-block sections.

Zahabi et al. (2011) used an ordered logit model to investigate the effects of crash location, roadway type, vehicle movement, vehicle type, environmental conditions, population density, road connectivity, and land use mix on injury severity of pedestrians and bicyclists involved in collision with motor vehicles in the City of Montreal, Canada. Crashes at signalized intersections were found to be more dangerous for bicyclists. 
Through movement of vehicles was found to have significant associations with sustaining an injury, i.e., increased the bicyclist's injury severity. Transit access and median income were not statistically significant. The authors did not find population density and lighting to be significant factors. This result is contradictory to the result from a later study by Hamann et al. (2014) which considered these factors to be significant.

Eluru et al. (2008) applied a mixed generalized ordered response logit model to analyze pedestrian and bicyclist injury severity using data from the 2004 General Estimates System (GES). Age (the elderly are more injury-prone), speed limit (higher speed limits lead to more severe injuries), crash location (crashes at signalized intersections are less severe compared to those that occurred elsewhere), and time-of-day (dark conditions resulted in more severe injuries) were identified as influential variables affecting the nonmotorist injury severity.

Kim et al. (2007) used a multinomial logit model to identify the factors leading to the four injury severity levels in bicyclists (i.e., fatal injury, incapacitating injury, nonincapacitating injury, and possible or no injury). The authors used crash data from 19972002 from North Carolina. Inclement weather, no streetlights, morning peak hour (06:00 AM to 09:59 AM), head-on crashes, speeding involving vehicle speeds over $30 \mathrm{mph}$, truck involvement, drunk driver, bicyclist age 55 or over, and drunk bicyclist were found to double the probability of a fatal injury in a bicycle crash. An estimated pre-crash speed of vehicles of more than $50 \mathrm{mph}$ was found to increase the bicyclist's probability of a fatal injury by more than 16 times. Compared to the bicycle crashes involving at-fault drivers, those involving at-fault bicyclists were identified to be more closely correlated with bicyclist injury severity. 


\section{Probit Models}

Klop and Khattak (1999) examined the impacts of physical and environmental factors on the bicyclist injury severity. North Carolina Highway Safety Information System (HSIS) crash and inventory data from 1990-1993 for state-controlled, two-lane, undivided roadways were analyzed. Using the KABCO scale of injury severity distribution, two ordered probit models, one with all crashes and the other one restricted to only those in rural areas were developed [In the $\mathrm{KABCO}$ scale, $\mathrm{K}=$ fatal, $\mathrm{A}=$ incapacitating injury, $\mathrm{B}=$ non-incapacitating injury, $\mathrm{C}=$ possible injury, and $\mathrm{O}=$ property damage only]. Roadway characteristics such as speed limit, both straight and curved grades; driver- and bicyclistrelated factors including impaired braking, acceleration, and maneuverability; environmental factors including fog and dark unlighted conditions showed increased severity trend, most probably due to their effect on driver reaction time and speed differentials at the time of impact. Annual average daily traffic (AADT), interaction between shoulder width and speed limit, and street lighting were found to be associated with decreased injury severity. Marginal effects of each factor on the likelihood of each injury severity class were identified. They highlighted the fact that in addition to vehicular traffic and scenery, decision makers should also review the frequency of both straight and curved grades on roadway segments, the presence of a shoulder, and the presence of foggy

conditions in selecting state bicycle routes. The authors concluded that reducing grades and curves on new two-lane roadway construction might have additional benefits in terms of reduced bicycle crash severity. 


\section{Odds Models}

Wang et al. (2015) investigated the factors associated with the severity of injuries sustained by bicyclists in bicycle crashes at unsignalized intersections. Bicycle crash data were extracted from Kentucky State Police's Kentucky Collision Database for the period 2002-2012. The authors employed a partial proportional odds model. Stop-controlled intersections, one-lane approaches, helmet usage, and lower speed limits were found to be associated with decreased injury severity. On the other hand, uncontrolled intersections, older drivers and bicyclists (age $>55$ years), child bicyclists (age $<16$ years), foggy and rainy weather, inadequate use of lights in dark conditions, and wet road surface were found to increase bicycle injury severity.

\section{Multivariate Poisson-Lognormal Models}

Kaplan and Prato (2015) utilized a multivariate Poisson-lognormal model to analyze land use and network effects on frequency and severity of bicycle crashes in the Copenhagen region. A total of 5,349 bicycle crashes from 2000-2013 were extracted for analysis from the National Crash Database compiled by the Danish Road Directorate. Traffic exposure of non-motorized and motorized transport modes was controlled in the model. The effect of infrastructure (e.g., the presence of bicycle lanes or paths, the presence of different types of intersections) and land use (e.g., the characteristics of the area where the roads were located and their interactions with the aforementioned infrastructure) was evaluated, and heterogeneity and spatial correlation across links was accounted in the model framework. The model resulted in reduced crash rates as bicycle traffic increased and this happened more for fatal and severe injury bicycle crashes. 
The study revealed that crash rates decreased with increasing traffic volume, and particularly severe crash rates reduced more with increasing level of congestion. Fatal and severe injury crashes were related to the presence of more heavy vehicles on the road. Bicycle lanes and segregated bicycle paths reduced the number of severe injury crashes, and the effects were more pronounced in suburban areas. Possible injury or no injury crashes were more concentrated at the Copenhagen city center; whereas, fatal and severe injury crashes were more associated with industrial zones. One-way streets were correlated with decreased number of crashes, although this relationship was found to be reversed for the city center. The model identified intersections to be more problematic than mid-block sections, and the difference was even more pronounced when located in suburban areas. Roundabouts were found to be the most problematic type of intersections. Giving the rightof-way, crossing a traffic signal, and crossing a roundabout triggered more bicycle crashes (Kaplan and Prato, 2015).

Regression Models

Boufous et al. (2012) examined the risk factors associated with the injury severity of bicyclists involved in traffic crashes in Victoria, Australia during 2004-2008. A logistic regression was used to ascertain the predictors of serious injury and fatal crashes. About $34 \%$ of 6,432 police-reported bicycle crashes resulted in severe injury. The multivariate analysis identified age (50 years and above), not wearing helmet, dark unlit roadway conditions, $70 \mathrm{kmph}$ or above speed zones $(43.5 \mathrm{mph})$, curved roadway sections, rural locations, head-on collisions, run-off-road crashes due to loss of control, striking the door of a parked vehicle on paths as the main factors increasing the severity of injuries in bicycle crashes. 
Schepers et al. (2011) also investigated the safety of bicyclists at unsignalized intersections within built-up areas in Netherlands using crash data from 2005-2008. The study focused on the association between intersection design characteristics and bicycle crashes. The authors classified bicycle crashes into two types based on the movements of the involved motorists and bicyclists: type I - through bicycle-related crashes where the bicyclist had the right-of-way, i.e., bicycle on the priority road; and type II - through motor vehicle-related crashes where the motorist had the right-of-way, i.e., motorist on the priority road. Negative Binomial (NB) method was employed for the study. The probability of each crash type was found related to its relative flows and independent variables. Type I crashes were found to occur more at intersections with two-way bicycle tracks, wellmarked, and reddish colored bicycle crossings; and these crashes are negatively related to raised bicycle crossings, i.e., speed humps and other speed-reducing measures. The intersections where the bicycle track approaches were 2-5 m away from the main carriageway were found to have lower crash probabilities. Roadway geometric factors such as raised medians did not have any significant impact on type II crashes. However, bicycle crashes were found to be less severe at intersections with speed-reducing devices.

Bíl et al. (2010) evaluated the critical factors in fatal crashes involving adult bicyclists (over 17 years) using multivariate regression analysis. The authors analyzed 1995-2007 crash data from the Traffic Police of Czech Republic. Inappropriate driving speeds, head-on collisions, and unlit roadways were identified as significant factors. Bicycle crashes were found to be more serious when associated with the consequence of bicyclist's denial of right-of-way on crossroads. Male bicyclists were found to be more prone to fatal injuries compared to female bicyclists. The most vulnerable age group was 
found to be 65 years and older. The authors also found that more crashes where bicyclists were at-fault resulted in a fatal injury compared to those where drivers were at-fault (598 vs. 370).

Oh et al. (2008) developed bicycle crash prediction models for urban signalized intersections. The authors conducted field surveys at 151 intersections in Inchon, Korea to identify the potential variables affecting bicycle crashes. The study revealed Poisson regression model to be most suitable for predicting bicycle crashes. The models identified the following factors (and their direction of association) to be the most critical for bicycle crashes at urban signalized intersections: AADT (+), presence of bus stops (-), sidewalk width (-), number of driveways (+), presence of speed restriction devices (-), presence of crosswalk $(+)$, and industrial land use (+). In addition, the study emphasized the need to incorporate driver characteristics, roadway geometric design, and operational features in the analysis.

\subsubsection{Spatial Frameworks}

Researchers have traditionally been using spatial analysis to study the influence of socio-economic and demographic factors such as population, median household income, vehicle ownership, etc., on bicycle crashes. This section presents the recent studies that have analyzed bicycle safety spatially in ArcGIS. More specifically, studies focusing on the spatial analysis of bicyclist injury severity trends, bicycle crash clusters, and the spatial correlation between bicycle safety and several engineering, socio-economic and demographic factors are reviewed and summarized.

Lawrence et al. (2015) conducted a geospatial analysis of bicyclist injury trends in Melbourne, Australia. The objective was to identify reduced bicyclist injury areas. The study examined crash characteristics and cycling environment to better understand the 
factors associated with bicycle safety. Two methods were employed: (a) cycling injury severity was calculated using a kernel density estimation method for the period 2000-2011 to study patterns in injury density across Melbourne over an extended time period; and (b) the absolute change in injury density was calculated between 2005 and 2011, which helped identify a geographic area which experienced a relatively more significant reduction in injury density. Figure 2-1 displays the spatial analysis results. The crash characteristics were then analyzed to identify the changes to the cycling environment that were associated with reduced injury rate. As shown in Figure 2-1, a geographical area to the southeast of Melbourne was found to have experienced a significant reduction in injury rate. It appeared that a combination of behavior and road infrastructure changes might be the contributing factors for the observed reduction. However, the lack of cycling exposure data prevented more conclusive remarks.

Chimba et al. (2014) also used GIS to geo-locate and cluster the pedestrian and bicycle crash locations on the roadway network in Tennessee. The study objective was to investigate demographic, socio-economic, roadway geometric, traffic, and land use characteristics affecting pedestrian and bicycle crash frequency. NB regression was employed to model the relationship between contributing factors and crashes. The findings were used to identify patterns of pedestrian and bicycle high crash locations in Tennessee. Population distribution by race, age group, mean household income, percentage in the labor force, poverty level, vehicle ownership, land use, number of lanes crossed by pedestrians or bicyclists, posted speed limit, and the presence of special speed zones were found to significantly influence the frequency of pedestrian and bicycle crashes. 


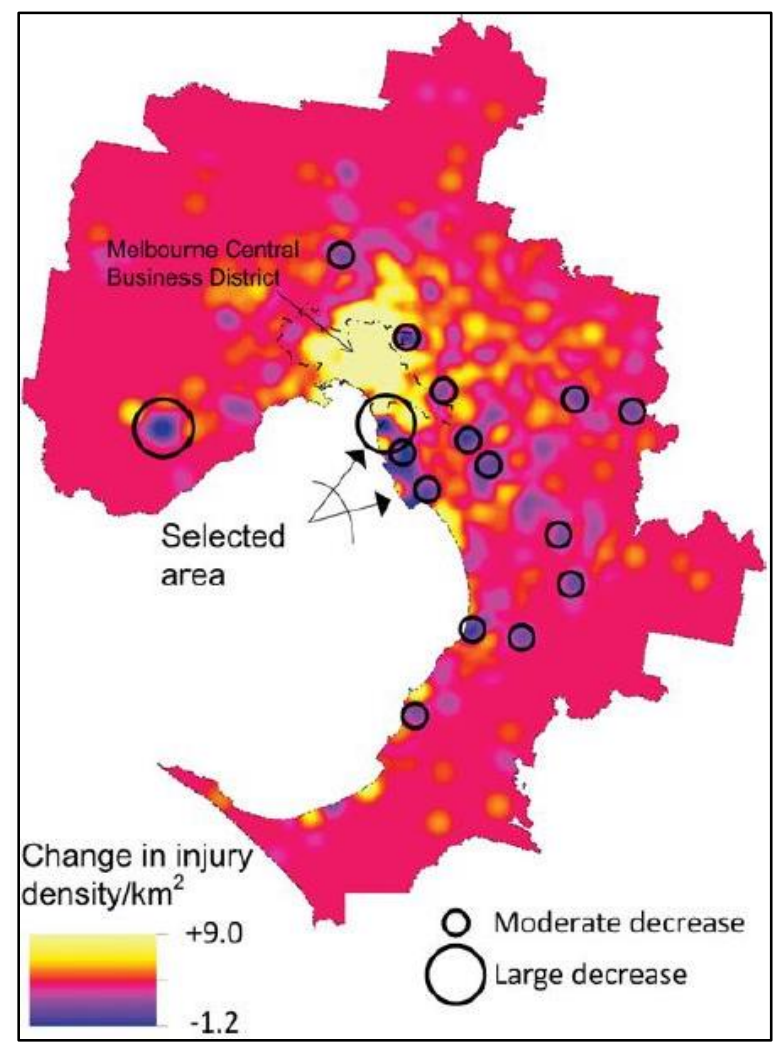

Figure 2-1: Geographic Region in Melbourne, Australia, Selected for Detailed Case Study Based on Spatial Analysis (Source: Lawrence et al., 2015)

Siddiqui et al. (2012) applied a Bayesian spatial framework to model bicycle crashes to investigate the spatial correlation at Traffic Analysis Zones (TAZs) level in Hillsborough and Pinellas counties in Florida. Roadway characteristics, environmental, demographic, and socio-economic variables associated with bicycle crashes were used to develop the aggregate (i.e., macroscopic) models. The Bayesian models were compared with the traditional NB models to assess the effect of spatial correlation. Two Bayesian models were developed, one with only the random effects which did not account for the spatial correlation, and the other with both the random effects and spatial correlation to compare the results and explicitly identify the effect of spatial correlation. A Heuristic approach, Bayesian Poisson-lognormal, was used along with the traditional forward and 
backward methods for variable selection while developing the non-Bayesian models. Florida Department of Transportation (FDOT) District Seven's bicycle crash data for 20052006 was analyzed. It was found that variations contributed by spatial correlations are about $79 \%$ for bicycle crashes in the TAZs; thus, Bayesian models controlled for spatial correlation resulted in a better fit.

The authors considered the following eleven significant variables for the nonBayesian NB model: (1) the total length of roadways with 15 mph posted speed limit, (2) total length of roadways with $35 \mathrm{mph}$ posted speed limit, (3) total number of intersections per TAZ, (4) median household income per TAZ, (5) total number of dwelling units, (6) $\log$ of population per square mile of a TAZ, (7) percentage of households with non-retired workers but zero auto, (8) percentage of households with non-retired workers and one auto, (9) urban flag for a TAZ, (10) number of kindergarten through 12th grade enrollment, and (11) log of total employment number in a TAZ. The Bayesian model which did not account for spatial correlation identified similar variables as significant; whereas, median household income per TAZ, urban flag for a TAZ, and number of kindergarten through 12th grade enrollments were found statistically insignificant when spatial correlation was considered in the Bayesian model. Neighborhood-related variables did not reveal any significant difference in the two models.

A similar conclusion was drawn by Kim et al. (2007) except for institutional areas (i.e., schools) which were found to be associated with higher probabilities of incapacitating injuries. Moran's I statistic identified the spatial orientation of kindergarten through 12th grade school enrollment as 'random' which explained the reason why it was not found significant in the model addressing the spatial relation by Siddiqui et al. (2012). Total 
roadway length with $15 \mathrm{mph}$ posted speed limit was found to be the only variable negatively associated with bicycle crashes. On the contrary, total roadway length with 35 mph posted speed limit was found to have positive association. A similar positive association between $30 \mathrm{mph}$ and $40 \mathrm{mph}$ was observed by Kim et al. (2007). The number of intersections was also found to be highly associated with bicycle crashes. A study by Carter and Council (2007) identified the similar relationship that about $48 \%$ of bicycle crashes are intersection-related in urban areas. The estimates for percent of households with non-retired workers with zero autos was found to be twice than that of non-retired workers with one auto in the model with spatial correlation, implying the latter is less critical than the former variable while other variables being controlled. Population density and total employment, the two possible surrogate measures for bicycle exposure, were also found to be positively associated with bicycle crashes. Siddiqui et al. (2012) concluded that Bayesian Poisson-lognormal models with spatial correlation to be the better one compared to other models that did not account for spatial correlation among TAZs. Quddus (2008) acknowledged the Bayesian framework as a more capable platform to account for spatial correlation and uncontrolled heterogeneity present in macro-level crash data.

Loo and Tsui (2010) conducted a spatial, circumstantial, and epidemiological study on bicycle crashes in Hong Kong, where bicycle is a minor mode of transport. The Traffic Accident Database System (TRADS) of Hong Kong police from 2005-2007 and a hospital based Road Casualty Information Database (RoCIS) were used. Spatial and statistical tools including buffer analysis, chi-square tests, analysis-of-variance, and binary logistic regression were used to analyze bicycle crashes. It was found that large proportion of crashes occurred on public roads near cycle tracks which triggered the careful 
consideration of fully integrated cycle tracks in the new territories and sufficient safe road network connecting the new cycle tracks. Majority of the bicycle crashes were found to have taken place on relatively simple road environment which highlighted the lack of sufficient training and practice. The bicycle safety problem was found to be more serious on roads outside the cycle tracks as these locations experienced bicycle crashes often resulting in serious and fatal injuries. These bicyclists were mainly middle-aged males (> 45 years) riding bicycles on public roads and were using bicycles as their mode of transportation for daily trips. Proper education for all bicyclists focusing on the use of helmets and protective gears was stressed in the study.

\subsubsection{Descriptive Data Analyses}

Descriptive data analysis is one of the oldest and the most common techniques in crash data analyses. It provides an overall understanding about the safety situation and helps to identify the most probable predictors that affect crash frequency and severity. This section discusses several recent studies that have used the descriptive data analysis techniques to improve bicycle safety.

Johnson et al. (2013) studied the crash characteristics and risk factors associated with bicyclists and open vehicle doors in Victoria, Australia. Three complementary data sources were used in this study: a total of 1,247 police-reported bicycle crashes from 20002011, a total of 401 hospitals' emergency department presentations for the period 20002010, and a sample of video footage from a naturalistic study of commuter bicyclists in Melbourne from 2009-2010. Bicyclist-open vehicle door crashes accounted for about 8.4\% of the police-reported crashes, and 3.1\% of the hospital-recorded crashes. Male population (police report: 67.1\%; hospital record: $65.8 \%$ ) comprised the higher portion of the injured 
bicyclists. Adults aged 18 years or older (police report: 97.5\%; hospital record: 96.3\%) were found to be the most vulnerable age group for bicyclists. A high percentage $(93.1 \%)$ of crashes took place within $60 \mathrm{kmph}(37.3 \mathrm{mph})$ speed zones. The study identified 13 door-related events with a rate of 0.59 events per trip from the naturalistic cycling study data; most drivers were found to not look in the direction of the bicyclist before opening their vehicle doors.

Schepers and Wolt (2012) investigated the single-bicycle crash types and their characteristics using a questionnaire survey conducted in the Netherlands. The survey targeted bicycle crash victims treated at an Emergency Care Department. The questionnaire had two types of questions: open-ended questions about the crash, and closed-ended questions focusing on possible direct causes, crash characteristics, and circumstances. About half of all single-bicycle crashes were found to be related to infrastructure: collision with an obstacle, run-off-road, bicycle skidding due to slippery road surface, the bicyclist was unable to stabilize the bicycle or stay on the bicycle because of an uneven road surface. Loss of control at low speed, forcing on the front wheel, poor or risky riding behavior, bicycle defects, and gust of wind were the other main contributing factors.

\subsubsection{Combination of Methods}

This section focuses on recent studies that have applied a combination of spatial methods and regression techniques in analyzing bicycle crash frequency and severity, and identifying bicycle crash causes, patterns, and contributing factors.

Hamann et al. (2014) examined bicycle crashes at intersections and nonintersections in Iowa for the period 2001-2011 to identify the influence of person, crash, environment, and population characteristics. The study employed descriptive statistics, 
GIS mapping, and multivariable logistic regression to examine factors associated with crash risk and crash location. These variables were identified as independent predictors of the crash location (i.e., intersection or non-intersection). It was found that young bicyclists ( $<10$ years old) were more prone to non-intersection bicycle crashes. Obscured vision was found to be a triggering factor for non-intersection crashes. Non-intersection crashes were found to take place outside the city limits, i.e., in rural areas, probably due different exposure or with reduced lighting. Failing to yield right-of-way was a less associated factor for non-intersection crashes. Densely populated, low income, and low education areas were found to be more crash prone; however, crash location did not make any difference on the crash statistics in these areas. Evans and Kantrowitz (2002) attributed bicycle crash issues to more traffic and/or poorer maintenance of these areas. On the other hand, Edwards et al. (2008) and Morency et al. (2012) recognized the socio-economic disparity inclusive of behavioral aspects has greater risk-taking likelihood for these bicycle crashes.

As mentioned earlier, Chimba et al. (2014) investigated demographic, socioeconomic, roadway geometric, traffic, and land use characteristics affecting pedestrian and bicycle crash frequency in Tennessee. In this study, GIS was used to geo-locate and cluster the crash locations, and NB regression was employed to model the relationship between contributing factors and pedestrian and bicycle crashes. Pedestrian and bicycle crash data for the period 2003-2009 from Tennessee Department of Transportation (TDOT) and Tennessee Department of Safety (TDOS) databases were used in the study. The crash data contained 5,360 pedestrian crashes and 2,558 bicycle crashes. TDOT's geospatial data and U.S. census website's demographic and socio-economic data at census tract level were also used for the GIS analysis. Population distribution by race, age group, mean household 
income, percentage in the labor force, poverty level, vehicle ownership, land use, number of lanes crossed by pedestrians or bicyclists, posted speed limit, and the presence of special speed zones were found to significantly influence the frequency of pedestrian and bicycle crashes. The findings were used to identify patterns of pedestrian and bicycle high crash locations in Tennessee. Emaasit (2013) recommended the similar approach to identify bicycle and pedestrian hot spots and identify the contributing factors for such crashes.

Rodgers (1997) used logistics regression technique to evaluate the crash risk factors associated with adult bicyclists by comparing information on the characteristics and travel patterns of bicyclists who had crashed with those who had not. The analysis was based on data from a national survey of over 3,000 bicyclists 18 years and older. The survey had the information on the characteristics and use patterns of the bicyclists and whether they had crashed or fallen from their bicycles during the preceding year. The crash risk was found higher for males than for females, and was lower for bicyclists in the 25-64 year age group than it was for bicyclists younger than 25 years and older than 64 years. Risk was found to be directly proportional to the miles traveled. Furthermore, risk was found to be substantially higher for off-road bicyclists compared to on-road bicyclists; for those who race; for all-terrain style bicycles as opposed to general-purpose bicycles; and for Pacific Coast states compared to eastern, midwestern, southern, and mountain states. Hands-on training geared toward adults, improvement of riding environment by bicycle paths and bicycle lanes, use of helmets, and further research were emphasized as injury reduction strategies. 


\subsubsection{Bicycle Crash Countermeasures and CMFs}

\subsubsection{Bicycle Lanes}

Bicycle lanes are defined as a portion of the roadway designated for the preferential or exclusive use of bicyclists and are separated from motor vehicle traffic through the use of pavement markings (Mead et al., 2014). Figure 2-2 shows an example of bicycle lanes in Chicago, IL.

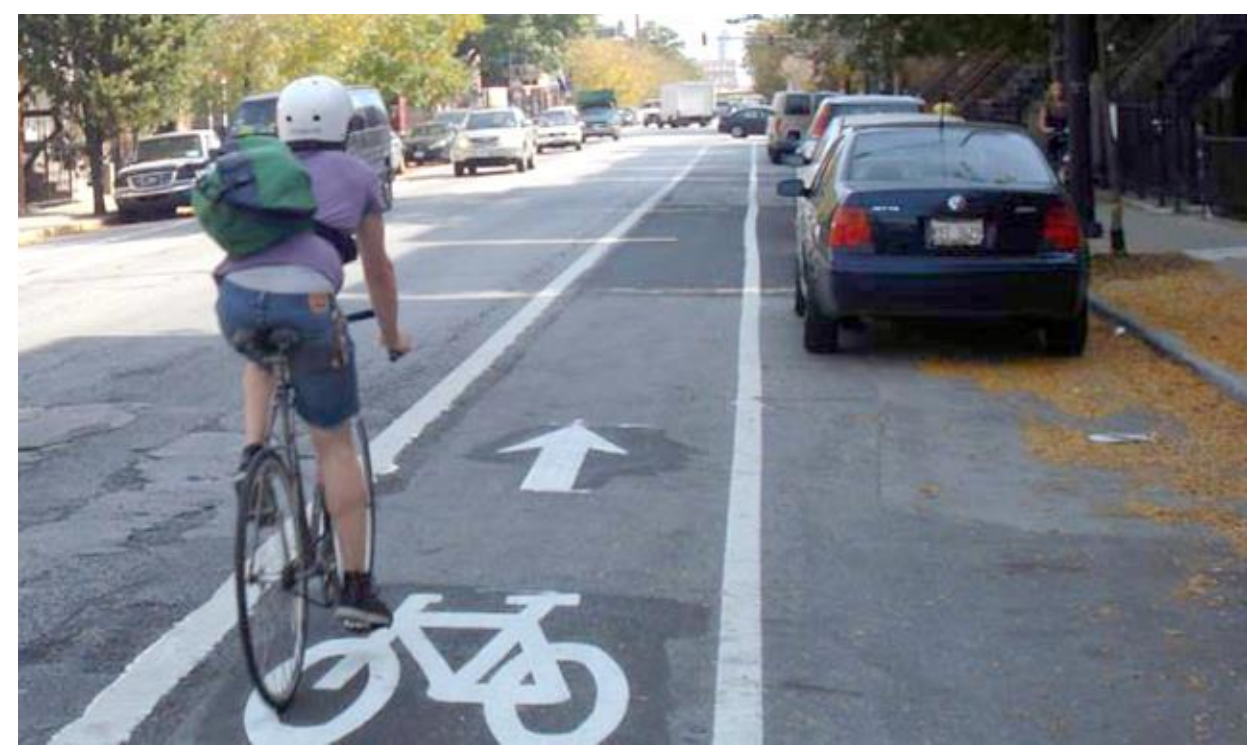

Figure 2-2: Bicycle Lanes in Chicago, IL (Source: NACTO, 2012; Photo: CDOT)

Park et al. (2015) determined the relationships between the safety effects of adding a bicycle lane and the roadway characteristics on urban arterial facilities in Florida. The authors used observational before-and-after with empirical Bayes (EB) and cross-sectional methods to develop the CMFs. Adding a bicycle lane on urban arterials had a positive safety effect (i.e., CMF < 1.0) for all crashes, and was more effective in reducing bicycle crashes (CMF of 0.439 with EB method and 0.422 with cross-sectional method). The CMFs were found to be varying across the sites with different roadway characteristics. AADT, number of lanes, AADT per lane, median width, bicycle lane width, and lane width 
were found to be the significant characteristics that affect the variation in safety effects for adding a bicycle lane. Socio-economic characteristics such as bicycle commuter rate and population density were also found to have significant effect on the CMFs. Full crash modification functions showed better model fit than simple crash modification functions since they account for the heterogeneous effects of multiple roadway and socio-economic characteristics.

Chen et al. (2012) evaluated the safety effects of bicycle lanes installed prior to 2007 in New York City on total crashes, bicycle crashes, pedestrian crashes, multi-vehicle crashes, and fatal and injury crashes. The impact of bicycle lane installation in a treatment group and a comparison group was studied using generalized estimation equation methodology. The study revealed that the number of bicyclists increased after the installation of bicycle lanes; however, the lanes did not increase bicycle crash frequency, most likely due to reduced vehicular speeds and fewer vehicle-bicycle conflicts.

Nosal and Miranda-Moreno (2012) studied the bicyclist injury risk on bicycle lanes in Montreal using relative risk ratios. Most bicycle lanes were found to exhibit lower bicyclist injury rates than the corresponding control streets. Operation way, visibility, physical separation, presence and location of parking, vehicular traffic, and the direction of vehicular traffic were identified as the prominent factors affecting the bicyclist injury risk.

Turner et al. (2011) analyzed three main safety studies undertaken in New Zealand and Adelaide, Australia. The authors applied generalized linear modeling and before-andafter, control-impact methods. Crash, traffic, and bicycle volumes, and layout data were collected for urban road links, traffic signals, and roundabouts. A safety-in-numbers effect, 
i.e., crash risk per bicyclist, was shown to be lower as bicycle volume increased. This was demonstrated by the flow-only models. Before-and-after analysis was employed to identify the presence of biasness toward the sites with bicycle facilities. The research findings on the impact of bicycle facilities on safety were mixed. The safety performance factor value with bicycle lane was 1.21 , indicating a $21 \%$ increase in bicycle crashes after the bicycle lanes were constructed. However, a before-and-after study using the EB method showed a $10 \%$ reduction in bicycle crashes at treatment sites, which indicated bias in the sites that were selected for treatment. Colored bicycle lanes decreased bicycle crashes by $39 \%$ in the before-and-after studies, and resulted in safety performance factors of less than 0.5 for most crash types. Thus, well-designed bicycle lane facilities with adequate width and color pavement performed best.

Hunter et al. (2009) examined bicycle counts and speeds associated with the installation of bicycle lanes in St. Petersburg, Florida. The study showed a total of 17.1\% increase in bicycle usage per day after the installation of bicycle lanes; however, one of the streets experienced almost no change in bicycle usage. The average bicycle speeds remained the same (approximately 11-12 $\mathrm{mph}$ ) both prior to and after the construction of bicycle lanes. The study highlighted the fact that the addition of bicycle lanes alone on a street could not guarantee an immediate increase in bicycle volume and/or speed; rather other factors such as adjacent land use, convenient origins and destinations, and connectivity of bicycle lanes to other bicycle facilities within the street system were critical in encouraging bicycling.

Hunter et al. (2008) studied the impact of green colored pavement and accompanying signing in a bicycle lane weaving area (Figure 2-3), where motor vehicles 
cross the bicycle lane near intersection on bicyclists' and motorists' behavior. The study was conducted in St. Petersburg, Florida. The authors compared the operational behavior of the bicyclists and motorists at selected locations using video footage recorded before and after the green pavement and signing treatments were installed. The authors found that $11.8 \%$ more motorists yielded to bicyclists, and $4 \%$ more motorists signaled their intention to turn right in the after-period. Overall, $6 \%$ more bicyclists scanned for proximate vehicles in the after-period; while the percentage of conflicts (i.e., sudden changes in speed and/or direction) was lower in the after-period, the differences were not statistically significant. The significant increase in yielding behavior by motorists was similar to the study findings by Hunter et al. (2000) in Portland, Oregon.

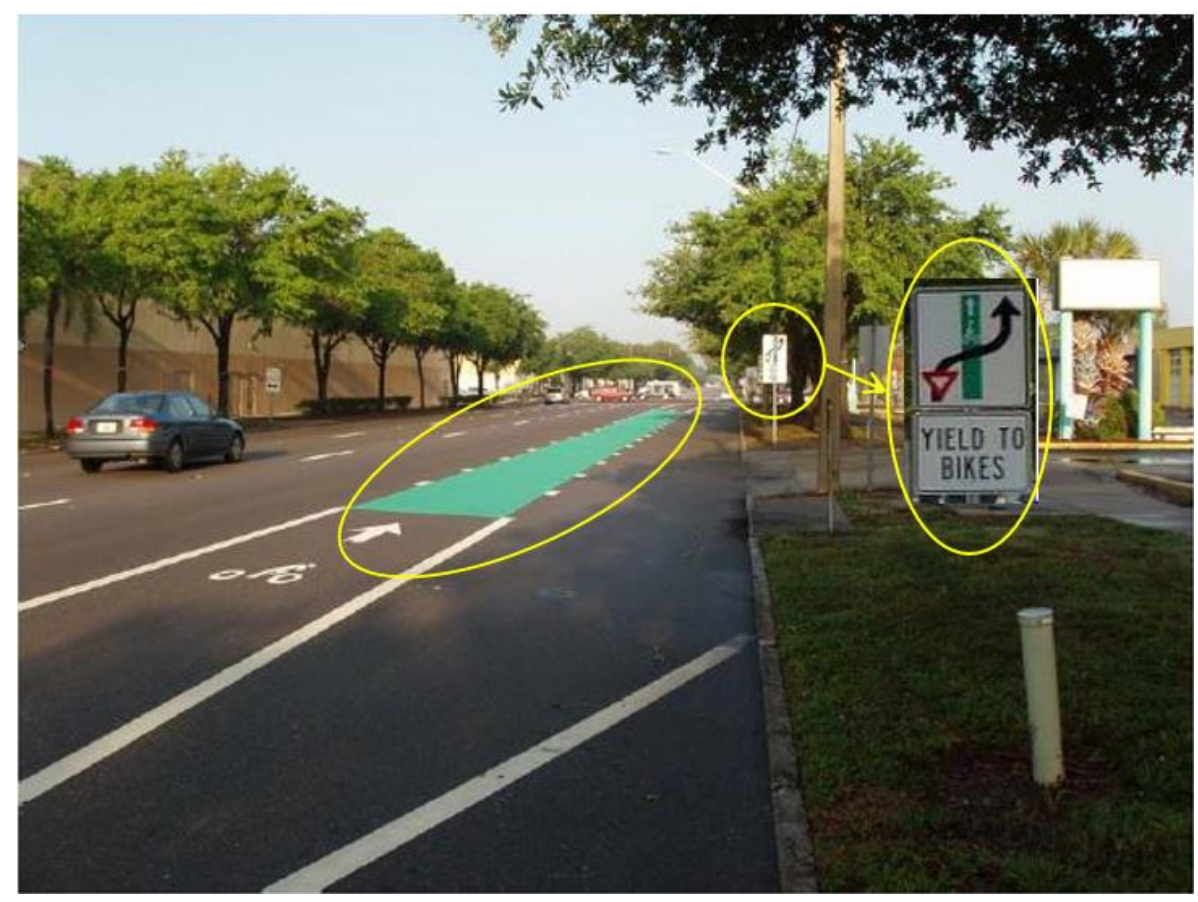

Figure 2-3: Green-colored Pavement and Accompanying Signing in a Bicycle Lane Weaving Area in St. Petersburg, FL (Source: Hunter et al., 2008)

Jensen (2008) conducted an observational before-and-after study to evaluate the safety performance of bicycle lanes in Copenhagen, Denmark. A general comparison group 
in the observational study was incorporated to address the changes in traffic volumes and crash frequency and crash severity trends through correction factors. Bicycle lanes in the study resulted in a $5 \%$ increase in crashes and a $15 \%$ increase in injuries in urban areas. Thus, the study revealed that safety for bicyclist's worsened at locations where bicycle lanes were constructed and safety was found to be the worst for bicyclists and moped riders with a $49 \%$ increase in injuries. The study findings are quite contradictory to the findings from several other studies including Rodegerdts et al (2004), Chen et al. (2012), Nosal and Miranda-Moreno (2012), and Park et al. (2015). Rodegerdts et al. (2004) concluded that bicycle lanes reduced fatal, serious, and minor injury bicycle crashes by $35 \%$, i.e., the study resulted in a CMF of 0.65 for bicycle lanes.

\subsubsection{Bicycle Tracks}

Bicycle track is a bicycle facility which is designated for the exclusive use of bicyclists. These are physically separated from the sidewalk and the roadway by curbs. Parked vehicles between the moving traffic and the bicycle track may offer an additional buffer from roadway traffic (Mead et al., 2014). Figure 2-4 depicts a schematic diagram of a bicycle track and a bicyclist using such a track in Copenhagen, Denmark.

Nosal and Miranda-Moreno (2012) studied the bicyclist injury risk on bicycle lanes and also the effect of bicycle tracks in Montreal using relative risk ratios. The performance of bicycle track was found to be similar to the performance of bicycle lanes. Most bicycle tracks were found to result in lower bicyclist injury rates than the corresponding control streets. Similar to the bicycle lanes, direction of traffic operation (i.e., bidirectional or not), visibility, physical separation, presence and location of on-street parking, vehicular traffic, 
and the direction of vehicular traffic were identified as the prominent factors affecting the bicyclist injury risk on bicycle tracks.
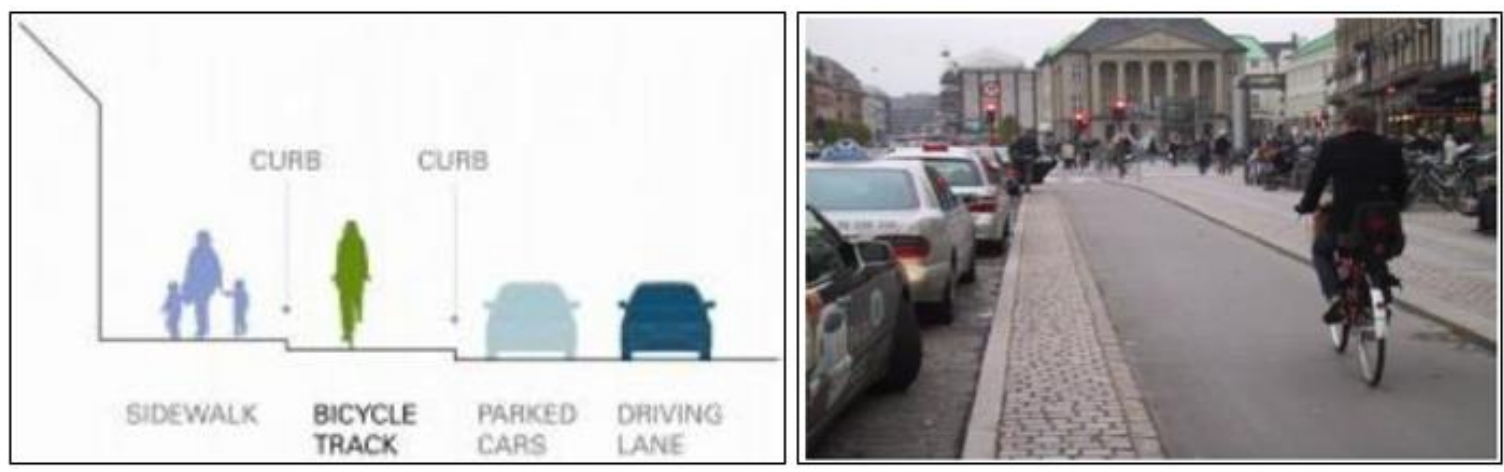

Figure 2-4: Bicycle Track (Source: Mead et al., 2014) (Photo Courtesy: Lars Gemzøe and Gehl Architects, Member of the Cycling Embassy of Denmark)

Schepers et al. (2011) also investigated the safety effects of bicyclists at intersections with two-way, well-marked, and reddish colored bicycle crossings in Netherlands. Bicycle crashes where the bicyclist had the right-of-way (i.e., bicyclist on the priority road) were found to be more prone to occur at these sites than where the motorist had the right-of-way (i.e., motorist on the priority road). Intersections where bicycle track approaches were 2-5 meters away from the main travel way were found to have decreased bicycle crash probability, with a CMF of 0.55 . Similarly, bicycle tracks that were over 5 meters away from the main travel way also resulted in a decreased bicycle crash probability with a CMF of 0.93 . However, the crash probability was found to be almost the same for bicycle lanes and bicycle paths when the distance between the bicycle track and the side of the main road is less than 2 meters. The red color and high quality markings did not improve the safety for bicyclists, and resulted in a CMF of 1.47 for red color, a CMF of 1.74 for high quality markings, and a CMF of 2.53 for the presence of both red color and high quality markings at bicycle crossings. 
Jensen (2008) conducted an observational before-and-after study to evaluate the safety performance of bicycle tracks in Copenhagen, Denmark. A general comparison group in the observational study was incorporated to address the changes in traffic volumes and crash and injury trends through correction factors. Bicycle tracks increased crashes and injuries by $10 \%$ in urban areas. Thus, the study revealed that safety for bicyclists worsened at locations with bicycle tracks. However, bicycle tracks resulted in a $20 \%$ increase in bicycle/moped traffic mileage and a 10\% decrease in AADT. The author calculated a CMF of 1.05 for all crash types and for all crash severities. The study also calculated the CMFs for different combinations of crash types and crash severities.

\subsubsection{Bicycle Boulevards}

Bicycle boulevards are defined as traffic-calmed side streets signed and improved for bicyclists to provide a safer alternative to riding on arterials. Figure 2-5 gives an example of a bicycle boulevard. Minikel (2012) studied bicyclist safety on bicycle boulevards and parallel arterial routes in Berkeley, California. Police-reported bicycle crashes and manually collected bicyclist count data from bicycle boulevards and parallel arterial routes in Berkeley, California from 2003 to 2010 were analyzed. The study identified that crash rates on Berkeley's bicycle boulevards are two to eight times lower than those on parallel, adjacent arterial routes, and resulted in a CMF of 0.37.

\subsubsection{Wide Curb Lanes}

An alternative to the installation of a five-foot bicycle lane is to design the curb lane wide enough so that it can accommodate bicyclists. It is a good provision when there is right-of-way limitation. The wide curb lanes are often enhanced with shared lane 
markings to increase awareness of the presence and position of bicyclists. Figure 2-6 gives an example of a wide curb lane in Virginia.

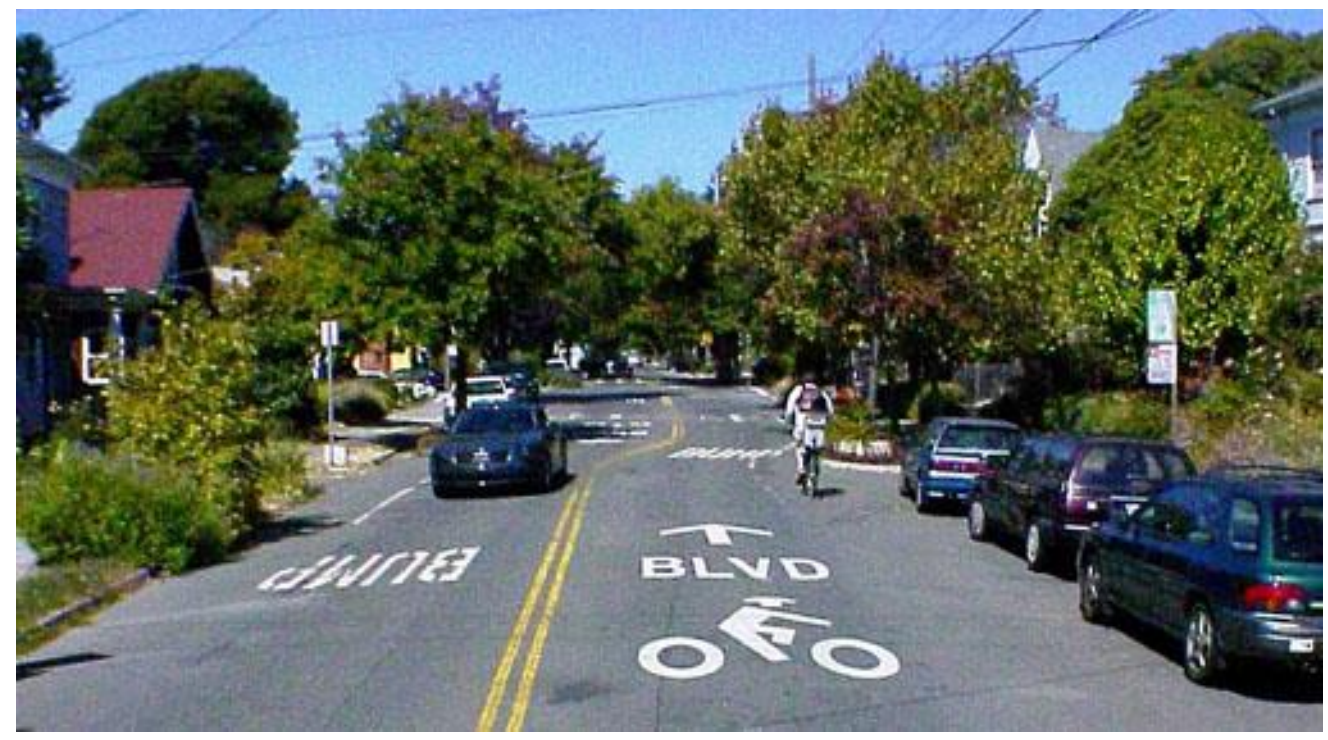

Figure 2-5: Bicycle Boulevard (Source: Williams, 2014)

Sando et al. (2011) studied the motorists' behavior when passing bicyclists on wide curb lanes. The authors video recorded 956 passing events at 10 sites in Tallahassee, St. Petersburg, and Brandon, Florida during peak hours. A multivariate regression model was developed to identify and understand the significant variables influencing the passing behavior. The authors concluded that motorist passing distance is influenced by environmental factors, such as lane width; contextual factors, such as the presence or absence of vehicles in adjacent lanes; and bicyclist characteristics, such as gender.

Hunter et al. (1999) conducted a comparative study of bicycle lanes versus wide curb lanes in Santa Barbara, California; Gainesville, Florida; and Austin, Texas. They video recorded motor vehicle-bicyclist interactions at 48 study sites and documented 276 conflicts between motor vehicles and bicyclists. It was found that while passing bicyclists on the left, a significantly higher percentage of vehicles encroached into the adjacent traffic 
lane at locations with wide curb lanes $(17 \%)$ than at locations with bicycle lanes $(7 \%)$. Lane encroachments hardly caused any conflict with motor vehicles using the other lane. Where the bicycle lane width was 5.2 feet or less, the average bicyclist distance from the curb was less than for wide curb lanes; however, at locations where the bicycle lane width was greater than 5.2 feet, the average bicyclist distance from the curb was greater than for wide curb lanes. The authors concluded that bicycle lanes and wide curb lanes were both effective in improving bicyclist safety; however, they recommended the installation of bicycle lanes if right-of-way permits.

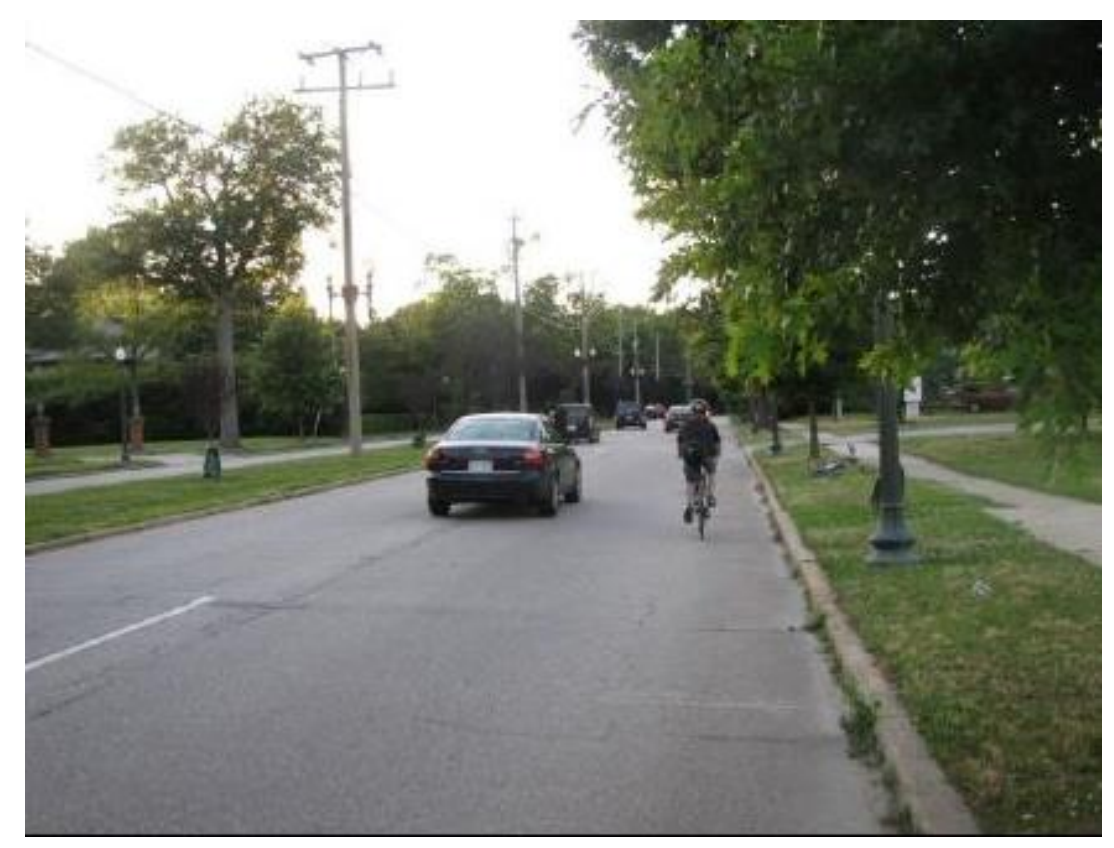

Figure 2-6: Wide Curb Lane (Source: Mead et al., 2014) (Photo Courtesy: James and Gilbert, 2012)

Harkey and Stewart (1997) examined motorist and bicyclist behavior on roadway segments with a bicycle lane, a wide curb lane, and a paved shoulder. The study revealed that motorists passed at a distance of approximately six feet irrespective of the facility type. Motorists tended to move about one foot laterally while passing a bicyclist in a bicycle lane, regardless of the width of the bicycle lane; whereas, motorists kept an additional 1.3 
feet when passing bicyclists in a wide curb lane compared to bicycle lanes and paved shoulders. Moreover, bicyclists were more likely to ride further from the curb in a bicycle lane or paved shoulder than in a wide curb lane. The authors conducted an observational study and concluded that bicycle lanes and paved shoulders offered a safety advantage over wide curb lanes.

\subsubsection{Traffic Calming Measures}

Traffic calming consists of modifications to the roadway design and signing to slow down and/or reduce traffic, and to improve safety. Several traffic calming measures including speed-reducing measures (e.g., speed humps) and road diets (i.e., lane reductions) are proven to be effective in improving bicycle safety.

\section{Speed-reducing Measures}

Schepers et al. (2011) studied the impacts of speed-reducing measures such as raised bicycle crossings and speed humps on bicycle safety. Similar to the findings of Gårder et al. (1998), Schepers et al. (2011) revealed that speed-reducing measures for drivers leaving or entering the main road (e.g., a raised bicycle path and/or exit construction) effectively improved safety and resulted in a CMF of 0.49 . The authors stated that speed-reducing measures on the minor road are suitable for most cases as they do not require additional right-of-way, in contrast to the construction of a bicycle path or a bicycle track. However, for through motorized vehicles on the main road where the motorists had the right-of-way, installation of speed-reducing measures such as a raised bicycle crossing resulted in a CMF of 1.28. Elvik and Vaa (2004) also recognized such negative effect of a raised bicycle crossing in reducing bicycle crashes and serious and minor injuries. Their study resulted in a $9 \%$ increase in bicycle crashes after the construction of raised bicycle 
crossings. Oh et al. (2008) concluded that the presence of speed restriction devices such as speed bumps and red light cameras improved bicycle safety (CMF of 0.28 ).

\section{Lane Reduction}

Chen et al. (2013) evaluated the effectiveness of lane reduction at intersections on bicycle safety. The researchers applied a pretest-posttest methodology to compare crash statistics after the implementation of lane reduction at 324 intersections in New York City. Five-year crash data before the lane reduction strategy implementation and two-year crash data after the implementation were analyzed. Analysis of covariance (ANCOVA) was used to control for potential regression-to-the-mean effects. The study identified that bicyclist crash incidence increased by $5.9 \%$ at treatment intersections compared to a $25.6 \%$ reduction at comparison intersection sites. Thus, an ANCOVA adjusted increase of $21 \%$ bicyclist crashes at intersections was calculated; however, the results were not significant at the 5\% significance level. The authors could not make a conclusive decision due to lack of bicycle volume data.

Hamann \& Peek-Asa (2013) examined the link between on-road bicycle facilities and bicycle crashes in Iowa during 2007-2010. A total of 147 crash sites were matched with 147 non-crash control sites, and conditional multivariate logistic regression was employed. It was found that for every 10 -foot increase in the total roadway width, the odds of the roadway being the site of a bicycle crash increased by $38 \%$. However, the researchers were not able to specify whether crashes took place when bicyclists were crossing the roadway or riding along the roadway. The results indicated that reducing the roadway width may be associated with a decreased crash risk for bicyclists. 


\subsubsection{Roadway and Intersection Geometry}

Schepers et al. (2011) studied the effect of number of lanes and intersection geometry on bicycle safety. The authors did not identify any statistically significant relation for bicycle crashes involving through motor vehicles where motorists had the right-of-way (i.e., motorist on the priority road).

Räsäsen and Summala (1998) found that the provision of raised middle islands at intersections that enclosed a left-turn section for both vehicles and bicyclists on roadways with more than two lanes resulted in a CMF of 0.96; on the other hand, raised middle islands at intersections on roadways with two lanes resulted in a reduction in safety, with a CMF of 1.48. The authors found that enabling bicyclists to cross in two phases might lower the demands and increase safety on roadways with more than two lanes.

Miranda-Moreno et al. (2011) concluded that the presence of medians produced a positive safety effect on bicycle crashes (CMF of 0.97), while a CMF of 1.67 was estimated for locations without the raised medians (Räsäsen and Summala, 1998).

Turner et al. (2011) analyzed the effect of left-turn lanes at signalized intersections in Christchurch, New Zealand and Adelaide, Australia. In New Zealand, intersections with exclusive left-turn lanes resulted in a CMF of 0.97 , and the intersections with shared left turn and through lanes resulted in a CMF of 0.60. However, bicycle safety worsened in Adelaide, Australia; intersections with exclusive left-turn lanes resulted in a CMF of 1.36, and those with shared left turn and through lanes resulted in a CMF of 1.40. Schepers et al. (2011) in their study observed a similar result. In their study, left-turn lane or left-turn section on the main road where bicyclists have right-of-way at the intersections in Netherlands resulted in a CMF of 1.12 . 
Schepers et al. (2011) concluded that restricted visibility of vehicles on a minor road to approaching bicyclists at intersections with bicyclist priority worsened the safety condition. The study resulted in a CMF of 1.37. Surprisingly, the authors found that very poor visibility improved the safety situation and resulted in a CMF of 0.54 for the same scenario. The same study identified that three-legged intersections are more bicyclist friendly (CMF 0.83) than four-legged intersections (CMF 1.28). Miranda-Moreno et al. (2011) also supported this observation, the authors calculated a CMF of 0.86 for threelegged intersections in Montreal, Canada.

Daniels et al. (2009) investigated the effect of converting intersections into roundabouts on bicycle safety. The study assumed that the effectiveness of roundabouts depend on the types of bicycles, bicycle facilities, and other geometric factors. Regression analyses on effectiveness-indices resulting from a before-and-after study of bicyclist injury crashes at 90 roundabouts in Flanders, Belgium were performed. Roundabouts with bicycle lanes performed significantly worse compared to three other design types (mixed traffic, separate bicycle paths, and grade-separated bicycle paths) for all injury crashes involving bicyclists. Conversion of traditional intersections into roundabouts with bicycle lanes resulted in a CMF of 1.93 for all injury crashes and a CMF of 1.37 for fatal and severe injury crashes. Conversion of traditional intersections into roundabouts with separated bicycle paths however improved the overall bicycle safety (CMF 0.83); however, degraded the fatal and severe bicycle crash scenario (CMF 1.42). Conversion of traditional intersections into roundabouts with grade separated bicycle paths also improved safety with a CMF of 0.56 for all crash severities, and a CMF of 1.31 for fatal and severe injury crashes. Elvik and Vaa (2004) also recognized the negative effect of raised intersections in reducing 
crashes. Their study resulted in a 5\% increase in serious and minor injury crashes and a $13 \%$ increase in property damage only (PDO) crashes.

\subsubsection{Crosswalks}

Oh et al. (2008) concluded that the presence of crosswalks is crucial in the prevention of bicycle crash probability at intersections. Their study for Korea indicated bicyclists might have a conflict with pedestrians and vehicles making a right turn when crossing an intersection. Permitting a RTOR (Right-Turn-On-Red) signal at signalized intersections increased the probability of crashes between pedestrians and bicyclists. Signs prohibiting a RTOR signal during certain hours could be more effective. The study also identified presence of bus stops as very favorable (CMF 0.18) in reducing bicycle crashes at intersections.

\subsubsection{Roadway Lighting}

Kim et al. (2007) investigated the factors that increase the probability of a severe or fatal injury in a bicycle crash using a multinomial logit model. The analysis was based on police-reported crash data from 1997-2002 from North Carolina. It was found that lack of street lights at night was associated with a $111 \%$ increase in the probability of a fatal injury. The researchers emphasized that lighting not only affected bicyclist visibility but also decreased the probability of a driver taking evasive action that would reduce injury severity. However, the study did not account for the presence or absence of illumination equipment on bicycles.

Wanvik (2009) examined the safety effect of roadway lighting on night time

crashes on Dutch roads. The author analyzed two decades of crash data. The study concluded that roadway lighting was associated with nearly $60 \%$ reduction in bicyclist 
injury crashes in dark conditions on rural roads. The observed safety effect was found to be significantly greater for bicyclists compared to vehicles.

\subsubsection{Parking Treatments}

The City of Toronto Transportation Services Division (2003) reported running into open car doors as the third most frequent type of bicycle crashes. The analysis was based on police-reported bicycle crashes that occurred from 1997-1998. The authors found that these crashes accounted for $11.9 \%$ of the 2,574 reported crashes, and resulted in more severe injuries compared to other types of bicycle crashes.

Duthie et al. (2010) studied the effects of on-street bicycle facility configuration on bicyclist and motorist behavior. Observational studies were conducted at 48 sites in three large Texas cities, Austin, Houston, and San Antonio. Bicyclist and motorist lateral position and motorist encroachment on an adjacent lane were observed. Two multivariate regression models were developed based on these observations. It was found that bicycle lanes created a safer and more predictable riding environment compared to wide outside lanes, and the provision of a buffer between parked vehicles and bicycle lanes was found to result in fewer conflicts between bicyclists and open car doors. Furthermore, the lateral position of bicyclists was found to be safer when riding next to a row of parked vehicles than riding next to only a few parked vehicles.

Teschke et al. (2012) examined the route infrastructure on injury risk to bicyclists. A total of 690 bicycle crashes in Toronto and Vancouver, Canada were analyzed, and the infrastructure of the crash location was compared to a randomly selected control site from the same trip. A case-crossover methodology was adopted in this research. It was found that bicycle riding on a major street route without parked vehicles and with bicycle 
infrastructure decreased bicyclists' injury risk by $37 \%$ when compared to the same type of road with on-street parking. Vancouver route preference survey also indicated a public preference for major streets without on-street parking and with shared lanes or bicycle lanes.

\subsubsection{Crash Frequency Modeling}

Crash frequency data are non-negative integer numbers. The standard ordinary least-square (OLS) regression which requires the dependent variable to be continuous is therefore not suitable to model crash data (Lord and Mannering, 2010). Since the dependent variable is a non-negative integer, Poisson and Negative Binomial (NB) regression models are the most common model forms for developing crash prediction models, i.e., Safety Performance Functions (SPFs). As NB models can handle over-dispersion, which is very common in crash data, these models have an advantage over Poisson models.

El-Basyouny and Sayed (2006) compared the traditional negative binomial (TNB) model and the modified negative binomial (MNB) model while developing the crash prediction models for British Columbia, Canada. The TNB approach assumes that the shape parameter of the negative binomial distribution is fixed for all locations, while the MNB approach assumes that this shape parameter varies with the location's characteristics. MNB provided a statistically significant improvement in model fit over the TNB model.

Cafiso et al. (2010) employed a NB structure to develop comprehensive crash models for two-lane rural highways using exposure, geometry, consistency, and context variables. Malyshkina and Mannering (2010) considered NB model while conducting an empirical assessment of the impact of highway design exceptions on vehicle crash 
frequency. Park et al. (2015) developed CMFs to assess the safety effects of adding bike lanes on urban arterials. The researchers used a NB model form while developing the SPFs. Lord and Bonneson (2007) tried different NB regression models using one-way and two-way frontage roads together in one model, and then in separate models; and finally used a Poisson regression model to develop CMFs for rural frontage road segments in Texas. Some of the NB models did not provide reasonable results due to low sample mean and small sample size. Models developed from datasets with such characteristics can show significant signs of instability during the model estimation process as the data may exhibit over-dispersion which cannot be captured by a NB regression model (Lord, 2006).

Since crashes are usually rare and random, there can be a large number of locations that have not experienced any crashes. Traditional Poisson and NB models may not be able to handle the datasets that have a large number of zero crash observations. Recent literature has suggested that motor vehicle crashes can be modeled successfully assuming a dualstate data-generating process to account for the excess zeros. This means the entities such as road segments, intersections, etc. exist in one of the two states - perfectly safe and unsafe. Please refer to Lord et al. (2005) for a detailed discussion on these two states. Thus, the zero-inflated Poisson (ZIP), and zero-inflated negative binomial (ZINB) models have frequently been applied to account for the preponderance of excess zeros observed in crash count data (Lord et al., 2005).

Miaou (1994) compared the performance of Poisson model, NB model, and ZIP model while establishing the relationship between truck crashes and geometric elements of road sections. All the three models were found to estimate the regression parameters consistently. In general, the author suggested that NB model estimated using the moment 
and regression-based methods should be used with caution. If the over-dispersion of crash data is found to be moderate or high, both the NB and ZIP models are recommended to be explored. Overall, the ZIP model appeared to be a potential model when data exhibit excess zeros. Shankar et al. (1997) examined ZIP and ZINB models, and proposed these models for modeling crash frequencies. Their study findings showed that ZIP model structures are promising and have the flexibility to uncover the processes that affect crash frequencies on roadway sections that experienced zero crashes and those with crash occurrences.

Carson and Mannering (2001) applied ZINB models to understand the effect of ice warning signs on ice-accident frequencies. The ZINB model was found to be the most appropriate to assess the effects of ice-warning signs on accident frequencies. Lee and Mannering (2002) studied the impact of roadside features on the frequency of run-off-road crashes using a ZINB model. Their findings showed significant promise in applying this method to run-off-road crash analysis. Kumara and Chin (2003) modeled accident occurrence at signalized Tee intersections with special emphasis on excess zeros. The authors compared the performance of NB model with ZINB model. Their study highlighted the fact that the latter was a better representative model than its parent NB model in detecting excess zeros after controlling for over-dispersion.

Shankar et al. (2003) presented an empirical note on the predictive modeling of pedestrian crashes. The researchers developed the models using NB and ZIP distributions, and discussed their applicability to pedestrian crash phenomena. The study results identified ZIP as a promising methodology for providing explanatory insights into the casualty behind pedestrian crashes. Qin et al. (2004) used ZIP approach to estimate models for predicting counts considering single-vehicle, multi-vehicle same direction, multi- 
vehicle opposite direction, and multi-vehicle intersecting crash types as a function of daily traffic volume, segment length, speed limit, and roadway width.

Lord et al. (2005) provided a comprehensive guidance on modeling crash data. The researchers examined the motor vehicle crash process from theoretical principles and from basic understanding of crash mechanism perspective. The study explored the progress of statistical models applied toward motor vehicle crash process and indicated how good they statistically approximate the process of crash occurrence. The research shed light on the application rationale of commonly used statistical models, such as, Poisson, Poissongamma (or negative binomial), ZIP, and ZINB. The study demonstrated that certain circumstances trigger excess zeros frequently observed in crash data; and these circumstances arise from low exposure and/or inappropriate selection of time/space scales, and not from underlying dual state process. The researchers concluded that careful selection of time/space scales for analysis, an improved set of explanatory variables and/or unobserved heterogeneity effects in count regression models, or small-area statistical methods (observations with low exposure) represent the most defensible modeling approaches for datasets with a preponderance of zeros.

Later, Lord et al. (2007) illustrated the logic problem with zero-inflated (ZI) models as they lack the boundary conditions delimiting the two states (i.e., perfectly safe and unsafe states) of such models. The researchers concluded that although ZI models offer improved statistical fit, these models could only be adopted when prediction is the sole research objective, which is seldom the research objective for safety. They added that "statistical methods and their underlying assumptions need to be applied judiciously in 
order to achieve model parsimony and to withstand detailed logical scrutiny" Lord et al. (2007).

Huang and Chin (2010) examined the performance of ZIP regression with sitespecific random effects (REZIP) model versus random effect Poisson (REP) model and standard ZIP model. Their study demonstrated that REZIP model may significantly improve the model-fitting and predictive performance of crash prediction models. However, the authors concluded that the differences in parameter in the REZIP, REP, and ZIP models may not be sufficient to justify the suitability of any one model. Furthermore, it was emphasized that modeling traffic crashes require serious examination of specific dataset with respect to special data structures, model fitting as well as predictive performance, and engineering judgment based on the results estimated from the models. Dong et al. (2014) proposed a multivariate random-parameter ZINB (MRZINB) regression model to account for unobserved heterogeneity. Prasetijo and Musa (2016) preferred ZIP and ZINB models over Poisson and NB models while analyzing road crashes in Malaysia.

This study concentrated on developing CMFs for bicycle crashes. Bicycle crashes are rare and random; therefore, the bicycle crash data is expected to be zero inflated. In other words, several locations (i.e., roadway segments and intersections) may not have experienced any bicycle crashes. The most common norm to develop CMFs using crosssectional method (detailed in Chapter 3) is through NB models. Crash prediction modeling techniques have advanced a lot in the past few years. However, researchers still consider NB and/or Poisson as the foundation for all models. This research has attempted to find a common ground where CMFs can be developed considering the recent advancements and 
guidance from the researchers as well as keeping the traditional norm intact. This study has used ZINB modeling approach for developing the CMFs for bicycle crashes.

It is quite clear from the previous studies that even ZINB has some methodological constrains (Lord et al., 2005; Lord et al., 2007). Therefore, to address the model's limitations identified in the previous studies, data for this research was processed very carefully keeping in mind the time/space scales and exposure issue while finalizing the dataset for modeling. Furthermore, an attempt has been made to address the logic problem of boundary conditions for two states by keeping all the independent variables for the count model component and developing zero-inflated model with only offset term (i.e., a constant term) resembling the boundary condition as latent. The true proportion of zeros was monitored and the model was accepted as long as the proportion of true zeros was found to be lower than $2 \%$.

\subsection{CMF Transferability}

Farid et al. (2016) explored the transferability of the Safety Performance Functions (SPFs). Rural divided multilane highway models from Florida, Ohio, and California were examined to understand the influence of SPF transferability. Single-state SPFs, two-state SPFs, and three-state SPFs were developed using traffic, roadway geometry, and crash data from the three states. SPFs were estimated through Negative Binomial (NB) models for different crash types and severities. A transfer index was used to evaluate the transferability of the models for other regions. Models from Florid and California were found to be more transferable compared to the models from Ohio. When pooled data (from two or three states) were used, the transferability index increased. The research proposed Modified 
Empirical Bayes (MEB) measure that provided segment specific calibration factors for transferring SPFs to local jurisdictions. MEB outperformed the Highway Safety Manual (HSM) calibration factor for transferring the SPFs.

Wang et al. (2016) estimated the CMFs for the effect of signalization at intersections in Florida. Empirical Bayes method was applied to derive the CMFs for $\mathrm{KABCO}, \mathrm{KABC}$, and rear-end crashes using SPFs from various jurisdiction, and adjusted by calibration factors. SPFs were developed using Florida and Ohio data. The SPFs suggested in the HSM were also used to calculate the CMFs. The research concluded that it is not suitable to apply SPFs from other states without thorough examination. The CMF was found 0.785 for KABCO with the SPF from Florida, significantly smaller than 1 indicating signalization at intersections resulted in fewer crashes. But the SPFs from Ohio and the HSM resulted in higher CMFs of 1.06 and 1.07, respectively, significantly larger than 1, indicating that the signalization resulted in more crashes. Therefore, the CMFs may be significantly different when SPFs developed from other states' data are applied. Thus, CMFs would be biased if SPFs are transferred from other states without proper adjustments.

Almasizadeh (2016) explored the transferability of CMFs for passing lanes and dual rumble strips on two-lane highways in Ontario, Canada using the prior research results from the United States. The study found consistent safety effects for passing lanes in Michigan and Ontario. The effects of center line and shoulder rumble strips were also found quite consistent in the study. Saleem et al. (2016) also explored the transferability of CMFs for Ontario. In addition to the study efforts by Almasizadeh (2016), the researchers investigated the impact of acceleration ramps for freeway ramps. The CMFs were found 
compatible to the values recommended in the HSM. Persaud et al. (2015) addressed the methodological issues and other factors that cause CMFs vary in different studies and in fostering the transferability of the CMFs. Several research results were summarized to demonstrate how CMFs could mathematically account for the factors that caused CMFs to vary in different applications. The research focused on the CMFs related to intersection, alignment, and cross section design of the roadways.

\subsection{Summary}

This chapter presented a comprehensive literature review on network screening, i.e., location prioritization practices and methods for highway improvements. Transportation agencies are still using simple scoring and ranking method for prioritization. Some agencies are using different methods which are basically alternate forms of simple scoring algorithm. However, researchers have used several methods including ANP, AHP, FANP, multi-layer prioritization, etc. to overcome the deficiencies of simple scoring and ranking algorithm for prioritization.

Furthermore, risk factors affecting bicycle safety, the bicycle crash countermeasures and bicycle CMFs, crash frequency modeling approach, and the transferability aspects of the CMFs were also reviewed. Researchers preferred to differentiate the risk factors affecting bicycle safety for intersections and mid-block locations due to the obvious variability in the operational characteristics. Roadway traffic, geometric, and socio-economic variables were investigated to determine their impact on bicycle crash frequency and severity. Spatial analysis, especially the use of ArcGIS, has evolved as an effective tool to better understand and model bicycle crash frequencies. 
Several studies, however, used a combination of different methods to identify and rank bicycle high crash locations.

In addition to the typical bicycle infrastructure such as bicycle lanes and bicycle slots, researchers have investigated the impact of several other roadway characteristics, including shared path width and separation, shoulder type, shoulder width, etc., on bicycle safety. One of the main challenges observed in improving bicycle safety is the lack of bicycle exposure data. Unlike traffic volumes, bicycle volumes are scarcely available, if at all. Researchers addressed this limitation by using surrogate measures of bicycle exposure such as number of transit stops in a region, population, etc.

This study also concentrated on CMFs for bicycle crashes. The most common norm to develop CMFs using cross-sectional method is through NB models. Crash prediction modeling techniques have advanced a lot in the past few years. However, researchers still consider NB and/or Poisson as the foundation for all models. Regarding the transferability of the CMFs, researchers used transferability indices to evaluate the transferability scopes. 


\section{CHAPTER 3 METHODOLOGY}

This chapter presents the methods in detail that were adopted to achieve the three research objectives mentioned in Chapter 1, Introduction.

\subsection{Network Screening}

The first objective of this dissertation was to determine the most suitable approach for network screening, i.e., prioritizing the highway locations for improvements. Three potential screening methodologies, AHP, ANP, and FANP were identified from the literature review. These three methods were compared while prioritizing the state maintained urban four-lane divided segments in Florida. The pertinence of these methods was also discussed. The following sections explain these three methods in detail.

\subsubsection{Analytic Hierarchy Process (AHP)}

The Analytic Hierarchy Process (AHP), developed by Professor Thomas L. Saaty, is perhaps one of the most commonly used multi-criteria decision-making techniques. AHP is designed to solve multi-criteria decision problems by comparing several alternatives based on the same set of attributes. These comparisons may be taken from actual measurements or from a fundamental scale which reflects the relative strength of preferences and feelings. AHP is being widely used in multi-criteria decision making, planning and resource allocation, and in conflict resolution (Saaty, 1987). The objective of AHP is to quantify relative priorities for a given set of alternatives on a ratio scale using the judgment of the decision maker. The method stresses the importance of the intuitive judgments of a decision maker as well as the consistency of the comparison of alternatives 
in the decision making process (Saaty, 1980). Further, it has the ability to organize tangible and intangible factors in a systematic way, and provide a structured yet relatively simple solution to decision making problem (Skibniewski and Chao, 1992).

The key steps of AHP are (Lind and Schurba, 2002):

- Dividing the problem into a hierarchy, i.e., one overall goal on the top level, several criteria contributing to the goal on the next level, and finally, several decision alternatives on the last level.

- Comparing pairs of alternatives with respect to each criterion and pairs of criteria with respect to the achievement of the overall goal.

- Synthesizing judgments and obtaining priority rankings of the alternatives with respect to each criterion and the overall priority ranking for the problem.

The computational steps of AHP are further elaborated in the following paragraphs.

\section{Model Construction and Problem Structuring}

The goal of network screening is to prioritize and rank highway improvement locations based on several criteria. Figure 3-1 illustrates the hierarchical structure for this goal. As can be observed from the figure, Level 0 is the analysis goal, i.e., to prioritize the highway improvement locations. Level 1 is the multi-criteria which are used for screening. Finally, Level 2 consists of the alternative choices, i.e., the highway locations. The lines between the three levels indicate the relationship between goal, criteria, and the alternatives (i.e., highway locations). Figure 3-2 depicts the AHP model structure for this scenario.

In Figure 3-2, each arrow has specific impacts on the interrelation of different levels, and on the next steps. $\mathrm{W}_{21}$ represents the impact of goal on each of the criterion and $\mathrm{W}_{32}$ represents the impact of criteria on each of the alternatives. The direction of arrows is 
dependent on the rationale of the problem structure. For the stated scenario, the goal of prioritizing highway locations can be achieved through the criteria, i.e., the criteria are impacting the goal; and these criteria determine the ranking of the alternatives.

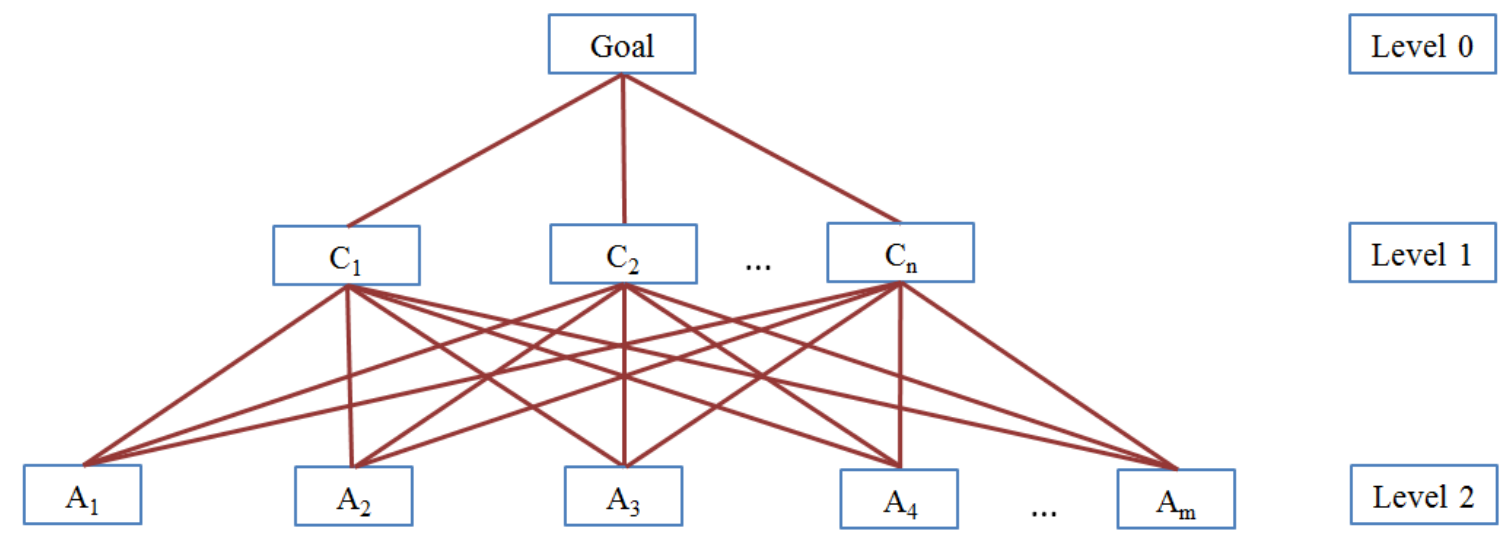

Figure 3-1: Hierarchical Structure of Highway Improvement Location Selection

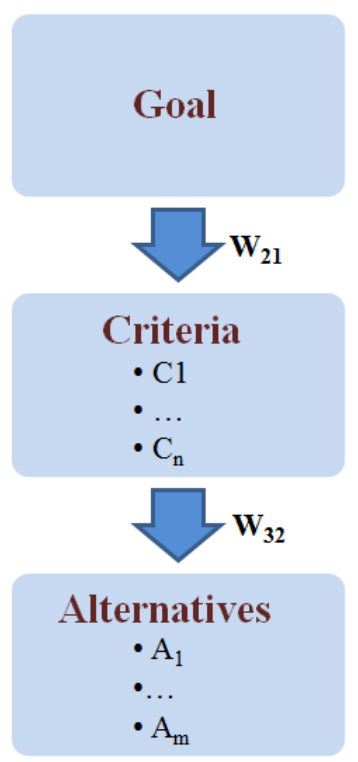

Figure 3-2: AHP Model Structure

$\underline{\text { Pair-wise Comparison Matrices and Priority Vectors }}$

When the AHP model structure is established, the next step is to determine the relative importance of each criterion and each alternative (i.e., highway segment) with respect to each criterion. It is achieved via pairwise comparisons that aim to compare the 
relative importance of two criteria (or, alternatives) at a time. This approach theorizes that an analyst can better assess the relative importance of a set of criteria when given only two criteria to compare at a time, than when given all at once. The pairwise comparisons are performed on a pre-defined relative scale of 1-9, which translates to comparing how much preference one criterion gets over the other. A reciprocal value is assigned to the inverse comparison.

Once the pairwise comparisons are performed, the next steps in the AHP model are to generate pairwise comparison matrices and priority vectors. Level 1 corresponds to one $n \times n$ comparison matrix for the pair-wise comparison between $n$ criteria with respect to the goal. Similarly, since the $m$ locations are connected to each of the $n$ criteria, $n$ number of $m \times m$ comparison matrices are created to evaluate the $m$ locations. The pair-wise comparison matrices are then used to generate priority vectors, which are the normalized Eigen vectors of the comparison matrices. A Priority vector, $w$, is computed as an estimate of the relative importance of the elements compared by solving (Saaty, 1987; Tuzkaya and Önüt, 2008)

$$
A w=\lambda_{\max } w
$$

where $\lambda_{\max }$ is the largest eigenvalue (i.e., Principal Eigenvalue corresponding to the Principal Eigen vector) of the pair-wise comparison matrix, A. Priority vectors are generated for all the $m$ highway locations with respect to each criterion, and for all the criteria at cluster level with respect to the $n$ criteria.

These pairwise comparisons might not always be completely logical. For example, if Measure A is more important than Measure B, and Measure B is more important than Measure $\mathrm{C}$, the selections would be inconsistent if Measure $\mathrm{C}$ is considered to be more 
important than Measure A, which is not logical. However, such conflicts will arise naturally, especially when several criteria are involved.

A comparison matrix $\mathrm{M}$ is considered to be consistent if $a_{i j} a_{j k}=a_{i k}$ for all $i, j$, and $k$. However, this consistency cannot be always expected because of subjective judgment. For instance, if $A>B$ has the numerical interpretation as $3>1$ and $C>A$ has numerical interpretation as $5>1$, then, $C>B$ may not result in value as $15>1$. However, the relation between $C$ and $B$ as $C>B$ should be consistent; i.e., the rank can be transitive but the values may not.

To help gauge the degree of consistency in a set of pairwise comparisons made, Professor Saaty (Saaty, 1987) developed the "consistency ratio" as a quick measure of the level of consistency. A $0 \%$ consistency ratio indicates that the pairwise comparisons are perfectly consistent, and a consistency ratio $<10 \%$ can be considered to be acceptable. Otherwise, the pairwise comparisons should be revised to improve their consistency. The following paragraphs explain this concept in detail.

Professor Saaty (Saaty, 1987) explained that if the largest Eigenvalue is equal to the number of performance measures, i.e., $\lambda_{\max }=n$, then the matrix is consistent. He also provided a measure called Consistency Index $(C I)$ as deviation or degree of consistency,

$$
\text { Consistency Index, } C I=\frac{\lambda_{\max }-n}{n-1}
$$

The next step is to compare the calculated consistency index with Random Consistency Index $(R I)$. Professor Saaty (Saaty, 1987) generated matrices using scale 1/9, $1 / 8,1 / 7, \ldots, 1, \ldots, 7,8,9$ (similar to the idea of Bootstrap) and calculated the standard RIs for comparison. Table 3-1 provides the average RIs estimated from a sample size of 500 matrices. 
Table 3-1: Values of Random Consistency Indices

\begin{tabular}{|c|c|c|c|c|c|c|c|c|c|c|}
\hline $\mathbf{n}$ & $\mathbf{1}$ & $\mathbf{2}$ & $\mathbf{3}$ & $\mathbf{4}$ & $\mathbf{5}$ & $\mathbf{6}$ & $\mathbf{7}$ & $\mathbf{8}$ & $\mathbf{9}$ & $\mathbf{1 0}$ \\
\hline $\mathrm{RI}$ & 0 & 0 & 0.58 & 0.9 & 1.12 & 1.24 & 1.32 & 1.41 & 1.45 & 1.49 \\
\hline
\end{tabular}

The comparison is termed as Consistency Ratio $(C R)$, and is calculated as:

$$
\text { Consistency Ratio, } C R=\frac{C I}{R I}
$$

\section{$\underline{\text { Ranking of Alternatives }}$}

Once the consistency checks are performed, the next and the final step in the AHP is to compute the overall composite weight of each alternative (i.e., highway location) based on the determined weight at Level 1 and Level 2 comparison matrices, i.e., from the cluster level priorities. The composite weight is simply the weighted sum of the criteria.

In brief, a set of evaluation criteria and a set of alternatives are considered at first. A weight is then generated for each evaluation criterion according to the decision maker's pairwise comparisons of the criteria. The higher the weight, the more important the corresponding criterion is. For each criterion, AHP assigns a score to each option according to the decision maker's pair-wise comparisons of the options based on that criterion. The higher the score, the better the performance of the option is with respect to the considered criterion. Finally, AHP combines the criteria weights and the options' scores to determine a global score for each option, and a consequent ranking. The global score for a given option is a weighted sum of the scores it obtained with respect to all the criteria (Saaty, 1980).

\subsubsection{Analytic Network Process (ANP)}

The Analytic Network Process is a multi-criteria decision algorithm. Unlike the AHP, the ANP, however, is not restricted to the traditional hierarchical top-down structure of decision making; rather it is a network which can address the interaction among elements of 
each cluster (i.e., goal, criteria, or alternatives) or between clusters of a decision process. Figure 3-3 illustrates the main difference between the hierarchical structure and the ANP's network structure in decision-making process. In the hierarchical structure the decision process follows a top-down approach from goal to criteria, and then from criteria to alternatives. The interaction among elements of each cluster or between clusters however cannot be addressed in this hierarchical structure. The ANP structure, on the other hand, considers possible interactions among different elements of a cluster and between clusters. Depending on its complexity, a decision problem may take any form of the network (Saaty, 2008).

The ANP is composed primarily of the following computational steps (Chung, 2005; Yüksel and Dağdeviren, 2007):

- model construction and problem structuring

- pair-wise comparison matrices and priority vectors

- $\quad$ supermatrix, weighted supermatrix, and limit matrix formations

- ranking of alternatives

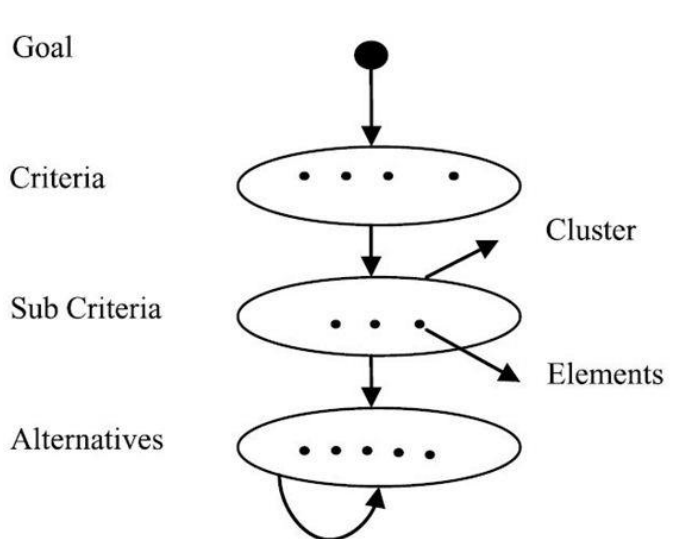

Hierarchy of decision-making

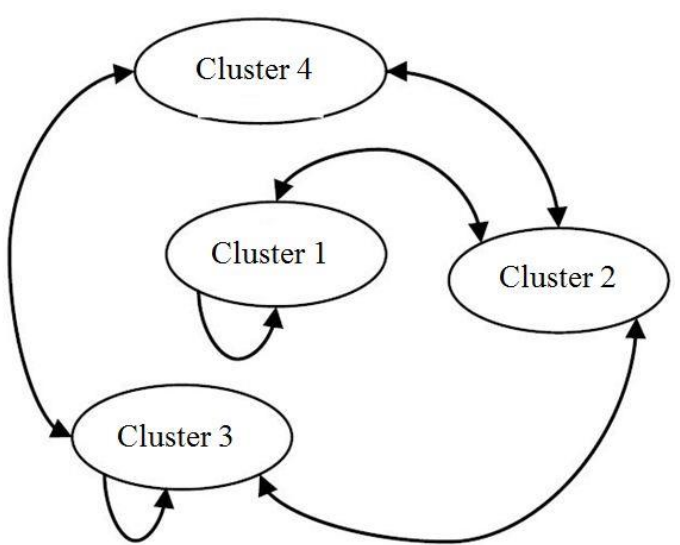

Network of decision-making

Figure 3-3: Difference between Hierarchy and Network Decision Making Process (Azis, 2003; and Sadeghi et al., 2012) 
Basically, ANP is a generalized form of AHP. Although both methods account for subjective judgment, the main difference lies in their model structure. Figure 3-4 highlights this difference schematically for network screening objective. Unlike the ANP, the AHP considers a simpler hierarchical structure, limiting its ability to account for interdependencies among the criteria and the alternatives. Since the ANP and the AHP are similar in the comparative judgment steps (i.e., with respect to pair-wise comparison and priority vectors), the following methodological steps are similar in the two methods: pairwise comparison, comparison matrix, priority vector, and consistency ratio. The ANP method and its computational steps are elaborated further in the following paragraphs.

\section{Model Construction and Problem Structuring}

As can be observed from Figure 3-1, the problem of network screening can be disintegrated into three levels (similar to hierarchical structure): goal to rank the alternatives, criteria to achieve the goal, and alternatives (i.e., the highway locations that need to be prioritized). The ANP addresses the interdependency of the criteria by including an inner dependence loop in the network structure. Figure 3-4 depicts the potential network structure for this scenario.

In Figure 3-4, $\mathrm{W}_{21}$ represents the impact of goal on each of the criterion and $\mathrm{W}_{32}$ represents the impact of criteria on each of the alternatives similar to AHP. However, in ANP, the interdependency within the criteria is represented by $\mathrm{W}_{22}$ additionally.

\section{$\underline{\text { Pair-wise Comparison Matrices and Priority Vectors }}$}

The computational step of ANP for pair-wise comparison matrices and priority vectors is exactly similar to AHP. However, ANP requires generating priority vectors also at sub-cluster level with respect to the $n$ criteria to address the interdependency issue. 


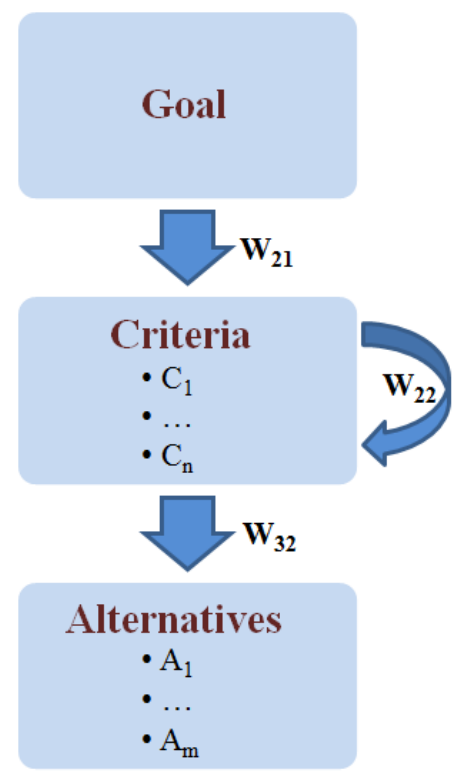

Network
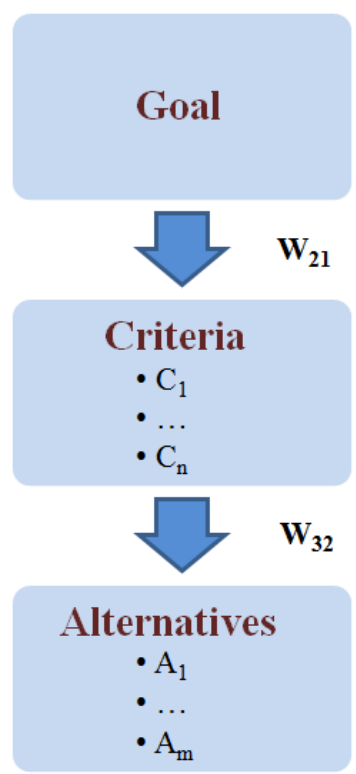

Hierarchy

Figure 3-4: Network and Hierarchical Model Structures

\section{$\underline{\text { Supermatrix, Weighted Supermatrix, and Limit Matrix Formations }}$}

A supermatrix is a comparatively large square matrix where the cluster priority vectors are entered in appropriate columns to obtain global priorities with interdependent influence (Yüksel and Dağdeviren, 2007). Supermatrix is used to represent the flow of influence from a component of elements to itself as in the loop that flows back to criteria ( $\mathrm{W}_{22}$ in Figure 3-4), or from a component from which an arrow is directed out to another component ( $\mathrm{W}_{21}$ and $\mathrm{W}_{32}$ in Figure 3-4). Special care should be taken to address the influence of the component at the end (Saaty and Vargas, 2006). The following supermatrix resembles the supermatrix framework developed in Model Construction and Problem Structuring step.

$\left.\begin{array}{c|ccc}\multicolumn{1}{c}{\text { Goal }} & \text { Criteria } & \text { Alternatives } \\ \text { Goal } & 0 & 0 & 0 \\ \text { Criteria } & \mathrm{W}_{21} & \mathrm{~W}_{22} & 0 \\ \text { Alternatives } & 0 & \mathrm{~W}_{32} & \mathrm{I}\end{array}\right]$


Note that, each of the elements in this supermatrix represents a submatrix. Zero (0) elements correspond to those elements which do not have any influence. Since each alternative depends only on itself, identity matrix (I) submatrix is used in the supermatrix framework in row: Alternatives and column: Alternatives. In other words, the level of alternatives in the adopted ANP model structure is a sink cluster of nodes that absorbs priorities but does not pass them on. This calls for using an identity matrix (I) in the supermatrix framework. In summary, supermatrix formation means placing the priority vectors in proper positions of a big matrix for synthesizing the judgments, i.e., decision making.

ANP's principle is to derive the limit priorities of influence from the supermatrix. Once the supermatrix is generated, the next step is to derive the limit priorities of influence from the supermatrix. To obtain such priorities, the supermatrix needs to be transformed to a matrix each of whose column sums to unity, known as column stochasticity (Saaty and Vargas, 2006). If the matrix is stochastic, the limit priorities can be viewed in a way to depend on the concepts of reducibility, primitivity, and cyclicity of the matrix. Saaty (2005) and Saaty (2001) provide detail explanation of these matrix properties. The resulting stochastic matrix is known as weighted supermatrix. The rationale behind this transformation is to convert the elements' local cluster priorities to global priorities.

The limit supermatrix is next obtained by raising the weighted supermatrix to exponential powers $2 k+1$, where $k$ is an arbitrary number; and it can be achieved when the weighted supermatrix is irreducible and primitive. If the supermatrix has the effect of cyclicity (irreducible and imprimitive) there can be other roots and the limiting matrix would be more than one. In that case, Cesaro sum is calculated to get the average priority. 
The Cesaro sum is used when the limits are not unique. As limiting priorities of the supermatrix depend on the reducibility, primitivity, and cyclicity of the matrix, there can be different forms of the limit depending on whether the matrix is reducible, and on the multiplicity of its principal eigenvalue, which must be equal to one or a complex root of one (Saaty, 2006). Thus, the limit priorities of the stochastic supermatrix must be computed according to whether it is irreducible, or whether it is reducible with one being a simple or a multiple root, or whether the system is cyclic. If the matrix is reducible, then the multiplicity of the roots of the principal eigenvalue needs to be considered to obtain the limit priorities of a reducible stochastic matrix with the principal eigenvalue being a multiple root (Tuzkaya and Önüt, 2008).

In summary, the limit supermatrix provides the long-term relative influences of the elements on each other through convergence on the importance weights. A detailed discussion regarding the steps and mathematical process of the ANP can be found in Raihan

et al. (2016), Tuzkaya and Önüt (2008), Ramik (2007), Meyer (2000), Saaty and Vargas (1998), and Saaty (1996).

\section{$\underline{\text { Ranking of Alternatives }}$}

The final priorities of all elements are obtained by normalizing each cluster of the limit matrix. Thus, when the locations are ranked from the highest value to the lowest value, the final prioritization list is obtained.

\subsubsection{Fuzzy Analytic Network Process (FANP)}

The fuzzy set theory, developed by Zadeh $(1965 ; 1976)$, is suitable for uncertain and qualitative decision making. Qualitative judgments are generally characterized by 
vague notions, such as, "equally", "moderately", "strongly", "very strongly", "extremely", and a "significant degree" (Tuzkaya and Önüt, 2008). It is difficult to do pairwise comparisons on a predefined relative scale of 1-9; rather in practice, qualitative decisions are more likely expressed through natural language such as, "possibly 5", "approximately 7" or "about 9" (Ramík, 2007). Fuzzy set theory provides the platform to translate the qualitative judgments of a decision maker into quantitative data. Triangular fuzzy numbers (Figure 3-5) are very useful in this regard.

A triangular fuzzy number $a$ is defined by a triple of real numbers, i.e., $a=\left(a^{\mathrm{L}} ; a^{\mathrm{M}}\right.$; $a^{\mathrm{U}}$ ), where $a^{\mathrm{L}}$ is the smallest possible value (lower bound), $a^{\mathrm{M}}$ is the modal value (middle number), and $a^{\mathrm{U}}$ is the largest possible value (upper bound), and $a^{\mathrm{L}} \leq a^{\mathrm{M}} \leq a^{\mathrm{U}}$. If $a^{\mathrm{L}}=a^{\mathrm{M}}$ $=a^{\mathrm{U}}$, then $a$ is said to be the crisp number (non-fuzzy number). Evidently, the set of all crisp numbers is isomorphic to the set of real numbers. In order to distinguish fuzzy and non-fuzzy numbers, the fuzzy numbers, vectors, and matrices can be denoted by the tilde above the symbol, e.g., $\tilde{a}=\left(a^{\mathrm{L}} ; a^{\mathrm{M}} ; a^{\mathrm{U}}\right)$ (Tuzkaya and Önüt, 2008; Ramík, 2007).

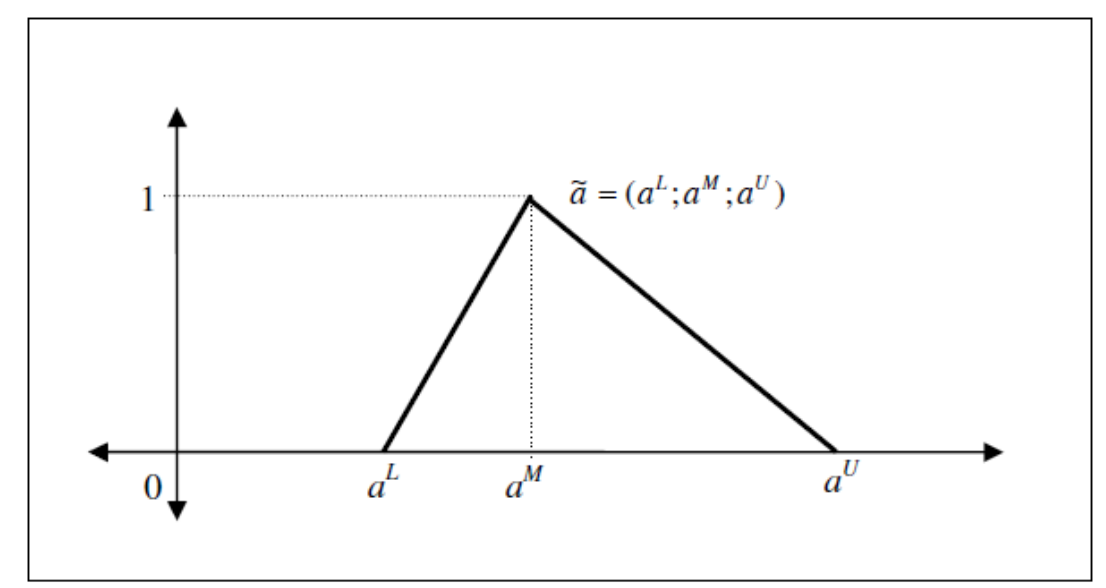

Figure 3-5: A Triangular Fuzzy Number (Source: Ramík, J., 2007) 
The arithmetic operations addition (+), subtraction (-), multiplication (x), and division (/) can be extended to fuzzy numbers by the extension principle (Chen et al., 1992).

Thus, if $\tilde{a}=(), \tilde{b}=(), a^{\mathrm{L}}>0, b^{\mathrm{L}}>0$, then,

$$
\begin{aligned}
& \tilde{a} \tilde{+} \tilde{b}=\left(a^{\mathrm{L}}+b^{\mathrm{L}} ; a^{\mathrm{M}}+b^{\mathrm{M}} ; a^{\mathrm{U}}+b^{\mathrm{U}}\right) ; \\
& \tilde{a} \widetilde{-} \tilde{b}=\left(a^{\mathrm{L}}-b^{\mathrm{L}} ; a^{\mathrm{M}}-b^{\mathrm{M}} ; a^{\mathrm{U}}-b^{\mathrm{U}}\right) ; \\
& \tilde{a} \tilde{\times} \tilde{b}=\left(a^{\mathrm{L}} \times b^{\mathrm{L}} ; a^{\mathrm{M}} \times b^{\mathrm{M}} ; a^{\mathrm{U}} \times b^{\mathrm{U}}\right) ; \\
& \tilde{a} \tilde{/} \tilde{b}=\left(a^{\mathrm{L}} / b^{\mathrm{L}} ; a^{\mathrm{M}} / b^{\mathrm{M}} ; a^{\mathrm{U}} / b^{\mathrm{U}}\right) .
\end{aligned}
$$

The detailed definitions and discussions regarding the arithmetic operations on triangular fuzzy numbers can be found in Ghatee and Hashemi (2007), Wagenknecht et al. (2001), Giachetti and Young (1997), Kaufmann and Gupta (1988), Dubois and Prade (1978), and Zadeh (1965).

In the fuzzy ANP method, instead of using the discrete scale of 1-9, a triangular fuzzy number (TFN) scale $\tilde{1}$ - $\widetilde{9}$ is used to state the preferences of the decision maker (Table 3-2, Figure 3-6).

Table 3-2: TFN-linguistic Scale for Importance (Source: Sevkil et al., 2011)

\begin{tabular}{|c|l|c|}
\hline TFN & Linguistic Scale for Importance & Triangular Fuzzy Scale \\
\hline$\tilde{1}$ & Equally preferred & $(1,1,1)$ \\
\hline$\tilde{2}$ & Equally to moderately preferred & $(1,3 / 2,3 / 2)$ \\
\hline$\tilde{3}$ & Moderately preferred & $(1,2,2)$ \\
\hline$\tilde{4}$ & Moderately to strongly preferred & $(3,7 / 2,4)$ \\
\hline$\tilde{5}$ & Strongly preferred & $(3,4,9 / 2)$ \\
\hline$\tilde{6}$ & Strongly to very strongly preferred & $(5,11 / 2,6)$ \\
\hline$\tilde{7}$ & Very strongly preferred & $(5,6,7)$ \\
\hline$\tilde{8}$ & Very strongly to extremely preferred & $(5,7,9)$ \\
\hline$\tilde{9}$ & Extremely preferred & \\
\hline
\end{tabular}




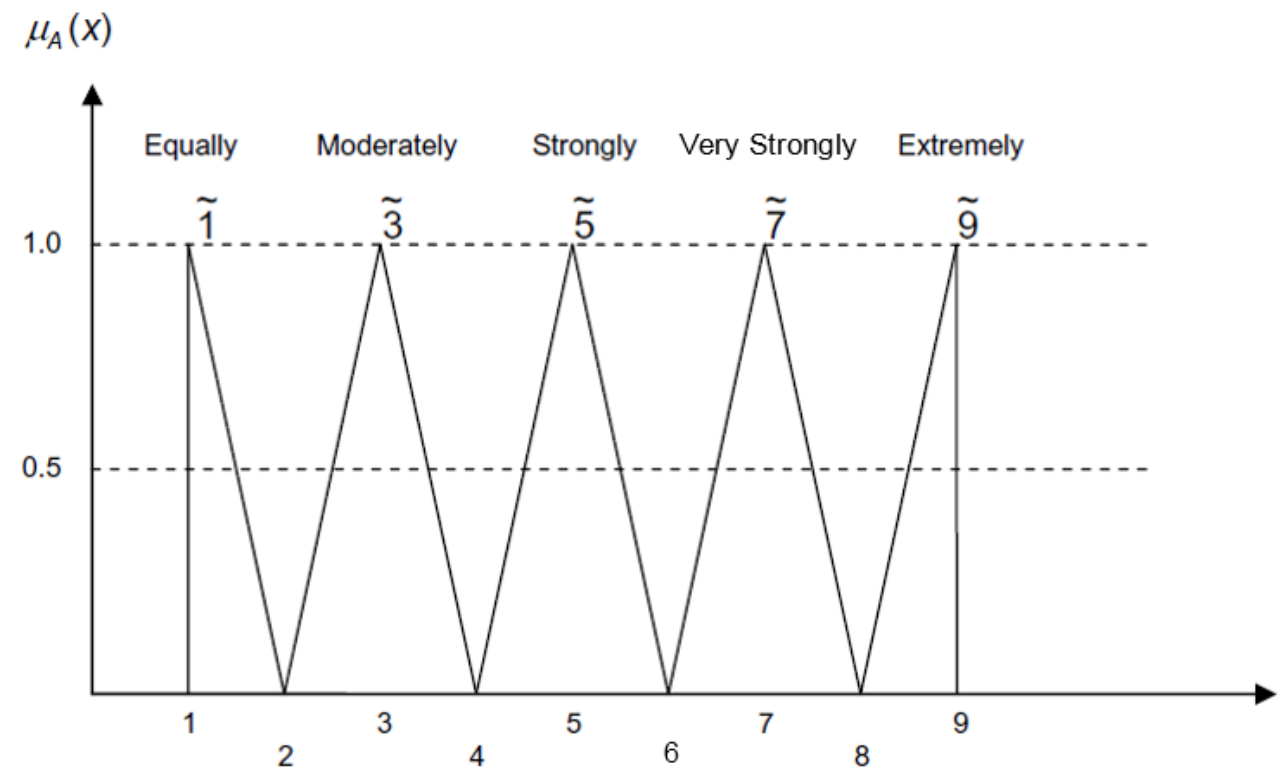

Figure 3-6: Fuzzy Membership Function Scale (Source: Tuzkaya and Önüt, 2008)

The difference between fuzzy ANP approach and ANP approach lies in fuzzy pairwise comparison matrix creation and calculating triangular fuzzy weights from it; and finally, rank the alternatives from limit supermatrix. These two steps are elaborated in the following paragraphs.

Fuzzy Weights from Fuzzy Pairwise Comparison Matrix

A triangular fuzzy matrix is composed of triples as follows:

$$
\tilde{\mathbf{A}}=\left[\begin{array}{ccc}
\left(a_{11}^{L} ; a_{11}^{M} ; a_{11}^{U}\right) & \cdots & \left(a_{1 n}^{L} ; a_{1 n}^{M} ; a_{1 n}^{U}\right) \\
\vdots & \ddots & \vdots \\
\left(a_{m 1}^{L} ; a_{m 1}^{M} ; a_{m 1}^{U}\right) & \cdots & \left(a_{m n}^{L} ; a_{m n}^{M} ; a_{m n}^{U}\right)
\end{array}\right]
$$

The generic form of a fuzzy pairwise comparison matrix is:

$$
\tilde{\mathbf{A}}=\left[\begin{array}{cccc}
(1 ; 1 ; 1) & \left(a_{11}^{L} ; a_{11}^{M} ; a_{11}^{U}\right) & \cdots & \left(a_{1 n}^{L} ; a_{1 n}^{M} ; a_{1 n}^{U}\right) \\
\left(\frac{1}{a_{11}^{U}} ; \frac{1}{a_{11}^{M}} ; \frac{1}{a_{11}^{L}}\right) & (1 ; 1 ; 1) & \cdots & \left(a_{2 n}^{L} ; a_{2 n}^{M} ; a_{2 n}^{U}\right) \\
\vdots & \vdots & \vdots & \vdots \\
\left(\frac{1}{a_{1 n}^{U}} ; \frac{1}{a_{1 n}^{M}} ; \frac{1}{a_{1 n}^{L}}\right) & \left(\frac{1}{a_{2 n}^{U}} ; \frac{1}{a_{2 n}^{M}} ; \frac{1}{a_{2 n}^{L}}\right) & \cdots & (1 ; 1 ; 1)
\end{array}\right]
$$


where $1 \leq a_{i j}^{L} \leq a_{i j}^{M} \leq a_{i j}^{U}, i, j=1,2, \ldots, n$.

The triangular fuzzy weights are calculated as evaluations of the relative importance of the criteria, and the relative importance of the alternatives with respect to each criterion. Logarithmic least square method (Chen et al., 1992; Tuzkaya and Önüt, 2008; Ramík, 2007) can be applied to estimate the fuzzy priorities, $\widetilde{w}_{i}$, where $\widetilde{w}_{i}=$ $\left(w_{i}^{L}, w_{i}^{M}, w_{i}^{U}\right)$, and $i=1,2, \ldots, n$, from the judgment matrix (fuzzy pairwise comparison matrix), $\tilde{A}$, which approximates the fuzzy ratios $\tilde{a}_{i j}$, so that $\tilde{a}_{i j} \approx \widetilde{w}_{i} / \widetilde{w}_{j}$. The logarithmic least square method calculates the fuzzy triangular weights as (Sevkil et al., 2011; Tuzkaya and Önüt, 2008; Ramík, 2007):

$$
\widetilde{w}_{k}=\left(w_{k}^{L}, w_{k}^{M}, w_{k}^{U}\right), k=1,2,3, \ldots, n
$$

where

$$
w_{k}^{S}=\frac{\left(\prod_{j=1}^{n} a_{k j}^{S}\right)^{1 / n}}{\sum_{i=1}^{n}\left(\prod_{j=1}^{n} a_{k j}^{M}\right)^{1 / n}}, S \in\{L, M, U\}
$$

\section{$\underline{\text { Ranking of the Alternatives }}$}

The first phase in this step is to transform the fuzzy numbers of the limit matrix to crisp numbers by defuzzification. There are different defuzzification methods, such as, center of gravity, maximum-membership principle, center of area, weighted average, smallest of maximum and largest of maximum (Tuzkaya and Önüt, 2008). The simplest method is the center of gravity method (Ramík, 2007). This method is based on computing the x-th coordinates $x_{i}^{g}$ of the center of gravity of every triangle given by the corresponding membership functions, $\tilde{z}_{i}, i=1,2, \ldots, n$. The concept can be illustrated as:

$$
x_{i}^{g}=\frac{z_{i}^{L}+z_{i}^{M}+z_{i}^{U}}{3}
$$


Chen et al. (1992), and Ramík (2006) provide a comprehensive review of other sophisticated defuzzification methods. Once the defuzzification is completed, the remaining step, i.e., ranking the alternative process is similar to the ANP methodology.

Once the urban four-lane divided segments were prioritized through ANP, AHP, and FANP, the ranks of the first 30 prioritized locations were compared with respect to the criteria. An attempt had been made to understand and find out which screening methodology ranked the locations most comprehensively, i.e., considered all the criteria, did not give any undue weight to any criterion, and addressed the limitations of the current simple scoring practice by the transportation agencies. As there were no direct methods or algorithms to compare the performance of these three approaches, the comparison with respect to the criteria was adopted.

\subsection{Crash Modification Factor (CMF) Development}

The second objective of this research is to quantify the safety impacts of roadway characteristics such as, lane width, median width, sidewalk, sidewalk barrier, shared path; bicycle infrastructure such as, bicycle lanes and slots; traffic characteristics such as section average daily traffic; and bicycle activity data obtained from Strava smartphone application on bicycle crashes. The study developed crash modification factors (CMFs) for bicycle crashes for different roadway segment and intersection facility types in urban areas to quantify the impacts.

This objective can be attained using two study designs: experimental study design and observational study design. These two study design types differ in terms of data collection effort. Experimental studies are planned; it means sites identified for a treatment 
are randomly assigned to either a treatment group or to a control group that is left untreated. The groups are identified before the treatment implementation. Observational studies are not planned; it means data are collected retrospectively by observing the performance of existing roadways, where the treatment has already been implemented, not on the basis of a planned experiment rather based on engineering judgment including safety. However, observational studies are more common in road safety research because of the ethical concerns with experimentation in road safety (Gross et al., 2010).

The preferred methods for developing CMFs with observational data can be classified again into two broad categories: (a) before-after design, and (b) cross-sectional design. For the before-after design, the CMFs are estimated from the change in crash frequency between the periods before and after a treatment is implemented. However, there is a need to account for changes in safety due to factors other than the treatment of interest. In an experimental study, the planned control group serves this purpose. For the crosssectional design, crash experience of locations with and without a specific feature is studied; and then the difference in safety is attributed to that feature, i.e., treatment or countermeasure. Although before-after study is usually preferred over cross-sectional design, it is not always practical because there could be insufficient situations to allow for credible results (Gross et al., 2010). Considering the data (detailed in Chapter 4) for this research, it was not practical to adopt the before-after studies. Cross-sectional design was therefore adopted in this research.

In this research, CMFs were developed for total bicycle crashes for different roadway facility types. Section 3.2.1 elaborates on the cross-sectional analysis. Section 3.2.2 details the modeling framework adopted in this research. 


\subsubsection{Cross-sectional Analysis}

Cross-sectional analysis was used to develop CMFs for bicycle crashes in this research. Cross-sectional studies are useful for CMF estimation when before-after studies cannot be conducted due to insufficient before and after crash data when a particular engineering countermeasure is implemented; or the date of the implemented treatment is unknown; or when it is difficult to distinguish the effect of a countermeasure from confounding factors. For example, there may be too few projects where lane width is reduced from 12-ft to $11-\mathrm{ft}$; however, there may be many road segments with 11-ft and 12ft lanes. In such cases, before-after study might not yield credible results, especially when sufficient before and after data are not available. Considering the datasets available for this study, and the methodological pros and cons, cross-sectional study was identified as the best suited approach.

In cross-sectional studies, crash experience at locations with and without a specific feature is studied; and then, the difference in safety is attributed to that feature. To obtain reliable results from cross-sectional studies, it is critical that all locations are similar to each other in all other factors affecting crash risk. However, in practice, it is difficult to collect data for enough locations that are similar in all other factors affecting crash risk. Therefore, cross-sectional studies are often conducted through multiple variable regression models.

The multiple variable regression models attempt to address all the variables that might potentially affect the safety performance of the locations. The models are developed using crash data from sites both with and without treatments (or, countermeasures). The 
change in crashes from a unit change in a specific variable can be estimated from regression model. The CMFs are then deduced from the model parameters (Gross et al., 2010).

\subsubsection{Zero Inflated Negative Binomial (ZINB) Models}

This research used generalized linear model (GLM) approach with a Zero Inflated Negative Binomial (ZINB) distribution to develop the relevant regression models. The ZINB models are applicable for count data that exhibit over-dispersion and excess zeros. Since bicycle crashes are relatively rare and random, the ZINB model was used to account for the segments with zero crashes that cannot be solely explained by the Negative Binomial (NB) models. The models have crash frequency as the response variable, and the roadway or intersection characteristics as explanatory variables. The probability distribution of the ZINB random variable $y_{i}$ (NCSS, 2018) is:

$$
\operatorname{Pr}\left(y_{i}=j\right)=\left\{\begin{array}{r}
\pi_{i}+\left(1-\pi_{i}\right) g\left(y_{i}=0\right), \text { if } j=0 \\
\left(1-\pi_{i}\right) g\left(y_{i}\right), \text { if } j>0
\end{array}\right.
$$

where $\pi_{i}$ is the proportion of true zeros that cannot be explained by NB model, and $g\left(y_{i}\right)$ follows the negative binomial distribution as (NCSS, 2018):

$$
g\left(y_{i}\right)=\operatorname{Pr}\left(Y=y_{i} \mid \mu_{i,} \alpha\right)=\frac{\Gamma\left(y_{i}+\alpha^{-1}\right)}{\Gamma\left(\alpha^{-1}\right) \Gamma\left(y_{i}+1\right)}\left(\frac{1}{1+\alpha \mu_{i}}\right)^{\alpha^{-1}}\left(\frac{\alpha \mu_{i}}{1+\alpha \mu_{i}}\right)^{y_{i}}
$$

where $\mu_{i}$ is the mean crash frequency, and $\alpha$ is the over-dispersion parameter. Cameron and Trivedi (2013), Hilbe (2014), and Garay et al. (2011) presented detailed discussion on count data models. The basic form of the NB regression model used in this study is:

$$
\mu_{i}=\exp \left(\beta_{0}+\beta_{1} \times \ln A A D T_{i}+\beta_{2} \times L W_{i}+\beta_{3} \times B L_{i}+\ldots+\beta_{k} \times X_{i k}+\text { OFFSET }\right)
$$


where

$$
\begin{aligned}
& \mu_{i} \quad=\text { crash frequency on a road section } i \\
& A A D T_{i} \quad=\text { average annual daily traffic on a road section } i \text { (vehicle/day), } \\
& L W_{i} \quad=\text { lane width of a road section } i(\mathrm{ft}) \\
& B L_{i} \quad=\text { presence of bicycle lane along a road section } i(0 \text { if absent, } 1 \text { if } \\
& \text { present), } \\
& X_{i k} \quad=\text { roadway characteristic } k \text { (i.e., countermeasure) of road section } i \text {, } \\
& \beta_{0} \quad=\text { model intercept } / \text { constant } \\
& \beta_{1}, \beta_{2}, \ldots, \beta_{k}=\text { model coefficients, and } \\
& \text { OFFSET }_{i}=\ln \left(4 \times\left(\text { section length of road section } i \text {, i.e., } S L_{i}\right)\right) \text { for segments and } \\
& \ln (4) \text { for intersections. Note that, the number } 4 \text { was used in the } \\
& \text { offset term because this study considered four years of crash data. }
\end{aligned}
$$

Variables that were found to be significant at 0.05 level of significance from the ZINB models were considered in the CMF development. The regression coefficients and over-dispersion parameter were estimated using the zeroinfl function of pscl package in the statistical software $\boldsymbol{R}$ (R Core Team, 2014). An offset term was added to the regression equation to predict the crash frequency in crashes per mile per year for segments and crashes per year for intersections, as shown in Equation 3-9.

The CMFs were inferred from the estimated model parameters, i.e., coefficients; and as the model form is log-linear, the CMFs were calculated as the exponent of the associated coefficient of the countermeasure variable as (Lord and Bonneson, 2007; Stamatiadis et al., 2009; Carter et al., 2012; Abdel-Aty et al., 2014):

$$
C M F_{k}=\exp \left(\beta_{k} \times\left(X_{k r}-X_{k b}\right)\right)
$$


where $X_{k r}$ is the range of values for roadway characteristic $k$, and $X_{k b}$ is the baseline condition for roadway characteristic $k$ (when needed or available). For example, according to Equation 3-9, the CMF for increasing lane width $(L W)$ by one foot is equal to $\exp \left(\beta_{2}\right)$. As ordinary regression was not used, the selection of variables for inclusion in the final models and statistical tests to determine the significance of the derived relationships cannot be done using conventional approaches; rather methods that do not assume normality of the dependent variable was used. Apart from checking the maximum loglikelihood estimates, Akaike Information Criterion was also reviewed (Hadi et al., 1995). Akaike Information Criterion (AIC) for Selection of Regressor Variables

The Akaike Information Criterion (AIC) was used to determine the subset of independent variables to be included in the crash estimation models. AIC can be defined as (Gilchrist, 1985; Hadi et al., 1995):

$$
A I C=-2 \times M L+2 \times K
$$

where $M L$ is the maximum log-likelihood, and $K$ is the number of parameters in subset selection used as a measure of model complexity.

The smaller the AIC value, the better the model. Starting with the full set of independent variables, a stepwise procedure was used to select the best model based on minimizing the AIC value. This was achieved by using the stepAIC function of MASS package in the statistical software $\boldsymbol{R}$ (R Core Team, 2014). Once the variables were selected, CMFs were estimated using the ZINB models. Note that, the stepAIC function was used in the NB environment as this research adopted the ZINB framework to develop the CMFs. This research also took into account the interaction between variables while 
developing the CMFs. Furthermore, the variables were scaled and centered as needed to ensure the robustness of the models.

\subsection{CMF Transferability}

This research explored the spatial and temporal transferability scopes for the developed CMFs. Urban four-lane divided facility was considered for the assessment. To study the spatial transferability, the seven Florida Department of Transportation (FDOT) districts were considered as seven different spatial zones. The CMFs developed using statewide data were applied to each district, and the scope of spatial transferability within intraFlorida was explored using the transferability index (TI) measure (discussed in Section 3.3.1) which indicates the performance of the transferred model for the jurisdiction of interest.

To explore the temporal phenomena, CMFs were first developed for the entire state using crash data for the period of 2013-2014; then, 2011-2012 and 2015 (the most recent data that were available during this research) crash data were used to examine the transferability of the CMFs. Additionally, the models were evaluated using different goodness of fit measures (discussed in Section 3.3.2) to estimate the prediction capabilities.

\subsubsection{Transferability Assessment}

The transferability of the developed ZINB models was assessed by calculating the Transfer Index (TI) (Hadayeghi et al., 2006; Sikder et al., 2013; Farid et al., 2016). The TI measure indicates the performance of the transferred model for the jurisdiction of interest (Farid et al., 2016). TI is calculated as: 


$$
T I_{j}\left(\beta_{i}\right)=\frac{L L_{j}\left(\beta_{i}\right)-L L_{j}\left(\beta_{\text {reference } j}\right)}{L L_{j}\left(\beta_{j}\right)-L L_{j}\left(\beta_{\text {reference } j}\right)}
$$

where

$$
\begin{aligned}
L L_{j}\left(\beta_{i}\right)= & \log \text {-likelihood of the SPF developed from data, } i \text {, that is being } \\
& \text { applied to data of a specific jurisdiction, } j ; \\
= & \log \text {-likelihood of jurisdiction } j \text { 's SPF; } \\
L L_{j}\left(\beta_{j}\right) \quad & \text { log-likelihood of jurisdiction } j \text { 's constant only SPF. }
\end{aligned}
$$

"The TI measure compares the performance of the model of interest with respect to the performance of a constant only model. The higher the $T I$ value the better is the performance relative to the constant only model. The closer $T I$ is to unity, the SPF, developed from data $i$, is more transferable to jurisdiction $j$. A negative $T I$ indicates that state j's constant only model performs better than the SPF of state $i$ applied to state $j$ ' (Farid et al., 2016).

\subsubsection{Goodness of Fit (GOF)}

Apart from Log-likelihood (LL) and AIC values, this research employed Mean Absolute Deviation (MAD), Mean Predicted Bias (MPB), and Mean Squared Predicted Error (MSPE) to assess the Goodness of Fit for the developed ZINB models which are commonly used by several researchers (Washington et al., 2005; Lord and Mannering, 2010; Mehta and Lou, 2013; Farid et al., 2016).

- Mean Absolute Deviation (MAD): MADs were calculated to assess the Goodness of Fit (GOF) of the ZINB models. MAD is defined as the difference between the predicted $\left(N_{S P F}\right)$ and observed number of crashes $\left(N_{o b s}\right)$ per segment, $i$. The equation below illustrates this concept (Farid et al., 2016). MAD gives the average variability 
of the prediction. Smaller values are preferred to larger values (Mehta and Lou, 2013).

$$
M A D=\frac{\sum_{i=1}^{n}\left|N_{S P F_{i}}-N_{o b s_{i}}\right|}{n}
$$

- Mean Predicted Bias (MPB): The MPB measure was suggested by Washington et al. (2005). The equation below defines this measure. $M P B$ measures the magnitude and direction of the average model bias. Unlike $M A D, M P B$ measures can be either positive or negative. A positive value indicates that the SPF is overestimating the number of crashes, while a negative value implies that the site is safer than it actually is (Mehta and Lou, 2013).

$$
M P B=\frac{\sum_{i=1}^{n}\left(N_{S P F_{i}}-N_{o b s_{i}}\right)}{n}
$$

- Mean Squared Predicted Error (MSPE): MSPEs were also calculated to assess the Goodness of Fit (GOF) of the ZINB models. MSPE is also defined from the difference between the predicted $\left(N_{S P F}\right)$ and observed number of crashes $\left(N_{o b s}\right)$ per segment, $i$. Equation below illustrates this concept (Farid et al., 2016). A lower value implies a better model (Mehta and Lou, 2013).

$$
M S P E=\frac{\sum_{\mathrm{i}=1}^{\mathrm{n}}\left(N_{S P F_{i}}-N_{o b s_{i}}\right)^{2}}{\mathrm{n}}
$$

The transferability indices and the GOF measures indicate whether the developed models from statewide data are applicable for spatial jurisdiction of interest and for different time periods. 


\subsection{Summary}

This chapter discussed the methodologies and the application steps that were adopted to achieve the three objectives of this research. Three potential network screening methods, ANP, AHP, and FANP were discussed in this chapter. The ZINB modeling approach was presented and the rationale of selecting this model for developing CMFs and the mathematical background of this approach was discussed in detail. Finally, for the spatial and temporal transferability assessment, transferability index $(T I)$ was described in this chapter. 


\section{CHAPTER 4 \\ DATA PREPARATION}

This research has three specific objectives. The first objective focused on screening highway locations for bicycle safety improvements. Florida's urban four-lane divided facility was considered for screening. Since application of the screening methods would be same for other roadway facilities, the analyses were not repeated for other facilities. The second objective focused on developing bicycle CMFs, and an attempt was made in this research to develop CMFs for all major urban facilities. The third objective explored the scope of spatial and temporal transferability of the developed CMFs. Similar to the facility considered in the first objective, only urban four-lane divided facility was researched for transferability assessments.

As mentioned, the second and third objectives focused on CMFs, and hence required similar data preparation efforts. Thus, the data preparation steps were broadly divided into two major categories: data preparation for network screening and data preparation for developing CMFs. The following sections elaborate the efforts that were undertaken in this research.

\subsection{Network Screening}

The first step in network screening was to identify all the potential criteria and assign them to each of the locations. The following seven criteria were considered for screening:

- bicycle crash frequency,

- bicycle facility (bicycle lane and/or bicycle slot), 
- bicycle volume,

- $\mathrm{AADT}$,

- auto ownership,

- land use, and

- transit stops.

The selection of these criteria was based on 2060 Florida Transportation Plan (FDOT, n.d.), the existing FDOT's prioritization practice (Gan et al., 2016), feedback from practicing transportation professionals in Florida, literature review, and obviously data availability. Data availability was confirmed before making the final list.

The following five databases were used for preparing the final dataset for screening the locations: FDOT's Crash Analysis Reporting (CAR) System for information on crashes, FDOT's Roadway Characteristics Inventory (RCI) database for information on roadway characteristics, Strava database for bicycle exposure data, Florida Geographic Data Library (FGDL) for census and land use data (U.S. Census Bureau, 2016), and Florida Transit Information System for data on transit stops (FDOT, 2018). The following subsections briefly discuss these databases.

\subsubsection{Crash Analysis Reporting (CAR) System}

Crash data for the years 2011-2014 were obtained from the FDOT's CAR system. The CAR database includes the following three files:

- crash level file,

- vehicle-driver-passenger level file, and

- non-motorist level file. 
Crash level file includes crash-related information such as crash number, roadway ID where the crash occurred, milepost of the crash location, crash severity, etc. The vehicledriver-passenger file includes the road user-related information for each crash record; thus it has information on crash number, all vehicles involved in the crash, all drivers and passengers involved in the crash, etc. Non-motorist level data file includes information about each non-motorist involved in a crash such as crash number, type of non-motorist, nonmotorist location, non-motorist injury severity, etc.

Bicycle crashes from 2011-2014 were identified first from the non-motorist level data file using the following codes for non-motorist type code variable (NON_MOTR_TYP_CD): 3 (bicyclist), and 4 (other cyclist). Since multiple bicyclists could be involved in a single crash, only the information of the bicyclist with highest injury severity in each crash was retrieved, and included in the analysis. Once bicycle crashes were identified from the non-motorist data file, the records were linked to the crash level data file using crash number. The bicycle crash database was then merged with the roadway segment database such that each site has the total number of bicycle crashes that occurred during 2011-2014.

\subsubsection{Roadway Characteristics Inventory (RCI)}

FDOT maintains and updates the RCI database every year for the state of Florida. This database has information on more than 200 roadway characteristics. Since 2011-2014 crash data were used in this research, roadway characteristics data from 2014, the most recent analysis year, were used. AADT and bicycle facility information were extracted from the RCI. GIS shapefiles of bicycle lane and slot were also incorporated. Segmentation 
was performed according to the guidelines provided in the HSM, i.e., a new segment starts either at each intersection, or whenever there is a slight change in any one of the variables. Segmentation is necessary to ensure homogeneity of each segment in terms of the variables considered in the analysis (AASHTO, 2010).

Once the database was prepared for urban four-lane divided segments containing AADT, bicycle lane, and bicycle slot information; bicycle lane and slot information were combined in a way that if either lane or slot is present along the roadway, the roadway was considered to have a bicycle facility. Finally, the bicycle crash data were merged with the roadway segment database such that crashes were assigned to the segments based on crash locations. Later, this database was linear referenced in ArcGIS based on on-system and off-system GIS shapefiles from FDOT. Linear referencing was performed to add the spatial information to the prepared database (i.e., to create a shapefile of the database).

\subsubsection{Strava Database}

The bicycle activity data was retrieved from the 2014 Strava dataset which includes distance of bicycle rides, time, pace, trail routes, and other geographic information data (collectively called "Activity Data"). This information was collected from the Strava smartphone application users who were biking in Florida. Since bicycle exposure provided in the Strava dataset is a sample and is dependent on the number of Strava smartphone application users in the area, the variables do not represent the overall population of bicyclists. Therefore, the raw Strava data representing the actual bicycle trips on each segment was processed to obtain a more representative bicycle exposure data. Bicycle

volumes in each census block group was estimated by counting the number of bicycle trips 
made on the roadway segments in each census block group. The bicycle activity was then categorized into the following three classes:

- Low Bicycle Activity (total bicycle trips per year $\leq 2,000$ )

- Medium Bicycle Activity (total bicycle trips per year $>2,000$ and $\leq 10,000$ )

- High Bicycle Activity (total bicycle trips per year > 10,000)

The roadway segments in each census block group were then assigned the bicycle activity of their census block group. However, bicycle volume data for prioritization was not only derived from Strava; rather, the processed Strava data were combined with bicycle commuters (who use bicycle for commuting purpose and represent the working population of 16 years and older) data from the census database. Detailed discussion on bicycle commuter data is provided in Section 4.1.4.

\subsubsection{Florida Geographic Data Library (FGDL)}

Bicycle commuters, auto ownership, and land use data were derived from FGDL database. The 2015 census data provided information on commuter population 16 years and older who were biking to work, and auto ownership information for the households. The census data are provided at the census block group level. The linear referenced RCI file was spatially joined (i.e., intersected) with census data in the GIS platform to extract the census information for the segments. It was made sure that if any roadway segment passes through multiple census blocks, then all blocks census information is reflected on that roadway segment. The census information was summed up using the Dissolve function of ArcMap for each roadway segment for this purpose. 
Bicycle commuting in each census block group was later re-categorized into the three classes ( similar to the categories for bicycle activity data).

- $\quad$ Low Commuting Block (\# of persons using bicycle for commuting =0)

- Medium Commuting Block (\# of persons using bicycle for commuting $\geq 1 \& \leq 50$ )

- High Commuting Block (\# of person using bicycle for commuting > 50)

The roadway segments in each census block group were then assigned the bicycle commuter class of their census block groups. This bicycle commuting category was merged with bicycle activity category, and was considered as the surrogate measure for bicycle volume when prioritizing methodologies were compared.

To extract the land use information, FGDL's shapefiles of generalized land use derived from 2015 parcels for FDOT districts were used. At first, DOT district level files were combined. Then, a 250 -ft buffer was created along the previously linear referenced RCI file. Finally, the RCI shapefile was intersected with the land use file in ArcGIS to extract the land use information along each segment. The intersected land use area was recalculated in GIS. The predominant land use in terms of area along any roadway segment was then considered as the land use for that particular segment. Note that, the University of Florida's GeoPlan Center is the publisher of this land use data. Parcel-level data were originally acquired from the State Department of Revenue (DOR). The GeoPlan Center generalized 99 land use classes into 15 classes in this database (Lin et al., 2017). However, for this research, these 15 classes were again generalized into five classes before intersecting the land use file with the RCI file. Table 4-1 presents the reclassified land use variables used in this research. 
Table 4-1: Reclassified Land Use

\begin{tabular}{|l|l|}
\hline Reclassified Land Use & GeoPlan Land Use \\
\hline \multirow{4}{*}{ Residential \& Institutional } & Residential \\
\cline { 2 - 2 } & Institutional \\
\cline { 2 - 2 } & Vacant Residential \\
\hline \multirow{4}{*}{ Remmercial } & Retail/Office \\
\cline { 2 - 2 } & Public/Semi-Public \\
\cline { 2 - 2 } & Industrial \\
\hline \multirow{5}{*}{ Other } & Recreation \\
\hline \multirow{5}{*}{ Low Bicycle Activity } & Vacant Nonresidential \\
\cline { 2 - 2 } & Centrally Assessed \\
\cline { 2 - 2 } & Acreage Not Zoned for Agriculture \\
\cline { 2 - 2 } & ROW \\
\cline { 2 - 2 } & Other \\
\hline & Parcels with No Values \\
\cline { 2 - 2 } & Agricultural \\
\cline { 2 - 2 } & Mining \\
\cline { 2 - 2 } & Water \\
\cline { 2 - 2 } & No Data Available \\
\hline
\end{tabular}

Note: ${ }^{a}$ Low Bicycle Activity stands for the Land Use where bicyclists are least expected.

\subsubsection{Florida Transit Information System (FTIS)}

Florida Transit Information System (FTIS) is a FDOT maintained web-based platform for transit planning in Florida. Transit stops shapefiles were collected from Florida Transit Data Exchange (FTDE) portal of FTIS. The available shapefiles from this portal were merged to form a combined transit stops shapefile. Once the census information were extracted to the linear referenced RCI shapefile, then a 40-ft buffer was created along the road segments in GIS on this RCI shapefile. Then, the buffered file was spatially joined (i.e., intersected) with the combined transit stops file to extract the number of stops along the route. As there could be more than one stop along any segment, thus, the number of stops for each segment were added to get the total number of stops for any segment. GIS platform was used to do the data processing.

Once transit stops data were added to the RCI file, each segment was then assigned with the seven performance measures - bicycle crash frequency, bicycle facility (bicycle 
lane and/or bicycle slot), bicycle volume, AADT, auto ownership, land use, and transit stops. Next step was to apply the location prioritization methodologies to determine the potential of these methods for prioritization.

\subsection{CMF Development}

RCI, CAR, and Strava databases were used for CMF development. Unlike network screening, several RCI variables were used to develop bicycle CMFs. The following subsections discuss the datasets and the data variables used to develop the CMFs in this research.

\subsubsection{Roadway Segment Data}

The following data were used to develop the CMFs:

- 2014 RCI data

- GIS shapefiles for:

- bicycle lane

- bicycle slot

$\circ$ shared path

- sidewalk barrier

- sidewalk width and separation

$\circ$ state roads

$\circ$ intersections

Detailed roadway characteristics information was extracted from the 2014 FDOT's RCI database. Of over 200 variables that are available in the RCI database, only those that 
could potentially affect bicycle safety were extracted. Table 4-2 lists these variables. The variables are also discussed in detail.

Table 4-2: RCI Variables Extracted for CMF Development

\begin{tabular}{|l|l|}
\hline RCI Variable & RCI Code \\
\hline Section Average Annual Daily Traffic & SECTADT \\
\hline Number of Lanes & NOLANES \\
\hline Median Width & MEDWIDTH \\
\hline Bicycle Lane & BIKELNCD \\
\hline Bicycle Slot & BIKSLTCD \\
\hline Shared Path Width and Separation & SHARDPTH \\
\hline Sidewalk Width and Separation & SIDWLKWD \\
\hline Sidewalk Barrier & SDWLKBCD \\
\hline Type of Road & TYPEROAD \\
\hline Type of Parking & TYPEOP \\
\hline Speed Limit & MAXSPEED \\
\hline Pavement Surface Width & SURWIDTH \\
\hline Type of Median & RDMEDIAN \\
\hline Shoulder Type & SHLDTYPE \\
\hline Functional Classification of Roadways & FUNCLASS \\
\hline
\end{tabular}

- Section AADT: It is an estimate of the AADT on the roadway section. The natural logarithm of AADT was considered in developing the regression models.

- Number of Lanes: Information on number of lanes was used to categorize segments into different facility types. When the roadway is divided, the RCI provides number of through lanes for each direction of travel. On the other hand, when the roadway is undivided, the RCI provides number of through lanes for both directions of travel combined. Since the total number of lanes for both directions of travel was considered for model fitting, the number of lanes information on undivided sections was used directly. However, when roadway is divided, the number of through lanes in each direction of travel were added to obtain the total number of through lanes along both directions of travel. 
- Median Width: It denotes the width of the median in feet. The actual value of median width varies from $2 \mathrm{ft}$ to over $100 \mathrm{ft}$. Since this level of detail was not required, the measured median width was rounded per the recommendations provided in the Highway Safety Manual (HSM). Table 4-3 presents the HSM guidance in rounding the median widths.

Table 4-3: HSM Recommended Rounded Median Widths (Source: AASHTO, 2010)

\begin{tabular}{|c|c|}
\hline Measured Median Width & Rounded Median Width \\
\hline 1 to $14 \mathrm{ft}$ & $10 \mathrm{ft}$ \\
\hline 15 to $24 \mathrm{ft}$ & $20 \mathrm{ft}$ \\
\hline 25 to $34 \mathrm{ft}$ & $30 \mathrm{ft}$ \\
\hline 35 to $44 \mathrm{ft}$ & $40 \mathrm{ft}$ \\
\hline 45 to $54 \mathrm{ft}$ & $50 \mathrm{ft}$ \\
\hline 55 to $64 \mathrm{ft}$ & $60 \mathrm{ft}$ \\
\hline 65 to $74 \mathrm{ft}$ & $70 \mathrm{ft}$ \\
\hline 75 to $84 \mathrm{ft}$ & $80 \mathrm{ft}$ \\
\hline 85 to $94 \mathrm{ft}$ & $90 \mathrm{ft}$ \\
\hline $95 \mathrm{ft}$ or $\mathrm{more}$ & $100 \mathrm{ft}$ \\
\hline
\end{tabular}

- Bicycle Lane: The 2014 RCI database includes bicycle lane information for approximately 1,100 miles of road network. However, the GIS shapefile for bicycle lanes include this information for nearly 1,600 miles. Since the GIS shapefile provides a more complete inventory of the road network with bicycle lanes, the bicycle lanes shapefile was appended to the RCI database. Although the shapefile includes different categories for bicycle lanes such as designated, colored, etc., only presence or absence of bicycle lane was considered in the analysis.

- Bicycle Slot: Bicycle slot data were prepared in the same manner as the bicycle lane data. However, since bicycle slots are always located at or near intersections, this variable was considered while analyzing intersections only. 
- Shared Path Width and Separation: Shared path width provides information about the actual width of the shared path in feet. If enough variability existed, then actual width and separation type (e.g., no barrier; on-street parking lane/meter; trees, planters, utility poles, etc.; guardrail/traffic railing barrier/swale) could have been used; however, only the presence or absence of shared path was considered while developing the regression models due to limited variability in the data. Similar to bicycle lane and bicycle slot data, this variable was extracted from FDOT's GIS shapefile.

- Sidewalk Width and Separation: Similar to shared path width and separation, only the presence or absence of sidewalk was considered. Since the FDOT's GIS shapefile had more complete information about sidewalks compared to the RCI, this variable was extracted from the FDOT's GIS shapefile.

- Sidewalk Barrier: Information on sidewalk barrier was also extracted from the GIS shapefile, and the presence or absence of sidewalk barrier was considered while developing the regression models.

- Type of Road: This variable denotes whether a roadway is undivided, divided, or oneway. This classification was used to divide the road network into different facility types.

- Type of Parking: This variable includes the following information: no parking allowed, parking permitted on one side, and parking permitted on both sides. The same information was considered while developing the regression models.

- Speed Limit: Information on speed limit is provided for each direction of travel on divided roads and for both directions of travel on undivided roads. If the speed limit 
is different for each direction of travel, the highest value was taken as the speed limit of the roadway. The speed limit value was used directly for undivided sections.

- Pavement Surface Width: Surface width is the total width of all through lanes. For divided roadway segments, the surface widths on each direction of travel was summed up to obtain the total surface width of the roadway segment. The surface width for undivided segments was used directly. Note that lane width, instead of surface width, was considered while developing the regression models. Lane widths were calculated by dividing the total surface width by the total number of lanes for each roadway segment. Furthermore, the calculated lane widths were rounded as per the recommendations provided in the HSM (see Table 4-4).

Table 4-4: HSM Recommended Rounded Lane Widths (Source: AASHTO, 2010)

\begin{tabular}{|c|c|}
\hline Measured Lane Width & Rounded Lane Width \\
\hline $9.2 \mathrm{ft}$ or less & $9 \mathrm{ft}$ or less \\
\hline 9.3 to $9.7 \mathrm{ft}$ & $9.5 \mathrm{ft}$ \\
\hline 9.8 to $10.2 \mathrm{ft}$ & $10 \mathrm{ft}$ \\
\hline 10.3 to $10.7 \mathrm{ft}$ & $10.5 \mathrm{ft}$ \\
\hline 10.8 to $11.2 \mathrm{ft}$ & $11 \mathrm{ft}$ \\
\hline 11.3 to $11.7 \mathrm{ft}$ & $11.5 \mathrm{ft}$ \\
\hline 11.8 or more & $12 \mathrm{ft}$ or more \\
\hline
\end{tabular}

- Type of Median: Table 4-5 lists the different types of medians included in the RCI. The codes were redefined to yield longer and more homogeneous segments. The table also provides the modified median types that was considered in the analysis.

- Shoulder Type: The RCI includes information about three shoulder types based on offset direction (left, right, and both left and right): highway shoulder type, highway shoulder type2, and highway shoulder type3. Each type has ten different codes. Due 
to limited variability in the data, the codes were re-categorized. Table 4-6 presents both the original and the modified codes for shoulder type. Note that when the same segment has different codes for the three shoulder types (shoulder type, shoulder type2, and shoulder type3), the shoulder type was coded as "mixed".

Table 4-5: Codes for Median Type

\begin{tabular}{|l|c|l|c|}
\hline Highway Median Type & $\begin{array}{c}\text { Original } \\
\text { RCI Code }\end{array}$ & \multicolumn{1}{|c|}{$\begin{array}{c}\text { Reclassified Median } \\
\text { Type }\end{array}$} & $\begin{array}{c}\text { Modified } \\
\text { Code }\end{array}$ \\
\hline Paved & 01 & Paved & 01 \\
\hline Raised Traffic Separator & 02 & Raised Traffic Separator & 02 \\
\hline Vegetation & 08 & Vegetation & 08 \\
\cline { 1 - 2 } Curb \& Vegetation & 17 & Curb \& Vegetation & 17 \\
\cline { 1 - 2 } Other & 20 & & \multirow{2}{*}{ Other } \\
\cline { 1 - 2 } Counted Roundabout & 41 & & \\
\cline { 1 - 2 } Non-counted Roundabout & 42 & \\
\cline { 1 - 2 } Counted Traffic Circle & 43 & & \\
\cline { 1 - 2 } Non-counted Traffic Circle & 44 & &
\end{tabular}

Table 4-6: Codes for Shoulder Type, Shoulder Type2, and Shoulder Type3

\begin{tabular}{|c|c|c|}
\hline RCI Code Description & $\begin{array}{l}\text { Original RCI } \\
\text { Code }\end{array}$ & $\begin{array}{l}\text { Modified } \\
\text { Code }\end{array}$ \\
\hline Raised Curb & 0 & 0 \\
\hline Paved (including paved parking and bicycle slots) & 1 & \multirow[b]{2}{*}{12} \\
\hline $\begin{array}{l}\text { Paved with Warning Device (any device that serves } \\
\text { to warn, guide, or regulate the motorist) }\end{array}$ & 2 & \\
\hline Lawn (number of feet to support roadbed) & 3 & \multirow{3}{*}{345} \\
\hline Gravel/Marl & 4 & \\
\hline Valley Gutter (not a barrier) & 5 & \\
\hline Curb \& Gutter & 6 & \multirow{2}{*}{68} \\
\hline Curb with Resurfaced Gutter & 8 & \\
\hline Other & 7 & 7 \\
\hline
\end{tabular}

- Functional Classification of Roadways: Since bicyclists are not expected on limited-access facilitates; these facilities were excluded from the analysis. Only the following roadway functional classifications were included in the analysis. Note that the number in parentheses is the RCI code.

○ Rural - Principal Arterial - Other (04) 
○ Rural - Minor Arterial (06)

○ Rural - Major Collector (07)

○ Rural - Minor Collector (08)

○ Urban - Principal Arterial - Other (14)

○ Urban - Minor Arterial (16)

○ Urban - Major Collector (17)

○ Urban - Minor Collector (18)

The entire road network was divided into the following facility types in this research for CMF development.

- Urban Two-lane Divided Segments

- Urban Four-lane Divided Segments

- Urban Six-lane Divided Segments

- Urban Two-lane Undivided Segments

- Urban Three-lane Undivided Segments

- Urban Four-lane Undivided Segments

- Rural Two-lane Undivided Segments

- Rural Two-lane Divided Segments

- Rural Four-lane Divided Segments

FDOT collects and maintains information for more than 200 variables in its RCI database. With this level of detail, segmentation of road network might result in shorter segments as roadways are segmented whenever there is a slight change in any one of these variables. However, not all these variables affect bicycle safety, and hence, are required for CMF development. Therefore, segmentation was conducted only by considering the 
potential RCI variables that might affect bicycle safety. Segmentation was performed according to the guidelines provided in the HSM, i.e., a new segment starts either at each intersection, or whenever there is a slight change in any one of the variables. Note that, segmentation is necessary to ensure homogeneity of the each segment in terms of the variables considered for bicycle safety.

\subsubsection{Intersection Data}

Intersection data were difficult to obtain directly from the existing FDOT databases. Therefore, intersection data collected for a recently completed FDOT Project BDK80-97737 (Alluri et al., 2014) were used to develop the models. The following intersection-related variables were included in the analysis:

- major road AADT

- minor road AADT

- intersection skew angle

- presence of lighting

- number of bus stops within intersection influence area (i.e., within 1,000 ft of the intersection)

- presence of schools within intersection influence area (i.e., within 1,000 ft of the intersection)

- number of alcohol sales establishments within intersection influence area (i.e., within $1,000 \mathrm{ft}$ of the intersection)

- number of approaches with left-turn lanes

- number of approaches with right-turn lanes 
- number of approaches with protected signal control

- number of approaches with permitted signal control

- number of approaches with protected-permitted signal control

- number of approaches with no Right-Turn-on-Red

- presence of red light running camera

In addition to the above-listed data variables, GIS shapefiles for bicycle slot and bicycle lane were included. If either bicycle slot or bicycle lane are located within $250-\mathrm{ft}$ of an intersection, the intersection was considered to have a bicycle facility. Due to sample size limitations, only urban four-leg signalized and urban three-leg stop-controlled intersections were analyzed.

\subsubsection{Bicycle Exposure Data}

The bicycle activity data was retrieved from the 2014 Strava dataset. Section 4.1.3 discussed the efforts that were undertaken to incorporate the bicycle activity data as bicycle exposure.

\subsubsection{Crash Data}

Bicycle crash data for the years 2011-2014 were obtained from FDOT's CAR repository. Crash data for CMF development was processed as discussed in Section 4.1.1. The bicycle crash data were merged with the roadway segment and intersection database such that each site was assigned the total number of bicycle crashes that occurred during 2011-2014. 


\subsection{Summary}

The databases, data variables, and how the data were processed to be included in the analyses in this research were discussed in this chapter. In summary, five databases were used in this research: FDOT's CAR database, FDOT's RCI database, Strava database, FGDL database, and FTIS database. For network screening, all the above mentioned databases were used to extract the seven screening criteria, bicycle crash frequency, presence of bicycle facility, surrogate measure for bicycle volume, AADT, auto ownership, land use, and number of transit stops along the roadways. For CMF development, CAR, RCI, and Strava databases were used. The roadway characteristics variables that could potentially affect bicycle safety were extracted from RCI for CMF development. 


\section{CHAPTER 5}

\section{ANALYSIS AND RESULTS}

This chapter is divided into three major sections. The first section presents the analyses, results, and discussion on the application of AHP, ANP, and FANP in network screening for bicycle safety improvements. The second section focuses on CMFs for bicycle crashes. Finally, the third section explores the possibility of spatial and temporal transferability of the developed CMFs.

\subsection{Network Screening}

The following sections detail the application of AHP, ANP, and FANP for prioritizing urban four-lane divided roadway segments in Florida, the facility with the largest available sample size.

\subsubsection{Analytic Hierarchy Process (AHP)}

As discussed in Section 3.1.1, the computational steps of AHP are: model construction and problem structuring, pair-wise comparison matrices and priority vectors, and ranking of alternatives. The model depicted in Figure 3-2 is used in this research. Therefore, the first step, model construction and problem structuring, is not repeated here again. The following sub-sections provide a detailed discussion on other steps. The second step, pair-wise comparison matrices and priority vectors, is discussed in subsequent sections so that the application is easily understandable.

\section{$\underline{\text { Pair-wise Comparison of the Criteria }}$}

Bicycle crash frequency, bicycle facility (bicycle lane and/or bicycle slot), bicycle volume, AADT, auto ownership, land use, and transit stops are the seven criteria that were 
selected for network screening purpose in this research. The pair-wise comparisons of these seven criteria were required and this comparison was very crucial. This research focused on the roadway facilities in Florida; thus, to drive the pragmatic results, the comparisons should come from the policy makers who are lead transportation decision makers in Florida. Therefore, an attempt had been made to reach out to the industry experts to obtain their feedback on these pair-wise comparisons. Feedbacks from five experts were received. The survey excel file that was sent out, and the five responses received from the expert panel are presented in the appendix. The responses were kept anonymous to have the results unbiased.

The number of pair-wise comparisons is a function of the number of criteria (or alternatives) (n) to be compared, and can be calculated as:

$$
\text { Number of pair-wise comparisons }=\frac{n(n-1)}{2}
$$

The seven criteria resulted in a total of 21 pair-wise comparisons.

\section{Pair-wise Comparison of the Segments}

There were 2,236 segments which needed pairwise comparisons for each of the seven criteria. Therefore, for each criterion, a total of 2,498,730 comparisons were required. It was quite impossible to do it manually; therefore, the range of values of the criteria were converted to the pre-defined 1-9 scale so that the pair-wise comparisons could be performed automatically. Furthermore, the conversion simplifies the process of incorporating outliers in a systematic manner. For example, if there are 100 segments, and if a couple of segments have unrealistically high AADT values (i.e., outliers), the pairwise comparisons, when generated automatically based on original values, will be biased toward 
these segments. The following sections discuss how each of the seven criterion was converted to the pre-defined 1-9 scale.

- Bicycle Crash Frequency: Bicycle crash frequency was first normalized based on segment length. All the segments with zero bicycle crashes were assigned to predefined scale 1 . The rest of the crash rates (bicycle crashes/mile), i.e., 0-1, 1-2, 24 , and $\geq 4$ crashes/mile were converted to Scale $3,5,7$, and 9, respectively. The scaling, i.e., this assignment was based on uniform percentiles of coverage (i.e., sum of segment lengths in miles).

- Bicycle Facility (Bicycle Lane andlor Bicycle Slot): Bicycle lane and slot information were combined such that if either lane or slot was present along the roadway, the roadway was considered to have bicycle facility. As this research focuses on prioritizing locations that needed improvements, locations with no bicycle facility were given priority, and were assigned a value of 7 in the predefined scale; and the locations having bicycle facility were assigned a value of 1 in the scale.

- Bicycle Volume: Bicycle activity from Strava and commuting bicyclist data from census database were combined to categorize bicycle volume. Table 5-1 presents the combined categories and the converted scales for each of the combined category. Sections 4.1.3 and 4.1.4 elaborated the activity and commuting data preparation and the representing category formation steps in detail.

- $A A D T$ : AADT data were also converted to pre-defined scale based on percentiles. First, the segments were organized in ascending order according to the segment AADT. Then, the segments were assigned to the pre-defined scale from 1 to 9 based 
on summation of segment lengths percentile, i.e., $1^{\text {st }}$ to $11^{\text {th }}$ percentile were given the scale of 1 , from $12^{\text {th }}$ to the $22^{\text {nd }}$ percentile were given the scale of 2 , and so on.

Table 5-1: Pre-defined Scaling for Bicycle Volume

\begin{tabular}{|l|l|l|c|}
\hline Bicycle Activity & Bicycle Commuting & $\begin{array}{l}\text { Combined Activity \& } \\
\text { Commuting }\end{array}$ & Scale \\
\hline Low & Low & Low + Low & 1 \\
\hline Medium & Low & Medium + Low & 3 \\
\hline High & Low & High + Low & 5 \\
\hline Low & Medium & Low + Medium & 3 \\
\hline Medium & Medium & Medium + Medium & 5 \\
\hline High & Medium & High + Medium & 7 \\
\hline Low & High & Low + High & 5 \\
\hline Medium & High & Medium + High & 7 \\
\hline High & High & High + High & 9 \\
\hline
\end{tabular}

- Auto Ownership: Auto ownership information was extracted from FGDL's 2015 census database. The households having zero and one auto were considered potential households of bicycle users. This information was normalized by the segment length. Then, the segments were organized in ascending order according to the normalized value. Finally, the segments were assigned to the pre-defined scale from 1 to 9 based on segments percentile, i.e., $1^{\text {st }}$ to $11^{\text {th }}$ percentile segments were given the scale of 1 , from $12^{\text {th }}$ to the $22^{\text {nd }}$ percentile were given the scale of 2 , and so on.

- Land Use: Section 4.1.4 elaborated how the land use information was reclassified in this research, and Table 4-1 presented the reclassified land use categories. The reclassified land use categories are: residential and institutional, commercial, recreational, other, and low bicycle activity. Scale 1, 3, 5, 7, 9 were assigned to these five land use categories depending on the possibility of potential bicyclists in each of the land use. Thus, Table 5-2 presents the scales assigned to each of the land use. 
Table 5-2: Pre-defined Scaling for Land Use

\begin{tabular}{|l|c|}
\hline Reclassified Land Use & Pre-defined Scale \\
\hline Residential and Institutional & 9 \\
\hline Recreational & 7 \\
\hline Commercial & 5 \\
\hline Other $^{\mathrm{a}}$ & 3 \\
\hline Low Bicycle Activity $^{\mathrm{b}}$ & 1 \\
\hline
\end{tabular}

Note: ${ }^{\mathrm{a}}$ Other land use includes acreage not zoned for agriculture, centrally assessed, right-of-way, vacant non-residential; ${ }^{b}$ Low Bicycle Activity includes parcels with no values, agricultural, mining, water, no data available.

- Transit Stops: Transit stops data were converted to pre-defined scale in the similar approach as it was done for bicycle crash frequency. Segments having zero transit stops/mile were allocated Scale 1. The rest of the segments were organized in ascending order based on transit stops (stops/mile); and then, were converted to Scale 3, 5, 7, and 9 based on uniform percentiles of segments for each category, i.e., uniform number of segments in each category.

Once the values of the crieria were converted to the pre-defined scale, the segments (i.e., the alternatives) were compared by calculating the ratio of the two alternatives. For example, if the converted value of AADT was 3 for segment A and 9 for segment $\mathrm{B}$, the pairwise comparison of segments A and B was given a value of 3/9. Similarly, if the predefined scale value of transit stops was 7 for segment $C$ and 1 for segment $D$, the pair-wise comparison of segments $\mathrm{C}$ and $\mathrm{D}$ was given a value of 7/1.

\section{Comparison Matrix and Priority Vector from the Criteria}

Section 3.1.1 detailed the concept of comparison matrix and priority vector. The prioritization of segments with respect to seven criteria requires eight comparison matrices and thus, eight priority vectors; of which, one comes from criteria's comparisons, while the remaining seven from segments' comparisons with respect to each of the criterion. 
Since this research received the pair-wise comparisons of the criteria from five transportation experts, all the feedbacks were incorporated in this study. The average priorities were considered in the final matrix. Table 5-3 presents the final priorities.

Table 5-3: Cluster Level Priorities with Respect to Goal

\begin{tabular}{|c|c|c|c|c|c|c|}
\hline \multirow{2}{*}{ Criteria } & \multicolumn{5}{|c|}{ Priorities Derived from Expert Panel Feedback } & \multirow{2}{*}{ Average } \\
\hline & Expert-A & Expert-B & Expert-C & Expert-D & Expert-E & \\
\hline Bicycle Crash & 32.49 & 41.73 & 43.51 & 44.90 & 4.88 & 33.50 \\
\hline Bicycle Facility & 16.81 & 10.73 & 11.29 & 12.18 & 14.20 & 13.04 \\
\hline Bicycle Volume & 10.23 & 9.69 & 14.58 & 7.33 & 5.60 & 9.49 \\
\hline AADT & 11.69 & 21.69 & 9.14 & 4.91 & 12.28 & 11.94 \\
\hline Auto Ownership & 7.15 & 2.97 & 5.42 & 8.49 & 27.56 & 10.32 \\
\hline Land Use & 9.95 & 4.90 & 5.42 & 7.99 & 18.12 & 9.28 \\
\hline Transit Stops & 11.67 & 8.29 & 10.62 & 14.20 & 17.36 & 12.43 \\
\hline Total & 100 & 100 & 100 & 100 & 100 & 100 \\
\hline
\end{tabular}

Comparison Matrices and Priority Vectors of the Segments

All the 2,236 segments were compared pair-wise with respect to each of the seven criteria. This step was performed automatically once the values of the seven criteria for all the segments were converted to the predefined 1-9 scale. Seven priority vectors were derived from the seven sets of pair-wise comparisons ( $\mathrm{W}_{32}$ in Figure 3-2).

\section{$\underline{\text { Ranking of Alternatives }}$}

The final step in the AHP was to compute the overall composite weight of each alternative (i.e., highway location) based on the determined weight at Level 1 and Level 2 comparison matrices, i.e., from the cluster level priorities. The composite weight is simply the weighted sum from the seven criteria. The final ranks of the locations were then determined from the calculated composite weights of the locations. The higher the score, the lower the rank, and the greater is the priority. 


\subsubsection{Analytic Network Process (ANP)}

As aforementioned, the ANP is a generalized form of AHP. Although both methods account for subjective judgment, the main difference lies in their model structure. As discussed in Section 3.1.2, the four sequential steps of ANP are: model construction and problem structuring; pair-wise comparison matrices and priority vectors; supermatrix, weighted supermatrix, and limit matrix formations; and ranking of alternatives. The ANP model structure presented in Figure 3-4 is used in this research. Therefore, the first step, model construction and problem structuring, is not repeated here.

Since the ANP and the AHP are similar in the comparative judgment steps (i.e., with respect to pair-wise comparison and priority vectors), the following computational steps in both the methods are similar: pair-wise comparison, comparison matrix, and priority vector. However, to account for interdependencies of the criteria, ANP requires another seven comparison matrices and priority vectors from the criteria in addition to the comparison matrices and priority vectors developed for AHP. Thus, a total of eight comparison matrices and priority vectors need to be developed from the criteria.

Of the eight comparison matrices from the criteria, one is at cluster level (from all criteria with respect to goal, $\mathrm{W}_{21}$ in Figure 3-4 similar to AHP) and the remaining seven are from sub-cluster level (comparison of the criteria when one criterion is omitted each time to account for interdependencies, $\mathrm{W}_{22}$ in Figure 3-4).

This research processed all the eight matrices for each expert's feedback deriving 40 (= 8 matrices $\times 5$ experts) matrices first. Then, the average priorities were considered for the final 8 matrices and for the supermatrix formation. Table 5-3 presents the cluster 
level final priorities of the criteria which is common for ANP and AHP. Tables 5-4 through 5-10 present the sub-cluster level priorities.

Table 5-4: Sub-cluster Level Priorities with Respect to Bicycle Crash

\begin{tabular}{|l|r|r|r|r|r|r|}
\hline \multirow{2}{*}{ Criteria } & \multicolumn{4}{|c|}{ Priorities Derived from Expert Panel Feedback } & \multirow{2}{*}{ Average } \\
\cline { 2 - 6 } & Expert-A & Expert-B & Expert-C & Expert-D & Expert-E & \\
\hline Bicycle Facility & 22.82 & 18.89 & 20.39 & 23.49 & 13.99 & 19.92 \\
\hline Bicycle Volume & 15.70 & 16.53 & 27.48 & 12.79 & 4.21 & 15.34 \\
\hline AADT & 18.37 & 40.46 & 16.11 & 7.79 & 10.51 & 18.65 \\
\hline Auto Ownership & 10.97 & 3.92 & 8.63 & 14.39 & 30.41 & 13.66 \\
\hline Land Use & 14.23 & 7.07 & 8.63 & 14.45 & 20.34 & 12.94 \\
\hline Transit Stops & 17.91 & 13.12 & 18.77 & 27.08 & 20.55 & 19.49 \\
\hline Total & 100 & 100 & 100 & 100 & 100 & 100 \\
\hline
\end{tabular}

Table 5-5: Sub-cluster Level Priorities with Respect to Bicycle Facility

\begin{tabular}{|c|c|c|c|c|c|c|}
\hline \multirow{2}{*}{ Criteria } & \multicolumn{5}{|c|}{ Priorities Derived from Expert Panel Feedback } & \multirow{2}{*}{ Average } \\
\hline & Expert-A & Expert-B & Expert-C & Expert-D & Expert-E & \\
\hline Bicycle Crash & 44.14 & 45.92 & 48.88 & 48.90 & 6.52 & 38.87 \\
\hline Bicycle Volume & 11.27 & 12.05 & 13.86 & 8.74 & 6.25 & 10.43 \\
\hline AADT & 16.41 & 23.64 & 11.82 & 6.03 & 17.55 & 15.09 \\
\hline Auto Own & 9.27 & 3.27 & 6.35 & 9.38 & 25.27 & 10.71 \\
\hline Land Use & 5.48 & 5.39 & 6.35 & 8.78 & 25.31 & 10.26 \\
\hline Transit Stops & 13.42 & 9.73 & 12.74 & 18.17 & 19.10 & 14.63 \\
\hline Total & 100 & 100 & 100 & 100 & 100 & 100 \\
\hline
\end{tabular}

Table 5-6: Sub-cluster Level Priorities with Respect to Bicycle Volume

\begin{tabular}{|c|c|c|c|c|c|c|}
\hline \multirow{2}{*}{ Criteria } & \multicolumn{5}{|c|}{ Priorities Derived from Expert Panel Feedback } & \multirow{2}{*}{ Average } \\
\hline & Expert-A & Expert-B & Expert-C & Expert-D & Expert-E & \\
\hline Bicycle Crash & 37.59 & 45.45 & 48.64 & 49.65 & 5.95 & 37.46 \\
\hline Bicycle Facility & 18.96 & 10.48 & 14.95 & 12.52 & 16.43 & 14.67 \\
\hline AADT & 7.67 & 22.66 & 10.14 & 4.90 & 11.26 & 11.33 \\
\hline Auto Ownership & 5.58 & 3.45 & 6.27 & 9.35 & 30.43 & 11.02 \\
\hline Land Use & 13.95 & 6.40 & 6.27 & 9.27 & 18.25 & 10.83 \\
\hline Transit Stops & 16.25 & 11.55 & 13.72 & 14.31 & 17.68 & 14.70 \\
\hline Total & 100 & 100 & 100 & 100 & 100 & 100 \\
\hline
\end{tabular}

Table 5-7: Sub-cluster Level Priorities with Respect to AADT

\begin{tabular}{|c|c|c|c|c|c|c|}
\hline \multirow{2}{*}{ Criteria } & \multicolumn{5}{|c|}{ Priorities Derived from Expert Panel Feedback } & \multirow{2}{*}{ Average } \\
\hline & Expert-A & Expert-B & Expert-C & Expert-D & Expert-E & \\
\hline Bicycle Crash & 38.33 & 46.99 & 48.44 & 49.85 & 6.95 & 38.11 \\
\hline Bicycle Facility & 16.21 & 16.19 & 9.91 & 12.37 & 10.90 & 13.11 \\
\hline Bicycle Volume & 12.80 & 14.66 & 16.76 & 7.78 & 7.82 & 11.97 \\
\hline Auto Ownership & 10.41 & 3.73 & 6.28 & 7.82 & 32.07 & 12.06 \\
\hline Land Use & 11.73 & 6.61 & 6.28 & 7.17 & 19.31 & 10.22 \\
\hline Transit Stops & 10.52 & 11.83 & 12.34 & 15.00 & 22.94 & 14.52 \\
\hline Total & 100 & 100 & 100 & 100 & 100 & 100 \\
\hline
\end{tabular}


Table 5-8: Sub-cluster Level Priorities with Respect to Auto Ownership

\begin{tabular}{|l|r|r|r|r|r|r|}
\hline \multirow{2}{*}{ Criteria } & \multicolumn{9}{|c|}{ Priorities Derived from Expert Panel Feedback } & \multirow{2}{*}{ Average } \\
\cline { 2 - 6 } & Expert-A & Expert-B & Expert-C & Expert-D & Expert-E & \\
\hline Bicycle Crash & 35.94 & 47.03 & 47.73 & 50.79 & 6.22 & 37.54 \\
\hline Bicycle Facility & 15.69 & 10.89 & 11.67 & 13.75 & 22.43 & 14.88 \\
\hline Bicycle Volume & 12.86 & 9.06 & 15.59 & 8.13 & 8.48 & 10.82 \\
\hline AADT & 11.63 & 22.28 & 9.22 & 5.80 & 17.13 & 13.21 \\
\hline Land Use & 10.65 & 3.74 & 5.69 & 9.01 & 26.61 & 11.14 \\
\hline Transit Stops & 13.23 & 7.00 & 10.10 & 12.52 & 19.14 & 12.40 \\
\hline Total & 100 & 100 & 100 & 100 & 100 & 100 \\
\hline
\end{tabular}

Table 5-9: Sub-cluster Level Priorities with Respect to Land Use

\begin{tabular}{|l|r|r|r|r|r|r|}
\hline \multirow{2}{*}{ Criteria } & \multicolumn{4}{|c|}{ Priorities Derived from Expert Panel Feedback } & \multirow{2}{*}{ Average } \\
\cline { 2 - 6 } & Expert-A & Expert-B & Expert-C & Expert-D & Expert-E & \\
\hline Bicycle Crash & 35.41 & 47.44 & 47.73 & 49.00 & 5.40 & 37.00 \\
\hline Bicycle Facility & 22.05 & 11.33 & 11.67 & 13.98 & 17.17 & 15.24 \\
\hline Bicycle Volume & 10.35 & 8.09 & 15.59 & 6.62 & 6.88 & 9.51 \\
\hline AADT & 13.52 & 22.29 & 9.22 & 5.68 & 15.98 & 13.34 \\
\hline Auto Ownership & 7.66 & 3.71 & 5.69 & 9.58 & 32.23 & 11.78 \\
\hline Transit Stops & 11.01 & 7.14 & 10.10 & 15.13 & 22.33 & 13.14 \\
\hline Total & 100 & 100 & 100 & 100 & 100 & 100 \\
\hline
\end{tabular}

Table 5-10: Sub-cluster Level Priorities with Respect to Transit Stops

\begin{tabular}{|c|c|c|c|c|c|c|}
\hline \multirow{2}{*}{ Criteria } & \multicolumn{5}{|c|}{ Priorities Derived from Expert Panel Feedback } & \multirow{2}{*}{ Average } \\
\hline & Expert-A & Expert-B & Expert-C & Expert-D & Expert-E & \\
\hline Bicycle Crash & 35.40 & 46.59 & 47.85 & 49.29 & 4.13 & 36.65 \\
\hline Bicycle Facility & 21.52 & 11.20 & 13.15 & 12.68 & 17.51 & 15.21 \\
\hline Bicycle Volume & 7.63 & 9.41 & 15.68 & 10.13 & 6.80 & 9.93 \\
\hline AADT & 13.41 & 22.81 & 10.24 & 5.87 & 13.83 & 13.23 \\
\hline Auto Ownership & 7.17 & 3.59 & 6.54 & 11.74 & 37.80 & 13.37 \\
\hline Land Use & 14.87 & 6.41 & 6.54 & 10.30 & 19.92 & 11.61 \\
\hline Total & 100 & 100 & 100 & 100 & 100 & 100 \\
\hline
\end{tabular}

The comparison matrices and priority vectors of the segments were exactly similar

to the ones developed for AHP. Thus, the priority vectors developed for AHP were directly for ANP. The following sub-sections provide a detailed discussion on the last two steps.

Supermatrix, Weighted Supermatrix, and Limit Matrix Formation

Priority vectors were placed in proper positions of the general supermatrix framework to derive the final supermatrix. Table 5-11 presents the expanded supermatrix framework that was used in this research. ANP's principle is to derive the limit priorities 
of influence from the supermatrix. To obtain such priorities, the supermatrix needs to be transformed to a matrix each of whose column sums to unity, known as column stochasticity. The resulting stochastic matrix is known as weighted supermatrix. Therefore, once the supermatrix was formed, the columns of the supermatrix were normalized to unity to obtain the weighted supermatrix.

Table 5-11: Expanded Supermatrix Framework

\begin{tabular}{|c|c|c|c|c|c|c|c|c|c|c|}
\hline & & \multirow{2}{*}{ Goal } & \multicolumn{3}{|c|}{ Criteria } & \multicolumn{5}{|c|}{ Alternatives } \\
\hline & & & C-1 & $\ldots$ & C-7 & A-1 & A-2 & A-3 & $\ldots$ & A-n \\
\hline \multicolumn{2}{|l|}{ Goal } & 0 & 0 & 0 & 0 & 0 & 0 & 0 & 0 & 0 \\
\hline \multirow{3}{*}{ Criteria } & C-1 & $\mathrm{W}_{21}$ & $\mathrm{~W}_{22}$ & $\mathrm{~W}_{22}$ & $\mathrm{~W}_{22}$ & 0 & 0 & 0 & 0 & 0 \\
\hline & $\ldots$ & $\mathrm{W}_{21}$ & $\mathrm{~W}_{22}$ & $\mathrm{~W}_{22}$ & $\mathrm{~W}_{22}$ & 0 & 0 & 0 & 0 & 0 \\
\hline & C-7 & $\mathrm{W}_{21}$ & $\mathrm{~W}_{22}$ & $\mathrm{~W}_{22}$ & $\mathrm{~W}_{22}$ & 0 & 0 & 0 & 0 & 0 \\
\hline \multirow{5}{*}{$\begin{array}{c}\text { Alternatives } \\
\text { (Segments) }\end{array}$} & A-1 & 0 & $\mathrm{~W}_{32}$ & $\mathrm{~W}_{32}$ & $\mathrm{~W}_{32}$ & 1 & 0 & 0 & 0 & 0 \\
\hline & A-2 & 0 & $\mathrm{~W}_{32}$ & $\mathrm{~W}_{32}$ & $\mathrm{~W}_{32}$ & 0 & 1 & 0 & 0 & 0 \\
\hline & A-3 & 0 & $\mathrm{~W}_{32}$ & $\mathrm{~W}_{32}$ & $\mathrm{~W}_{32}$ & 0 & 0 & 1 & 0 & 0 \\
\hline & $\ldots$ & 0 & $\mathrm{~W}_{32}$ & $\mathrm{~W}_{32}$ & $\mathrm{~W}_{32}$ & 0 & 0 & 0 & 1 & 0 \\
\hline & A-n & 0 & $\mathrm{~W}_{32}$ & $\mathrm{~W}_{32}$ & $\mathrm{~W}_{32}$ & 0 & 0 & 0 & 0 & 1 \\
\hline
\end{tabular}

Note: $\mathrm{n}=2,236$ in this study.

The limit supermatrix is obtained by raising the weighted supermatrix to exponential powers $2 k+1$, where $k$ is an arbitrary number. It provides the long-term relative influences of the elements on each other through convergence on the importance weights. In this research, the weighted supermatrix was raised to power 22 to obtain the convergence of the alternatives' priorities up to 12 decimal places. Interested readers are referred to Raihan et al. (2016) for step by step calculations of the complete procedure with an example.

\section{$\underline{\text { Ranking of Alternatives }}$}

The final priorities of all elements were obtained by normalizing each cluster of the limit matrix. 


\subsubsection{Fuzzy Analytic Network Process (FANP)}

The difference between FANP approach and ANP approach lies in fuzzy pairwise comparison matrix formation and in calculating triangular fuzzy weights; and finally, in ranking the alternatives from the limit supermatrix. In the FANP method, instead of using the discrete scale of 1-9, a triangular fuzzy number (TFN) scale $\tilde{1}-\tilde{9}$ is used to state the preferences of the decision maker. Table 3-2 was used in this research for this purpose. Three sets of cluster level $\left(\mathrm{W}_{21}\right)$ and sub-cluster level $\left(\mathrm{W}_{22}\right)$ priority vectors (lower bound, middle value, and upper bound) were generated involving the criteria while applying the FANP approach. Tables 5-12 through 5-35 present the priority vectors. To synthesize the final ranks for the locations from three limit matrices, gravity method was employed in this research.

Table 5-12: Lower Bound Cluster Level Priorities with Respect to Goal

\begin{tabular}{|c|c|c|c|c|c|c|}
\hline \multirow{2}{*}{ Criteria } & \multicolumn{5}{|c|}{ Priorities Derived from Expert Panel Feedback } & \multirow{2}{*}{ Average } \\
\hline & Expert-A & Expert-B & Expert-C & Expert-D & Expert-E & \\
\hline Bicycle Crash & 32.62 & 33.77 & 33.33 & 33.24 & 7.03 & 28.00 \\
\hline Bicycle Facility & 15.05 & 10.47 & 11.11 & 11.08 & 14.32 & 12.41 \\
\hline Bicycle Volume & 8.74 & 9.73 & 11.11 & 11.08 & 7.65 & 9.66 \\
\hline AADT & 10.99 & 19.61 & 11.11 & 11.08 & 13.17 & 13.19 \\
\hline Auto Ownership & 8.74 & 6.54 & 11.11 & 9.47 & 24.40 & 12.05 \\
\hline Land Use & 10.99 & 7.65 & 11.11 & 11.08 & 18.03 & 11.77 \\
\hline Transit Stops & 12.86 & 12.24 & 11.11 & 12.96 & 15.41 & 12.92 \\
\hline Total & 100 & 100 & 100 & 100 & 100 & 100 \\
\hline
\end{tabular}

Table 5-13: Modal Cluster Level Priorities with Respect to Goal

\begin{tabular}{|l|r|r|r|r|r|r|}
\hline \multirow{2}{*}{ Criteria } & \multicolumn{4}{|c|}{ Priorities Derived from Expert Panel Feedback } & \multirow{2}{*}{ Average } \\
\cline { 2 - 6 } & Expert-A & Expert-B & Expert-C & Expert-D & Expert-E & \\
\hline Bicycle Crash & 37.27 & 37.98 & 39.50 & 40.32 & 5.60 & 32.14 \\
\hline Bicycle Facility & 15.71 & 11.25 & 11.09 & 11.91 & 13.58 & 12.71 \\
\hline Bicycle Volume & 8.35 & 9.57 & 12.97 & 8.85 & 6.30 & 9.21 \\
\hline AADT & 10.05 & 21.70 & 10.04 & 6.85 & 12.53 & 12.23 \\
\hline Auto Ownership & 7.58 & 4.11 & 7.52 & 9.19 & 25.98 & 10.88 \\
\hline Land Use & 9.46 & 5.76 & 7.52 & 9.44 & 19.46 & 10.33 \\
\hline Transit Stops & 11.57 & 9.63 & 11.36 & 13.44 & 16.54 & 12.51 \\
\hline Total & 100 & 100 & 100 & 100 & 100 & 100 \\
\hline
\end{tabular}


Table 5-14: Upper Bound Cluster Level Priorities with Respect to Goal

\begin{tabular}{|c|c|c|c|c|c|c|}
\hline \multirow{2}{*}{ Criteria } & \multicolumn{5}{|c|}{ Priorities Derived from Expert Panel Feedback } & \multirow{2}{*}{ Average } \\
\hline & Expert-A & Expert-B & Expert-C & Expert-D & Expert-E & \\
\hline Bicycle Crash & 39.16 & 40.16 & 42.35 & 43.06 & 5.12 & 33.97 \\
\hline Bicycle Facility & 15.53 & 10.62 & 10.57 & 11.36 & 13.67 & 12.35 \\
\hline Bicycle Volume & 7.92 & 9.08 & 12.36 & 8.42 & 5.95 & 8.75 \\
\hline AADT & 9.66 & 21.96 & 9.57 & 6.52 & 12.24 & 11.99 \\
\hline Auto Ownership & 7.23 & 3.69 & 7.16 & 8.57 & 26.68 & 10.67 \\
\hline Land Use & 9.10 & 5.26 & 7.16 & 9.01 & 19.82 & 10.07 \\
\hline Transit Stops & 11.39 & 9.23 & 10.83 & 13.07 & 16.51 & 12.20 \\
\hline Total & 100 & 100 & 100 & 100 & 100 & 100 \\
\hline
\end{tabular}

Table 5-15: Lower Bound Sub-cluster Level Priorities with Respect to Bicycle Crash

\begin{tabular}{|l|r|r|r|r|r|r|}
\hline \multirow{2}{*}{ Criteria } & \multicolumn{4}{|c|}{ Priorities Derived from Expert Panel Feedback } & \multirow{2}{*}{ Average } \\
\cline { 2 - 6 } & Expert-A & Expert-B & Expert-C & Expert-D & Expert-E & 16.47 \\
\hline Bicycle Facility & 19.79 & 15.26 & 16.67 & 16.57 & 14.03 & 13.79 \\
\hline Bicycle Volume & 13.72 & 15.26 & 16.67 & 16.57 & 6.75 & 18.84 \\
\hline AADT & 16.48 & 31.75 & 16.67 & 16.57 & 12.72 & 15.83 \\
\hline Auto Ownership & 13.72 & 8.81 & 16.67 & 13.80 & 26.12 & 16.47 \\
\hline Land Use & 16.48 & 10.58 & 16.67 & 16.57 & 22.03 & 18.61 \\
\hline Transit Stops & 19.79 & 18.33 & 16.67 & 19.90 & 18.35 & 100 \\
\hline Total & 100 & 100 & 100 & 100 & 100 & \\
\hline
\end{tabular}

Table 5-16: Modal Sub-cluster Level Priorities with Respect to Bicycle Crash

\begin{tabular}{|c|c|c|c|c|c|c|}
\hline \multirow{2}{*}{ Criteria } & \multicolumn{5}{|c|}{ Priorities Derived from Expert Panel Feedback } & \multirow{2}{*}{ Average } \\
\hline & Expert-A & Expert-B & Expert-C & Expert-D & Expert-E & \\
\hline Bicycle Facility & 21.91 & 17.77 & 18.55 & 20.70 & 12.96 & 18.38 \\
\hline Bicycle Volume & 13.92 & 15.52 & 22.27 & 14.35 & 5.29 & 14.27 \\
\hline AADT & 16.72 & 38.25 & 16.52 & 10.65 & 11.31 & 18.69 \\
\hline Auto Ownership & 12.45 & 5.49 & 11.79 & 14.67 & 27.62 & 14.40 \\
\hline Land Use & 15.29 & 8.14 & 11.79 & 15.80 & 22.71 & 14.74 \\
\hline Transit Stops & 19.71 & 14.83 & 19.08 & 23.84 & 20.11 & 19.51 \\
\hline Total & 100 & 100 & 100 & 100 & 100 & 100 \\
\hline
\end{tabular}

Table 5-17: Upper Bound Sub-cluster Level Priorities with Respect to Bicycle Crash

\begin{tabular}{|l|r|r|r|r|r|r|}
\hline \multirow{2}{*}{ Criteria } & \multicolumn{4}{|c|}{ Priorities Derived from Expert Panel Feedback } & \multirow{2}{*}{ Average } \\
\cline { 2 - 6 } & Expert-A & Expert-B & Expert-C & Expert-D & Expert-E & 18.29 \\
\hline Bicycle Facility & 22.14 & 17.27 & 18.55 & 20.65 & 12.83 & 14.03 \\
\hline Bicycle Volume & 13.61 & 15.09 & 22.27 & 14.32 & 4.86 & 19.00 \\
\hline AADT & 16.63 & 40.33 & 16.52 & 10.62 & 10.87 & 14.27 \\
\hline Auto Ownership & 12.23 & 5.03 & 11.79 & 14.32 & 27.99 & 14.74 \\
\hline Land Use & 15.24 & 7.61 & 11.79 & 15.76 & 23.31 & 19.67 \\
\hline Transit Stops & 20.15 & 14.67 & 19.08 & 24.32 & 20.14 & 100 \\
\hline Total & 100 & 100 & 100 & 100 & 100 & \\
\hline
\end{tabular}


Table 5-18: Lower Bound Sub-cluster Level Priorities with Respect to Bicycle Facility

\begin{tabular}{|c|c|c|c|c|c|c|}
\hline \multirow{2}{*}{ Criteria } & \multicolumn{5}{|c|}{ Priorities Derived from Expert Panel Feedback } & \multirow{2}{*}{ Average } \\
\hline & Expert-A & Expert-B & Expert-C & Expert-D & Expert-E & \\
\hline Bicycle Crash & 41.97 & 37.39 & 37.50 & 37.34 & 8.85 & 32.61 \\
\hline Bicycle Volume & 9.02 & 10.51 & 12.50 & 12.45 & 8.13 & 10.52 \\
\hline AADT & 14.17 & 23.81 & 12.50 & 12.45 & 18.41 & 16.27 \\
\hline Auto Ownership & 10.84 & 6.61 & 12.50 & 10.36 & 24.08 & 12.88 \\
\hline Land Use & 9.83 & 7.94 & 12.50 & 12.45 & 22.11 & 12.96 \\
\hline Transit Stops & 14.17 & 13.75 & 12.50 & 14.95 & 18.41 & 14.76 \\
\hline Total & 100 & 100 & 100 & 100 & 100 & 100 \\
\hline
\end{tabular}

Table 5-19: Modal Sub-cluster Level Priorities with Respect to Bicycle Facility

\begin{tabular}{|l|r|r|r|r|r|r|}
\hline \multirow{2}{*}{ Criteria } & \multicolumn{4}{|c|}{ Priorities Derived from Expert Panel Feedback } & \multirow{2}{*}{ Average } \\
\cline { 2 - 6 } & Expert-A & Expert-B & Expert-C & Expert-D & Expert-E & \\
\hline Bicycle Crash & 48.24 & 41.76 & 43.94 & 44.18 & 6.97 & 37.02 \\
\hline Bicycle Volume & 8.42 & 11.83 & 13.45 & 10.35 & 6.49 & 10.11 \\
\hline AADT & 13.43 & 24.40 & 12.57 & 8.06 & 18.22 & 15.34 \\
\hline Auto Ownership & 9.67 & 4.41 & 8.55 & 10.11 & 25.48 & 11.64 \\
\hline Land Use & 7.91 & 6.24 & 8.55 & 10.44 & 24.16 & 11.46 \\
\hline Transit Stops & 12.32 & 11.36 & 12.94 & 16.86 & 18.69 & 14.43 \\
\hline Total & 100 & 100 & 100 & 100 & 100 & 100 \\
\hline
\end{tabular}

Table 5-20: Upper Bound Sub-cluster Level Priorities with Respect to Bicycle Facility

\begin{tabular}{|l|r|r|r|r|r|r|}
\hline \multirow{2}{*}{ Criteria } & \multicolumn{3}{|c|}{ Priorities Derived from Expert Panel Feedback } & \multirow{2}{*}{ Average } \\
\cline { 2 - 6 } & Expert-A & Expert-B & Expert-C & Expert-D & Expert-E & \\
\hline Bicycle Crash & 50.66 & 43.76 & 46.86 & 46.98 & 6.43 & 38.94 \\
\hline Bicycle Volume & 7.85 & 11.13 & 12.75 & 9.80 & 6.08 & 9.52 \\
\hline AADT & 12.94 & 24.78 & 11.92 & 7.63 & 18.12 & 15.08 \\
\hline Auto Ownership & 9.23 & 3.89 & 8.10 & 9.34 & 25.96 & 11.30 \\
\hline Land Use & 7.33 & 5.61 & 8.10 & 9.90 & 24.74 & 11.14 \\
\hline Transit Stops & 11.99 & 10.82 & 12.26 & 16.35 & 18.68 & 14.02 \\
\hline Total & 100 & 100 & 100 & 100 & 100 & 100 \\
\hline
\end{tabular}

Table 5-21: Lower Bound Sub-cluster Level Priorities with Respect to Bicycle Volume

\begin{tabular}{|l|r|r|r|r|r|r|}
\hline \multirow{2}{*}{ Criteria } & \multicolumn{4}{|c|}{ Priorities Derived from Expert Panel Feedback } & \multirow{2}{*}{ Average } \\
\cline { 2 - 6 } & Expert-A & Expert-B & Expert-C & Expert-D & Expert-E & \\
\hline Bicycle Crash & 33.69 & 35.96 & 37.50 & 37.34 & 9.19 & 30.74 \\
\hline Bicycle Facility & 17.86 & 11.99 & 12.50 & 12.45 & 17.55 & 14.47 \\
\hline AADT & 10.31 & 20.76 & 12.50 & 12.45 & 13.25 & 13.85 \\
\hline Auto Ownership & 7.89 & 6.92 & 12.50 & 10.36 & 24.99 & 12.53 \\
\hline Land Use & 12.39 & 9.98 & 12.50 & 12.45 & 19.11 & 13.28 \\
\hline Transit Stops & 17.86 & 14.39 & 12.50 & 14.95 & 15.91 & 15.12 \\
\hline Total & 100 & 100 & 100 & 100 & 100 & 100 \\
\hline
\end{tabular}


Table 5-22: Modal Sub-cluster Level Priorities with Respect to Bicycle Volume

\begin{tabular}{|l|r|r|r|r|r|r|}
\hline \multirow{2}{*}{ Criteria } & \multicolumn{4}{|c|}{ Priorities Derived from Expert Panel Feedback } & \multirow{2}{*}{ Average } \\
\cline { 2 - 6 } & Expert-A & Expert-B & Expert-C & Expert-D & Expert-E & \\
\hline Bicycle Crash & 38.58 & 41.10 & 43.85 & 44.90 & 7.39 & 35.17 \\
\hline Bicycle Facility & 18.71 & 11.76 & 14.09 & 12.74 & 16.84 & 14.83 \\
\hline AADT & 8.65 & 22.56 & 11.18 & 7.15 & 11.93 & 12.29 \\
\hline Auto Ownership & 6.49 & 4.58 & 8.53 & 10.08 & 27.01 & 11.34 \\
\hline Land Use & 11.08 & 7.62 & 8.53 & 11.13 & 20.33 & 11.74 \\
\hline Transit Stops & 16.50 & 12.37 & 13.81 & 13.99 & 16.50 & 14.63 \\
\hline Total & 100 & 100 & 100 & 100 & 100 & 100 \\
\hline
\end{tabular}

Table 5-23: Upper Bound Sub-cluster Level Priorities with Respect to Bicycle Volume

\begin{tabular}{|l|r|r|r|r|r|r|}
\hline \multirow{2}{*}{ Criteria } & \multicolumn{4}{|c|}{ Priorities Derived from Expert Panel Feedback } & \multirow{2}{*}{ Average } \\
\cline { 2 - 6 } & Expert-A & Expert-B & Expert-C & Expert-D & Expert-E & \\
\hline Bicycle Crash & 40.30 & 43.47 & 46.77 & 47.67 & 6.86 & 37.02 \\
\hline Bicycle Facility & 18.47 & 11.06 & 13.35 & 12.10 & 17.10 & 14.42 \\
\hline AADT & 8.12 & 22.55 & 10.60 & 6.77 & 11.50 & 11.91 \\
\hline Auto Ownership & 6.01 & 4.06 & 8.09 & 9.31 & 27.69 & 11.03 \\
\hline Land Use & 10.59 & 7.03 & 8.09 & 10.57 & 20.54 & 11.36 \\
\hline Transit Stops & 16.52 & 11.83 & 13.10 & 13.58 & 16.30 & 14.26 \\
\hline Total & 100 & 100 & 100 & 100 & 100 & 100 \\
\hline
\end{tabular}

Table 5-24: Lower Bound Sub-cluster Level Priorities with Respect to AADT

\begin{tabular}{|l|r|r|r|r|r|r|}
\hline \multirow{2}{*}{ Criteria } & \multicolumn{3}{|c|}{ Priorities Derived from Expert Panel Feedback } & \multirow{2}{*}{ Average } \\
\cline { 2 - 6 } & Expert-A & Expert-B & Expert-C & Expert-D & Expert-E & \\
\hline Bicycle Crash & 37.02 & 39.18 & 37.50 & 37.34 & 8.76 & 31.96 \\
\hline Bicycle Facility & 15.01 & 11.99 & 12.50 & 12.45 & 13.94 & 13.18 \\
\hline Bicycle Volume & 11.48 & 13.23 & 12.50 & 12.45 & 9.67 & 11.86 \\
\hline Auto Ownership & 11.48 & 8.32 & 12.50 & 10.36 & 31.17 & 14.77 \\
\hline Land Use & 12.50 & 9.99 & 12.50 & 12.45 & 18.23 & 13.13 \\
\hline Transit Stops & 12.50 & 17.30 & 12.50 & 14.95 & 18.23 & 15.10 \\
\hline Total & 100 & 100 & 100 & 100 & 100 & 100 \\
\hline
\end{tabular}

Table 5-25: Modal Sub-cluster Level Priorities with Respect to AADT

\begin{tabular}{|l|r|r|r|r|r|r|}
\hline \multirow{2}{*}{ Criteria } & \multicolumn{4}{|c|}{ Priorities Derived from Expert Panel Feedback } & \multirow{2}{*}{ Average } \\
\cline { 2 - 6 } & Expert-A & Expert-B & Expert-C & Expert-D & Expert-E & \\
\hline Bicycle Crash & 41.12 & 44.10 & 43.82 & 45.07 & 7.31 & 36.28 \\
\hline Bicycle Facility & 15.01 & 15.08 & 11.17 & 12.19 & 12.68 & 13.23 \\
\hline Bicycle Volume & 11.85 & 14.02 & 15.06 & 9.68 & 8.38 & 11.80 \\
\hline Auto Ownership & 10.39 & 5.23 & 8.53 & 9.01 & 31.81 & 12.99 \\
\hline Land Use & 10.68 & 7.76 & 8.53 & 9.31 & 19.72 & 11.20 \\
\hline Transit Stops & 10.95 & 13.82 & 12.90 & 14.73 & 20.11 & 14.50 \\
\hline Total & 100 & 100 & 100 & 100 & 100 & 100 \\
\hline
\end{tabular}


Table 5-26: Upper Bound Sub-cluster Level Priorities with Respect to AADT

\begin{tabular}{|c|c|c|c|c|c|c|}
\hline \multirow{2}{*}{ Criteria } & \multicolumn{5}{|c|}{ Priorities Derived from Expert Panel Feedback } & \multirow{2}{*}{ Average } \\
\hline & Expert-A & Expert-B & Expert-C & Expert-D & Expert-E & \\
\hline Bicycle Crash & 43.05 & 46.65 & 46.74 & 47.83 & 6.71 & 38.19 \\
\hline Bicycle Facility & 14.63 & 14.25 & 10.59 & 11.57 & 12.55 & 12.72 \\
\hline Bicycle Volume & 11.41 & 13.58 & 14.28 & 9.16 & 7.99 & 11.29 \\
\hline Auto Ownership & 10.08 & 4.75 & 8.08 & 8.32 & 32.89 & 12.83 \\
\hline Land Use & 10.26 & 7.19 & 8.08 & 8.83 & 19.75 & 10.82 \\
\hline Transit Stops & 10.57 & 13.58 & 12.23 & 14.29 & 20.10 & 14.16 \\
\hline Total & 100 & 100 & 100 & 100 & 100 & 100 \\
\hline
\end{tabular}

Table 5-27: Lower Bound Sub-cluster Level Priorities with Respect to Auto Ownership

\begin{tabular}{|l|r|r|r|r|r|r|}
\hline \multirow{2}{*}{ Criteria } & \multicolumn{4}{|c|}{ Priorities Derived from Expert Panel Feedback } & \multirow{2}{*}{ Average } \\
\cline { 2 - 6 } & Expert-A & Expert-B & Expert-C & Expert-D & Expert-E & \\
\hline Bicycle Crash & 34.55 & 38.46 & 37.50 & 37.50 & 9.08 & 31.42 \\
\hline Bicycle Facility & 15.25 & 11.77 & 12.50 & 12.50 & 22.69 & 14.94 \\
\hline Bicycle Volume & 11.67 & 10.81 & 12.50 & 12.50 & 10.91 & 11.68 \\
\hline AADT & 10.58 & 20.39 & 12.50 & 12.50 & 15.73 & 14.34 \\
\hline Land Use & 12.70 & 6.80 & 12.50 & 12.50 & 22.69 & 13.44 \\
\hline Transit Stops & 15.25 & 11.77 & 12.50 & 12.50 & 18.89 & 14.18 \\
\hline Total & 100 & 100 & 100 & 100 & 100 & 100 \\
\hline
\end{tabular}

Table 5-28: Modal Sub-cluster Level Priorities with Respect to Auto Ownership

\begin{tabular}{|c|c|c|c|c|c|c|}
\hline \multirow{2}{*}{ Criteria } & \multicolumn{5}{|c|}{ Priorities Derived from Expert Panel Feedback } & \multirow{2}{*}{ Average } \\
\hline & Expert-A & Expert-B & Expert-C & Expert-D & Expert-E & \\
\hline Bicycle Crash & 40.01 & 42.93 & 44.03 & 45.75 & 7.21 & 35.98 \\
\hline Bicycle Facility & 15.10 & 11.65 & 11.78 & 13.58 & 21.83 & 14.79 \\
\hline Bicycle Volume & 11.43 & 9.65 & 14.14 & 9.61 & 8.91 & 10.75 \\
\hline AADT & 9.14 & 22.35 & 10.49 & 8.00 & 16.00 & 13.20 \\
\hline Land Use & 10.74 & 4.76 & 8.01 & 10.37 & 26.73 & 12.12 \\
\hline Transit Stops & 13.58 & 8.67 & 11.55 & 12.70 & 19.33 & 13.16 \\
\hline Total & 100 & 100 & 100 & 100 & 100 & 100 \\
\hline
\end{tabular}

Table 5-29: Upper Bound Sub-cluster Level Priorities with Respect to Auto Ownership

\begin{tabular}{|l|r|r|r|r|r|r|}
\hline \multirow{2}{*}{ Criteria } & \multicolumn{4}{|c|}{ Priorities Derived from Expert Panel Feedback } & \multirow{2}{*}{ Average } \\
\cline { 2 - 6 } & Expert-A & Expert-B & Expert-C & Expert-D & Expert-E & \\
\hline Bicycle Crash & 41.96 & 45.21 & 46.95 & 48.49 & 6.67 & 37.85 \\
\hline Bicycle Facility & 14.70 & 10.96 & 11.16 & 12.91 & 22.40 & 14.43 \\
\hline Bicycle Volume & 11.05 & 9.13 & 13.41 & 9.11 & 8.49 & 10.24 \\
\hline AADT & 8.60 & 22.36 & 9.95 & 7.58 & 15.64 & 12.82 \\
\hline Land Use & 10.31 & 4.22 & 7.59 & 9.85 & 27.44 & 11.88 \\
\hline Transit Stops & 13.38 & 8.13 & 10.95 & 12.06 & 19.36 & 12.78 \\
\hline Total & 100 & 100 & 100 & 100 & 100 & 100 \\
\hline
\end{tabular}


Table 5-30: Lower Bound Sub-cluster Level Priorities with Respect to Land Use

\begin{tabular}{|l|r|r|r|r|r|r|}
\hline \multirow{2}{*}{ Criteria } & \multicolumn{4}{|c|}{ Priorities Derived from Expert Panel Feedback } & \multirow{2}{*}{ Average } \\
\cline { 2 - 6 } & Expert-A & Expert-B & Expert-C & Expert-D & Expert-E & \\
\hline Bicycle Crash & 36.02 & 38.63 & 37.50 & 37.34 & 7.20 & 31.34 \\
\hline Bicycle Facility & 21.06 & 11.82 & 12.50 & 12.45 & 16.52 & 14.87 \\
\hline Bicycle Volume & 9.30 & 9.04 & 12.50 & 12.45 & 9.54 & 10.57 \\
\hline AADT & 12.16 & 20.48 & 12.50 & 12.45 & 17.99 & 15.12 \\
\hline Auto Ownership & 9.30 & 8.20 & 12.50 & 10.36 & 30.76 & 14.22 \\
\hline Transit Stops & 12.16 & 11.82 & 12.50 & 14.95 & 17.99 & 13.88 \\
\hline Total & 100 & 100 & 100 & 100 & 100 & 100 \\
\hline
\end{tabular}

Table 5-31: Modal Sub-cluster Level Priorities with Respect to Land Use

\begin{tabular}{|l|r|r|r|r|r|r|}
\hline \multirow{2}{*}{ Criteria } & \multicolumn{4}{|c|}{ Priorities Derived from Expert Panel Feedback } & \multirow{2}{*}{ Average } \\
\cline { 2 - 6 } & Expert-A & Expert-B & Expert-C & Expert-D & Expert-E & \\
\hline Bicycle Crash & 39.95 & 42.99 & 44.03 & 44.27 & 5.99 & 35.45 \\
\hline Bicycle Facility & 22.63 & 12.24 & 11.78 & 13.71 & 15.74 & 15.22 \\
\hline Bicycle Volume & 8.21 & 8.61 & 14.14 & 9.06 & 8.09 & 9.62 \\
\hline AADT & 10.91 & 22.38 & 10.49 & 8.07 & 17.65 & 13.90 \\
\hline Auto Ownership & 7.85 & 5.10 & 8.01 & 10.13 & 31.34 & 12.49 \\
\hline Transit Stops & 10.44 & 8.68 & 11.55 & 14.76 & 21.19 & 13.32 \\
\hline Total & 100 & 100 & 100 & 100 & 100 & 100 \\
\hline
\end{tabular}

Table 5-32: Upper Bound Sub-cluster Level Priorities with Respect to Land Use

\begin{tabular}{|l|r|r|r|r|r|r|}
\hline \multirow{2}{*}{ Criteria } & \multicolumn{3}{|c|}{ Priorities Derived from Expert Panel Feedback } & \multirow{2}{*}{ Average } \\
\cline { 2 - 6 } & Expert-A & Expert-B & Expert-C & Expert-D & Expert-E & \\
\hline Bicycle Crash & 41.53 & 45.31 & 46.95 & 47.09 & 5.40 & 37.26 \\
\hline Bicycle Facility & 22.86 & 11.53 & 11.16 & 13.01 & 15.85 & 14.88 \\
\hline Bicycle Volume & 7.73 & 7.99 & 13.41 & 8.58 & 7.72 & 9.09 \\
\hline AADT & 10.42 & 22.41 & 9.95 & 7.64 & 17.56 & 13.60 \\
\hline Auto Ownership & 7.44 & 4.61 & 7.59 & 9.36 & 32.33 & 12.27 \\
\hline Transit Stops & 10.02 & 8.15 & 10.95 & 14.32 & 21.14 & 12.91 \\
\hline Total & 100 & 100 & 100 & 100 & 100 & 100 \\
\hline
\end{tabular}

Table 5-33: Lower Bound Sub-cluster Level Priorities with Respect to Transit Stops

\begin{tabular}{|c|c|c|c|c|c|c|}
\hline \multirow{2}{*}{ Criteria } & \multicolumn{5}{|c|}{ Priorities Derived from Expert Panel Feedback } & \multirow{2}{*}{ Average } \\
\hline & Expert-A & Expert-B & Expert-C & Expert-D & Expert-E & \\
\hline Bicycle Crash & 36.09 & 38.69 & 37.50 & 37.50 & 7.16 & 31.39 \\
\hline Bicycle Facility & 17.57 & 11.84 & 12.50 & 12.50 & 16.42 & 14.17 \\
\hline Bicycle Volume & 7.76 & 10.88 & 12.50 & 12.50 & 9.48 & 10.62 \\
\hline AADT & 14.63 & 20.51 & 12.50 & 12.50 & 14.89 & 15.01 \\
\hline Auto Ownership & 9.32 & 8.21 & 12.50 & 12.50 & 30.58 & 14.62 \\
\hline Land Use & 14.63 & 9.86 & 12.50 & 12.50 & 21.47 & 14.19 \\
\hline Total & 100 & 100 & 100 & 100 & 100 & 100 \\
\hline
\end{tabular}


Table 5-34: Modal Sub-cluster Level Priorities with Respect to Transit Stops

\begin{tabular}{|l|r|r|r|r|r|r|}
\hline \multirow{2}{*}{ Criteria } & \multicolumn{4}{|c|}{ Priorities Derived from Expert Panel Feedback } & \multirow{2}{*}{ Average } \\
\cline { 2 - 6 } & Expert-A & Expert-B & Expert-C & Expert-D & Expert-E & \\
\hline Bicycle Crash & 39.83 & 42.81 & 44.04 & 44.56 & 5.43 & 35.33 \\
\hline Bicycle Facility & 18.68 & 12.19 & 12.60 & 12.90 & 16.31 & 14.53 \\
\hline Bicycle Volume & 7.09 & 9.62 & 14.15 & 10.95 & 7.99 & 9.96 \\
\hline AADT & 13.67 & 22.78 & 11.23 & 7.75 & 13.87 & 13.86 \\
\hline Auto Ownership & 7.99 & 5.07 & 8.99 & 12.57 & 34.74 & 13.87 \\
\hline Land Use & 12.74 & 7.53 & 8.99 & 11.27 & 21.66 & 12.44 \\
\hline Total & 100 & 100 & 100 & 100 & 100 & 100 \\
\hline
\end{tabular}

Table 5-35: Upper Bound Sub-cluster Level Priorities with Respect to Transit Stops

\begin{tabular}{|l|r|r|r|r|r|r|}
\hline \multirow{2}{*}{ Criteria } & \multicolumn{4}{|c|}{ Priorities Derived from Expert Panel Feedback } & \multirow{2}{*}{ Average } \\
\cline { 2 - 6 } & Expert-A & Expert-B & Expert-C & Expert-D & Expert-E & \\
\hline Bicycle Crash & 41.55 & 45.12 & 46.96 & 47.44 & 4.87 & 37.19 \\
\hline Bicycle Facility & 18.47 & 11.48 & 11.95 & 12.25 & 16.36 & 14.10 \\
\hline Bicycle Volume & 6.56 & 9.11 & 13.41 & 10.38 & 7.58 & 9.41 \\
\hline AADT & 13.37 & 22.75 & 10.64 & 7.34 & 13.45 & 13.51 \\
\hline Auto Ownership & 7.57 & 4.59 & 8.52 & 11.88 & 35.70 & 13.65 \\
\hline Land Use & 12.47 & 6.95 & 8.52 & 10.70 & 22.05 & 12.14 \\
\hline Total & 100 & 100 & 100 & 100 & 100 & 100 \\
\hline
\end{tabular}

\subsubsection{Comparison of Results}

There are no direct methods to compare the performance of AHP, ANP, and FANP in screening highway improvement locations. Therefore, an attempt has been made in this research to compare the top 30 prioritized locations considering the criteria. Table 5-36 presents the top 30 locations ranked by AHP, ANP, and FANP approaches. It was difficult to compare all the locations at once and understand the logical explanation of the rankings by these three methods. Therefore, two pairs of locations were studied at the site specific level to understand the logical difference in the rankings from the three methods.

It can be observed from Table 5-36 that the top 30 prioritized locations were common in all three methods; however, the ranks of the locations based on the methods are quite different. The following sub-sections compare the rankings from the three methods at the site specific levels. 
Table 5-36: Top 30 Prioritized Locations using AHP, ANP, and FANP Approaches

\begin{tabular}{|c|c|c|c|c|c|c|c|c|c|c|c|c|c|c|}
\hline \multirow[b]{2}{*}{$\#$} & \multirow[b]{2}{*}{$\begin{array}{l}\text { Segment } \\
\text { Length }\end{array}$} & \multirow[b]{2}{*}{ AADT } & \multirow{2}{*}{$\begin{array}{c}\text { Presence } \\
\text { of } \\
\text { Bicycle } \\
\text { Facility }\end{array}$} & \multirow{2}{*}{$\begin{array}{c}\text { Total } \\
\text { Bicycle } \\
\text { Crashes }\end{array}$} & \multirow{2}{*}{$\begin{array}{c}\text { Total } \\
\text { Bicycle } \\
\text { Crashes } \\
\text { per mile }\end{array}$} & \multirow[b]{2}{*}{$\begin{array}{l}\text { Scaled } \\
\text { Bicycle } \\
\text { Volume }\end{array}$} & \multirow{2}{*}{\begin{tabular}{|c}
$\#$ of Households \\
with 0 \& 1 \\
Vehicle along \\
the Segment
\end{tabular}} & \multirow{2}{*}{\begin{tabular}{|c|}
$\#$ of Households \\
having 0 and 1 \\
Vehicle per mile \\
along the Segment
\end{tabular}} & \multirow[b]{2}{*}{$\begin{array}{c}\# \text { of Bus } \\
\text { Stops }\end{array}$} & \multirow[b]{2}{*}{$\begin{array}{c}\# \text { of Bus } \\
\text { Stops } \\
\text { per mile }\end{array}$} & \multirow[b]{2}{*}{ Land Use } & \multicolumn{3}{|c|}{ Rank } \\
\hline & & & & & & & & & & & & AHP & ANP & FANP \\
\hline 1 & 0.706 & 40,000 & 0 & 4 & 5.67 & 7 & 2,062 & $2,920.68$ & 7 & 9.91 & Residential & 1 & 1 & 1 \\
\hline 2 & 0.327 & 36,000 & 0 & 4 & 12.23 & 7 & 1,806 & $5,522.94$ & 3 & 9.17 & Commercial & 2 & 2 & 2 \\
\hline 3 & 0.232 & 39,000 & 0 & 1 & 4.31 & 7 & 502 & $2,163.79$ & 2 & 8.62 & Commercial & 3 & 3 & 3 \\
\hline 4 & 0.244 & 30,000 & 0 & 1 & 4.10 & 7 & 969 & $3,971.31$ & 3 & 12.29 & Commercial & 4 & 4 & 4 \\
\hline 5 & 0.753 & 45,500 & 0 & 7 & 9.30 & 9 & 2,011 & $2,670.65$ & 6 & 7.97 & Commercial & 5 & 5 & 7 \\
\hline 6 & 1.377 & 33,500 & 0 & 7 & 5.08 & 7 & 4,745 & $3,445.90$ & 8 & 5.81 & Residential & 6 & 6 & 5 \\
\hline 7 & 0.184 & 36,500 & 0 & 5 & 27.17 & 9 & 664 & $3,608.70$ & 1 & 5.43 & Commercial & 7 & 7 & 8 \\
\hline 8 & 0.094 & 30,500 & 0 & 1 & 10.64 & 5 & 189 & $2,010.64$ & 1 & 10.64 & Residential & 8 & 8 & 6 \\
\hline 9 & 0.738 & 21,200 & 0 & 3 & 4.07 & 7 & 2,546 & $3,449.86$ & 8 & 10.84 & Residential & 9 & 9 & 9 \\
\hline 10 & 0.152 & 40,000 & 0 & 1 & 6.58 & 7 & 690 & $4,539.47$ & 1 & 6.58 & Commercial & 10 & 11 & 11 \\
\hline 11 & 0.381 & 33,000 & 0 & 2 & 5.25 & 7 & 750 & $1,968.50$ & 3 & 7.87 & Residential & 11 & 10 & 10 \\
\hline 12 & 0.400 & 17,100 & 0 & 2 & 5.00 & 9 & 995 & $2,487.50$ & 4 & 10.00 & Residential & 12 & 13 & 12 \\
\hline 13 & 1.320 & 33,500 & 0 & 6 & 4.55 & 9 & 926 & 701.52 & 14 & 10.60 & Commercial & 13 & 12 & 14 \\
\hline 14 & 0.563 & 34,000 & 0 & 4 & 7.10 & 5 & 1,911 & $3,394.32$ & 6 & 10.66 & Commercial & 14 & 14 & 13 \\
\hline 15 & 0.625 & 27,000 & 0 & 3 & 4.80 & 9 & 1,091 & $1,745.60$ & 7 & 11.20 & Commercial & 15 & 15 & 16 \\
\hline 16 & 0.255 & 22,000 & 0 & 2 & 7.84 & 9 & 706 & $2,768.63$ & 3 & 11.76 & Commercial & 16 & 16 & 17 \\
\hline 17 & 0.150 & 32,000 & 0 & 1 & 6.67 & 7 & 333 & $2,220.00$ & 1 & 6.67 & Residential & 17 & 17 & 15 \\
\hline 18 & 0.126 & 30,500 & 0 & 1 & 7.94 & 3 & 1,212 & $9,619.05$ & 2 & 15.87 & Commercial & 18 & 18 & 18 \\
\hline 19 & 0.313 & 21,700 & 0 & 2 & 6.39 & 7 & 1,227 & $3,920.13$ & 4 & 12.78 & Commercial & 19 & 19 & 19 \\
\hline 20 & 0.176 & 25,500 & 0 & 2 & 11.36 & 5 & 649 & $3,687.50$ & 3 & 17.04 & Commercial & 20 & 20 & 20 \\
\hline 21 & 0.158 & 16,600 & 0 & 1 & 6.33 & 7 & 1,038 & $6,569.62$ & 2 & 12.66 & Commercial & 21 & 21 & 21 \\
\hline 22 & 0.776 & 28,000 & 0 & 4 & 5.15 & 7 & 832 & $1,072.16$ & 11 & 14.17 & Commercial & 22 & 22 & 23 \\
\hline 23 & 0.319 & 24,000 & 0 & 2 & 6.27 & 9 & 1,048 & $3,285.27$ & 2 & 6.27 & Commercial & 23 & 24 & 24 \\
\hline 24 & 0.249 & 43,000 & 0 & 1 & 4.02 & 7 & 50 & 200.80 & 2 & 8.03 & Residential & 24 & 23 & 22 \\
\hline 25 & 0.178 & 46,000 & 0 & 1 & 5.62 & 5 & 437 & $2,455.05$ & 1 & 5.62 & Commercial & 25 & 25 & 25 \\
\hline 26 & 0.503 & 47,500 & 0 & 4 & 7.95 & 5 & 964 & $1,916.50$ & 3 & 5.96 & Commercial & 26 & 26 & 26 \\
\hline 27 & 0.432 & 15,900 & 0 & 4 & 9.26 & 7 & 2,189 & $5,067.13$ & 4 & 9.30 & Commercial & 27 & 27 & 29 \\
\hline 28 & 0.257 & 25,000 & 0 & 3 & 11.67 & 9 & 141 & 548.64 & 3 & 11.67 & Commercial & 28 & 28 & 35 \\
\hline 29 & 0.318 & 47,500 & 0 & 2 & 6.29 & 5 & 189 & 594.34 & 2 & 6.29 & Residential & 29 & 29 & 28 \\
\hline 30 & 0.466 & 23,000 & 0 & 2 & 4.29 & 7 & 578 & $1,240.34$ & 4 & 8.58 & Commercial & 30 & 30 & 32 \\
\hline
\end{tabular}




\section{$\underline{\text { Scenario } 1}$}

Table 5-37 presents the first scenario. Segment \#10 experienced an AADT of 40,000 veh/day and Segment \#11 experienced an AADT of 33,000 veh/day. It can be seen that ANP and FANP ranked Segment \#11 on the top; AHP however, ranked the locations in reverse order (Segment \#10 on the top). Note that, Segment \#10 is comparatively shorter than Segment \# 11, and normalization with respect to total length was done for some criteria so that the segments could be compared. If the criteria are considered, \#10 had higher AADT than \#11; none of the locations had any bicycle facility; \#11 had higher total bicycle crash, but, after normalizing by segment length \#10 weighted more; and scaled bicycle volume were same for the two locations. Considering auto ownership \#11 was more potential location for bicyclists, however, the order switched once normalized by segment length; \#11 had more bus stops than \#10; and \#11's land use would generate more bicyclists than \#10.

The pair-wise comparison of the criteria for the two locations depicts that, ANP and FANP approach ranked the locations more comprehensively considering all the criteria and keeping a reasonable consideration of segment length. On the other hand, AHP ranked Segment \#10 on the top considering the location having higher value on the criteria which weighted more; and segment length played a biased role here. Thus, ANP and FANP could be considered to be more holistic approaches. 
Table 5-37: Scenario 1 - Comparison of Ranks from AHP, ANP, and FANP

\begin{tabular}{|c|c|c|c|c|c|c|c|c|c|c|c|c|c|c|}
\hline \multirow[b]{2}{*}{ \# } & \multirow[b]{2}{*}{$\begin{array}{l}\text { Segment } \\
\text { Length }\end{array}$} & \multirow[b]{2}{*}{ AADT } & \multirow{2}{*}{\begin{tabular}{|} 
Presence \\
of \\
Bicycle \\
Facility
\end{tabular}} & \multirow[b]{2}{*}{$\begin{array}{c}\text { Total } \\
\text { Bicycle } \\
\text { Crashes }\end{array}$} & \multirow{2}{*}{$\begin{array}{l}\text { Total } \\
\text { Bicycle } \\
\text { Crashes } \\
\text { per mile }\end{array}$} & \multirow[b]{2}{*}{$\begin{array}{l}\text { Scaled } \\
\text { Bicycle } \\
\text { Volume }\end{array}$} & \multirow{2}{*}{\begin{tabular}{|c}
$\#$ of Households \\
with 0 \& 1 \\
Vehicle along \\
the Segment
\end{tabular}} & \multirow{2}{*}{$\begin{array}{c}\text { \# of Households } \\
\text { having } 0 \text { and } 1 \\
\text { Vehicle per mile } \\
\text { along the Segment }\end{array}$} & \multirow[b]{2}{*}{$\begin{array}{c}\# \text { of Bus } \\
\text { Stops }\end{array}$} & \multirow[b]{2}{*}{$\begin{array}{c}\text { \# of Bus } \\
\text { Stops } \\
\text { per mile }\end{array}$} & \multirow[b]{2}{*}{ Land Use } & \multicolumn{3}{|c|}{ Rank } \\
\hline & & & & & & & & & & & & AHP & ANP & FANP \\
\hline 10 & 0.152 & 40,000 & 0 & 1 & 6.58 & 7 & 690 & $4,539.47$ & 1 & 6.58 & nercial & 10 & 11 & 11 \\
\hline 11 & 0.381 & 33,000 & 0 & 2 & 5.25 & 7 & 750 & $1,968.50$ & 3 & 7.87 & Residential & 11 & 10 & 10 \\
\hline
\end{tabular}

Table 5-38: Scenario 2 - Comparison of Ranks from AHP, ANP, and FANP

\begin{tabular}{|c|c|c|c|c|c|c|c|c|c|c|c|c|c|c|}
\hline \multirow[b]{2}{*}{ \# } & \multirow[b]{2}{*}{$\begin{array}{c}\text { Segment } \\
\text { Length }\end{array}$} & \multirow[b]{2}{*}{ AADT } & \multirow{2}{*}{\begin{tabular}{|c|} 
Presence \\
of \\
Bicycle \\
Facility
\end{tabular}} & \multirow[b]{2}{*}{$\begin{array}{c}\text { Total } \\
\text { Bicycle } \\
\text { Crashes }\end{array}$} & \multirow{2}{*}{$\begin{array}{c}\text { Total } \\
\text { Bicycle } \\
\text { Crashes } \\
\text { per mile }\end{array}$} & \multirow[b]{2}{*}{$\begin{array}{l}\text { Scaled } \\
\text { Bicycle } \\
\text { Volume }\end{array}$} & \multirow{2}{*}{$\begin{array}{c}\text { \# of Households } \\
\text { with } 0 \text { \& } 1 \\
\text { Vehicle along } \\
\text { the Segment }\end{array}$} & \multirow{2}{*}{\begin{tabular}{|c|} 
\# of Households \\
having 0 and 1 \\
Vehicle per mile \\
along the Segment
\end{tabular}} & \multirow[b]{2}{*}{$\begin{array}{c}\# \text { of Bus } \\
\text { Stops }\end{array}$} & \multirow[b]{2}{*}{$\begin{array}{c}\text { \# of Bus } \\
\text { Stops } \\
\text { per mile }\end{array}$} & \multirow[b]{2}{*}{ Land Use } & \multicolumn{3}{|c|}{ Rank } \\
\hline & & & & & & & & & & & & AHP & ANP & FANP \\
\hline 5 & 0.753 & 45,500 & 0 & 7 & 9.30 & 9 & 2,011 & $2,670.65$ & 6 & 7.97 & rcial & 5 & 5 & 7 \\
\hline 6 & 1.377 & 33,500 & 0 & 7 & 5.08 & 7 & 4,745 & $3,445.90$ & 8 & 5.81 & Residential & 6 & 6 & 5 \\
\hline
\end{tabular}




\section{$\underline{\text { Scenario } 2}$}

Table 5-38 presents the second scenario. The location with AADT 45,500 veh/day is labeled as Segment \#5, and location with AADT 33,500 veh/day as Segment \#6 for this scenario. ANP and AHP ranked \#5 over \#6, whereas, FANP ranked \#6 over \#5. If the criteria are considered, \#5 had more AADT than \#6; none of the locations had bicycle facilities; total bicycle crash count were same for the two locations, however, \#5 was shorter than \#6, thus triggering \#5's crash count per mile over \#6's crash rate; scaled bicycle volume was more for Segment \#5; considering auto ownership, \#6 was a more suitable location for improvements; \#6 had more bus stops than \#5 but the rate (bus stops per mile) calculation swapped the positions; being residential and institutional type of land use along the roadway, \#6 had more potential to be considered for prioritization.

Unlike Scenario 1, here ANP rank was not in line with FANP's rank choice. Segment \#5 was not that a small segment; it was about 0.75 mile long and Segment \#6 was about 1.3 miles. The normalization of the variables with respect to length affected the choice expectation of the location or sensitivity of the approaches. It seems that if the decision is to be made based on a comprehensive review of the criteria Segment \#6 might be chosen over Segment \#5. However, in this example, ANP and AHP ranked the locations in a similar order.

Thus, FANP was found to be relatively the most comprehensive network screening method among AHP, ANP, and FANP, if the locations need to be prioritized in a holistic manner considering all criteria. 


\subsection{CMF Development}

Bicycle CMFs for urban two-lane, four-lane, six-lane divided roadway segments, and urban four-leg signalized intersections were developed. Depending on the extent (i.e., coverage in miles and variation within each predictor) of the following 11 variables, NB models for segment facilities were developed: AADT, median width, presence of bicycle lane, presence of shared path, presence of sidewalk, presence of sidewalk barrier, type of on-street parking, speed limit, lane width, median type, shoulder type, and bicycle activity. The Akaike Information Criterion (AIC) was then used to determine the subset of independent variables to be included in the final NB models. Once the variables were selected, bicycle CMFs were estimated using the ZINB models.

Similar approach was adopted for urban four-leg signalized intersections considering the following 15 variables: major road AADT, minor road AADT, presence of lighting, number of bus stops within intersection influence area, presence of schools within intersection influence area, number of alcohol establishments within intersection influence area, number of approaches with left-turn lanes, number of approaches with right-turn lanes, number of approaches with protected signal control, number of approaches with permitted signal control, number of approaches with protected-permitted signal control, number of approaches with no right-turn-on-red sign, presence of red light camera, presence of bicycle facility, and bicycle activity.

Two sets of CMFs were developed for each segment and intersection facility type: one set considered the bicycle activity data, and the other set did not consider the bicycle activity data. The coefficients of the developed models and the associated CMFs estimated from the models from the two sets were then compared for each facility type to assess the 
impact of bicycle activity data on the developed bicycle CMFs. The models with and without bicycle activity data were also compared using the Likelihood ratio test to determine whether the models are significantly different.

\subsubsection{Urban Two-lane Divided Segments}

Table 5-39 presents the descriptive statistics of the initial set of variables considered while developing the CMFs for urban two-lane divided segments. Median width, shared path, type of on-street parking, and median type were excluded from further analysis considering the limited variability in the extent of coverage of these variables within the dataset. For example, median width of $10 \mathrm{ft}$ was found for a total of 362.9 miles; while only 36.4 miles have median width over $10 \mathrm{ft}$. Thus, due to limited variability within the predictor space, this variable was not considered for further analysis. Furthermore, lane width was re-categorized into two categories, $12-\mathrm{ft}$ lanes, and $<12$-ft lanes, to ensure sufficient variability within this variable.

Table 5-40 presents the model coefficients, Confidence Interval (CI) of the coefficients at 0.05 level of significance, and the CMFs for bicycle crashes developed for urban two-lane divided highways in Florida with and without considering the bicycle activity data. The presence of bicycle lane was found to be insignificant at 0.05 level of significance for both cases. When bicycle activity data is considered, the presence of sidewalk barrier has a coefficient of 0.60497 and a CMF of 1.83 . Thus, it can be inferred from the CMF that, the presence of sidewalk barrier increases the probability of bicycle crashes by $83 \%$ per year per mile on urban two-lane divided roadways in Florida. 
Table 5-39: Descriptive Statistics for Segment Facility Types

\begin{tabular}{|c|c|c|c|c|}
\hline Attribute & Attribute Category & $2 \mathbf{L}^{\mathrm{a}}$ & $4 L^{b}$ & $6 \mathbf{L}^{\mathrm{c}}$ \\
\hline Roadway Length (mi.) & -- & 399.3 & $1,573.4$ & 782.7 \\
\hline \multirow{2}{*}{$\begin{array}{l}\text { Bicycle Crash Frequency } \\
(2011-2014)\end{array}$} & Total & 178 & 1,174 & 1,283 \\
\hline & FS & 43 & 197 & 227 \\
\hline \multirow{4}{*}{ Section AADT (veh/day) } & Minimum & 1,300 & 2,300 & 8,000 \\
\hline & Maximum & 42,000 & 120,000 & 98,500 \\
\hline & Mean & 12,017 & 24,826 & 42,703 \\
\hline & Standard Deviation & 5,374 & 10,260 & 13,056 \\
\hline \multirow{3}{*}{ Bicycle Activity } & Low $(\leq 2,000)^{\mathrm{d}}$ & 98.4 & 365.1 & 182.5 \\
\hline & Medium $(>2,000 \text { and } \leq 10,000)^{d}$ & 117.3 & 553.2 & 290.2 \\
\hline & High $(>10,000)^{\mathrm{d}}$ & 183.7 & 655.1 & 310.1 \\
\hline \multirow{4}{*}{ Median Width (ft) } & Minimum & 10 & 10 & 20 \\
\hline & Maximum & 100 & 60 & 40 \\
\hline & Mean & 12.24 & 26.22 & 25.76 \\
\hline & Standard Deviation & 7.78 & 12.92 & 6.7 \\
\hline \multirow{2}{*}{ Bicycle Lane (mi.) } & No & 293.2 & 1,153 & 481.8 \\
\hline & Yes & 106.1 & 420.4 & 300.9 \\
\hline \multirow{2}{*}{ Shared Path (mi.) } & No & 386.9 & $1,527.3$ & 751.8 \\
\hline & Yes & 12.4 & 46.1 & 30.9 \\
\hline \multirow{2}{*}{ Sidewalk (mi.) } & No & 212.6 & 600.3 & 103.3 \\
\hline & Yes & 186.7 & 973.1 & 679.5 \\
\hline \multirow{2}{*}{ Sidewalk Barrier (mi.) } & No & 212.4 & 607.3 & 105.4 \\
\hline & Yes & 189.9 & 966.1 & 677.4 \\
\hline \multirow{4}{*}{ Type of On-street Parking } & No & 65 & 299.5 & 138.5 \\
\hline & On-street Parking on One Side & 0.3 & 2.5 & 0.9 \\
\hline & On-street Parking on Both Sides & 7.9 & 34.3 & 10.8 \\
\hline & Data Unavailable & 326.1 & 1,237 & 632.5 \\
\hline \multirow{4}{*}{ Speed Limit (mph) } & Minimum & 30 & 35 & 40 \\
\hline & Maximum & 55 & 60 & 55 \\
\hline & Mean & 43.7 & 45.06 & 46 \\
\hline & Standard Deviation & 7.5 & 6.65 & 3.8 \\
\hline \multirow{4}{*}{ Lane Width (ft) } & Minimum & 9 & 10 & 10 \\
\hline & Maximum & 12 & 12 & 12 \\
\hline & Mean & 11.8 & 11.75 & 11.5 \\
\hline & Standard Deviation & 0.45 & 0.5 & 0.6 \\
\hline \multirow{4}{*}{ Median Type } & Paved & 380.9 & 334.2 & -- \\
\hline & Raised Traffic Separator & \multirow{3}{*}{18.4} & 124.8 & 166.1 \\
\hline & Vegetation & & 640.9 & \\
\hline & Curb \& Vegetation & & 473.5 & 616.6 \\
\hline \multirow{4}{*}{ Shoulder Type } & Paved & 336.1 & 1,178 & 543.1 \\
\hline & Curb \& Gutter & \multirow{3}{*}{63.2} & 394.5 & 239.7 \\
\hline & Raised Curb & & -- & -- \\
\hline & Lawn, Gravel/Marl, Valley Gutter & & -- & -- \\
\hline
\end{tabular}

Note: -- is not applicable due to data unavailability; ${ }^{\mathrm{a}}$ urban two-lane divided; ${ }^{\mathrm{b}}$ urban four-lane divided; ${ }^{\mathrm{c}}$ urban six-lane divided; FS stands for Fatal and Severe/Incapacitating Injury crashes; ${ }^{\mathrm{d}}$ total \# of bicycle trips per year; the sub-category lengths may not add up to facility length due to rounding issues. 
However, without considering the bicycle activity data, the coefficient and the corresponding CMF are 0.564051 and 1.76 , respectively. It implies that the probability of bicycle crash increases by $76 \%$ per year per mile.

The CMFs with and without bicycle activity data were found to be consistent in quantifying the impact of the presence of sidewalk barrier on bicycle crashes. In other words, both the models predict that the presence of sidewalk barrier increase bicycle crash frequency. Other CMFs, with and without the activity data, presented in Table 5-40 can be interpreted in a similar way. When bicycle activity data were considered, the CMFs for bicycle crashes for urban two-lane divided roadways in Florida are:

- $\quad$ segments with higher speed limit have a $6 \%$ reduced crash probability;

- $\quad$ segments with narrower lanes $(<12-\mathrm{ft})$ increase the bicycle crash probability by $72 \%$;

- $\quad$ segments with raised curb, lawn, gravel/marl, valley gutter, and curb and gutter type shoulders reduce the bicycle crash probability by $52 \%$ compared to the segments with paved shoulders; and

- segments with medium bicycle activity decrease the bicycle crash probability by $49 \%$ compared to the segments with low bicycle activity.

Presence of sidewalk barrier was found to increase bicycle crash probability. This could be because barriers reduce the lateral clearance between travel way and sidewalk, and force bicyclists to ride closer to the motorists, increasing their crash probability. Speed limit was found to have a positive impact on crash risks. Bicycle exposure and AADT were carefully checked to cross-validate this result. AADT was found to be relatively lower on higher speed urban two-lane divided highways; thus, reducing the bicycle crash 
probability. Another possibility could be that bicyclists might be riding carefully on high speed corridors. However, an in-depth field investigation and research on this issue is needed.

Lane width was found to have a significant impact on bicycle crashes. Segments with narrower lanes $(<12-\mathrm{ft})$ increased the bicycle crash probability by $72 \%$ when bicycle exposure was considered, and by $81 \%$ when bicycle exposure was not considered. This is expected as wider lanes provide safe lateral distance between the vehicles and the bicyclists. It is worth mentioning that increased bicycle activity reduces the probability of bicycle crashes. Segments with medium activity were found to be relatively safer for bicyclists compared to the segments with low bicycle activity. Motorists on two-lane roadways with medium-high bicycle activity may get accustomed to seeing bicyclists, and share the roadway accordingly.

The following interaction terms (two variables interacting with each other) were considered while developing the ZINB model: presence of bicycle lane \& speed limit, presence of bicycle lane \& lane width, presence of bicycle lane \& bicycle volume, speed limit \& lane width, speed limit \& bicycle volume, and lane width \& bicycle volume. However, the latter two interaction terms were found to be highly correlated with the individual terms, and were discarded from the final model. The final model did not recognize any of the first four interaction terms as significant at 0.05 level of significance. The zero-inflated component of the ZINB model predicted the intercept coefficient as insignificant at 0.05 level of significance; thus, the developed CMFs were considered to be reliable and the segments with zero crash frequencies follow the NB distribution. 
As can be observed from Table 5-40, the CMFs estimated from the models that considered bicycle activity data were similar to the CMFs derived from the models that did not consider bicycle activity data. The Likelihood ratio test comparing the models with and without bicycle activity found no statistical difference between the two models at 0.05 level of significance (p-value 0.9971).

\subsubsection{Urban Four-lane Divided Segments}

Table 5-39 presents the descriptive statistics of the variables for urban four-lane divided segments considered in this study. Shared path and type of on-street parking were excluded from further analysis considering their limited variability. Table 5-41 presents the CMFs for bicycle crashes developed for urban four-lane divided roadways in Florida. Unlike urban two-lane divided segments, the bicycle activity variable was found to be insignificant in the NB model. In other words, the same variables were significant in both the cases (i.e., with and without considering the bicycle activity data).

Presence of sidewalk was found to increase bicycle crash probability. Motorists probably do not expect moving traffic on a sidewalk, and do not expect bicyclists while backing out of driveways or turning. However, bicyclists may tend to ride on the sidewalk, when available, and sidewalks may suddenly force the bicyclists onto a road where motorist do not expect them. Furthermore, sidewalks probably increase the chance of conflicts between bicyclists and pedestrians. NHTSA (n.d.), Cornell University (n.d.), and Godwin and Price (2016) have drawn analogous conclusion regarding bicycling on sidewalks. 
Table 5-40: Bicycle CMFs for Urban Two-lane Divided Segments

\begin{tabular}{|c|c|c|c|c|c|c|}
\hline \multirow{2}{*}{ Variable } & \multicolumn{3}{|c|}{ With Bicycle Exposure } & \multicolumn{3}{|c|}{ Without Bicycle Exposure } \\
\hline & Coefficient & $\mathrm{CI}^{\mathrm{a}}$ of the Coefficient & CMF & Coefficient & $\mathrm{CI}^{\mathrm{a}}$ of the Coefficient & CMF \\
\hline Presence of Bicycle Lane & -- & -- & -- & -- & -- & -- \\
\hline Presence of Sidewalk Barrier & 0.60497 & $0.20734-1.0026$ & 1.83 & 0.564051 & $0.16855-0.95955$ & 1.76 \\
\hline Speed Limit & -0.06230 & $(-0.09946)-(-0.02514)$ & 0.94 & -0.063124 & $(-0.10024)-(-0.02600)$ & 0.94 \\
\hline Lane Width $(<12-\mathrm{ft})^{\mathrm{b}}$ & 0.54265 & $(-0.10295)-1.18825$ & 1.72 & 0.596342 & $(-0.04631)-1.23899$ & 1.81 \\
\hline $\begin{array}{l}\text { Shoulder Type (Raised Curb, Lawn, } \\
\text { Gravel/Marl, Valley Gutter, \& Curb \& } \\
\text { Gutter) }\end{array}$ & -0.73602 & $(-1.28658)-(-0.18545)$ & 0.48 & -0.699246 & $(-1.25289)-(-0.14559)$ & 0.50 \\
\hline $\begin{array}{l}\text { Medium Bicycle Activity (Annual Trips > } \\
2,000 \text { and } \leq 10,000)^{\mathrm{d}}\end{array}$ & -0.67723 & $(-1.22861)-(-0.12584)$ & 0.51 & NA & NA & NA \\
\hline $\begin{array}{l}\text { High Bicycle Activity (Annual Trips > } \\
10,000)^{\mathrm{d}}\end{array}$ & -- & -- & -- & NA & NA & NA \\
\hline Bicycle Lane : Speed Limit ${ }^{\mathrm{d}}$ & -- & -- & -- & -- & -- & -- \\
\hline Bicycle Lane : Lane Width $(<12-\mathrm{ft})^{\mathrm{e}}$ & -- & -- & -- & -- & -- & -- \\
\hline Bicycle Lane : Bicycle Activity (Med, High) & -- & -- & -- & NA & NA & NA \\
\hline Speed Limit : Lane Width $(<12-\mathrm{ft})^{\mathrm{e}}$ & -- & -- & -- & -- & -- & -- \\
\hline
\end{tabular}

Note: -- Not significant; NA is Not Applicable; ${ }^{\mathrm{a}} \mathrm{CI}$ stands for confidence interval at 0.05 level of significance; ${ }^{\mathrm{b}}$ The base condition for lane width is 12 -ft; ${ }^{\mathrm{c}}$ the base condition for shoulder type is paved; ${ }^{\mathrm{d}}$ the base condition for bicycle exposure is low bicycle activity (Annual Trips $\leq 2,000$ ); ${ }^{\mathrm{e}}$ interaction term.

\section{Table 5-41: Bicycle CMFs for Urban Four-lane Divided Segments}

\begin{tabular}{|l|c|c|}
\hline Variable & Coefficient & CI $^{\mathrm{a}}$ of the Coefficient \\
\hline Presence of Sidewalk & 0.424809 & $0.16004-0.68957$ \\
\hline Speed Limit & -0.045234 & $(-0.07537)-(-0.01509)$ \\
\hline Lane Width & -0.343627 & $(-0.54722)-(-0.14002)$ \\
\hline Median Type (Raised Traffic Separator) $^{\mathrm{b}}$ & 0.237202 & $0.00790-0.46650$ \\
\hline Median Type (Vegetation) & \\
\hline Median Type (Curb \& Vegetation) & 0.71 \\
\hline Lane Width : Shoulder Type (Curb \& Gutter) $^{\mathrm{c}, \mathrm{d}}$ & -0.325210 & $(-0.58925)-(-0.06116)$ \\
\hline
\end{tabular}

Note: -- Not significant; ${ }^{a}$ CI stands for confidence interval at 0.05 level of significance; ${ }^{\mathrm{b}}$ the base condition for median type is paved; -- Not significant;

${ }^{\mathrm{c}}$ interaction term; ${ }^{\mathrm{d}}$ the base condition for shoulder type is paved. 
Similar to urban two-lane divided facilities, speed limit was found to have a positive impact on bicycle crash risk. Wider lanes provide safe lateral distance between the vehicles and the bicycles, and hence, were found to decrease the bicycle crash probability. Raised traffic separators which do not provide any refuge area for bicyclists were found to increase the bicycle crash probability for urban four-lane divided segments; whereas, vegetation in the median which provide refuge area for bicyclists was found to reduce crash probability.

The following interaction terms were considered while developing the ZINB model: AADT \& speed limit, presence of sidewalk \& speed limit, speed limit \& lane width, presence of sidewalk \& shoulder type, and lane width \& shoulder type. Lane width's interaction with shoulder type was found to be significant at 0.05 level of significance; and thus, was included in the final model. When shoulder is curb and gutter type, the lane width increment was found to have no positive impact on urban four-lane divided segments. The zero-inflated component of the ZINB model estimated the true zero proportion to be $0.7 \%$; implying that $0.7 \%$ of the total segments that have zero crashes could not be explained by the NB models. The developed CMFs are therefore considered to be reliable.

\subsubsection{Urban Six-lane Divided Segments}

The descriptive statistics of the variables for the urban six-lane divided segments considered in this study are presented in Table 5-39. Shared path and type of on-street parking were excluded from further analysis. Median width and lane width were recategorized to ensure proper variability within the predictor space.

Table 5-42 presents the CMFs for bicycle crashes developed for urban six-lane divided roadways in Florida. The CMFs for the presence of sidewalk, speed limit, lane 
Table 5-42: Bicycle CMFs for Urban Six-lane Divided Segments

\begin{tabular}{|c|c|c|c|c|c|c|}
\hline \multirow{2}{*}{ Variable } & \multicolumn{3}{|c|}{ With Bicycle Exposure } & \multicolumn{3}{|c|}{ Without Bicycle Exposure } \\
\hline & Coefficient & CI ${ }^{a}$ of the Coefficient & CMF & Coefficient & CI ${ }^{a}$ of the Coefficient & CMF \\
\hline Presence of Sidewalk & 1.12690 & $0.13913-2.11466$ & 3.08 & 1.03095 & $0.69614-1.36575$ & 2.80 \\
\hline Speed Limit & -0.09328 & $(-0.12268)-(-0.06388)$ & 0.91 & -0.09392 & $(-0.12332)-(-0.06452)$ & 0.91 \\
\hline Lane Width $(<12-\mathrm{ft})^{\mathrm{b}}$ & 0.22334 & $0.06301-0.38366$ & 1.25 & 0.22840 & $0.06766-0.38913$ & 1.25 \\
\hline $\begin{array}{l}\text { Median Type (Vegetation } \\
\text { \& Curb \& Vegetation) }\end{array}$ & -0.35914 & $(-0.51474)-(-0.20353)$ & 0.70 & -0.37480 & $(-0.53101)-(-0.21858)$ & 0.69 \\
\hline $\begin{array}{l}\text { Shoulder Type (Curb \& } \\
\text { Gutter) }^{\mathrm{d}}\end{array}$ & 0.19035 & $0.03292-0.34777$ & 1.21 & 0.23181 & $0.07591-0.38770$ & 1.26 \\
\hline $\begin{array}{l}\text { Medium Bicycle Activity } \\
(\text { Annual Trips }>2,000 \text { and } \\
\leq 10,000)^{\mathrm{e}}\end{array}$ & -- & -- & -- & NA & NA & NA \\
\hline $\begin{array}{l}\text { High Bicycle Activity } \\
(\text { Annual Trips }>10,000)^{\mathrm{e}}\end{array}$ & -- & -- & -- & NA & NA & NA \\
\hline $\begin{array}{l}\text { Speed Limit : Lane Width } \\
(<12-\mathrm{ft})^{\mathrm{f}}\end{array}$ & 0.04793 & $0.00218-0.09367$ & 1.05 & 0.04884 & $0.00218-0.09486$ & 1.05 \\
\hline $\begin{array}{l}\text { Presence of Sidewalk: } \\
\text { Bicycle Activity }{ }^{\mathrm{f}}\end{array}$ & -- & -- & -- & NA & NA & $\mathrm{NA}$ \\
\hline
\end{tabular}

Note: -- Not significant; NA is Not Applicable; ${ }^{a}$ CI stands for confidence interval at 0.05 level of significance; ${ }^{\mathrm{b}}$ the base lane width is $12 \mathrm{ft} ;{ }^{\mathrm{c}}$ the base condition for median type is raised traffic separator; ${ }^{\mathrm{d}}$ the base condition for shoulder type is paved; ${ }^{\mathrm{e}}$ the base condition for bicycle exposure is low bicycle activity (Annual Trips $\leq 2,000$ ); ${ }^{\text {interaction term. }}$ 
width, and median type are consistent with urban two-lane and four-lane divided facilities. The rationale for these observations was discussed in the earlier sections. Curb \& gutter shoulder type was found to increase the bicycle crash probability when compared to paved shoulders. Bicyclists might prefer to ride on shoulder when it is available and well maintained; and while driving through an urban six-lane divided facility, drivers might not expect bicyclists on the roadways at all. However, when the shoulder is not paved bicyclists might ride on the roadways thinking that the drivers have enough maneuvering space. No refuge area for bicyclists might trigger the crash to go high on such corridors.

The following interaction terms were considered while developing the ZINB model: speed limit \& lane width, presence of sidewalk \& bicycle volume, presence of sidewalk \& shoulder type, speed limit \& bicycle volume, and lane width \& bicycle volume. However, the latter three interaction terms were found to be highly correlated with the individual terms; and hence, were discarded from the final model. The final model only recognized the interaction of speed limit \& lane width as significant at 0.05 level of significance. It can be interpreted as narrow lanes even with speed limit's positive interaction increases the bicycle crash probability.

The zero-inflated part (logit part) of the ZINB model predicted the intercept coefficient (-3.8105) as significant at 0.05 level of significance. This signifies that the true zero not explained by the NB distribution is only 2\%; thus, the developed CMFs were considered reliable and the segments with zero crash frequencies follow the NB distribution. Again, similar to the other facility types, the CMFs for urban six-lane divided segments developed with and without the bicycle activity data were found to be consistent in quantifying the impact of the cross-sectional characteristics on bicycle safety. The 
Likelihood ratio test comparing the models (p-value 0.999) also supported that the models are not significantly different.

\subsubsection{Urban Four-leg Signalized Intersections}

Table 5-43 presents the descriptive statistics of the variables for urban four-leg signalized intersections considered in this study. Number of alcohol sales establishments within intersection influence area, number of approaches with left turn lanes, number of approaches with protected signal control, and number of approaches with no right-turn-onred variables were re-categorized to make sure sufficient variability is present within the predictor space. For example, number of alcohol sales establishments were re-categorized into absence and presence of alcohol sales establishments; number of approaches with leftturn lanes were re-categorized into less than or equal to three approaches with left-turn lanes and four approaches with left-turn lanes; number of approaches with protected signal control were re-categorized into absence and presence of protected signal controls; and number of approaches with no right-turn-on-red signal were re-categorized into absence and presence of no right-turn-on-red signal.

Table 5-44 presents the bicycle CMFs for urban four-leg signalized intersections in Florida. The reliable CMFs are:

- presence of three or more bus stops within intersection influence area was found to increase the probability of bicycle crashes by $61 \%$ when bicycle activity was considered; however, the increment was $97 \%$ when activity was not considered in the model development; 
- intersection approaches with protected signal control resulted in a $31 \%$ and $43 \%$ reduction in the probability of bicycle crashes with and without considering bicycle activity; and

- medium and high bicycle activity at intersections were found to increase bicycle crash probability by almost three times compared to the intersections with low bicycle activity.

As expected, bus stops were found to increase the probability of bicycle crashes. Higher bicycle crash probability at intersections with increased bicycle exposure could be attributed to improper and/or inadequate bicycle facilities at these intersections. However, protected signal control system at the intersections provide the users a better understanding of the crossing maneuvers, thus reducing bicycle crash probability. Note that none of the interaction terms were included during model development as they are not logical.

The zero-inflated component of the ZINB model predicted the intercept coefficient as insignificant at 0.05 level of significance; thus, the developed CMFs were considered to be reliable. However, the Likelihood ratio test (p-value 0.010) did not conclude that there was no difference between the two models.

Table 5-43: Descriptive Statistics for Urban Four-leg Signalized Intersections

\begin{tabular}{|c|c|c|}
\hline Attribute & Attribute Category & Urban Four-leg Sig. Int. \\
\hline Number of Intersections & --- & 397 \\
\hline \multirow{2}{*}{ Total Bicycle Crashes (2011-2014) } & Total & 380 \\
\hline & FS & 57 \\
\hline \multirow{4}{*}{ AADT on Major Road (veh/day) } & Minimum & 1,500 \\
\hline & Maximum & 74,500 \\
\hline & Mean & 31,829 \\
\hline & Standard Deviation & 14,214 \\
\hline \multirow{4}{*}{ AADT on Minor Road (veh/day) } & Minimum & 1,025 \\
\hline & Maximum & 55,250 \\
\hline & Mean & 18,532 \\
\hline & Standard Deviation & 11,708 \\
\hline Presence of Lighting & No & 27 \\
\hline
\end{tabular}




\begin{tabular}{|c|c|c|}
\hline Attribute & Attribute Category & Urban Four-leg Sig. Int. \\
\hline & Yes & 370 \\
\hline \multirow{3}{*}{$\begin{array}{l}\text { \# of Bus Stops within Intersection } \\
\text { Influence Area }\end{array}$} & 0 & 127 \\
\hline & $1-2$ & 72 \\
\hline & $\geq 3$ & 198 \\
\hline \multirow{2}{*}{$\begin{array}{l}\text { Presence of Schools within Intersection } \\
\text { Influence Area }\end{array}$} & No & 330 \\
\hline & Yes & 67 \\
\hline \multirow{3}{*}{$\begin{array}{l}\text { \# of Alcohol Sales Establishments } \\
\text { within Intersection Influence Area }\end{array}$} & 0 & 40 \\
\hline & $1-8$ & 355 \\
\hline & $\geq 9$ & 2 \\
\hline \multirow{5}{*}{ \# of Approaches with Left-Turn Lanes } & 0 & 2 \\
\hline & 1 & 10 \\
\hline & 2 & 20 \\
\hline & 3 & 31 \\
\hline & 4 & 334 \\
\hline \multirow{5}{*}{ \# of Approaches with Right-Turn Lanes } & 0 & 77 \\
\hline & 1 & 95 \\
\hline & 2 & 80 \\
\hline & 3 & 77 \\
\hline & 4 & 68 \\
\hline \multirow{5}{*}{$\begin{array}{l}\text { \# of Approaches with Protected Signal } \\
\text { Control }\end{array}$} & 0 & 328 \\
\hline & 1 & 28 \\
\hline & 2 & 23 \\
\hline & 3 & 10 \\
\hline & 4 & 8 \\
\hline \multirow{5}{*}{$\begin{array}{l}\text { \# of Approaches with Permitted Signal } \\
\text { Control }\end{array}$} & 0 & 159 \\
\hline & 1 & 32 \\
\hline & 2 & 62 \\
\hline & 3 & 13 \\
\hline & 4 & 131 \\
\hline \multirow{5}{*}{$\begin{array}{l}\text { \# of Approaches with Protected- } \\
\text { Permitted Signal Control }\end{array}$} & 0 & 163 \\
\hline & 1 & 28 \\
\hline & 2 & 70 \\
\hline & 3 & 31 \\
\hline & 4 & 105 \\
\hline \multirow{5}{*}{$\begin{array}{l}\text { \# of Approaches with No Right-Turn- } \\
\text { on-Red Signal }\end{array}$} & 0 & 387 \\
\hline & 1 & 8 \\
\hline & 2 & 1 \\
\hline & 3 & 1 \\
\hline & 4 & 0 \\
\hline \multirow{2}{*}{ Presence of Red Light Camera } & No & 300 \\
\hline & Yes & 97 \\
\hline \multirow{2}{*}{ Presence of Bicycle Facility } & No & 194 \\
\hline & Yes & 203 \\
\hline \multirow{3}{*}{ Bicycle Activity } & Low $(\leq 2,000)^{\mathrm{a}}$ & 236 \\
\hline & $\begin{array}{l}\text { Medium }(>2,000 \text { and } \\
\leq 10,000)^{\mathrm{a}}\end{array}$ & 83 \\
\hline & High $(>10,000)^{\mathrm{a}}$ & 78 \\
\hline
\end{tabular}

--- Not Applicable; ${ }^{a}$ total \# of bicycle trips per year. 
Table 5-44: Bicycle CMFs for Urban Four-leg Signalized Intersections

\begin{tabular}{|c|c|c|c|c|c|c|}
\hline \multirow{2}{*}{ Variable } & \multicolumn{3}{|c|}{ With Bicycle Exposure } & \multicolumn{3}{|c|}{ Without Bicycle Exposure } \\
\hline & Coefficient & $\mathrm{CI}^{\mathrm{a}}$ of the Coefficient & CMF & Coefficient & CI ${ }^{\mathrm{a}}$ of the Coefficient & CMF \\
\hline $\begin{array}{l}\text { 1-2 Bus Stops within Intersection } \\
\text { Influence Area }\end{array}$ & -- & -- & -- & -- & -- & -- \\
\hline $\begin{array}{l}\geq 3 \text { Bus Stops within Intersection } \\
\text { Influence Area }\end{array}$ & 0.47876 & $0.18346-0.77405$ & 1.61 & 0.68031 & $0.36402-0.99659$ & 1.97 \\
\hline \# of Approaches with Right-Turn Lanes & -- & -- & -- & -- & -- & -- \\
\hline $\begin{array}{l}\text { Approaches with Protected Signal } \\
\text { Control }^{\mathrm{c}}\end{array}$ & -0.36754 & $(-0.76012)-0.02504$ & 0.69 & -0.56403 & $(-0.97762)-(-0.15043)$ & 0.57 \\
\hline $\begin{array}{l}\text { Medium Bicycle Activity (Annual } \\
\text { Trips }>2,000 \text { and } \leq 10,000)^{\mathrm{d}}\end{array}$ & 1.38275 & $1.10392-1.66157$ & 3.98 & NA & NA & NA \\
\hline $\begin{array}{l}\text { High Bicycle Activity (Annual Trips > } \\
10,000)^{\mathrm{d}}\end{array}$ & 1.35349 & $1.06852-1.63845$ & 3.87 & NA & NA & NA \\
\hline
\end{tabular}

Note: -- Not significant; NA is Not Applicable; ${ }^{\mathrm{a}} \mathrm{CI}$ stands for confidence interval at 0.05 level of significance; ${ }^{\mathrm{b}}$ The base condition for bus stops is absence of bus stops within intersection influence area; ${ }^{\mathrm{c}}$ The base condition for approaches with protected signal control is absence of protected signal; ${ }^{\mathrm{d}}$ The base condition for bicycle activity is low bicycle activity (Annual Trips $\leq 2,000$ ). 


\subsubsection{Reflection on Strava Data}

Bicycle volume data are crucial in quantifying the safety impacts of roadway and traffic characteristics. Bicycle activity data from Strava used in this study is a crowdsourced biking data. This was the only available bicycle activity data for the entire state of Florida. Constrained by the limitations of crowdsourced data, this research attempted to check the adequacy of this data on bicycle safety evaluation. CMFs developed with and without considering the Strava data were found to be consistent for urban twolane, six-lane divided segment facilities, and for urban four-leg signalized intersections. However, the bicycle activity data for urban four-lane divided segments was found to be insignificant.

Thus, Strava data did not affect the CMFs significantly as the developed CMFs with and without this data for urban facilities were very close. Furthermore, the Likelihood ratio test based on the Log-likelihood estimates derived from the models with and without activity data for each facility type was conducted to check whether the model without activity data is significantly different from the model with activity data. It was found that, for urban two-lane and six-lane divided facility the models derived with and without activity data were not statistically different at 0.05 level of significance. The impact of the activity data was only observed on the models for urban four-leg signalized intersections.

As CMFs are critical for roadway infrastructure, actual bicycle volume (i.e., ground truth) data once available need to be used to cross-validate and/or calibrate Strava data; until then, using Strava may not yield representative results. However, the consistency found in the developed CMFs renders the potential approach to incorporate Strava data for future safety studies. 


\subsection{Transferability Assessment}

The applicability of a CMF depends on the data from which the CMF is estimated. Thus, it instigates the question of spatial and temporal transferability of the developed CMFs, i.e., whether CMFs developed using state-wide data are applicable to different jurisdictions, and for different time periods. This dissertation addressed this question by assessing the transferability of the developed CMFs using Transferability Index (TI). Although CMFs were developed for multiple facilities in this dissertation, transferability assessment was conducted only for urban four-lane divided segments. As the assessment approach would be similar for all facilities, thus, only one facility was chosen to demonstrate the framework; and urban four-lane divided facility was chosen as comparatively this facility had more comprehensive data in terms of coverage and other crash predictors. The following sections, Section 5.3.1 and Section 5.3.2, focus on spatial and temporal transferability, respectively.

\subsubsection{Spatial Transferability}

To explore the scope for spatial transferability, the seven FDOT districts were considered as seven different spatial zones (Figure 5-1). The data for urban four-lane divided segments were divided into seven DOT districts' databases. This was done from the roadway identification (RDWYID) number. The first two digits of the RDWYID denotes the county. Once the county number was derived, then the segments were assigned to the respective DOT districts based on these counties. Table 5-45 provides a brief coverage summary of district-wise urban four-lane divided segments. 
Table 5-45: FDOT District-wise Urban Four-lane Divided Segments

\begin{tabular}{|c|rr|rr|rr|}
\hline $\begin{array}{c}\text { FDOT } \\
\text { District }\end{array}$ & \multicolumn{2}{|c|}{ Coverage in Miles (\%) } & \multicolumn{2}{|c|}{ \# of Segments (\%) } & \multicolumn{2}{c|}{ Bicycle Crashes (\%) } \\
\hline D1 & 248.21 & $(15.93 \%)$ & 733 & $(16.19 \%)$ & 145 & $(12.65 \%)$ \\
\hline D2 & 248.39 & $(15.94 \%)$ & 661 & $(14.60 \%)$ & 160 & $(13.96 \%)$ \\
\hline D3 & 243.57 & $(15.63 \%)$ & 694 & $(15.33 \%)$ & 124 & $(10.82 \%)$ \\
\hline D4 & 155.56 & $(9.98 \%)$ & 488 & $(10.78 \%)$ & 141 & $(12.30 \%)$ \\
\hline D5 & 361.90 & $(23.23 \%)$ & 1,045 & $(23.08 \%)$ & 273 & $(23.82 \%)$ \\
\hline D6 & 97.38 & $(6.25 \%)$ & 219 & $(4.84 \%)$ & 157 & $(13.70 \%)$ \\
\hline D7 & 202.87 & $(13.02 \%)$ & 687 & $(15.17 \%)$ & 146 & $(12.74 \%)$ \\
\hline Total & $1,557.88$ & $(100 \%)$ & 4,527 & $(100 \%)$ & 1,146 & $(100 \%)$ \\
\hline
\end{tabular}

Note: The sub-categories may not add up to total due to rounding errors.

Equation 3-12 provided in Chapter 3 was used to assess the spatial transferability.

The state-wide model was applied to each district, and district-wise complete and constantonly models were developed using the same set of regressor and interaction terms. Table 5-46 presents the $T I$ indices that were calculated using Equation 3-12 from the loglikelihood estimations. Table 5-47 depicts the GOF measures for the district complete models.

Table 5-46: Spatial TI Indices for FDOT Districts

\begin{tabular}{|c|c|c|c|c|c|c|c|}
\hline \multirow{2}{*}{ Measure } & \multicolumn{7}{|c|}{ FDOT Districts } \\
\cline { 2 - 8 } & I & II & III & IV & V & VI & VII \\
\hline$T I$ & 0.80 & 0.75 & 1.40 & 0.66 & 0.93 & 0.27 & 0.70 \\
\hline
\end{tabular}

Note: $T I$ close to unity indicates better transferability.

Table 5-47: Spatial GOF Indices for FDOT Districts

\begin{tabular}{|c|c|c|c|c|c|c|c|}
\hline \multirow{2}{*}{ Measure } & \multicolumn{7}{|c|}{ FDOT Districts } \\
\cline { 2 - 8 } & I & II & III & IV & V & VI & VII \\
\hline$M A D$ & 0.278 & 0.306 & 0.255 & 0.414 & 0.335 & 0.670 & 0.322 \\
\hline$M P B$ & 0.002 & 0.001 & 0.022 & 0.053 & 0.001 & 0.086 & 0.039 \\
\hline$M S P E$ & 0.003 & 0.001 & 0.361 & 1.371 & 0.001 & 1.625 & 1.054 \\
\hline
\end{tabular}

The GOF measures indicate that the district models fitted well. However, the TI indices are far from unity except for District 5 (D5). Since CMFs quantify the potential safety benefits of improvements which may also be used to derive the benefit-cost ratios to prioritize improvements, thus even the TI 0.93 for D5 may raise question about the 
applicability of the developed state-wide CMFs for local jurisdictions. The worst result was observed for D6 probably because of low representative sample for the models. Therefore, as implied by the derived $T I$ indices, the CMFs from state-wide models may not represent the actual safety performance in the local jurisdictions. It would always be a better approach to develop local models.

\subsubsection{Temporal Transferability}

To explore the temporal phenomena, crash data for the periods 2011-2012, 20132014, and 2015 were analyzed. At first, state-wide model was developed using crash data for the period 2013-2014, and this model served as the base model. Then, individual complete and constant-only models using crash data 2011-2012 and 2015 were developed. Finally, the base model developed with 2013-2014 crash data was applied for 2011-2012 and 2015 time periods to assess the possibility of temporal transferability. Again, Equation 3-12 was used to calculate the $T I$ indices. Table 5-48 presents the $T I$ indices that were calculated from the log-likelihood estimations and Table 5-49 provides the GOF measures. Please note that, model could not be fitted for 2015 crash data; because, the model assumption for the ZINB model was not met.

Table 5-48: Temporal TI Indices for 2011-2012 and 2015 Periods

\begin{tabular}{|c|c|c|}
\hline Measure & $\mathbf{2 0 1 1 - 2 0 1 2}$ & $\mathbf{2 0 1 5}$ \\
\hline$T I$ & 0.87 & -- \\
\hline
\end{tabular}

Note: $T I$ close to unity indicates better transferability; -- model assumption was not met.

Table 5-49: Temporal GOF Indices for 2011-2012 and 2015 Periods

\begin{tabular}{|c|c|c|}
\hline Measure & $\mathbf{2 0 1 1 - 2 0 1 2}$ & $\mathbf{2 0 1 5}$ \\
\hline$M A D$ & 0.201 & -- \\
\hline$M P B$ & 0.005 & -- \\
\hline$M S P E$ & 0.142 & -- \\
\hline
\end{tabular}

Note: -- model assumption was not met. 


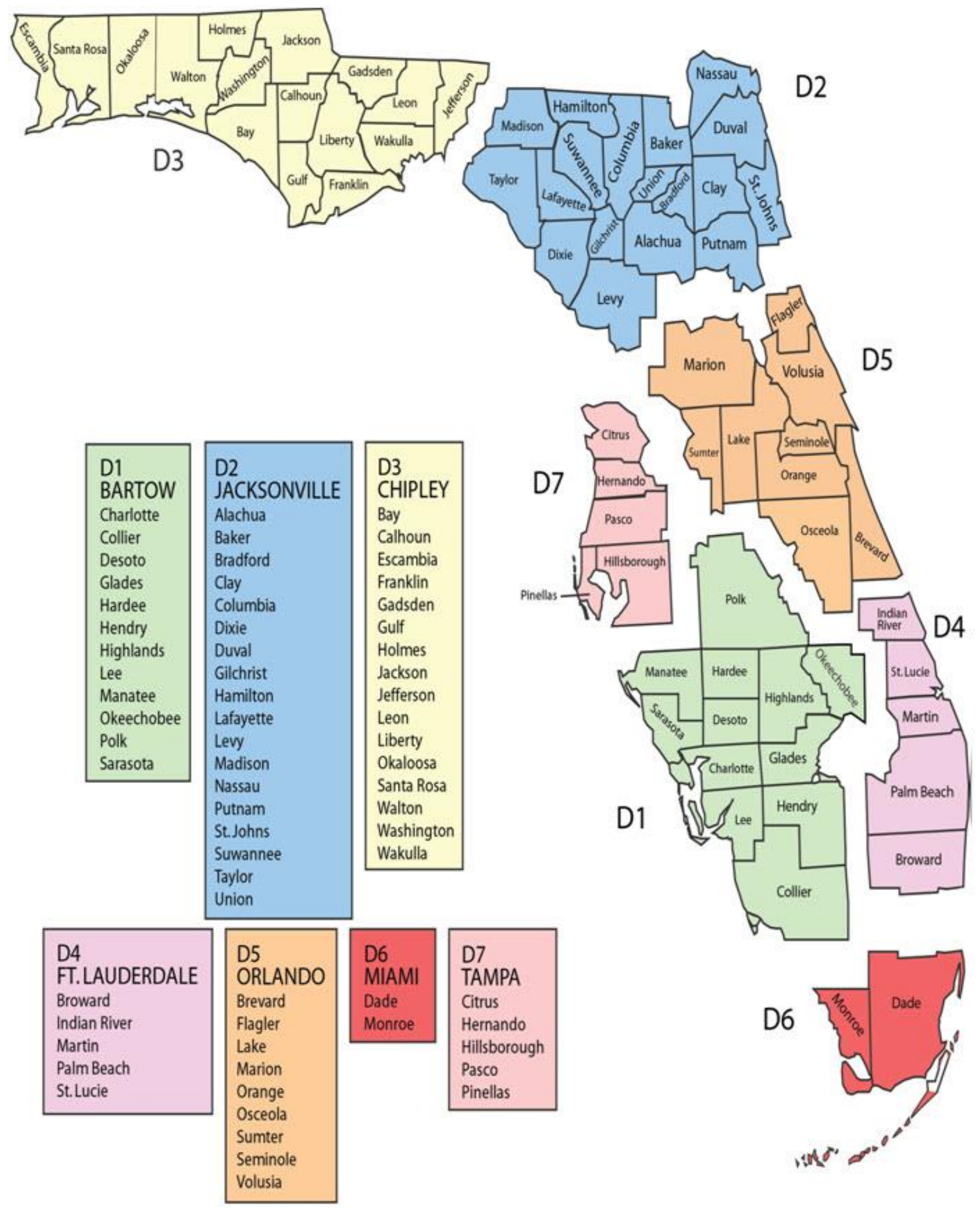

Figure 5-1: FDOT District Map (Source: Google Image, 2018)

(Image Courtesy: Teach America \& FDOT) 
The GOF measures indicate that the 2011-2012 model fitted well. However, the TI index is far from unity; thus, the TI 0.87 for 2011-2012 may raise question for temporal transferability of the CMFs. However, if the temporal phenomena would have been assessed with a longer time span, i.e., the models would have been developed with more years of crash data, a better conclusion could have been drawn.

Another attempt has been made in this research to assess the spatial-temporal transferability. The idea was to assess the temporal transferability within a local jurisdiction. The best spatial transferability index was derived for FDOT D5. The D5 data was then used to explore the possibility of temporal transferability. The approach was exactly similar to the temporal transferability assessment using the entire state's data. The $T I$ index was not encouraging, as can be observed in Table 5-50. Table 5-51 presents the GOF indices.

Table 5-50: Temporal D5 TI Indices for 2011-2012 and 2015 Periods

\begin{tabular}{|c|c|c|}
\hline Measure & $\mathbf{2 0 1 1 - 2 0 1 2}$ & $\mathbf{2 0 1 5}$ \\
\hline$T I$ & 0.68 & -- \\
\hline
\end{tabular}

Note: $T I$ close to unity indicates better transferability; -- model assumption was not met.

Table 5-51: Temporal D5 GOF Indices for 2011-2012 and 2015 Periods

\begin{tabular}{|c|c|c|}
\hline Measure & $\mathbf{2 0 1 1 - 2 0 1 2}$ & $\mathbf{2 0 1 5}$ \\
\hline$M A D$ & 0.204 & -- \\
\hline$M P B$ & 0.011 & -- \\
\hline$M S P E$ & 0.143 & -- \\
\hline
\end{tabular}

Note: -- model assumption was not met.

\subsection{Summary}

In summary, three potential methods, AHP, ANP, and FANP were compared while screening urban four-lane divided highways in Florida for bicycle safety improvements. The seven criteria considered for screening were: bicycle crash frequency, presence of bicycle facility, bicycle volume, AADT, auto ownership, land use, and transit stops. FANP 
was found to be the most suitable method among the three if the locations are to be prioritized in a holistic manner considering all criteria.

CMFs were also developed for bicycle crashes using cross-sectional analysis and the scopes of spatial and temporal transferability of the developed CMFs within Florida were assessed. Furthermore, Safety researchers have been looking for ways to consider bicycle exposure in developing bicycle crash prediction models. Unfortunately, bicycle volumes, the most accurate measure of bicycle exposure, are only scarcely available. As such, several surrogate measures of bicycle exposure are usually considered. This research has, for the first time, considered bicycle exposure by incorporating the bicycle activity data from Strava smartphone application and compared the bicycle CMFs with and without this activity data.

Lane width, speed limit, and vegetation in the median were found to have positive and presence of sidewalk and sidewalk barrier were found to negative impact on bicycle crash probabilities. Increased bicycle activity was found to reduce the bicycle crash probabilities on segments, while resulted in higher bicycle crash probabilities at intersections. Bus stops were found to increase the bicycle crash probabilities at intersections, whereas, protected signal control had a positive impact on bicycle safety. It was found that the developed CMFs developed from state-wide data should not be directly transferred to local jurisdictions, spatially or temporally. 


\section{CHAPTER 6 CONCLUSIONS}

This research explored the available network screening methodologies, discussed the pertinence of the approaches, and determined the most suitable screening method for bicycle safety improvements. Furthermore, Florida-specific crash modification factors (CMFs) were developed to quantify the impacts of roadway characteristics, bicycle infrastructure, and bicycle exposure on bicycle safety. The spatial and temporal transferability of the developed CMFs were also assessed among the Florida Department of Transportation (FDOT) Districts. This chapter summarizes the findings of this research and outlines the precincts for future research.

\subsection{Summary and Conclusions}

Network screening is a multi-criteria complex decision making process that prioritizes and ranks the potential locations based on specific criteria. It is considered as the most important aspect of making investment decisions for highway location improvements. The decision making criteria for screening can either be quantitative or qualitative. Qualitative criteria require subjective judgments. Therefore, a method that can effectively measure quantitative and qualitative criteria on the same platform is required. Another issue with using multiple criteria in location prioritization for improvement is that the criteria are often correlated. Thus, a method that can take into account the impacts of such interdependencies, and does not give undue weight to a specific criterion is desired. Transportation agencies are still using simple scoring and ranking algorithm which cannot address these issues efficiently. 
Three methods, which could potentially address the above mentioned screening issues, Analytic Hierarchy Process (AHP), Analytic Network Process (ANP), and Fuzzy Analytic Network Process (FANP), were applied to prioritize state maintained urban fourlane divided highways of Florida. The roadways were prioritized based on seven criteria: bicycle crash frequency, presence of bicycle facility, bicycle volume, AADT, auto ownership, land use, and transit stops. The key findings on the network screening methods are:

- AHP is more similar to simple ranking in the sense that the criteria which is weighted more has significant impact on the ranking.

- ANP's performance was found to be better than AHP's performance while prioritizing the highway locations for improvements.

- ANP and FANP do prioritize locations giving importance to all criteria; not only to the criteria which weighs more.

- FANP is found to be comparatively the most suitable screening method among AHP, ANP, and FANP if the locations are to be prioritized in a holistic manner considering all criteria.

Once the locations are prioritized for improvement, the next important step is to identify the specific improvements. How changes in the roadway characteristics affect safety is one of the most critical issues to be evaluated or studied. CMFs provide greater insight into how the roadway geometric characteristics affect safety; thus, makes it easier for the decision makers to improve any location with appropriate geometric features.

To quantify the impact of roadway characteristics, bicycle infrastructure, and bicycle exposure on bicycle safety for urban facilities in Florida, this research focused on 
developing Florida-specific CMFs for bicycle crashes. Roadway characteristics such as shared path, sidewalk, sidewalk barrier, type of on-street parking, lane width, median width, etc.; bicycle infrastructure such as bicycle lane, and bicycle slot; and bicycle exposure from Strava smartphone application were considered in this study. Crosssectional analysis was used to develop the CMFs for bicycle crashes. Generalized Linear Model approach with a Zero Inflated Negative Binomial distribution was adopted to develop the relevant regression models. The research focused on urban two-lane, four-lane, and six-lane divided roadway facilities, and urban four-leg signalized intersections. Some key findings from the developed CMFs are:

- Lane width, speed limit, and vegetation in the median were observed to have positive impacts on reducing bicycle crashes.

- Presence of sidewalk and sidewalk barrier were found to increase the bicycle crash probabilities.

- Increased bicycle activity was found to reduce the bicycle crash probabilities on segments, while increased bicycle activity resulted in higher bicycle crash probabilities at intersections.

- Bus stops were found to increase the bicycle crash probabilities at intersections, whereas, protected signal control had a positive impact on bicycle safety.

The applicability of a CMF depends on the data from which the CMF is estimated. This instigates the question of transferability of the CMFs; whether the CMFs developed using state-wide data are applicable to different jurisdictions and to different time periods. The scope of spatial and temporal transferability of the developed CMFs within FDOT districts for urban four-lane divided highways was assessed using transferability index (TI). 
When spatial transferability was considered, the $T I$ measure indicated the performance of the transferred model for the jurisdiction of interest; and when temporal transferability was considered the $T I$ measure indicated the performance of the transferred model for the time period of interest. The seven FDOT districts were considered as seven different spatial zones to explore the spatial transferability. Crash data for the period 2011-2012, 20132014, and 2015 were analyzed to assess the temporal phenomena. It was found that the developed CMFs should not be directly transferred, spatially or temporally. If possible, it would always be a better approach to develop local models or calibrate the CMFs.

This research provides agencies with an equitable and reliable solution to prioritize and improve locations such that the limited available funding is allocated to the locations which will yield the highest positive impact.

\subsection{Research Contributions}

This research has presented the shortcomings of current network screening practice and recommended an improved method FANP. The potential of FANP was demonstrated while prioritizing 2,236 urban four-lane divided highway segments in Florida for bicycle safety improvements. FANP and ANP were shown to provide more reasonable rankings, with FANP providing the best results among FANP, ANP, and AHP. Moreover, this research is one of the very few studies that addressed the network screening step for bicycle safety improvements in a holistic manner.

Furthermore, ZINB models were used to develop the CMFs for bicycle crashes, a topic that is seldom considered by researchers and practitioners. The interaction effect of different roadway factors were also considered while developing the CMFs. This research 
has, for the first time, considered bicycle exposure by incorporating the bicycle activity data from Strava smartphone application; and investigated the impact of bicycle activity data on bicycle CMFs. Spatial and temporal transferability of the developed CMFs within FDOT districts were also assessed to determine if the CMFs developed using state-wide data were applicable to different jurisdictions and for different time periods.

\subsection{Recommendations for Future Research}

Future studies to extend this research could focus on network screening and CMF estimation. The potential research scopes are discussed below.

\subsubsection{Network Screening}

FANP and ANP are computationally rigorous. If a new location is added to the existing list of locations, the entire process needs to be redone to rank the new location. This would be a tedious process. Future research could focus on incorporating any new location in the prioritization process reasonably. Furthermore, ANP and FANP cannot eliminate the human judgments completely from the prioritization process; rather, incorporate such judgments systematically and in a logical manner. An automated process would help the decision makers to provide consistent judgments.

\subsubsection{CMF Development}

CMFs were developed using ZINB models. Future research could validate the study findings, i.e., the CMFs, by conducting a before-after study. This research recommends to develop local CMFs if possible. An attempt can be made in the future research to transfer the models developed from state-wide data to local jurisdictions through calibration, i.e., 
future research can focus on calibrating the state models for local domains. Furthermore, future research may extend the scope of temporal transferability assessment with more years of data. 


\section{REFERENCES}

1. Abdel-Aty, M., Lee, C., Park, J., Wang, J., Abuzwidah, M., and Al-Arifi, S. (2014). Validation and Application of Highway Safety Manual (Part D) in Florida. Florida Department of Transportation, Tallahassee, Florida.

2. Alluri, P., Saha, D., Liu, K., and Gan, A. (2014). Improved Processes for Meeting the Data Requirements for Implementing the Highway Safety Manual and SafetyAnalyst in Florida. Final Research Report, Florida Department of Transportation, Tallahassee, FL.

3. Almasizadeh, S. (2016). Exploring the Transferability of Crash Modification Factors: Case Studies on Passing lanes and Dual Rumple Strips on Ontario Twolane Highways. Master's Thesis, Department of Civil Engineering, Ryerson University, Toronto, Ontario.

4. American Association of State Highway and Transportation Officials [AASHTO]. (2010). Highway Safety Manual (1st ed.). Washington, D.C.: Transportation Research Board of the National Academies.

5. Amponsah, C. T. (2013). An Integrated Approach for Prioritizing Projects for Implementation using AHP. Proceedings of the International Symposium on the Analytic Hierarchy Process 2013. Retrieved April 02, 2014, from http://www.isahp.org/uploads/8.pdf

6. Ayağ, Z., and Özdemir, R. G. (2007). An Intelligent Approach to ERP Software Selection through Fuzzy ANP. International Journal of Production Research, 45(10), 2169-2194.

7. Ayă̆, Z., and Özdemir, R. G. (2012). Evaluating Machine Tool Alternatives through Modified TOPSIS and Alpha-cut based Fuzzy ANP. International Journal of Production Economics, 140(2), 630-636.

8. Azis, I. J. (2003). Analytic Network Process with Feedback Influence: A New Approach to Impact Study. Presented at a Seminar Organized by the Department of Urban and Regional Planning, University of Illinois at Urbana-Champaign, in Conjunction with the Investiture Ceremony for Professor John Kim, Illinois. Retrieved June 4, 2017, from https://www.researchgate.net/profile/Iwan_Azis/publication/228906756_Analytic Network_Process_With_Feedback_Influence_A_New_Approach_to_Impact_Study /links/556b0a4908aefcb861d60c57.pdf

9. Banai, R. (2010). Evaluation of Land Use-Transportation Systems with the Analytic Network Process. Journal of Transport and Land Use, 3(1). 
10. Berechman, J., and Paaswell, R. E. (2005). Evaluation, Prioritization and Selection of Transportation Investment Projects in New York City. Transportation, 32(3), 223249.

11. Bhattacharya, A., Mohapatra, P., Kumar, V., Dey, P. K., Brady, M., Tiwari, M. K., and Nudurupati, S. S. (2014). Green Supply Chain Performance Measurement using Fuzzy ANP-based Balanced Scorecard: A Collaborative Decision-making Approach. Production Planning \& Control, 25(8), 698-714.

12. Bíl, M., Bílová, M., \& Müller, I. (2010). Critical Factors in Fatal Collisions of Adult Cyclists with Automobiles. Accident Analysis \& Prevention, 42(6), 1632-1636.

13. Boufous, S., de Rome, L., Senserrick, T., and Ivers, R. (2012). Risk Factors for Severe Injury in Cyclists Involved in Traffic Crashes in Victoria, Australia. Accident Analysis \& Prevention, 49, 404-409.

14. Bowman, B. L., Vecellio, R. L., and Miao, J. (1995). Vehicle and Pedestrian Accident Models for Median Locations. Journal of transportation engineering, 121(6), 531537.

15. Büyüközkan, G., and Çifçi, G. (2012). A Novel Hybrid MCDM Approach based on fuzzy DEMATEL, fuzzy ANP and fuzzy TOPSIS to Evaluate Green Suppliers. Expert Systems with Applications, 39(3), 3000-3011.

16. Cafiso, S., Di Graziano, A., Di Silvestro, G., La Cava, G., and Persaud, B. (2010). Development of Comprehensive Accident Models for Two-lane Rural Highways using Exposure, Geometry, Consistency and Context Variables. Accident Analysis \& Prevention, 42(4), 1072-1079.

17. Cameron, A. C., and Trivedi, P. K. (2013). Regression Analysis of Count Data. New York, NY: Cambridge University Press.

18. Carson, J., and Mannering, F. (2001). The Effect of Ice Warning Signs on Iceaccident Frequencies and Severities. Accident Analysis \& Prevention, 33(1), 99-109.

19. Carter, D., and Council, F. (2007). Factors Contributing to Pedestrian and Bicycle Crashes on Rural Highways. In Transportation Research Board 86th Annual Meeting (No. 07-2457).

20. Carter, D., Srinivasan, R., Gross, F., and Council, F. (2012). Recommended Protocols for Developing Crash Modification Factors. NCHRP 20-7(314) Final Report.

21. Cheng, E. W., Li, H. (2005). Analytic Network Process Applied to Project Selection. Journal of Construction Engineering and Management, 131(4), 459-466. 
22. Cheng, E. W., Li, H. (2004). Contractor Selection using the Analytic Network Process. Construction Management and Economics, 22(10), 1021-1032, (2004)

23. Chen, J. K., and Chen, I. S. (2010). Using a Novel Conjunctive MCDM Approach based on DEMATEL, fuzzy ANP, and TOPSIS as an Innovation Support System for Taiwanese Higher Education. Expert Systems with Applications, 37(3), 1981-1990.

24. Chen, L., Chen, C., Ewing, R., McKnight, C. E., Srinivasan, R., and Roe, M. (2013). Safety Countermeasures and Crash Reduction in New York City-Experience and Lessons Learned. Accident Analysis \& Prevention, 50, 312-322.

25. Chen, L., Chen, C., Srinivasan, R., McKnight, C. E., Ewing, R., and Roe, M. (2012). Evaluating the Safety Effects of Bicycle Lanes in New York City. American Journal of Public Health, 102(6), 1120-1127.

26. Chen, S. J., Hwang, C. L., and Hwang, F. P. (1992). Fuzzy Multiple Attribute Decision Making (Methods and Applications). Lecture Notes in Economics and Mathematical Systems, 375, Berlin - Heidelberg: Springer-Verlag, ISBN 3-54054998-6.

27. Chimba, D., Emaasit, D., Cherry, C. R., and Pannell, Z. (2014). Patterning Demographic and Socioeconomic Characteristics Affecting Pedestrian and Bicycle Crash Frequency. In Transportation Research Board 93rd Annual Meeting (No. 140600).

28. Chung, S. H., Lee, A. H. L., and Pearn, W. L. (2005). Analytic Network Process (ANP) Approach for Product Mix Planning in Semiconductor Fabricator. International Journal of Production Economics, 96, 15-36.

29. City of Toronto Transportation Services Division. (2003). Toronto Bicycle/MotorVehicle Collision Study. Retrieved December 18, 2015, from http://www1.toronto.ca/city_of_toronto/transportation_services/cycling/files/pdf/car -bike_collision_report.pdf

30. Cornell University. (n.d.). Bicycling on Sidewalks. Retrieved June 1, 2018, from http://www.bike.cornell.edu/pdfs/Sidewalk_biking_FAQ.pdf

31. Dağdeviren, M., Yüksel, İ., and Kurt, M. (2008). A Fuzzy Analytic Network Process (ANP) Model to Identify Faulty Behavior Risk (FBR) in Work System. Safety Science, 46(5), 771-783.

32. Daniels, S., Brijs, T., Nuyts, E., \& Wets, G. (2009). Injury Crashes with Bicyclists at Roundabouts: Influence of Some Location Characteristics and the Design of Cycle Facilities. Journal of Safety Research, 40(2), 141-148. 
33. Dong, C., Clarke, D. B., Yan, X., Khattak, A., and Huang, B. (2014). Multivariate Random-parameters Zero-inflated Negative Binomial Regression Model: An application to Estimate Crash Frequencies at Intersections. Accident Analysis \& Prevention, 70, 320-329.

34. Dubois, D., and Prade, H. (1978). Operation on Fuzzy Numbers. The International Journal of Systems Sciences, 9(6), 613-626.

35. Duthie, J., Brady, J., Mills, A., and Machemehl, R. (2010). Effects of On-Street Bicycle Facility Configuration on Bicyclist and Motorist Behavior. Transportation Research Record: Journal of the Transportation Research Board, 2190, 37-44.

36. El-Abbasy, M. S., Zayed, T., Ahmed, M., Alzraiee, H., Abouhamad, M. (2013). Contractor Selection Model for Highway Projects using Integrated Simulation and Analytic Network process. Journal of Construction Engineering and Management, 139(7), 755-767.

37. El-Basyouny, K., and Sayed, T. (2006). Comparison of Two Negative Binomial Regression Techniques in Developing Accident Prediction Models. Transportation Research Record: Journal of the Transportation Research Board, (1950), 9-16.

38. Eluru, N., Bhat, C. R., and Hensher, D. A. (2008). A Mixed Generalized Ordered Response Model for Examining Pedestrian and Bicyclist Injury Severity Level in Traffic Crashes. Accident Analysis \& Prevention, 40(3), 1033-1054.

39. Elvik, R., and Vaa, T. (2004). The Handbook of Road Safety Measures.

40. Emaasit, D. (2013). Framework to Identify Factors associated with High Pedestrian and Bicycle Crash Locations using Geographic Information System and Statistical Analysis (Master's Thesis). Retrieved December 22, 2015, from http://www.slideshare.net/DanielEmaasit/masters-thesis-38264362

41. ESRI. (2010). Linear Referencing Tutorial. Retrieved November 22, 2017, from http://help.arcgis.com/en/arcgisdesktop/10.0/pdf/linear-referencing-tutorial.pdf

42. Evans, G. W., and Kantrowitz, E. (2002). Socioeconomic Status and Health: The Potential Role of Environmental Risk Exposure. Annual Review of Public Health, 23(1), 303-331.

43. Farid, A., Abdel-Aty, M., Lee, J., Eluru, N., and Wang, J. H. (2016). Exploring the Transferability of Safety Performance Functions. Accident Analysis \& Prevention, 94, 143-152.

44. Florida Department of Transportation (FDOT). (n.d.). 2060 Florida Transportation Plan. Retrieved December 7, 2017, from http://www.fdot.gov/planning/ftp/2060FTP.pdf 
45. Florida Department of Transportation (FDOT). (2018). Florida Transit Information System (FTIS): Florida Transit Data Exchange (FTDE). Retrieved March 15, 2018, from

http://ftis.org/Posts.aspx

46. Gan, A., Raihan, M. A., Alluri, P., Liu, K., and Saha, D. (2016). Updating and Improving Methodology for Prioritizing Highway Project Locations on the Strategic Intermodal System (SIS), Final Research Report, Florida Department of Transportation District One, Bartow, Florida.

47. Garay, A. M., Hashimoto, E. M., Ortega, E. M., and Lachos, V. H. (2011). On Estimation and Influence Diagnostics for Zero-Inflated Negative Binomial Regression Models. Computational Statistics \& Data Analysis, 55(3), 1304-1318.

48. Ghatee, M., and Hashemi, S. M. (2007). Ranking Function-based Solutions of Fully Fuzzified Minimal Cost Flow Problem. Information Sciences, 177(20), 4271-4294.

49. Giachetti, R. E., and Young, R. E. (1997). A Parametric Representation of Fuzzy Numbers and their Arithmetic Operators. Fuzzy Sets and Systems, 91(2), 185-202.

50. Gilchrist, W. (1985). Statistical Modelling. New York, NY: John Wiley and Sons, Inc..

51. Godwin, A., and Price, A. M. (2016). Bicyclists on Sidewalks: Why They're Not Going Away, and What We Can Do About It. Retrieved June 1, 2018, from https://www.planetizen.com/node/84910/bicyclists-sidewalks-why-theyre-notgoing-away-and-what-we-can-do-about-it

52. Gross, F., Persaud, B., and Lyon, C. (2010). A Guide to Developing Quality Crash Modification Factors (No. FHWA-SA-10-032).

53. Guneri, A. F., Cengiz, M., and Seker, S. (2009). A Fuzzy ANP Approach to Shipyard Location Selection. Expert Systems with Applications, 36(4), 7992-7999.

54. Hadayeghi, A., Shalaby, A. S., Persaud, B. N., and Cheung, C. (2006). Temporal Transferability and updating of Zonal Level Accident Prediction Models. Accident Analysis \& Prevention, 38(3), 579-589.

55. Hadi, M. A., Aruldhas, J., Chow, L. F., and Wattleworth, J. A. (1995). Estimating Safety Effects of Cross-section Design for Various Highway Types using Negative Binomial Regression. Transportation Research Record, (1500), 169-177.

56. Hamann, C., and Peek-Asa, C. (2013). On-Road Bicycle Facilities and Bicycle Crashes in Iowa, 2007-2010. Accident Analysis \& Prevention, 56, 103-109. 
57. Hamann, C. J., Peek-Asa, C., Lynch, C. F., Ramirez, M., and Hanley, P. (2014). Epidemiology and Spatial Examination of Bicycle-Motor Vehicle Crashes in Iowa, 2001-2011. Journal of Transport \& Health, 2, 178-188.

58. Harkey, D., and Stewart, J. (1997). Evaluation of Shared-Use Facilities for Bicycles and Motor Vehicles. Transportation Research Record: Journal of the Transportation Research Board, 1578, 111-118.

59. Herbel S., Laing, L., and McGovern, C. (2010). Highway Safety Improvement Program (HSIP) Manual. Retrieved April 02, 2014, from http://safety.fhwa.dot.gov/hsip/resources/fhwasa09029/sec4.cfm

60. Hilbe, J. M. (2014). Modeling Count Data. New York, NY: Cambridge University Press.

61. Huang, H., and Chin, H. C. (2010). Modeling Road Traffic Crashes with Zeroinflation and Site-specific Random Effects. Statistical Methods \& Applications, 19(3), 445-462.

62. Hunter, W., Harkey, D., Stewart, J., and Birk, M. (2000). Evaluation of blue bikelane treatment in Portland, Oregon. Transportation Research Record: Journal of the Transportation Research Board, 1705, 107-115.

63. Hunter, W. W., Srinivasan, R., and Martell, C. (2009). An Examination of Bicycle Counts and Speeds Associated with the Installation of Bike Lanes in St. Petersburg, Florida. Highway Safety Research Center, University of North Carolina (FDOT Contract BA784), Chapel Hill, NC.

64. Hunter, W. W., Srinivasan, R., and Martell, C. A. (2008). Evaluation of a Green Bike Lane Weaving Area in St. Petersburg, Florida. University of North Carolina Highway Safety Research Center (FDOT Contract BA784), Chapel Hill, NC.

65. Hunter, W. W., Stewart, J. R., Stutts, J. C., Huang, H. H., and Pein, W. E. (1999). A Comparative Analysis of Bicycle Lanes versus Wide Curb Lanes: Final Report. Retrieved December 18, 2015, from http://www.fhwa.dot.gov/publications/research/safety/pedbike/99034/99034.pdf

66. Jensen, S. U. (2008). Bicycle Tracks and Lanes: A Before-After Study. In 87th Annual Meeting of the Transportation Research Board. Transportation Research Board (No. 08-2095).

67. Johnson, M., Newstead, S., Oxley, J., and Charlton, J. (2013). Cyclists and Open Vehicle Doors: Crash Characteristics and Risk Factors. Safety Science, 59, 135-140. 
68. Kaplan, S., and Prato, C. G. (2015). A Spatial Analysis of Land Use and Network Effects on Frequency and Severity of Cyclist-Motorist Crashes in the Copenhagen Region. Traffic Injury Prevention, 16, 724-731.

69. Kaufmann, A., and. Gupta, M. M. (1988). Fuzzy Mathematical Models in Engineering and Management Science, North-Holland, Amsterdam: Elsevier Science Inc..

70. Kim, J. K., Kim, S., Ulfarsson, G. F., and Porrello, L. A. (2007). Bicyclist Injury Severities in Bicycle-Motor Vehicle Accidents. Accident Analysis \& Prevention, 39(2), 238-251.

71. Klassen, J., El-Basyouny, K., and Islam, M. T. (2014). Analyzing the Severity of Bicycle-Motor Vehicle Collision using Spatial Mixed Logit Models: A City of Edmonton Case Study. Safety Science, 62, 295-304.

72. Klop, J., and Khattak, A. (1999). Factors Influencing Bicycle Crash Severity on TwoLane, Undivided Roadways in North Carolina. Transportation Research Record: Journal of the Transportation Research Board, 1674, 78-85.

73. Knuiman, M. W., Council, F. M., and Reinfurt, D. W. (1993). The Effect of Median Width on Highway Accident Rates. Transportation Research Record, (1401). 70-80.

74. Kumara, S. S. P., and Chin, H. C. (2003). Modeling Accident Occurrence at Signalized Tee Intersections with Special Emphasis on Excess Zeros. Traffic Injury Prevention, 4(1), 53-57.

75. Lawrence, B. M., Stevenson, M. R., Oxley, J. A., and Logan, D. B. (2015). Geospatial Analysis of Cyclist Injury Trends: An Investigation in Melbourne, Australia. Traffic Injury Prevention, 16(5), 513-518.

76. Lee, J., and Mannering, F. (2002). Impact of Roadside Features on the Frequency and Severity of Run-off-roadway Accidents: An Empirical Analysis. Accident Analysis \& Prevention, 34(2), 149-161.

77. Lind, J., and Schurba, A. (2002). Facility Location Planning using the Analytic Hierarchy Process. Retrieved August 17, 2014 from https://www.google.com/url?sa=t\&rct=j\&q=\&esrc=s\&source=web\&cd=1\&cad=rja \&uact $=8 \&$ ved $=0 \mathrm{CCIQFjAA} \& u r l=\mathrm{http} \% 3 \mathrm{~A} \% 2 \mathrm{~F} \% 2 \mathrm{Fwww}$.wiwi.unifrankfurt.de\%2F luft\%2Fvortrag\%2FThema5.ppt\&ei=WWTxU4qkENLlsATUiIKI BQ\&usg=AFQjCNFb6icNU7_uZMJwAyDbcJ6hvtapjw\&bvm=bv.73231344,d.cW $\underline{\mathrm{c}}$ 
78. Lin, P. S., Kourtellis, A., Zhang, Y., Guo, R., and Jelinska, E. B. (2017). Application of Demographic Analysis to Pedestrian Safety, Final Report, Florida Department of Transportation (FDOT), Tallahassee, Florida.

79. Loo, B. P., and Tsui, K. L. (2010). Bicycle Crash Casualties in a Highly Motorized City. Accident Analysis \& Prevention, 42(6), 1902-1907.

80. Lord, D., and Bonneson, J. (2007). Development of Accident Modification Factors for Rural Frontage Road Segments in Texas. Transportation Research Record: Journal of the Transportation Research Board, (2023), 20-27.

81. Lord, D., Washington, S., and Ivan, J. N. (2007). Further Notes on the Application of Zero-inflated Models in Highway Safety. Accident Analysis \& Prevention, 39(1), 5357.

82. Lord, D., and Mannering, F. (2010). The Statistical Analysis of Crash-frequency Data: A Review and Assessment of Methodological Alternatives. Transportation Research Part A: Policy and Practice, 44(5), 291-305.

83. Lord, D., Washington, S. P., and Ivan, J. N. (2005). Poisson, Poisson-gamma and Zero-inflated Regression Models of Motor Vehicle Crashes: Balancing Statistical Fit and Theory. Accident Analysis \& Prevention, 37(1), 35-46.

84. Lord, D. (2006). Modeling Motor Vehicle Crashes using Poisson-gamma Models: Examining the Effects of Low Sample Mean Values and Small Sample Size on the Estimation of the Fixed Dispersion Parameter. Accident Analysis \& Prevention, 38(4), 751-766.

85. Lu, J. J., and Wang, Z. (2005). Development of a Procedure for Prioritizing Intersections for Improvements Considering Safety and Operational Factors. Retrieved April 02, 2014, from http://www.dot.state.fl.us/researchcenter/Completed_Proj/Summary_TE/FDOT_BD 544_13_rpt.pdf

86. Macura, D., Boškovic, B., Bojovic, N., Milenkovic, M. (2011). A Model for Prioritization of Rail Infrastructure Projects using ANP. Rivista Internazionale di Economia dei Trasporti, 38(3), 285.

87. Malyshkina, N. V., and Mannering, F. L. (2010). Empirical Assessment of the Impact of Highway Design Exceptions on the Frequency and Severity of Vehicle Accidents. Accident Analysis \& Prevention, 42(1), 131-139.

88. Mead, J., McGrane, A., Zegeer, C., and Thomas, L. (2014). Evaluation of BicycleRelated Roadway Measures: A Summary of Available Research. Retrieved December 22, 2015, from http://www.pedbikeinfo.org/cms/downloads/06\%2013\%202014\%20BIKESAFE\%2 0Lit\%20Review_FINAL.pdf 
89. Mehta, G., and Lou, Y. (2013). Calibration and Development of Safety Performance Functions for Alabama: Two-lane, Two-way Rural Roads and Four-lane Divided Highways. Transportation Research Record: Journal of the Transportation Research Board, 2398, 75-82.

90. Meyer, C. D. (2000). Matrix Analysis and Applied Linear Algebra (Volume 2). PA: Society for Industrial and Applied Mathematics (SIAM).

91. Miaou, S. P., Hu, P. S., Wright, T., Rathi, A. K., and Davis, S. C. (1992). Relationship between Truck Accidents and Highway Geometric Design: A Poisson Regression Approach. Transportation Research Record, 1376, 10-18.

92. Miaou, S. P. (1994). The Relationship between Truck Accidents and Geometric Design of Road Sections: Poisson versus Negative Binomial Regressions. Accident Analysis \& Prevention, 26(4), 471-482.

93. Minikel, E. (2012). Cyclist Safety on Bicycle Boulevards and Parallel Arterial Routes in Berkeley, California. Accident Analysis \& Prevention, 45, 241-247.

94. Miranda-Moreno, L. F., Strauss, J., and Morency, P. (2011). Exposure Measures and Injury Frequency Models for Analysis of Cyclist Safety at Signalized Intersections. In 90th Annual Meeting of the Transportation Research Board (No. 11-2286).

95. Mohanty, R. P., Agarwal, R., Choudhury, A. K., and Tiwari, M. K. (2005). A Fuzzy ANP-based Approach to R\&D Project Selection: A Case Study. International Journal of Production Research, 43(24), 5199-5216.

96. Morency, P., Gauvin, L., Plante, C., Fournier, M., and Morency, C. (2012). Neighborhood Social Inequalities in Road Traffic Injuries: The Influence of Traffic Volume and Road Design. American Journal of Public Health, 102(6), 1112-1119.

97. National Highway Traffic Safety Administration (NHTSA). (2017). Fatality Analysis Reporting System (FARS) Encyclopedia, NCSA Data Resource Website. Retrieved June 22, 2017, from www-fars.nhtsa.dot.gov/Main/index.aspx.

98. National Highway Traffic Safety Administration (NHTSA). (n.d.). Bicycle Safety. Retrieved June 1, 2018, from https://www.nhtsa.gov/road-safety/bicycle-safety

99. National Highway Traffic Safety Administration (NHTSA). (2016). Quick Facts 2015 (Updated). Retrieved May 29, 2017, from https://crashstats.nhtsa.dot.gov/\#/ 
100. NCSS. (2018). Zero-Inflated Negative Binomial Regression. NCSS Statistical Software, 2018. Retrieved January 22, 2018, from

https://ncss-wpengine.netdna-ssl.com/wpcontent/themes/ncss/pdf/Procedures/NCSS/Zero-

Inflated_Negative_Binomial_Regression.pdf

101. Nosal, T., and Miranda-Moreno, L. F. (2012). Cycle-Tracks, Bicycle Lanes, and Onstreet Cycling in Montreal, Canada: A Preliminary Comparison of the Cyclist Injury Risk. In Transportation Research Board 91st Annual Meeting (No. 12-2987).

102. Oh, J., Jun, J., Kim, E., and Kim, M. (2008). Assessing Critical Factors Associated with Bicycle Collisions at Urban Signalized Intersections. In 87th Annual Meeting of the Transportation Research Board, Washington, DC.

103. Organisation for Economic Cooperation and Development (OECD). (2012). Sharing Road Safety: Developing an International Framework for Crash Modification Functions. OECD Publishing. Retrieved June 14, 2017, from http://dx.doi.org/10.1787/9789282103760-en

104. Outwater, M. L., Adler, T., Dumont, J., Kitchen, M., and Bassok, A. (2011). Quantitative Approaches for Project Prioritization: A Puget Sound Case Study. Retrieved April 03, 2014, from http://www.rsginc.com/sites/default/files/publications/SHRP\%202\%20C18\%20Tec hnical\%20TRB\%20Paper\%20Revised\%20Final\%20v2.pdf

105. Park, J., Abdel-Aty, M., Lee, J., and Lee, C. (2015). Developing Crash Modification Functions to Assess Safety Effects of Adding Bike Lanes for Urban Arterials with Different Roadway and Socio-Economic Characteristics. Accident Analysis \& Prevention, 74, 179-191.

106. Persaud, B., Lyon, C., and Srinivasan, R. (2015). On the Transferability of Crash Modification Factors for Highway Geometric Design Elements. Retrieved June 27, 2017, from https://static1.squarespace.com/static/51cc8d46e4b0b242fc8d0f33/t/55c4fe4fe4b01 $\underline{\text { 0d2627a3b04/1438973519945/114.+On+the+Transferability+of+Crash+Modificati }}$ on+Factors+for+Highway+Geometric+Design+Elements.pdf

107. Prasetijo, J., and Musa, W. Z. (2016). Modeling Zero-inflated Regression of Road Accidents at Johor Federal Road F001. In MATEC web of conferences (Vol. 47). EDP Sciences.

108. Pucher, J., Buehler, R., Merom, D., and Bauman, A. (2011). Walking and Cycling in the United States, 2001-2009: Evidence from the National Household Travel Surveys. American Journal of Public Health, 101(S1), S310-S317. 
109. Qin, X., Ivan, J. N., and Ravishanker, N. (2004). Selecting Exposure Measures in Crash Rate Prediction for Two-lane Highway Segments. Accident Analysis \& Prevention, 36(2), 183-191.

110. Quddus, M. A. (2008). Modelling Area-Wide Count Outcomes with Spatial Correlation and Heterogeneity: An Analysis of London Crash Data. Accident Analysis \& Prevention, 40(4), 1486-1497.

111. Raihan, M. A., Alluri, P., Gan, A., and Jung, R. (2016). Application of the Analytic Network Process (ANP) in Prioritizing Highway Improvement Locations. In Transportation Research Board 95th Annual Meeting (No. 16-5908).

112. Ramík, J. (2007). A Decision System using ANP and Fuzzy Inputs. International Journal of Innovative Computing, Information and Control, 3(4), 825-837.

113. Ramík, J. (2006). Duality in Fuzzy Linear Programming with Possibility and Necessity Relations. Fuzzy Sets and Systems, 157(10), 1283-1302.

114. R Core Team (2016). R: A Language and Environment for Statistical Computing. R Foundation for Statistical Computing, Vienna, Austria. URL https://www.Rproject.org/.

115. Räsänen, M., and Summala, H. (1998). Attention and Expectation Problems in Bicycle-Car Collisions: An In-Depth Study. Accident Analysis \& Prevention, 30(5), 657-666.

116. Rodegerdts, L. A., Nevers, B., Robinson, B., Ringert, J., Koonce, P., Bansen, J., and Neuman, T. (2004). Signalized Intersections: Informational Guide (No. FHWA-HRT04-091).

117. Rodgers, G. B. (1998). Factors Associated with the Crash Risk of Adult Bicyclists. Journal of Safety Research, 28(4), 233-241.

118. Saaty, T. L. (1980). The Analytic Hierarchy Process: Planning, Priority Setting, Resource Allocation. New York: McGraw-Hill.

119. Saaty, R. W. (1987). The Analytic Hierarchy Process - What It is and How It is Used. Mathematical Modelling, 9(3), 161-176.

120. Saaty, T. L. (1996). Decision Making with Dependence and Feedback: The Analytic Network Process. Pittsburgh: RWS Publications.

121. Saaty, T. L. (2001). The Analytic Network Process. Pittsburgh: RWS Publications. 
122. Saaty, T. L. (2005). Theory and Applications of the Analytic Network Process. Pittsburgh: RWS Publications.

123. Saaty, T. L. (2006). The Analytic Network Process-Dependence and Feedback in Decision-Making: Theory and Validation Examples. In Business Applications and Computational Intelligence, 360-387, IGI Global.

124. Saaty, T. L. (2008). The Analytic Network Process. Iranian Journal of Operations Research, 1(1), 1-27.

125. Saaty, T. L., and Vargas, L. G. (1998). Diagnosis with Dependent Symptoms: Bayes Theorem and the Analytic Network Process, Operations Research, 46(4), 491-502.

126. Saaty, T. L., and Vargas, L. G. (2006). Decision Making with the Analytic Network Process - Economic, Political, Social and Technological Applications with Benefits, Opportunities, Costs and Risks. Springer, Pittsburgh.

127. Sadeghi, M., Rashidzadeh, M. A., Soukhakian, M. A. (2012). Using Analytic Network Process in a Group Decision-making for Supplier Selection. Informatica An International Journal of Computing and Informatics, 23(4), 621-643.

128. Saleem, T., Qin, L., Almasi, S., Persaud, B., and Lyon, C. (2016). Exploring the Transferability of Crash Modification factors - Ontario Case Studies. Retrieved June 27, 2017, from https://www.researchgate.net/publication/316123836_Exploring the Transferabilit ע_of_Crash_Modification_Factors_-_Ontario_Case_Studies

129. Sando, T., Chimba, D., Kwigizile, V., and Moses, R. (2011). Operational Analysis of Interaction Between Vehicles and Bicyclists on Highways with Wide Curb Lanes. In Transportation Research Board 90th Annual Meeting (No.11-0087).

130. Schepers, J. P., Kroeze, P. A., Sweers, W., and Wüst, J. C. (2011). Road Factors and Bicycle-Motor Vehicle Crashes at Unsignalized Priority Intersections. Accident Analysis \& Prevention, 43(3), 853-861.

131. Schepers, P., and Wolt, K. K. (2012). Single-Bicycle Crash Types and Characteristics. Cycling Research International, 2, 119-135.

132. Schweikert, A., and Chinowsky, P. (2013). Re-Defining "Project Impact": Incorporating Social Considerations into the Rural Road Prioritization Process. Engineering Project Organization Conference 2013. Retrieved April 02, 2014, from http://www.epossociety.org/epoc2013/Papers/Schweikert_Chinowsky.pdf 
133. Sevkli, M., Oztekin, A., Uysal, O., Torlak, G., Turkyilmaz, A., and Delen, D. (2012). Development of a Fuzzy ANP based SWOT Analysis for the Airline Industry in Turkey. Expert systems with Applications, 39(1), 14-24.

134. Shankar, V., Mannering, F., and Barfield, W. (1995). Effect of Roadway Geometrics and Environmental Factors on Rural Freeway Accident Frequencies. Accident Analysis \& Prevention, 27(3), 371-389.

135. Shankar, V., Milton, J., and Mannering, F. (1997). Modeling Accident Frequencies as Zero-altered Probability Processes: An Empirical Inquiry. Accident Analysis \& Prevention, 29(6), 829-837.

136. Shankar, V. N., Ulfarsson, G. F., Pendyala, R. M., and Nebergall, M. B. (2003). Modeling Crashes Involving Pedestrians and Motorized Traffic. Safety Science, 41(7), 627-640.

137. Siddiqui, C., Abdel-Aty, M., and Choi, K. (2012). Macroscopic Spatial Analysis of Pedestrian and Bicycle Crashes. Accident Analysis \& Prevention, 45, 382-391.

138. Sikder, S., Augustin, B., Pinjari, A. R., and Eluru, N. (2013). Spatial Transferability of Tour-based Time-of-day Choice Models: An Empirical Assessment. ProcediaSocial and Behavioral Sciences, 104, 640-649.

139. Skibniewski, M. J., and Chao, L. (1992). Evaluation of Advanced Construction Technology with AHP Method. Journal of Construction Engineering and Management, 118(3), 577-593.

140. Stamatiadis, N., Pigman, J., Sacksteder, J., Ruff, W., and Lord, D. (2009) Impact of Shoulder Width and Median Width on Safety. NCHRP Report 633, Transportation Research Board, Washington, DC.

141. Teschke, K., Harris, M. A., Reynolds, C. C. O., Winters, M., Babul, S., Chipman, M., Cusimano, M. D., Brubacher, J. R., Hunte, G., Friedman, S. M., Monro, M., Shen, H., Vernich, L., and Cripton, P. A. (2012). Route Infrastructure and the Risk of Injuries to Bicyclists: A Case-Crossover Study. American Journal of Public Health, 102(12), 2336-2343.

142. Turner, S., Wood, G., Hughes, T., \& Singh, R. (2011). Safety Performance Functions for Bicycle Crashes in New Zealand and Australia. Transportation Research Record: Journal of the Transportation Research Board, 2236, 66-73.

143. Tuzkaya, U. R., \& Önüt, S. (2008). A Fuzzy Analytic Network Process based Approach to Transportation-mode Selection between Turkey and Germany: A Case Study. Information Sciences, 178(15), 3133-3146. 
144. U.S. Census Bureau. (2016). 2015 Census Block Groups in Florida (with Selected Fields from the 2011-2015 American Community Survey). Retrieved January 28, 2018, from https://www.fgdl.org/metadataexplorer/full_metadata.jsp?docId=\%7B7261C8B7BC1D-4C78-ACFF-E9D5D0C7B372\%7D\&loggedIn=false

145. Wagenknecht, M., Hampel, R., and Schneider, V. (2001). Computational Aspects of Fuzzy Arithmetics based on Archimedean t-norms. Fuzzy Sets and Systems, 123(1), 49-62.

146. Wang, J. H., Abdel-Aty, M., and Lee, J. (2016). Examination of the Transferability of Safety Performance Functions for Developing Crash Modification Factors: Using the Empirical Bayes Method. Transportation Research Record: Journal of the Transportation Research Board, 2583, 73-80.

147. Wang, C., Lu, L., and Lu, J. (2015). Statistical Analysis of Bicyclists' Injury Severity at Unsignalized Intersections. Traffic Injury Prevention, 16(5), 507-512.

148. Wanvik, P. O. (2009). Effects of Road Lighting: An Analysis based on Dutch Accident Statistics 1987-2006. Accident Analysis \& Prevention, 41(1), 123-128.

149. Washington, S. P., Persaud, B. N., Lyon, C., and Oh, J. (2005). Validation of Accident Models for Intersections. Report FHWA-RD-03-037, FHWA, U.S. Department of Transportation.

150. Williams, K. (2014). Could Bicycle Boulevards Encourage More Cycling in Stockton? Retrieved March 17, 2017, from https://stocktoncitylimits.com/2014/03/31/could-bicycle-boulevards-encouragemore-cycling-in-stockton/

151. Yücenur, G. N., Vayvay, Ö., and Demirel, N. Ç. (2011). Supplier Selection Problem in Global Supply Chains by AHP and ANP Approaches under Fuzzy Environment. The International Journal of Advanced Manufacturing Technology, 56(5), 823-833.

152. Yüksel, İ., Dağdeviren, M. (2007). Using the Analytic Network Process (ANP) in a SWOT Analysis - A Case Study for a Textile Firm. Journal of Information Sciences, 177(16), 3364-3382.

153. Zadeh, L. A. (1965). Fuzzy Sets. Information and Control, 8(3), 338-358.

154. Zadeh, L. A. (1976). A Fuzzy-algorithmic Approach to the Definition of Complex or Imprecise Concepts. International Journal of Man-Machine Studies, 8, 249-291. 
155. Zahabi, S., Strauss, J., Manaugh, K., and Miranda-Moreno, L. (2011). Estimating Potential Effect of Speed Limits, Built Environment, and Other Factors on Severity of Pedestrian and Cyclist Injuries in Crashes. Transportation Research Record: Journal of the Transportation Research Board, 2247, 81-90. 


\section{APPENDIX}

Pair-wise Comparisons of the Criteria 


\begin{tabular}{|c|c|c|c|c|c|c|c|c|c|c|c|c|c|c|c|c|c|c|}
\hline \multirow{3}{*}{ Criteria } & \multicolumn{17}{|c|}{ Preference Scale } & \multirow{3}{*}{ Criteria } \\
\hline & Extreme & \begin{tabular}{|c|} 
Very \\
Strong to \\
Extreme
\end{tabular} & $\begin{array}{l}\text { Very } \\
\text { Strong }\end{array}$ & \begin{tabular}{|c|} 
Strong to \\
Very \\
Strong
\end{tabular} & Strong & \begin{tabular}{|} 
Moderate \\
to Strong
\end{tabular} & Moderate & $\begin{array}{c}\text { Equal to } \\
\text { Moderate }\end{array}$ & Equal & $\mid \begin{array}{c}\text { Equal to } \\
\text { Moderate }\end{array}$ & Moderate & $\begin{array}{l}\text { Moderate } \\
\text { to Strong }\end{array}$ & Strong & \begin{tabular}{|c|} 
Strong to \\
Very \\
Strong
\end{tabular} & $\begin{array}{c}\text { Very } \\
\text { strong }\end{array}$ & \begin{tabular}{|c|} 
Very \\
Strong to \\
Extreme
\end{tabular} & Extreme & \\
\hline & 9 & 8 & 7 & 6 & 5 & 4 & 3 & 2 & 1 & 2 & 3 & 4 & 5 & 6 & 7 & 8 & 9 & \\
\hline Bicycle Crash Frequency & $\square$ & $\square$ & $\square$ & $\square$ & $\square$ & $\square$ & $\square$ & $\square$ & $\square$ & $\square$ & $\square$ & $\square$ & $\square$ & $\square$ & $\square$ & $\square$ & $\square$ & Bicycle Facility \\
\hline Bicycle Crash Frequency & $\square$ & $\square$ & $\square$ & $\square$ & $\square$ & $\square$ & $\square$ & $\square$ & $\square$ & $\square$ & $\square$ & $\square$ & $\square$ & $\square$ & $\square$ & $\square$ & $\square$ & Bicycle Volume \\
\hline Bicycle Crash Frequency & $\square$ & $\square$ & $\square$ & $\square$ & $\square$ & $\square$ & $\square$ & $\square$ & $\square$ & $\square$ & $\square$ & $\square$ & $\square$ & $\square$ & $\square$ & $\square$ & $\square$ & AADT \\
\hline Bicycle Crash Frequency & $\square$ & $\square$ & $\square$ & $\square$ & $\square$ & $\square$ & $\square$ & $\square$ & $\square$ & $\square$ & $\square$ & $\square$ & $\square$ & $\square$ & $\square$ & $\square$ & $\square$ & Auto Ownership \\
\hline Bicycle Crash Frequency & $\square$ & $\square$ & $\square$ & $\square$ & $\square$ & $\square$ & $\square$ & $\square$ & $\square$ & $\square$ & $\square$ & $\square$ & $\square$ & $\square$ & $\bar{\square}$ & $\square$ & $\square$ & Land Use \\
\hline Bicycle Crash Frequency & $\square$ & $\square$ & $\square$ & $\square$ & $\square$ & $\square$ & $\square$ & $\square$ & $\square$ & $\square$ & $\square$ & $\square$ & $\square$ & $\square$ & $\square$ & $\square$ & $\square$ & Transit Stops \\
\hline Bicycle Facility & $\square$ & $\square$ & $\square$ & $\square$ & $\square$ & $\square$ & $\square$ & $\square$ & $\square$ & $\square$ & $\square$ & $\square$ & $\square$ & $\square$ & $\square$ & $\square$ & $\square$ & Bicycle Volume \\
\hline Bicycle Facility & $\square$ & $\square$ & $\square$ & $\square$ & $\square$ & $\square$ & $\square$ & $\square$ & $\square$ & $\square$ & $\square$ & $\square$ & $\square$ & $\square$ & $\square$ & $\square$ & $\square$ & AADT \\
\hline Bicycle Facility & $\square$ & $\square$ & $\square$ & $\square$ & $\square$ & $\square$ & $\square$ & $\square$ & $\square$ & $\square$ & $\square$ & $\square$ & $\square$ & $\square$ & $\square$ & $\square$ & $\square$ & Auto Ownership \\
\hline Bicycle Facility & $\square$ & $\square$ & $\square$ & $\square$ & $\square$ & $\square$ & $\square$ & $\square$ & $\square$ & $\square$ & $\square$ & $\square$ & $\square$ & $\square$ & $\square$ & $\square$ & $\square$ & Land Use \\
\hline Bicycle Facility & $\square$ & $\square$ & $\square$ & $\square$ & $\square$ & $\square$ & $\square$ & $\square$ & $\square$ & $\square$ & $\square$ & $\square$ & $\square$ & $\square$ & $\square$ & $\square$ & $\square$ & Transit Stops \\
\hline Bicycle Volume & $\square$ & $\square$ & $\square$ & $\square$ & $\square$ & $\square$ & $\square$ & $\square$ & $\square$ & $\square$ & $\square$ & $\square$ & $\square$ & $\square$ & $\square$ & $\square$ & $\square$ & AADT \\
\hline Bicycle Volume & $\square$ & $\square$ & $\square$ & $\square$ & $\square$ & $\square$ & $\square$ & $\square$ & $\square$ & $\square$ & $\square$ & $\square$ & $\square$ & $\square$ & $\square$ & $\square$ & $\square$ & Auto Ownership \\
\hline Bicycle Volume & $\square$ & $\square$ & $\square$ & $\square$ & $\square$ & $\square$ & $\square$ & $\square$ & $\square$ & $\square$ & $\square$ & $\square$ & $\square$ & $\square$ & $\square$ & $\square$ & $\square$ & Land Use \\
\hline Bicycle Volume & $\square$ & $\square$ & $\square$ & $\square$ & $\square$ & $\square$ & $\square$ & $\square$ & $\square$ & $\square$ & $\square$ & $\square$ & $\square$ & $\square$ & $\square$ & $\square$ & $\square$ & Transit Stops \\
\hline AADT & $\square$ & $\square$ & $\square$ & $\square$ & $\square$ & $\square$ & $\square$ & $\square$ & $\square$ & $\square$ & $\square$ & $\square$ & $\square$ & $\square$ & $\square$ & $\square$ & $\square$ & Auto Ownership \\
\hline AADT & $\square$ & $\square$ & $\square$ & $\square$ & $\square$ & $\square$ & $\square$ & $\square$ & $\square$ & $\square$ & $\square$ & $\square$ & $\square$ & $\square$ & $\square$ & $\square$ & $\square$ & Land Use \\
\hline AADT & $\square$ & $\square$ & $\square$ & $\square$ & $\square$ & $\square$ & $\square$ & $\square$ & $\square$ & $\square$ & $\square$ & $\square$ & $\square$ & $\square$ & $\square$ & $\square$ & $\square$ & Transit Stops \\
\hline Auto Ownership & $\square$ & $\square$ & $\square$ & $\square$ & $\square$ & $\square$ & $\square$ & $\square$ & $\square$ & $\square$ & $\square$ & $\square$ & $\square$ & $\square$ & $\square$ & $\square$ & $\square$ & Land Use \\
\hline Auto Ownership & $\square$ & $\square$ & $\square$ & $\square$ & $\square$ & $\square$ & $\square$ & $\square$ & $\square$ & $\square$ & $\square$ & $\square$ & $\square$ & $\square$ & $\square$ & $\square$ & $\square$ & Transit Stops \\
\hline Land Use & $\square$ & $\square$ & $\square$ & $\square$ & $\square$ & $\square$ & $\square$ & $\square$ & $\square$ & $\square$ & $\square$ & $\square$ & $\square$ & $\square$ & $\square$ & $\square$ & $\square$ & Transit Stops \\
\hline
\end{tabular}

Figure A-1: Pair-wise Comparison Survey Sheet 


\begin{tabular}{|c|c|c|c|c|c|c|c|c|c|c|c|c|c|c|c|c|c|c|}
\hline \multirow{3}{*}{ Criteria } & \multicolumn{17}{|c|}{ Preference Scale } & \multirow{3}{*}{ Criteria } \\
\hline & Extreme & \begin{tabular}{|c|} 
Very \\
Strong to \\
Extreme \\
\end{tabular} & $\begin{array}{l}\text { Very } \\
\text { strong }\end{array}$ & \begin{tabular}{|c|} 
Strong to \\
Very \\
Strong \\
\end{tabular} & Strong & $\begin{array}{c}\text { Moderate } \\
\text { to Strong }\end{array}$ & Moderate & $\begin{array}{l}\text { Equal to } \\
\text { Moderate }\end{array}$ & Equal & $\begin{array}{c}\text { Equal to } \\
\text { Moderate }\end{array}$ & Moderate & $=\begin{array}{c}\text { Moderate } \\
\text { to Strong }\end{array} \mid$ & Strong & \begin{tabular}{|c|} 
Strong to \\
Very \\
Strong \\
\end{tabular} & $\begin{array}{c}\text { Very } \\
\text { Strong }\end{array}$ & \begin{tabular}{|c|} 
Very \\
Strong to \\
Extreme
\end{tabular} & Extreme & \\
\hline & 9 & 8 & 7 & 6 & 5 & 4 & 3 & 2 & 1 & 2 & 3 & 4 & 5 & 6 & 7 & 8 & 9 & \\
\hline Bicycle Crash Frequency & $\square$ & $\square$ & $\square$ & $\square$ & $\square$ & $\square$ & $\square$ & $\square$ & $\nabla$ & $\square$ & $\square$ & $\square$ & $\square$ & $\square$ & $\square$ & $\square$ & $\square$ & Bicycle Facility \\
\hline Bicycle Crash Frequency & $\square$ & $\square$ & $\nabla$ & $\square$ & $\square$ & $\square$ & $\square$ & $\square$ & $\square$ & $\square$ & $\square$ & $\square$ & $\square$ & $\square$ & $\square$ & $\square$ & $\square$ & Bicycle Volume \\
\hline Bicycle Crash Frequency & $\square$ & $\square$ & $\square$ & $\nabla$ & $\square$ & $\square$ & $\square$ & $\square$ & $\square$ & $\square$ & $\square$ & $\square$ & $\square$ & $\square$ & $\square$ & $\square$ & $\square$ & AADT \\
\hline Bicycle Crash Frequency & $\square$ & $\square$ & $\nabla$ & $\square$ & $\square$ & $\square$ & $\square$ & $\square$ & $\square$ & $\square$ & $\square$ & $\square$ & $\square$ & $\square$ & $\square$ & $\square$ & $\square$ & Auto Ownership \\
\hline Bicycle Crash Frequency & $\square$ & $\square$ & $\square$ & $\square$ & $\nabla$ & $\square$ & $\square$ & $\square$ & $\square$ & $\square$ & $\square$ & $\square$ & $\square$ & $\square$ & $\square$ & $\square$ & $\square$ & Land Use \\
\hline Bicycle Crash Frequency & $\square$ & $\square$ & $\square$ & $\nabla$ & $\square$ & $\square$ & $\square$ & $\square$ & $\square$ & $\square$ & $\square$ & $\square$ & $\square$ & $\square$ & $\square$ & $\square$ & $\square$ & Transit Stops \\
\hline Bicycle Facility & $\square$ & $\square$ & $\square$ & $\square$ & $\square$ & $\square$ & $\square$ & $\square$ & $\nabla$ & $\square$ & $\square$ & $\square$ & $\square$ & $\square$ & $\square$ & $\square$ & $\square$ & Bicycle Volume \\
\hline Bicycle Facility & $\square$ & $\square$ & $\square$ & $\nabla$ & $\square$ & $\square$ & $\square$ & $\square$ & $\square$ & $\square$ & $\square$ & $\square$ & $\square$ & $\square$ & $\square$ & $\square$ & $\square$ & AADT \\
\hline Bicycle Facility & $\square$ & $\square$ & $\square$ & $\nabla$ & $\square$ & $\square$ & $\square$ & $\square$ & $\square$ & $\square$ & $\square$ & $\square$ & $\square$ & $\square$ & $\square$ & $\square$ & $\square$ & Auto Ownership \\
\hline Bicycle Facility & $\square$ & $\square$ & $\square$ & $\square$ & $\square$ & $\square$ & $\square$ & $\square$ & $\square$ & $\square$ & $\square$ & $\nabla$ & $\square$ & $\square$ & $\square$ & $\square$ & $\square$ & Land Use \\
\hline Bicycle Facility & $\square$ & $\square$ & $\square$ & $\square$ & $\square$ & $\square$ & $\square$ & $\square$ & $\nabla$ & $\square$ & $\square$ & $\square$ & $\square$ & $\square$ & $\square$ & $\square$ & $\square$ & Transit Stops \\
\hline Bicycle Volume & $\square$ & $\square$ & $\square$ & $\square$ & $\square$ & $\square$ & $\square$ & $\square$ & $\square$ & $\square$ & $\square$ & $\square$ & $\square$ & $\nabla$ & $\square$ & $\square$ & $\square$ & AADT \\
\hline Bicycle Volume & $\square$ & $\square$ & $\square$ & $\square$ & $\square$ & $\square$ & $\square$ & $\square$ & $\square$ & $\square$ & $\square$ & $\nabla$ & $\square$ & $\square$ & $\square$ & $\square$ & $\square$ & Auto Ownership \\
\hline Bicycle Volume & $\square$ & $\square$ & $\square$ & $\square$ & $\square$ & $\square$ & $\square$ & $\nabla$ & $\square$ & $\square$ & $\square$ & $\square$ & $\square$ & $\square$ & $\square$ & $\square$ & $\square$ & Land Use \\
\hline Bicycle Volume & $\square$ & $\square$ & $\square$ & $\square$ & $\nabla$ & $\square$ & $\square$ & $\square$ & $\square$ & $\square$ & $\square$ & $\square$ & $\square$ & $\square$ & $\square$ & $\square$ & $\square$ & Transit Stops \\
\hline AADT & $\square$ & $\square$ & $\square$ & $\square$ & $\nabla$ & $\square$ & $\square$ & $\square$ & $\square$ & $\square$ & $\square$ & $\square$ & $\square$ & $\square$ & $\square$ & $\square$ & $\square$ & Auto Ownership \\
\hline AADT & $\square$ & $\square$ & $\square$ & $\square$ & $\square$ & $\square$ & $\square$ & $\square$ & $\nabla$ & $\square$ & $\square$ & $\square$ & $\square$ & $\square$ & $\square$ & $\square$ & $\square$ & Land Use \\
\hline AADT & $\square$ & $\square$ & $\square$ & $\square$ & $\square$ & $\square$ & $\square$ & $\square$ & $\square$ & $\square$ & $\square$ & $\nabla$ & $\square$ & $\square$ & $\square$ & $\square$ & $\square$ & Transit Stops \\
\hline Auto Ownership & $\square$ & $\square$ & $\square$ & $\square$ & $\square$ & $\square$ & $\square$ & $\square$ & $\nabla$ & $\square$ & $\square$ & $\square$ & $\square$ & $\square$ & $\square$ & $\square$ & $\square$ & Land Use \\
\hline Auto Ownership & $\square$ & $\square$ & $\square$ & $\square$ & $\square$ & $\square$ & $\square$ & $\square$ & $\nabla$ & $\square$ & $\square$ & $\square$ & $\square$ & $\square$ & $\square$ & $\square$ & $\square$ & Transit Stops \\
\hline Land Use & $\square$ & $\square$ & $\square$ & $\square$ & $\square$ & $\square$ & $\square$ & $\bar{\square}$ & $\square$ & $\square$ & $\square$ & 田 & $\square$ & $\square$ & $\bar{\square}$ & $\square$ & $\square$ & Transit Stops \\
\hline
\end{tabular}

Figure A-2: Expert-A's Feedback on Pair-wise Comparison 


\begin{tabular}{|c|c|c|c|c|c|c|c|c|c|c|c|c|c|c|c|c|c|c|}
\hline \multirow{3}{*}{ Criteria } & \multicolumn{17}{|c|}{ Preference Scale } & \multirow{3}{*}{ Criteria } \\
\hline & Extreme & \begin{tabular}{|c} 
Very \\
Strong to \\
Extreme
\end{tabular} & $\begin{array}{c}\text { Very } \\
\text { Strong }\end{array}$ & \begin{tabular}{|c} 
Strong to \\
Very \\
Strong
\end{tabular} & Strong & $\begin{array}{l}\text { Moderate } \\
\text { to Strong }\end{array}$ & Moderate & $\begin{array}{c}\text { Equal to } \\
\text { Moderate }\end{array}$ & Equal & $\begin{array}{c}\text { Equal to } \\
\text { Moderate }\end{array}$ & Moderate & $=\begin{array}{l}\text { Moderate } \\
\text { to Strong }\end{array}$ & Strong & \begin{tabular}{|c|} 
Strong to \\
Very \\
Strong
\end{tabular} & $\begin{array}{c}\text { Very } \\
\text { strong }\end{array}$ & \begin{tabular}{|c|} 
Very \\
Strong to \\
Extreme
\end{tabular} & Extreme & \\
\hline & 9 & 8 & 7 & 6 & 5 & 4 & 3 & 2 & 1 & 2 & 3 & 4 & 5 & 6 & 7 & 8 & 9 & \\
\hline Bicycle Crash Frequency & $\square$ & $\square$ & $\square$ & $\square$ & $\nabla$ & $\square$ & $\square$ & $\square$ & $\square$ & $\square$ & $\square$ & $\square$ & $\square$ & $\square$ & $\square$ & $\square$ & $\square$ & Bicycle Facility \\
\hline Bicycle Crash Frequency & $\square$ & $\square$ & $\nabla$ & $\square$ & $\square$ & $\square$ & $\square$ & $\square$ & $\square$ & $\square$ & $\square$ & $\square$ & $\square$ & $\square$ & $\square$ & $\square$ & $\square$ & Bicycle Volume \\
\hline Bicycle Crash Frequency & $\square$ & $\square$ & $\square$ & $\square$ & 四 & $\square$ & $\square$ & $\square$ & $\square$ & $\square$ & $\square$ & $\square$ & $\square$ & $\square$ & $\square$ & $\square$ & $\square$ & AADT \\
\hline Bicycle Crash Frequency & $\square$ & $\square$ & $\square$ & $\square$ & $\nabla$ & $\square$ & $\square$ & $\square$ & $\square$ & $\square$ & $\square$ & $\square$ & $\square$ & $\square$ & $\square$ & $\square$ & $\square$ & Auto Ownership \\
\hline Bicycle Crash Frequency & $\square$ & $\square$ & $\square$ & $\square$ & 田 & $\square$ & $\square$ & $\square$ & $\square$ & $\square$ & $\square$ & $\square$ & $\square$ & $\square$ & $\square$ & $\square$ & $\square$ & Land Use \\
\hline Bicycle Crash Frequency & $\square$ & $\square$ & $\square$ & $\square$ & 四 & $\square$ & $\square$ & $\square$ & $\square$ & $\square$ & $\square$ & $\square$ & $\square$ & $\square$ & $\square$ & $\square$ & $\square$ & Transit Stops \\
\hline Bicycle Facility & $\square$ & $\square$ & $\square$ & $\square$ & $\square$ & $\square$ & $\nabla$ & $\square$ & $\square$ & $\square$ & $\square$ & $\square$ & $\square$ & $\square$ & $\square$ & $\square$ & $\square$ & Bicycle Volume \\
\hline Bicycle Facility & $\square$ & $\square$ & $\square$ & $\square$ & $\square$ & $\square$ & $\square$ & $\square$ & $\square$ & $\square$ & 田 & $\square$ & $\square$ & $\square$ & $\square$ & $\square$ & $\square$ & AADT \\
\hline Bicycle Facility & $\square$ & $\square$ & $\square$ & $\square$ & $\square$ & $\square$ & $\nabla$ & $\square$ & $\square$ & $\square$ & $\square$ & $\square$ & $\square$ & $\square$ & $\square$ & $\square$ & $\square$ & Auto Ownership \\
\hline Bicycle Facility & $\square$ & $\square$ & $\square$ & $\square$ & $\square$ & $\square$ & $\square$ & 四 & $\square$ & $\square$ & $\square$ & $\square$ & $\square$ & $\square$ & $\square$ & $\square$ & $\square$ & Land Use \\
\hline Bicycle Facility & $\square$ & $\square$ & $\square$ & $\square$ & $\square$ & $\square$ & $\square$ & 四 & $\square$ & $\square$ & $\square$ & $\square$ & $\square$ & $\square$ & $\square$ & $\square$ & $\square$ & Transit Stops \\
\hline Bicycle Volume & $\square$ & $\square$ & $\square$ & $\square$ & $\square$ & $\square$ & $\square$ & $\square$ & $\square$ & $\square$ & $\square$ & $\square$ & 四 & $\square$ & $\square$ & $\square$ & $\square$ & AADT \\
\hline Bicycle Volume & $\square$ & $\square$ & $\square$ & $\square$ & $\square$ & $\square$ & $\nabla$ & $\square$ & $\square$ & $\square$ & $\square$ & $\square$ & $\square$ & $\square$ & $\square$ & $\square$ & $\square$ & Auto Ownership \\
\hline Bicycle Volume & $\square$ & $\square$ & $\square$ & $\square$ & $\nabla$ & $\square$ & $\square$ & $\square$ & $\square$ & $\square$ & $\square$ & $\square$ & $\square$ & $\square$ & $\square$ & $\square$ & $\square$ & Land Use \\
\hline Bicycle Volume & $\square$ & $\square$ & $\square$ & $\square$ & $\square$ & $\square$ & $\nabla$ & $\square$ & $\square$ & $\square$ & $\square$ & $\square$ & $\square$ & $\square$ & $\square$ & $\square$ & $\square$ & Transit Stops \\
\hline AADT & $\square$ & $\square$ & $\square$ & $\square$ & $\nabla$ & $\square$ & $\square$ & $\square$ & $\square$ & $\square$ & $\square$ & $\square$ & $\square$ & $\square$ & $\square$ & $\square$ & $\square$ & Auto Ownership \\
\hline AADT & $\square$ & $\square$ & $\square$ & $\square$ & $\nabla$ & $\square$ & $\square$ & $\square$ & $\square$ & $\square$ & $\square$ & $\square$ & $\square$ & $\square$ & $\square$ & $\square$ & $\square$ & Land Use \\
\hline AADT & $\square$ & $\square$ & $\square$ & $\square$ & $\square$ & 田 & $\square$ & $\square$ & $\square$ & $\square$ & $\square$ & $\square$ & $\square$ & $\square$ & $\square$ & $\square$ & $\square$ & Transit Stops \\
\hline Auto Ownership & $\square$ & $\square$ & $\square$ & $\square$ & $\square$ & $\square$ & $\square$ & $\square$ & $\square$ & $\square$ & $\square$ & $\square$ & $\nabla$ & $\square$ & $\square$ & $\square$ & $\square$ & Land Use \\
\hline Auto Ownership & $\square$ & $\square$ & $\square$ & $\square$ & $\square$ & $\square$ & $\square$ & $\square$ & $\square$ & $\square$ & $\square$ & $\square$ & 四 & $\square$ & $\square$ & $\square$ & $\square$ & Transit Stops \\
\hline Land Use & $\square$ & $\square$ & $\square$ & $\square$ & $\square$ & $\square$ & $\square$ & $\square$ & $\square$ & $\square$ & $\square$ & $\square$ & $\nabla$ & $\square$ & $\square$ & $\square$ & $\square$ & Transit Stops \\
\hline
\end{tabular}

Figure A-3: Expert-B's Feedback on Pair-wise Comparison 


\begin{tabular}{|c|c|c|c|c|c|c|c|c|c|c|c|c|c|c|c|c|c|c|}
\hline \multirow{3}{*}{ Criteria } & \multicolumn{17}{|c|}{ Preference Scale } & \multirow{3}{*}{ Criteria } \\
\hline & Extreme & \begin{tabular}{|c|} 
Very \\
Strong to \\
Extreme
\end{tabular} & $\begin{array}{l}\text { Very } \\
\text { strong }\end{array}$ & \begin{tabular}{|c|} 
Strong to \\
Very \\
Strong
\end{tabular} & Strong & $\begin{array}{c}\text { Moderate } \\
\text { to Strong }\end{array}$ & Moderate & $\begin{array}{c}\text { Equal to } \\
\text { Moderate }\end{array}$ & Equal & $\begin{array}{l}\text { Equal to } \\
\text { Moderate }\end{array}$ & Moderate & $=\begin{array}{l}\text { Moderate } \\
\text { to Strong }\end{array}$ & Strong & \begin{tabular}{|c} 
Strong to \\
Very \\
Strong
\end{tabular} & $\begin{array}{c}\text { Very } \\
\text { strong }\end{array}$ & \begin{tabular}{|c|} 
Very \\
Strong to \\
Extreme
\end{tabular} & Extreme & \\
\hline & 9 & 8 & 7 & 6 & 5 & 4 & 3 & 2 & 1 & 2 & 3 & 4 & 5 & 6 & 7 & 8 & 9 & \\
\hline Bicycle Crash Frequency & $\square$ & $\square$ & $\square$ & $\square$ & $\nabla$ & $\square$ & $\square$ & $\square$ & $\square$ & $\square$ & $\square$ & $\square$ & $\square$ & $\square$ & $\square$ & $\square$ & $\square$ & Bicycle Facility \\
\hline Bicycle Crash Frequency & $\square$ & $\square$ & $\square$ & $\square$ & $\nabla$ & $\square$ & $\square$ & $\square$ & $\square$ & $\square$ & $\square$ & $\square$ & $\square$ & $\square$ & $\square$ & $\square$ & $\square$ & Bicycle Volume \\
\hline Bicycle Crash Frequency & $\square$ & $\square$ & $\square$ & $\square$ & $\nabla$ & $\square$ & $\square$ & $\square$ & $\square$ & $\square$ & $\square$ & $\square$ & $\square$ & $\square$ & $\square$ & $\square$ & $\square$ & AADT \\
\hline Bicycle Crash Frequency & $\square$ & $\square$ & $\square$ & $\square$ & $\nabla$ & $\square$ & $\square$ & $\square$ & $\square$ & $\square$ & $\square$ & $\square$ & $\square$ & $\square$ & $\square$ & $\square$ & $\square$ & Auto Ownership \\
\hline Bicycle Crash Frequency & $\square$ & $\square$ & $\square$ & $\square$ & $\nabla$ & $\square$ & $\square$ & $\square$ & $\square$ & $\square$ & $\square$ & $\square$ & $\square$ & $\square$ & $\square$ & $\square$ & $\square$ & Land Use \\
\hline Bicycle Crash Frequency & $\square$ & $\square$ & $\square$ & $\square$ & $\nabla$ & $\square$ & $\square$ & $\square$ & $\square$ & $\square$ & $\square$ & $\square$ & $\square$ & $\square$ & $\square$ & $\square$ & $\square$ & Transit Stops \\
\hline Bicycle Facility & $\square$ & $\square$ & $\square$ & $\square$ & $\square$ & $\square$ & $\square$ & $\square$ & $\square$ & $\square$ & v & $\square$ & $\square$ & $\square$ & $\square$ & $\square$ & $\square$ & Bicycle Volume \\
\hline Bicycle Facility & $\square$ & $\square$ & $\square$ & $\square$ & $\square$ & $\square$ & 田 & $\square$ & $\square$ & $\square$ & $\square$ & $\square$ & $\square$ & $\square$ & $\square$ & $\square$ & $\square$ & AADT \\
\hline Bicycle Facility & $\square$ & $\square$ & $\square$ & $\square$ & $\square$ & $\square$ & $\square$ & $\nabla$ & $\square$ & $\square$ & $\square$ & $\square$ & $\square$ & $\square$ & $\square$ & $\square$ & $\square$ & Auto Ownership \\
\hline Bicycle Facility & $\square$ & $\square$ & $\square$ & $\square$ & $\square$ & $\square$ & $\square$ & 四 & $\square$ & $\square$ & $\square$ & $\square$ & $\square$ & $\square$ & $\square$ & $\square$ & $\square$ & Land Use \\
\hline Bicycle Facility & $\square$ & $\square$ & $\square$ & $\square$ & $\square$ & $\square$ & $\square$ & $\square$ & $\nabla$ & $\square$ & $\square$ & $\square$ & $\square$ & $\square$ & $\square$ & $\square$ & $\square$ & Transit Stops \\
\hline Bicycle Volume & $\square$ & $\square$ & $\square$ & $\square$ & $\square$ & $\square$ & $\square$ & $\square$ & $\nabla$ & $\square$ & $\square$ & $\square$ & $\square$ & $\square$ & $\square$ & $\square$ & $\square$ & AADT \\
\hline Bicycle Volume & $\square$ & $\square$ & $\square$ & $\square$ & $\square$ & $\square$ & $\square$ & v & $\square$ & $\square$ & $\square$ & $\square$ & $\square$ & $\square$ & $\square$ & $\square$ & $\square$ & Auto Ownership \\
\hline Bicycle Volume & $\square$ & $\square$ & $\square$ & $\square$ & $\square$ & $\square$ & $\square$ & v & $\square$ & $\square$ & $\square$ & $\square$ & $\square$ & $\square$ & $\square$ & $\square$ & $\square$ & Land Use \\
\hline Bicycle Volume & $\square$ & $\square$ & $\square$ & $\square$ & $\square$ & $\square$ & $\square$ & v & $\square$ & $\square$ & $\square$ & $\square$ & $\square$ & $\square$ & $\square$ & $\square$ & $\square$ & Transit Stops \\
\hline AADT & $\square$ & $\square$ & $\square$ & $\square$ & $\square$ & $\square$ & $\square$ & v & $\square$ & $\square$ & $\square$ & $\square$ & $\square$ & $\square$ & $\square$ & $\square$ & $\square$ & Auto Ownership \\
\hline AADT & $\square$ & $\square$ & $\square$ & $\square$ & $\square$ & $\square$ & $\square$ & v & $\square$ & $\square$ & $\square$ & $\square$ & $\square$ & $\square$ & $\square$ & $\square$ & $\square$ & Land Use \\
\hline AADT & $\square$ & $\square$ & $\square$ & $\square$ & $\square$ & $\square$ & $\square$ & $\square$ & $\nabla$ & $\square$ & $\square$ & $\square$ & $\square$ & $\square$ & $\square$ & $\square$ & $\square$ & Transit Stops \\
\hline Auto Ownership & $\square$ & $\square$ & $\square$ & $\square$ & $\square$ & $\square$ & $\square$ & $\square$ & $\nabla$ & $\square$ & $\square$ & $\square$ & $\square$ & $\square$ & $\square$ & $\square$ & $\square$ & Land Use \\
\hline Auto Ownership & $\square$ & $\square$ & $\square$ & $\square$ & $\square$ & $\square$ & $\square$ & $\square$ & $\square$ & $\square$ & $\nabla$ & $\square$ & $\square$ & $\square$ & $\square$ & $\square$ & $\square$ & Transit Stops \\
\hline Land Use & $\square$ & $\square$ & $\square$ & $\square$ & $\square$ & $\square$ & $\square$ & $\square$ & $\square$ & $\square$ & $\nabla$ & $\square$ & $\square$ & $\square$ & $\square$ & $\square$ & $\square$ & Transit Stops \\
\hline
\end{tabular}

Figure A-4: Expert-C's Feedback on Pair-wise Comparison 


\begin{tabular}{|c|c|c|c|c|c|c|c|c|c|c|c|c|c|c|c|c|c|c|}
\hline \multirow{3}{*}{ Criteria } & \multicolumn{17}{|c|}{ Preference Scale } & \multirow{3}{*}{ Criteria } \\
\hline & Extreme & \begin{tabular}{|c|} 
Very \\
Strong to \\
Extreme
\end{tabular} & $\begin{array}{l}\text { Very } \\
\text { Strong }\end{array}$ & \begin{tabular}{|c|} 
Strong to \\
Very \\
Strong
\end{tabular} & Strong & $\begin{array}{c}\text { Moderate } \\
\text { to Strong }\end{array}$ & Moderate & $\begin{array}{c}\text { Equal to } \\
\text { Moderate }\end{array}$ & Equal & $\begin{array}{c}\text { Equal to } \\
\text { Moderate }\end{array}$ & Moderate & \begin{tabular}{|l|} 
Moderate \\
to Strong
\end{tabular} & Strong & \begin{tabular}{|c} 
Strong to \\
Very \\
Strong
\end{tabular} & $\begin{array}{l}\text { Very } \\
\text { Strong }\end{array}$ & \begin{tabular}{|c|} 
Very \\
Strong to \\
Extreme
\end{tabular} & Extreme & \\
\hline & 9 & 8 & 7 & 6 & 5 & 4 & 3 & 2 & 1 & 2 & 3 & 4 & 5 & 6 & 7 & 8 & 9 & \\
\hline Bicycle Crash Frequency & $\square$ & $\square$ & $\square$ & $\nabla$ & $\square$ & $\square$ & $\square$ & $\square$ & $\square$ & $\square$ & $\square$ & $\square$ & $\square$ & $\square$ & $\square$ & $\square$ & $\square$ & Bicycle Facility \\
\hline Bicycle Crash Frequency & $\square$ & $\square$ & $\square$ & $\square$ & $\nabla$ & $\square$ & $\square$ & $\square$ & $\square$ & $\square$ & $\square$ & $\square$ & $\square$ & $\square$ & $\square$ & $\square$ & $\square$ & Bicycle Volume \\
\hline Bicycle Crash Frequency & $\square$ & $\square$ & $\square$ & $\square$ & $\nabla$ & $\square$ & $\square$ & $\square$ & $\square$ & $\square$ & $\square$ & $\square$ & $\square$ & $\square$ & $\square$ & $\square$ & $\square$ & AADT \\
\hline Bicycle Crash Frequency & $\square$ & $\square$ & $\square$ & $\square$ & $\square$ & $\nabla$ & $\square$ & $\square$ & $\square$ & $\square$ & $\square$ & $\square$ & $\square$ & $\square$ & $\square$ & $\square$ & $\square$ & Auto Ownership \\
\hline Bicycle Crash Frequency & $\square$ & $\square$ & $\square$ & 四 & $\square$ & $\square$ & $\square$ & $\square$ & $\square$ & $\square$ & $\square$ & $\square$ & $\square$ & $\square$ & $\square$ & $\square$ & $\square$ & Land Use \\
\hline Bicycle Crash Frequency & $\square$ & $\square$ & $\square$ & 四 & $\square$ & $\square$ & $\square$ & $\square$ & $\square$ & $\square$ & $\square$ & $\square$ & $\square$ & $\square$ & $\square$ & $\square$ & $\square$ & Transit Stops \\
\hline Bicycle Facility & $\square$ & $\square$ & $\square$ & $\square$ & $\square$ & $\square$ & $\square$ & $\nabla$ & $\square$ & $\square$ & $\square$ & $\square$ & $\square$ & $\square$ & $\square$ & $\square$ & $\square$ & Bicycle Volume \\
\hline Bicycle Facility & $\square$ & $\square$ & $\square$ & $\square$ & $\square$ & $\square$ & $\nabla$ & $\square$ & $\square$ & $\square$ & $\square$ & $\square$ & $\square$ & $\square$ & $\square$ & $\square$ & $\square$ & AADT \\
\hline Bicycle Facility & $\square$ & $\square$ & $\square$ & $\square$ & $\square$ & $\square$ & $\square$ & $\square$ & $\nabla$ & $\square$ & $\square$ & $\square$ & $\square$ & $\square$ & $\square$ & $\square$ & $\square$ & Auto Ownership \\
\hline Bicycle Facility & $\square$ & $\square$ & $\square$ & $\square$ & $\square$ & $\square$ & $\square$ & $\square$ & $\nabla$ & $\square$ & $\square$ & $\square$ & $\square$ & $\square$ & $\square$ & $\square$ & $\square$ & Land Use \\
\hline Bicycle Facility & $\square$ & $\square$ & $\square$ & $\square$ & $\square$ & $\square$ & $\square$ & 四 & $\square$ & $\square$ & $\square$ & $\square$ & $\square$ & $\square$ & $\square$ & $\square$ & $\square$ & Transit Stops \\
\hline Bicycle Volume & $\square$ & $\square$ & $\square$ & $\square$ & $\square$ & $\square$ & $\square$ & $\square$ & $\nabla$ & $\square$ & $\square$ & $\square$ & $\square$ & $\square$ & $\square$ & $\square$ & $\square$ & AADT \\
\hline Bicycle Volume & $\square$ & $\square$ & $\square$ & $\square$ & $\square$ & $\square$ & $\square$ & $\square$ & $\nabla$ & $\square$ & $\square$ & $\square$ & $\square$ & $\square$ & $\square$ & $\square$ & $\square$ & Auto Ownership \\
\hline Bicycle Volume & $\square$ & $\square$ & $\square$ & $\square$ & $\square$ & $\square$ & $\square$ & 田 & $\square$ & $\square$ & $\square$ & $\square$ & $\square$ & $\square$ & $\square$ & $\square$ & $\square$ & Land Use \\
\hline Bicycle Volume & $\square$ & $\square$ & $\square$ & $\square$ & $\square$ & $\square$ & $\square$ & $\square$ & $\square$ & $\square$ & $\nabla$ & $\square$ & $\square$ & $\square$ & $\square$ & $\square$ & $\square$ & Transit Stops \\
\hline AADT & $\square$ & $\square$ & $\square$ & $\square$ & $\square$ & $\square$ & $\square$ & $\square$ & $\square$ & $\square$ & $\nabla$ & $\square$ & $\square$ & $\square$ & $\square$ & $\square$ & $\square$ & Auto Ownership \\
\hline AADT & $\square$ & $\square$ & $\square$ & $\square$ & $\square$ & $\square$ & $\square$ & $\square$ & $\square$ & $\square$ & $\nabla$ & $\square$ & $\square$ & $\square$ & $\square$ & $\square$ & $\square$ & Land Use \\
\hline AADT & $\square$ & $\square$ & $\square$ & $\square$ & $\square$ & $\square$ & $\square$ & $\square$ & $\square$ & $\nabla$ & $\square$ & $\square$ & $\square$ & $\square$ & $\square$ & $\square$ & $\square$ & Transit Stops \\
\hline Auto Ownership & $\square$ & $\square$ & $\square$ & $\square$ & $\square$ & $\square$ & $\square$ & $\square$ & $\nabla$ & $\square$ & $\square$ & $\square$ & $\square$ & $\square$ & $\square$ & $\square$ & $\square$ & Land Use \\
\hline Auto Ownership & $\square$ & $\square$ & $\square$ & $\square$ & $\square$ & $\square$ & $\square$ & $\square$ & $\square$ & $\square$ & $\square$ & $\nabla$ & $\square$ & $\square$ & $\square$ & $\square$ & $\square$ & Transit Stops \\
\hline Land Use & $\square$ & $\square$ & $\square$ & $\square$ & $\square$ & $\square$ & $\square$ & $\square$ & $\square$ & v & $\square$ & $\square$ & $\square$ & $\square$ & $\square$ & $\square$ & $\square$ & Transit Stops \\
\hline
\end{tabular}

Figure A-5: Expert-D's Feedback on Pair-wise Comparison 


\begin{tabular}{|c|c|c|c|c|c|c|c|c|c|c|c|c|c|c|c|c|c|c|}
\hline \multirow{3}{*}{ Criteria } & \multicolumn{17}{|c|}{ Preference Scale } & \multirow{3}{*}{ Criteria } \\
\hline & Extreme & \begin{tabular}{|c} 
Very \\
Strong to \\
Extreme
\end{tabular} & $\begin{array}{c}\text { Very } \\
\text { Strong }\end{array}$ & \begin{tabular}{|c} 
Strong to \\
Very \\
Strong
\end{tabular} & Strong & $\begin{array}{c}\text { Moderate } \\
\text { to Strong }\end{array}$ & Moderate & $\begin{array}{l}\text { Equal to } \\
\text { Moderate }\end{array}$ & Equal & $\begin{array}{c}\text { Equal to } \\
\text { Moderate }\end{array}$ & Moderate & $=\begin{array}{l}\text { Moderate } \\
\text { to Strong }\end{array}$ & Strong & \begin{tabular}{|c|} 
Strong to \\
Very \\
Strong \\
\end{tabular} & $\begin{array}{c}\text { Very } \\
\text { Strong }\end{array}$ & \begin{tabular}{|c} 
Very \\
Strong to \\
Extreme \\
\end{tabular} & Extreme & \\
\hline & 9 & 8 & 7 & 6 & 5 & 4 & 3 & 2 & 1 & 2 & 3 & 4 & 5 & 6 & 7 & 8 & 9 & \\
\hline Bicycle Crash Frequency & $\square$ & $\square$ & $\square$ & $\square$ & $\square$ & $\square$ & $\square$ & $\square$ & $\square$ & $\square$ & $\square$ & $\nabla$ & $\square$ & $\square$ & $\square$ & $\square$ & $\square$ & Bicycle Facility \\
\hline Bicycle Crash Frequency & $\square$ & $\square$ & $\square$ & $\square$ & $\square$ & $\square$ & $\square$ & $\square$ & $\square$ & $\square$ & $\square$ & $\nabla$ & $\square$ & $\square$ & $\square$ & $\square$ & $\square$ & Bicycle Volume \\
\hline Bicycle Crash Frequency & $\square$ & $\square$ & $\square$ & $\square$ & $\square$ & $\square$ & $\square$ & $\square$ & $\square$ & $\square$ & $\square$ & $\square$ & $\square$ & $\nabla$ & $\square$ & $\square$ & $\square$ & AADT \\
\hline Bicycle Crash Frequency & $\square$ & $\square$ & $\square$ & $\square$ & $\square$ & $\square$ & $\square$ & $\square$ & $\square$ & $\square$ & $\square$ & 四 & $\square$ & $\square$ & $\square$ & $\square$ & $\square$ & Auto Ownership \\
\hline Bicycle Crash Frequency & $\square$ & $\square$ & $\square$ & $\square$ & $\square$ & $\square$ & $\square$ & $\square$ & $\square$ & 四 & $\square$ & $\square$ & $\square$ & $\square$ & $\square$ & $\square$ & $\square$ & Land Use \\
\hline Bicycle Crash Frequency & $\square$ & $\square$ & $\square$ & $\square$ & $\square$ & $\square$ & $\square$ & $\square$ & $\square$ & $\square$ & $\square$ & $\square$ & $\square$ & $\square$ & $\square$ & $\square$ & $\square$ & Transit Stops \\
\hline Bicycle Facility & $\square$ & $\square$ & $\square$ & $\square$ & $\square$ & $\square$ & $\square$ & $\square$ & $\nabla$ & $\square$ & $\square$ & $\square$ & $\square$ & $\square$ & $\square$ & $\square$ & $\square$ & Bicycle Volume \\
\hline Bicycle Facility & $\square$ & $\square$ & $\square$ & $\square$ & $\nabla$ & $\square$ & $\square$ & $\square$ & $\square$ & $\square$ & $\square$ & $\square$ & $\square$ & $\square$ & $\square$ & $\square$ & $\square$ & AADT \\
\hline Bicycle Facility & $\square$ & $\square$ & $\square$ & $\square$ & $\square$ & $\square$ & $\square$ & $\square$ & $\square$ & $\square$ & $\square$ & $\square$ & $\square$ & $\square$ & $\nabla$ & $\square$ & $\square$ & Auto Ownership \\
\hline Bicycle Facility & $\square$ & $\square$ & $\square$ & $\square$ & $\square$ & $\square$ & $\square$ & $\square$ & $\nabla$ & $\square$ & $\square$ & $\square$ & $\square$ & $\square$ & $\square$ & $\square$ & $\square$ & Land Use \\
\hline Bicycle Facility & $\square$ & $\square$ & $\square$ & $\square$ & $\square$ & $\square$ & $\square$ & $\square$ & $\square$ & v & $\square$ & $\square$ & $\square$ & $\square$ & $\square$ & $\square$ & $\square$ & Transit Stops \\
\hline Bicycle Volume & $\square$ & $\square$ & $\square$ & $\square$ & $\square$ & $\square$ & $\square$ & $\square$ & $\square$ & $\square$ & $\square$ & $\square$ & $\square$ & 四 & $\square$ & $\square$ & $\square$ & AADT \\
\hline Bicycle Volume & $\square$ & $\square$ & $\square$ & $\square$ & $\square$ & $\square$ & $\square$ & $\square$ & $\square$ & $\square$ & $\square$ & $\square$ & $\square$ & $\square$ & $\nabla$ & $\square$ & $\square$ & Auto Ownership \\
\hline Bicycle Volume & $\square$ & $\square$ & $\square$ & $\square$ & $\square$ & $\square$ & $\square$ & $\square$ & $\square$ & $\square$ & $\square$ & $\square$ & $\nabla$ & $\square$ & $\square$ & $\square$ & $\square$ & Land Use \\
\hline Bicycle Volume & $\square$ & $\square$ & $\square$ & $\square$ & $\square$ & $\square$ & $\square$ & $\square$ & $\square$ & $\square$ & $\square$ & $\square$ & $\square$ & $\nabla$ & $\square$ & $\square$ & $\square$ & Transit Stops \\
\hline AADT & $\square$ & $\square$ & $\square$ & $\square$ & $\square$ & $\square$ & $\square$ & $\square$ & $\square$ & 四 & $\square$ & $\square$ & $\square$ & $\square$ & $\square$ & $\square$ & $\square$ & Auto Ownership \\
\hline AADT & $\square$ & $\square$ & $\square$ & $\square$ & $\square$ & $\square$ & $\square$ & $\square$ & $\square$ & $\square$ & $\square$ & 田 & $\square$ & $\square$ & $\square$ & $\square$ & $\square$ & Land Use \\
\hline AADT & $\square$ & $\square$ & $\square$ & $\square$ & $\square$ & $\square$ & $\square$ & $\square$ & $\nabla$ & $\square$ & $\square$ & $\square$ & $\square$ & $\square$ & $\square$ & $\square$ & $\square$ & Transit Stops \\
\hline Auto Ownership & $\square$ & $\square$ & $\square$ & $\square$ & $\square$ & $\square$ & $\square$ & 田 & $\square$ & $\square$ & $\square$ & $\square$ & $\square$ & $\square$ & $\square$ & $\square$ & $\square$ & Land Use \\
\hline Auto Ownership & $\square$ & $\square$ & $\square$ & $\square$ & $\square$ & $\square$ & $\square$ & $\square$ & $\square$ & v & $\square$ & $\square$ & $\square$ & $\square$ & $\square$ & $\square$ & $\square$ & Transit Stops \\
\hline Land Use & $\square$ & $\square$ & $\square$ & $\square$ & $\square$ & $\square$ & $\square$ & 田 & $\square$ & $\square$ & $\square$ & $\square$ & $\square$ & $\square$ & $\square$ & $\square$ & $\square$ & Transit Stops \\
\hline
\end{tabular}

Figure A-6: Expert-E's Feedback on Pair-wise Comparison 
VITA

\section{ASIF RAIHAN}

\section{EDUCATION}

$2001-2008$ B.S., Civil Engineering

Bangladesh University of Engineering \& Technology, Dhaka, Bangladesh

2008 - 2013 M.S., Civil Engineering (Transportation)

Bangladesh University of Engineering \& Technology, Dhaka, Bangladesh

2014 - 2018 Graduate Research/Teaching Assistant

Department of Civil and Environmental Engineering

Florida International University, Miami, Florida

2016 - 2018 Doctoral Candidate

Department of Civil and Environmental Engineering

Florida International University, Miami, Florida

\section{PUBLICATIONS \& PRESENTATIONS}

1. Raihan, M. A., Alluri, P., Wu, W., and Gan, A. (under review). Estimation of Bicycle Crash Modification Factors (CMFs) on Urban Facilities using Zero Inflated Negative Binomial Models. Accident Analysis \& Prevention.

2. Vargas, H., Raihan, M. A., Alluri, P., and Gan, A. (under review). Jurisdiction-specific versus SafetyAnalyst-default Safety Performance Functions: A Case Study on Twolane and Multi-lane Arterials. Transportation Research Record: Journal of the Transportation Research Board.

3. Haule, H. J., Alluri, P., Sando, T., and Raihan, M. A. (2019). Investigating the Impact of Rain on Crash Clearance Duration. In Proceedings of the 98th Annual Meeting of the Transportation Research Board (No. 19-02331), January 13-17, Washington, DC.

4. Gonzalez, M., Alluri, P., and Raihan, M. A. (2018). Prioritizing Locations for Installing Street Lights: A Case Study on the City of Doral. In Proceedings of the 97th Annual Meeting of the Transportation Research Board (No. 18-01493), January 7-11, Washington, DC.

5. Raihan, M. A., and Alluri, P. (2017). Impact of Roadway Characteristics on Bicycle Safety. ITE Journal, 87(9), 33-40 (Recipient of the 2017 ITE Daniel B. Fambro Student Award).

6. Alluri, P., Gonzalez, M., and Raihan, M. A. (2017). Doral Citywide Roadway Lighting Study. Final Research Report, City of Doral, Doral, Florida. 
7. Gan, A., Alluri, P., Raihan, M. A., Liu, K., Saha, D., and Jung, R. (2017). An Automated System for Prioritizing Highway Improvement Locations and Analyzing Project Alternatives. Transportation Research Record No. 2654: Journal of the Transportation Research Board, 65-75.

8. Raihan, M. A., Hossain, M., and Hasan, T. (2017). Data Mining in Road Crash Analysis: The Context of Developing Countries. International Journal of Injury Control and Safety Promotion, 25(1) 41-52.

9. Alluri, P., Raihan, M. A., Saha, D., Wu, W., Huq, A., Nafis, S., and Gan, A. (2017). Statewide Analysis of Bicycle Crashes. Final Research Report, Florida Department of Transportation Research Center, Tallahassee, Florida.

10. Raihan, M. A., Alluri, P., Gan, A., and Jung, R. (2016). Application of the Analytic Network Process (ANP) in Prioritizing Highway Improvement Locations. In Proceedings of the 95th Annual Meeting of the Transportation Research Board (No. 16-5908), Washington, DC.

11. Raihan, M. A., Hossain, M., and Hasan, T. (2016). Data Mining in Road Traffic Crash Analysis: The Context of Bangladesh. In Proceedings of the 95th Annual Meeting of the Transportation Research Board (No. 16-1241), Washington, DC.

12. Gan, A., Raihan, M. A., Alluri, P., Liu, K., and Saha, D. (2016). Updating and Improving Methodology for Prioritizing Highway Project Locations on the Strategic Intermodal System (SIS). Final Research Report, Florida Department of Transportation District One, Bartow, Florida.

13. Raihan, M. A., Alluri, P. and Gan, A. (2018). How Can We Fairly Prioritize Our Highways for Improvements? Presented at the 2018 Florida Section ITE Summer Meeting, June 13-15, Ponte Vedra, FL.

14. Raihan, M. A. (2018). Exploration of Highway Location Prioritization and Evaluation Methods for Bicycle Safety Improvements. Presented at the 97th Annual Meeting of the Transportation Research Board Hybrid Session on Doctoral Student Research in Transportation Safety, January 8, Washington, DC.

15. Nafis, S. R., Raihan, M. A., and Alluri, P. (2018). Factors Affecting Run-off-road Crashes on Rural Two-lane Undivided Roads. Presented at the 2018 Florida International University (FIU) Civil and Environmental Engineering (CEE) Graduate Research Day, February 23, Miami, FL.

16. Raihan, M. A., and Alluri, P. (2017). Exploring the Scope for Spatial and Temporal Transferability of Bicycle Crash Modification Factors. Presented at the 5th Annual University Transportation Centers (UTC) Conference for the Southeastern Region, November 16-17, Gainesville, FL. 